\title{
HYPERFORIN PROMOTES MITOCHONDRIAL FUNCTION AND DEVELOPMENT OF OLIGODENDROCYTES
}

\author{
A Thesis Submitted to the College of \\ Graduate Studies and Research \\ in Partial Fulfillment of the Requirements \\ for a Master's Degree \\ in the Department of Psychiatry \\ University of Saskatchewan \\ Saskatoon
}

By

Yanlin Wang

(C) Copyright Yanlin Wang, December 2009. All rights reserved. 


\title{
PERMISSION TO USE
}

In presenting this thesis in partial fulfillment of the requirements for a Master's degree from the University of Saskatchewan, I agree that the Libraries of this University may make it freely available for inspection. I further agree that permission for copying of this thesis in any manner, in whole or in part, for scholarly purposes may be granted by the professor or professors who supervised my thesis work or, in their absence, by the Head of the Department or the Dean of the College in which my thesis work was done. It is understood that any copying or publication or use of this thesis or parts thereof for financial gain shall not be allowed without my written permission. It is also understood that due recognition shall be given to me and to the University of Saskatchewan in any scholarly use which may be made of any material in my thesis.

Requests for permission to copy or to make other use of material in this thesis in whole or part should be addressed to:

\author{
Head, the Department of Psychiatry \\ University of Saskatchewan \\ Saskatoon, Saskatchewan \\ Canada, S7N 5E4
}




\begin{abstract}
Major depressive disorder is a common severe psychiatric disorder with unknown etiology. Recent studies show that the loss and malfunction of oligodendrocytes are closely related to the neuropathological changes in depression, which can be reversed by antidepressant treatment. St. John's wort is an effective and safe herbal treatment for depression in several clinical trials. However, the underlying mechanism of its therapeutic effects is unclear. In this study, we evaluated the effects of hyperforin, a major active component of this herb, on the proliferation, mitochondrial function and development of oligodendrocytes. We have demonstrated that hyperforin increases mitochondrial function and prevents mitochondrial toxin-induced cytotoxicity in oligodendrocyte lineage cells. Hyperforin promotes the maturation of oligodendrocytes but does not increase the proliferation of oligodendrocyte progenitor cell line and neural stem/progenitor cells. Our findings suggest that chronic hyperforin treatment may stimulate the development and function of oligodendrocytes. These results suggest a new mechanism of hyperforin in depression treatment. Future in vitro and in vivo studies are required to further characterize the mechanisms of hyperforin.
\end{abstract}




\section{ACKNOWLEDGEMENTS}

I would like to thank my supervisor Dr. Xin-Min Li for providing me with a great opportunity to study neuroscience. He guided me to complete meaningful graduate studies and instilled in me a commitment to medical research. His generous and continuing support provided me with a great opportunity to acquire knowledge and practice various techniques. As a supervisor with great passion and encouragement in research and in life, he helps me be confident and resilient and to strive to achieve a high standard of excellence in my research and career. I would also like to thank Drs. Wolfgang Walz, Adil Nazarali and Darrell Mousseau for their kind support, thoughtful guidance and inspiring suggestions. I give my special thanks to Dr. Adil Nazarali for providing me the CG-4 cell line in this study. I would also like to thank my external examiner, Dr. Lingyun $\mathrm{Wu}$, for her guidance and expert suggestions on this thesis. I give my thanks to Dr. Jiming Kong at the University of Manitoba for his generous support and insightful suggestions on my thesis project. I also thank Drs. Yanbo Zhang and Jue He for their unconditional help and constructive suggestions for my study. I would also like to extend my appreciation to my colleagues and student fellows at the Department of Psychiatry, University of Saskatchewan and the Department of Human Anatomy \& Cell Science, University of Manitoba for their outstanding collaboration, extensive suggestions and close friendship during my studies and research.

I would like to thank the Canadian Institute of Health Research and the Alfred E. Molstad Trust graduate award from the Department of Psychiatry, University of Saskatchewan, which supported my thesis project. I also extend my thanks to University of Saskatchewan and the College of Medicine, University of Saskatchewan for the scholarship and travel awards to support my studies and research.

I would like to give many thanks to my parents and my wife for their consistent support and encouragement during the pursuit of my graduate studies. 


\section{TABLE OF CONTENTS}

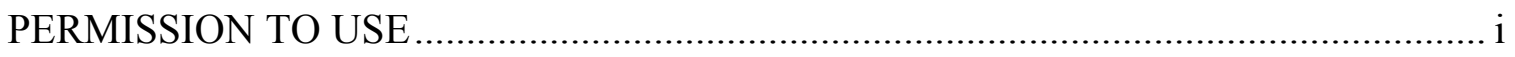

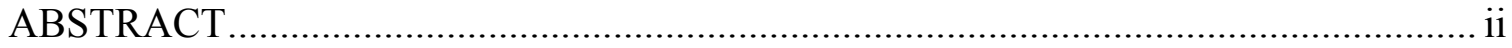

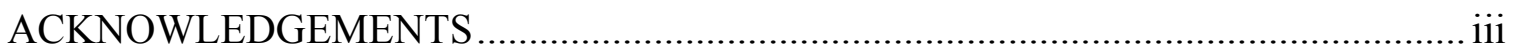

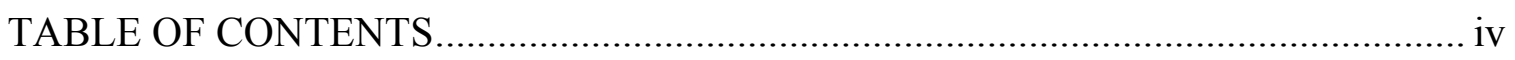

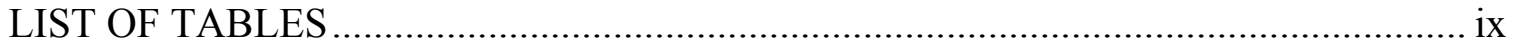

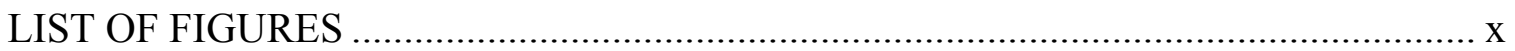

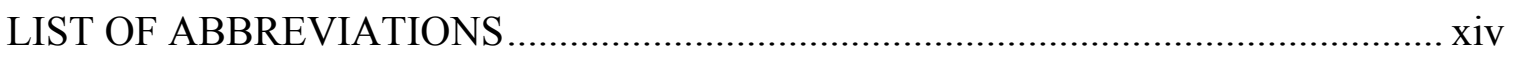

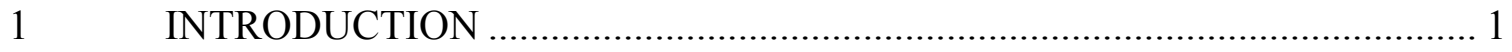

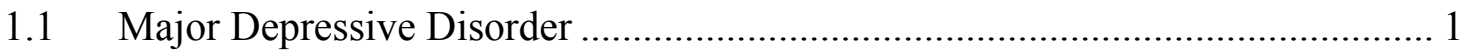

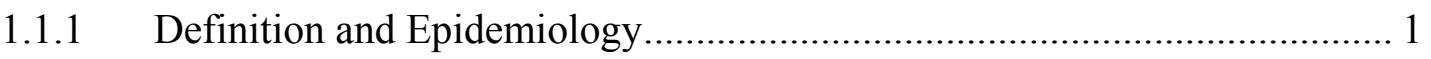

1.1.2 Etiology and Pathophysiology ................................................................ 1

1.1.2.1 Monoamine Deficiency in MDD .................................................... 2

1.1.2.2 Hippocampal Neuron Loss in MDD............................................. 2

1.1.2.3 Oligodendrocyte Loss in MDD ........................................................ 3

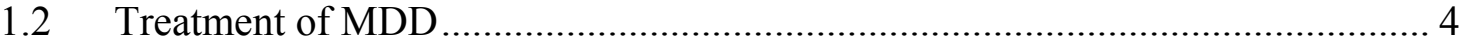

1.2.1 Antidepressants Increase Monoaminergic Neurotransmission...................... 5

1.2.2 Antidepressants Induce Neurogenesis in the Hippocampus .......................... 5

1.2.3 Treatment of MDD and Increased Genesis and Survival of

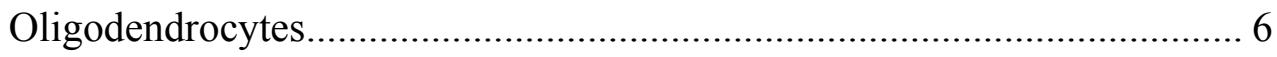

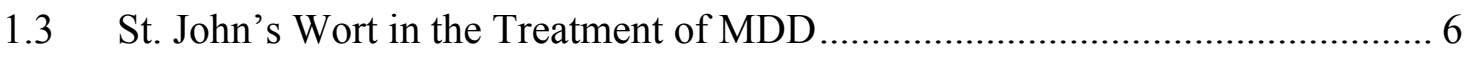

1.3.1 St. John's Wort as a Medicinal Herb for Psychiatric Disorders .................... 6

1.3.2 Clinical Efficacy of SJW for MDD ....................................................... 7

1.4 Hyperforin as an Antidepressant Extract of SJW ............................................ 8

1.4.1 Pharmacokinetics of Hyperforin as an Antidepressant Compound .............. 9

1.4.2 Mechanisms of Action for Hyperforin as an Antidepressant Compound... 10

1.5 Does Hyperforin Increase Genesis and Survival of Oligodendrocytes? ............ 10

1.5.1 Does Hyperforin Favor the Genesis of Oligodendrocytes? ……………..... 11

1.5.2 Does Hyperforin Increase Energy Metabolism in Oligodendrocytes? ....... 11 


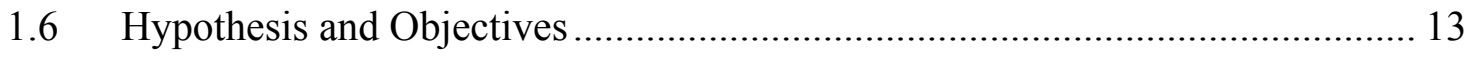

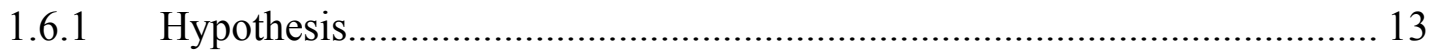

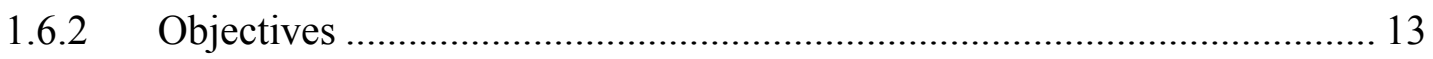

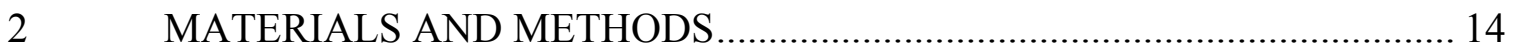

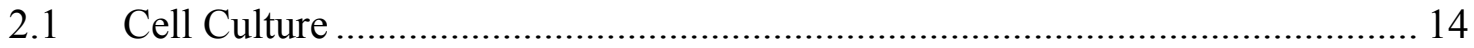

2.1.1 The Central Glia-4 Cell Line ............................................................. 14

2.1.1.1 Conditioned Medium of B104 Cell Culture ........................................ 14

2.1.1.2 Propagation and Differentiation of CG-4 Cells.................................. 15

2.1.1.3 Cryopreservation and Recovery of CG-4 Cells................................... 16

2.1.2 Neural Stem Cells and Neural Progenitor Cells ....................................... 17

2.1.2.1 Collection of Embryonic Brain Tissue ............................................... 17

2.1.2.2 Primary Culture of NS/PCs from the Cortex...................................... 18

2.1.2.3 Characterization and Differentiation of NS/PCs ................................. 19

2.1.2.4 Propagation and Cryopreservation of NS/PCs ................................... 19

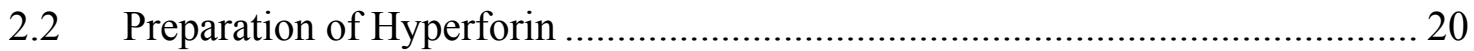

2.2.1 Treatment of CG-4 Cells with Hyperforin............................................... 21

2.2.2 Treatment of NS/PCs with Hyperforin ...................................................... 21

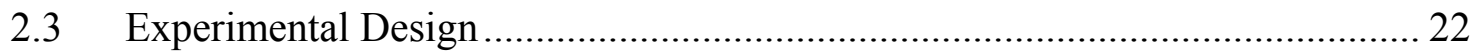

2.3.1 Effect of Hyperforin on Proliferation in CG-4 Cells and NS/PCs.............. 22

2.3.2 Effect of Hyperforin on Mitochondrial Function in CG4 Cells and NS/PCs

2.3.3 Effect of Hyperforin on Rotenone-induced ATP Depletion ....................... 23

2.3.4 Effect of Hyperforin on the Development of Oligodendrocytes in Differentiating NS/PCs.......................................................................... 23

$2.4 \quad$ Tetrazolium Microplate Assays ………………............................................. 24

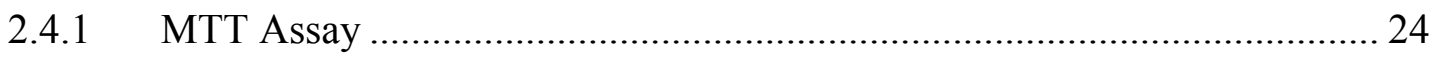

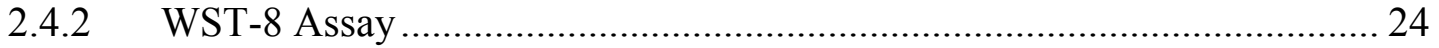

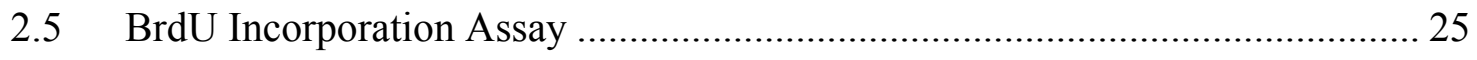

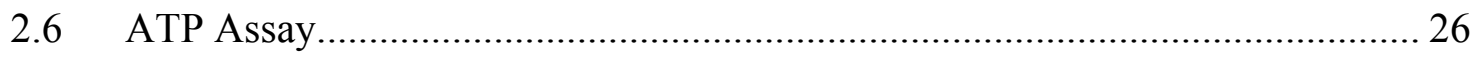

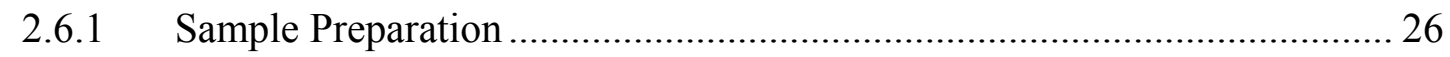




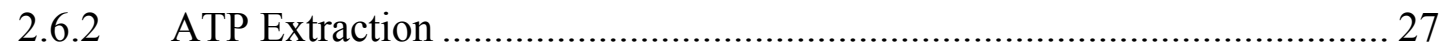

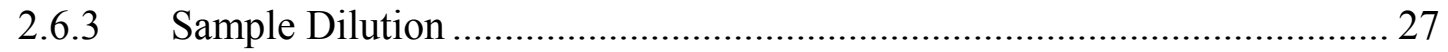

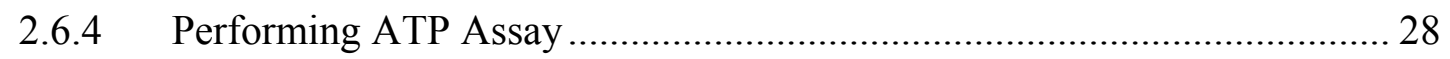

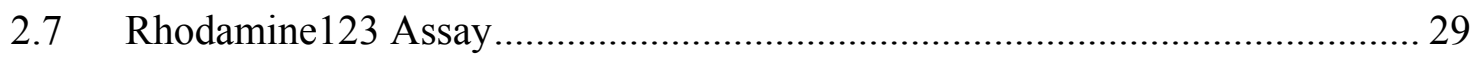

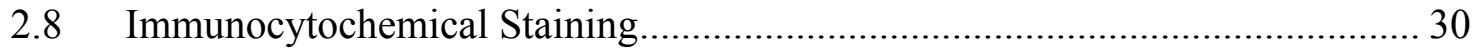

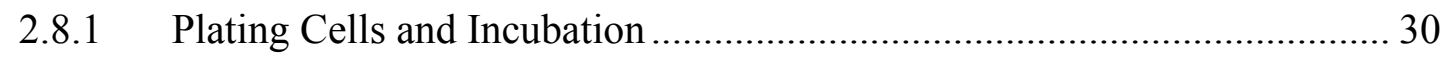

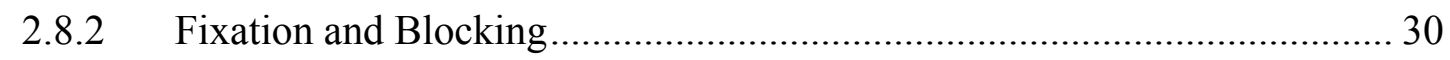

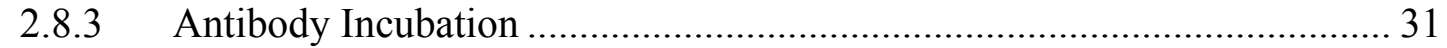

2.8.4 Hoechst 33342 Staining ....................................................................... 31

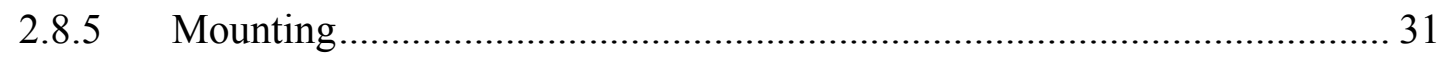

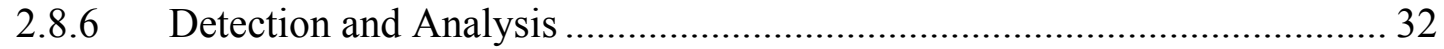

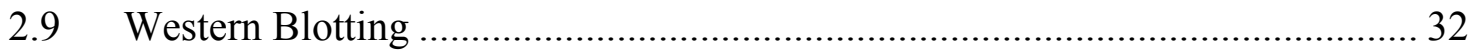

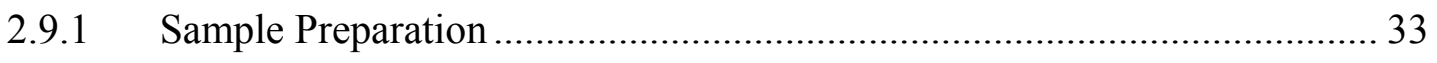

2.9.1.1 Extraction of Protein..................................................................... 33

2.9.1.2 Quantitation of Protein .................................................................... 33

2.9.2 Acrylamide Gel Preparation and Electrophoresis........................................ 34

2.9.2.1 Acrylamide Gel Preparation .......................................................... 34

2.9.2.2 Electrophoresis ......................................................................... 34

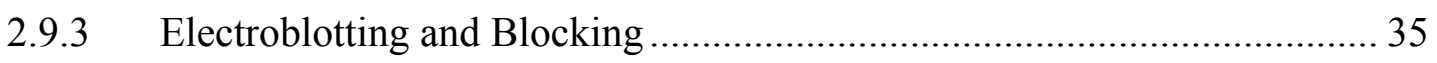

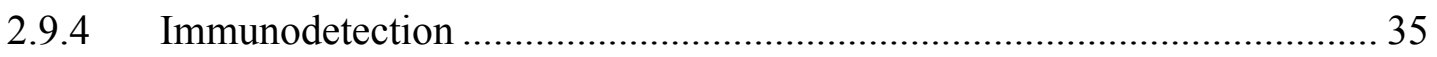

2.9.4.1 Blocking the Membrane ............................................................... 35

2.9.4.2 Incubation with Primary and Secondary Antibodies ........................... 36

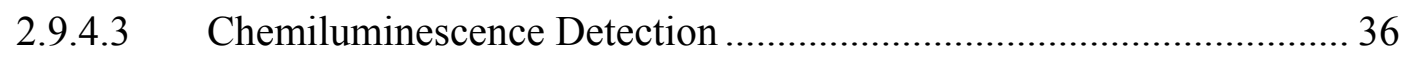

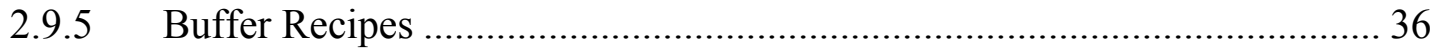

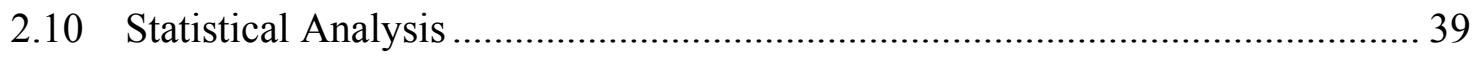

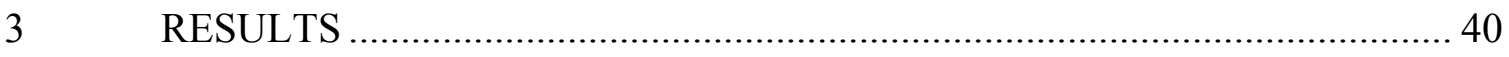

3.1 Effect of Hyperforin on the Proliferation of CG-4 Cells and NS/PCs ............... 40

3.1.1 Hyperforin Did Not Affect the Cell Viability of Proliferating CG-4 Cells at Concentrations between $0.0 \mu \mathrm{M}$ and $0.1 \mu \mathrm{M}$ but Inhibited the Cell Viability of Proliferating CG-4 Cells at Higher Concentrations 
3.1.2 Hyperforin Did Not Affect the Cell Viability of Proliferating NS/PCs at Concentrations between $0.0 \mu \mathrm{M}$ and $2.5 \mu \mathrm{M}$

3.2 Effects of Hyperforin on Mitochondrial Function in Differentiating CG-4 Cells and NS/PCs 45

3.2.1 Effects of Hyperforin on Mitochondrial Function-related Parameters and Cell Numbers of Differentiating CG-4 Cells at Different Concentrations. 46

3.2.1.1 MTT and WST-8 Assays................................................................. 46

3.2.1.2 Intracellular ATP Levels ............................................................... 51

3.2.1.3 Rhodamine123 Uptake ................................................................. 53

3.2.1.4 BrdU Incorporation and Viable Cell Number .................................... 55

3.2.2 Hyperforin Prevented Rotenone-induced ATP Depletion in Differentiating

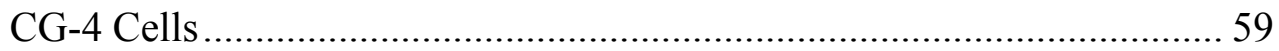

3.2.3 Effects of Hyperforin on Mitochondrial Function-related Parameters of Differentiating NS/PCs at Different Concentrations ................................... 61

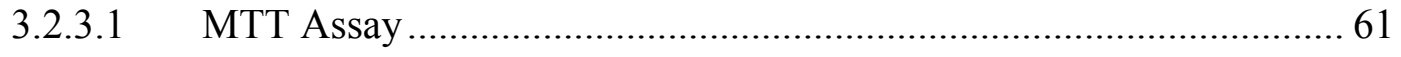

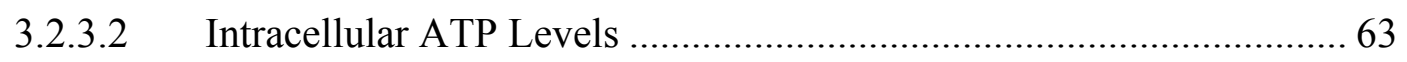

3.3 Effects of Hyperforin on Development of Oligodendrocytes in Differentiating

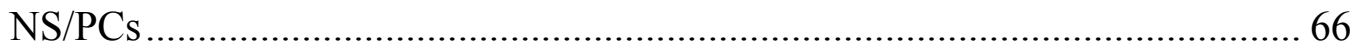

3.3.1 Characterization and Differentiation of NS/PCs......................................... 66

3.3.2 Hyperforin Increased Expressions of Proteins Related to Oligodendrocyte Development but not the Ratio of Oligodendrocyte Lineage Cells in

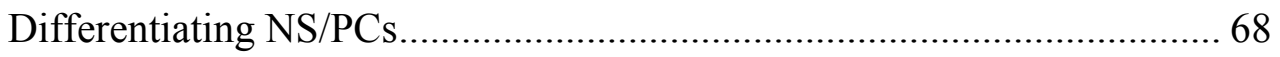

3.3.2.1 Hyperforin Increased both Ratios of MBP-positive Cells and Expressions of MBP in Differentiating NS/PCs................................. 69

3.3.2.2 Hyperforin Increased Expressions of CNPase in Differentiating

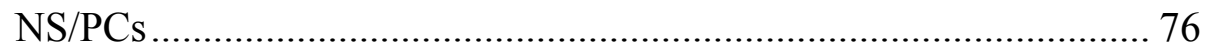

3.3.2.3 Hyperforin Increased Expressions of Olig2 but not Ratios of Olig2positive Cells in Differentiating NS/PCs ............................................ 79

3.3.3 Hyperforin did not Change Ratios of Astrocytes and Neurons and the Expression of GFAP in Differentiating NS/PCs 90 
4.1 Effects of Hyperforin on the Proliferation of CG-4 Cells and NS/PCs ........... 98

4.2 Effects of Hyperforin on Mitochondrial Function and Survival of Differentiating

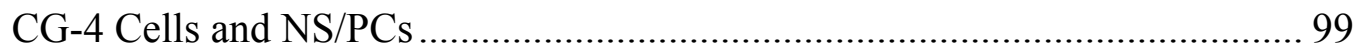

4.2.1 Hyperforin Increases Mitochondrial Function of Differentiating CG-4 Cells

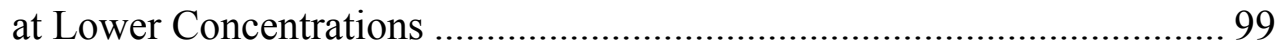

4.2.2 Hyperforin Protects CG-4 Cells from Rotenone-induced ATP Depletion 101

4.2.3 Hyperforin Increases Mitochondrial Function of CG-4 Cells and NS/PCs at Different Dose Ranges

4.3 Effects of Hyperforin on Development of Oligodendrocytes ........................ 103

4.3.1 The Relationship between Increased Mitochondrial Function and Accelerated Development of Oligodendrocytes................................. 105

4.4 Implications of Antidepressant Treatment on Mitochondrial Function and Development of Oligodendrocytes in MDD.............................................. 107

4.4.1 Antidepressant Treatment May Prevent the Mitochondrial DysfunctionRelated Oligodendrocyte Malfunction in MDD .................................. 108

4.4.2 Antidepressant Treatment May Increase Functioning of Oligodendrocytes in MDD.

4.4.3 The Mechanism of Action for Chronic Antidepressant Treatment May be Mediated through Oligodendrocytes. 112

4.5 Future Studies Are Needed to Decipher the Underlying Mechanism of Hyperforin in Promoting Oligodendrocyte Function.................................... 113 


\section{LIST OF TABLES}

Table 2.1 Recipes of growth medium and differentiation medium for CG-4 cells .......... 15

Table 2.2 Recipes of growth medium and differentiation medium for NS/PCs .............. 19

Table 2.3 Recipes of separating gel and stacking gel for SDS-PAGE .......................... 34

Table 3.1 Ratios of MBP-positive cells to total NS/PCs after $96 \mathrm{~h}$ of hyperforin treatment

Table 3.2 Ratios of Olig2-positive cells to total NS/PCs after $24 \mathrm{~h}$ of hyperforin treatment

Table 3.3 Ratios of Olig2-positive cells to total NS/PCs after $96 \mathrm{~h}$ of hyperforin treatment

Table 3.4 Ratios of GFAP-positive cells to total NS/PCs after $96 \mathrm{~h}$ of hyperforin treatment. 93

Table 3.5 Ratios of $\beta$-III tubulin-positive cells to total NS/PCs after $96 \mathrm{~h}$ of hyperforin treatment 


\section{LIST OF FIGURES}

Figure 1.1 Chemical structures of hyperforin and Hyp.DCHA salt ............................. 9

Figure 2.1 Areas of cell counting in immunocytochemical staining ............................ 32

Figure 3.1 Cell viability of proliferating CG-4 cells after $24 \mathrm{~h}$ of hyperforin treatment by

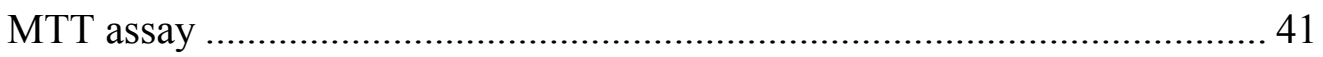

Figure 3.2 Cell viability of proliferating CG-4 cells after $48 \mathrm{~h}$ of hyperforin treatment by

MTT assay .....

Figure 3.3 Cell viability of proliferating NS/PCs after $24 \mathrm{~h}$ of hyperforin treatment by WST-8 assay 43

Figure 3.4 Cell viability of proliferating NS/PCs after $48 \mathrm{~h}$ of hyperforin treatment by WST-8 assay 44

Figure 3.5 Cell viability of differentiating CG-4 cells after $24 \mathrm{~h}$ of hyperforin treatment by MTT assay 47

Figure 3.6 Cell viability of differentiating CG-4 cells after $48 \mathrm{~h}$ of hyperforin treatment by MTT assay 48

Figure 3.7 Cell viability of differentiating CG-4 cells after $24 \mathrm{~h}$ of hyperforin treatment by WST-8 assay

Figure 3.8 Cell viability of differentiating CG-4 cells after $48 \mathrm{~h}$ of hyperforin treatment by WST-8 assay 50

Figure 3.9 Intracellular ATP levels in differentiating CG-4 cells after $24 \mathrm{~h}$ of hyperforin treatment 51

Figure 3.10 Intracellular ATP levels in differentiating CG-4 cells after $48 \mathrm{~h}$ of hyperforin treatment

Figure 3.11 Rhodamine123 uptake in differentiating CG-4 cells after $24 \mathrm{~h}$ of hyperforin treatment 53

Figure 3.12 Rhodamine123 uptake in differentiating CG-4 cells after $48 \mathrm{~h}$ of hyperforin treatment....... 54

Figure 3.13 BrdU incorporation in differentiating CG-4 cells after $24 \mathrm{~h}$ of hyperforin treatment 56 
Figure 3.14 BrdU incorporation in differentiating CG-4 cells after $48 \mathrm{~h}$ of hyperforin treatment

Figure 3.15 Viable cell numbers in differentiating CG-4 cell culture after $48 \mathrm{~h}$ of hyperforin treatment. 58

Figure 3.16 Intracellular ATP levels in differentiating CG-4 cells after $24 \mathrm{~h}$ pretreatment of hyperforin and $24 \mathrm{~h}$ insult of rotenone

Figure 3.17 Cell viability of differentiating NS/PCs after 24 h of hyperforin treatment.. 61

Figure 3.18 Cell viability of differentiating NS/PCs after 48 h of hyperforin treatment.. 62 Figure 3.19 Intracellular ATP levels in differentiating NS/PCs after $24 \mathrm{~h}$ of hyperforin treatment 64

Figure 3.20 Intracellular ATP levels in differentiating NS/PCs after $48 \mathrm{~h}$ of hyperforin treatment

Figure 3.21 Fluorescent microphotographs of proliferating NS/PCs and differentiating NS/PCs 67

Figure 3.22 Fluorescent microphotographs of NS/PCs expressing MBP after $96 \mathrm{~h}$ of differentiation. 70

Figure 3.23 Fluorescent microphotographs of differentiating NS/PCs expressing MBP after $96 \mathrm{~h}$ of differentiation with hyperforin treatment 71

Figure 3.24 Total viable cell numbers of NS/PCs after $96 \mathrm{~h}$ of differentiation with hyperforin treatment. 73

Figure 3.25 Ratios of MBP-positive cells to total NS/PCs after $96 \mathrm{~h}$ of differentiation with hyperforin treatment

Figure 3.26 Chemiluminescent detections of MBP and $\beta$-actin in NS/PCs after $96 \mathrm{~h}$ of differentiation with hyperforin treatment. 75

Figure 3.27 Chemiluminescent detections of CNPase and $\beta$-actin in NS/PCs after $48 \mathrm{~h}$ of differentiation with hyperforin treatment.

Figure 3.28 Chemiluminescent detections of CNPase and $\beta$-actin in NS/PCs after $96 \mathrm{~h}$ of differentiation with hyperforin treatment. 78

Figure 3.29 Fluorescent microphotographs of differentiating NS/PCs expressing Olig2 after $96 \mathrm{~h}$ of differentiation..... 80 
Figure 3.30 Fluorescent microphotographs of differentiating NS/PCs expressing Olig2 and MBP after $96 \mathrm{~h}$ of differentiation.

Figure 3.31 Fluorescent microphotographs of differentiating NS/PCs expressing Olig2 after $24 \mathrm{~h}$ of differentiation with hyperforin treatment

Figure 3.32 Ratios of Olig2-positive cells to total NS/PCs after $24 \mathrm{~h}$ of differentiation with hyperforin treatment

Figure 3.33 Fluorescent microphotographs of differentiating NS/PCs expressing Olig2 after $96 \mathrm{~h}$ of differentiation with hyperforin treatment 84

Figure 3.34 Ratios of Olig2-positive cells to total NS/PCs after $96 \mathrm{~h}$ of differentiation with hyperforin treatment

Figure 3.35 Chemiluminescent detections of Olig2 and $\beta$-actin in NS/PCs after $24 \mathrm{~h}$ of differentiation with hyperforin treatment 86

Figure 3.36 Chemiluminescent detections of Olig2 and $\beta$-actin in NS/PCs after $48 \mathrm{~h}$ of differentiation with hyperforin treatment.

Figure 3.37 Chemiluminescent detections of Olig2 and $\beta$-actin in NS/PCs after $96 \mathrm{~h}$ of differentiation with hyperforin treatment. 88

Figure 3.38 Expressions of Olig2, CNPase and MBP in NS/PCs after $96 \mathrm{~h}$ of hyperforin treatment

Figure 3.39 Fluorescent microphotographs of differentiating NS/PCs expressing GFAP after $96 \mathrm{~h}$ of differentiation. 91

Figure 3.40 Fluorescent microphotographs of differentiating NS/PCs expressing GFAP after $96 \mathrm{~h}$ of differentiation with hyperforin treatment

Figure 3.41 Ratios of GFAP-positive cells to total NS/PCs after $96 \mathrm{~h}$ of differentiation with hyperforin treatment 93

Figure 3.42 Chemiluminescent detections of GFAP and $\beta$-actin in NS/PCs after $96 \mathrm{~h}$ of differentiation with hyperforin treatment.

Figure 3.43 Fluorescent microphotographs of differentiating NS/PCs expressing $\beta$-III tubulin after $96 \mathrm{~h}$ of differentiation 95

Figure 3.44 Fluorescent microphotographs of differentiating NS/PCs expressing $\beta$-III tubulin after $96 \mathrm{~h}$ of differentiation with hyperforin treatment. 96 
Figure 3.45 Ratios of $\beta$-III tubulin-positive cells to total NS/PCs after $96 \mathrm{~h}$ of differentiation with hyperforin treatment.............................................. 97 


\section{LIST OF ABBREVIATIONS}

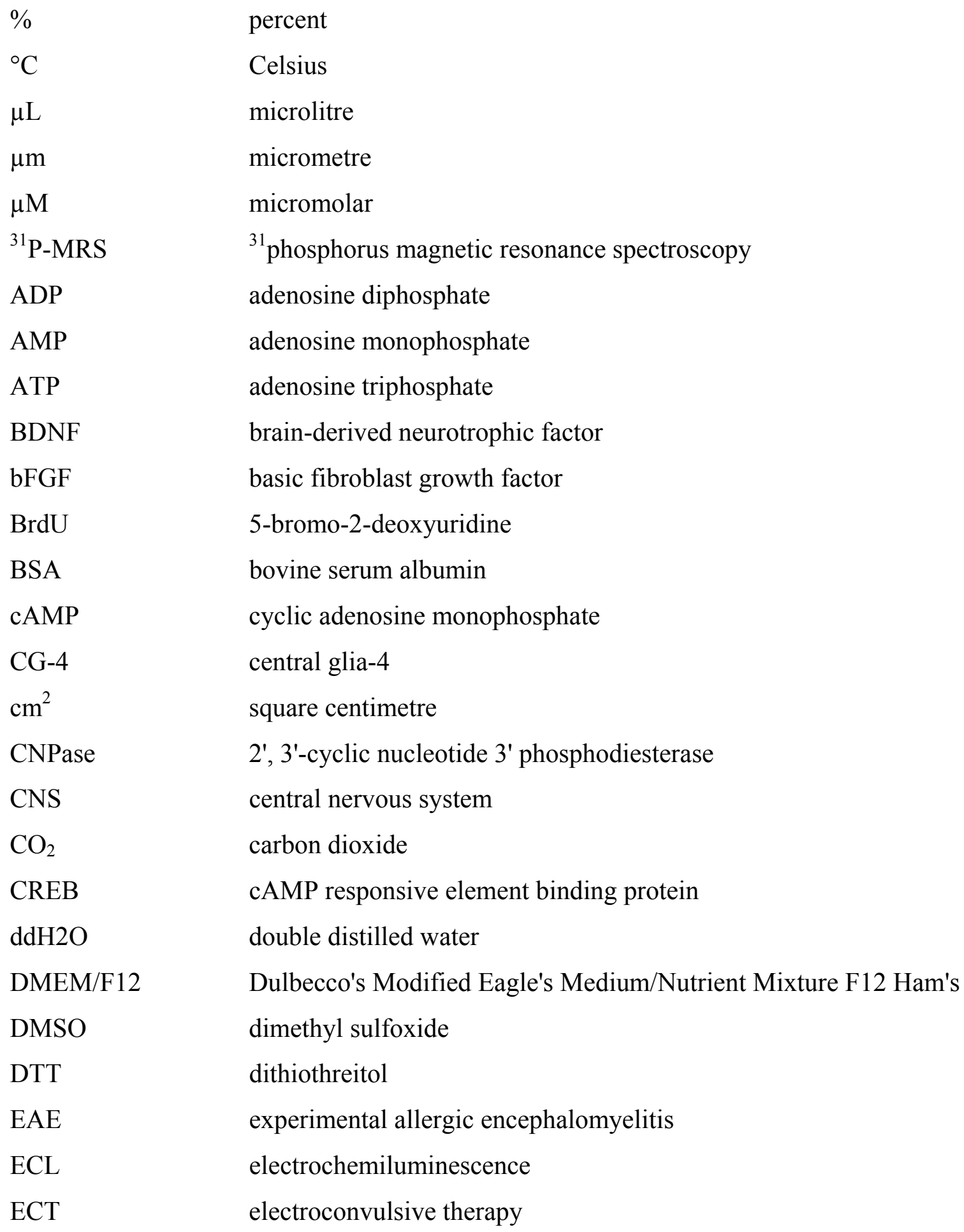




\begin{tabular}{|c|c|}
\hline EDTA & ethylene diamine tetraacetic acid \\
\hline EGF & epidermal growth factor \\
\hline ELISA & enzyme linked immunosorbent assay \\
\hline FBS & fetal bovine serum \\
\hline $\mathrm{g}$ & gram \\
\hline GABA & gamma-aminobutyric acid \\
\hline GalC & galactocerebroside \\
\hline GFAP & glial fibrillary acidic protein \\
\hline $\mathrm{GI}_{50}$ & growth inhibition 50 \\
\hline h & hour \\
\hline $\mathrm{H}_{2} \mathrm{SO}_{4}$ & sulphuric acid \\
\hline HBSS & Hank's balanced salt solution \\
\hline HPLC & high-performance liquid chromatography \\
\hline HPLC/MS/MS & $\begin{array}{l}\text { high-performance liquid chromatography tandem } \\
\text { spectroscopy }\end{array}$ \\
\hline Hyp.DCHA & hyperforin.dicyclohexylammonium salt \\
\hline $\mathrm{IC}_{50}$ & inhibitory concentration 50 \\
\hline $\mathrm{IFN} \gamma$ & interferon gamma \\
\hline IGF & insulin-like growth factor \\
\hline IGF-I & insulin-like growth factor I \\
\hline M & molar \\
\hline MAG & myelin associated glycoprotein \\
\hline MAOI & monoamine oxidase inhibitor \\
\hline MBP & myelin basic protein \\
\hline MDD & major depressive disorder \\
\hline $\mathrm{mg}$ & milligram \\
\hline $\min$ & minute \\
\hline $\mathrm{mL}$ & millilitre \\
\hline $\mathrm{mm}$ & millimeter \\
\hline $\mathrm{mM}$ & millimolar \\
\hline
\end{tabular}




\begin{tabular}{|c|c|}
\hline MRI & magnetic resonance imaging \\
\hline MS & multiple sclerosis \\
\hline MTT & 3-(4, 5-Dimethylthiazol-2-yl)-2, 5-diphenyltetrazolium bromide \\
\hline NADH & nicotinamide adenine dinucleotide \\
\hline ng & nanogram \\
\hline NGF & nerve growth factor \\
\hline $\mathrm{Nkx} 2.2$ & NK2 homeobox 2 \\
\hline $\mathrm{nm}$ & nanometre \\
\hline $\mathrm{NS} / \mathrm{PC}$ & neural stem/progenitor cell \\
\hline NT-3 & neurotrophin-3 \\
\hline $\mathrm{O}-2 \mathrm{~A}$ & oligodendrocyte-type 2 astrocyte \\
\hline Olig2 & oligodendrocyte lineage transcription factor 2 \\
\hline $\mathrm{OPC}$ & oligodendrocyte progenitor cell \\
\hline PBS & phosphate buffered saline \\
\hline PDGF & platelet-derived growth factor \\
\hline PET & positron emission tomography \\
\hline PFA & paraformaldehyde \\
\hline $\mathrm{Pi}$ & inorganic phosphate \\
\hline PMSF & phenylmethylsulfonyl Fluoride \\
\hline PNS & peripheral nervous system \\
\hline PPAR $-\gamma$ & peroxisome proliferator activated receptor- $\gamma$ \\
\hline PPi & inorganic pyrophosphate \\
\hline PVDF & polyvinylidene fluoride \\
\hline RIPA & radio immunoprecipitation assay \\
\hline ROS & reactive oxygen species \\
\hline SD rat & Sprague-Dawley rat \\
\hline SDS-PAGE & sodium dodecyl sulphate- polyacrylamide gel electrophoresis \\
\hline SEM & standard error of the mean \\
\hline SJW & St. John's wort \\
\hline SNRI & serotonin norepinephrine reuptake inhibitor \\
\hline
\end{tabular}


SSRI

TBST

TCA

WST-8

X g selective serotonin reuptake inhibitor

Tris-Buffered Saline Tween-20

tricyclic antidepressant

2-(2-methoxy-4-nitrophenyl)-3-(4-nitrophenyl)-5-(2,4-

disulfophenyl)-2H tetrazolium, monosodium salt

times gravity 


\section{INTRODUCTION}

\subsection{Major Depressive Disorder}

\subsubsection{Definition and Epidemiology}

Major depressive disorder (MDD), also known as clinical depression, is a very common psychiatric disorder. The overall lifetime prevalence of MDD is estimated at $17.1 \%$ in the United States and 8.6\% in Canada (2001; Blazer et al., 1994). Patients with depression usually experience fatigue, poor sleep, irritability, feeling of hopelessness and loss of interest and pleasure (2000). Depression causes cognitive impairment, psychomotor activity retardation and social withdrawal in patients. Severe depression induces suicidal ideation, which increases the potential risk of mortality of this disease. The risk of suicide for severe MDD patients is estimated to be 15\% (Guze and Robins, 1970) and approximately $8.6 \%$ of hospitalized MDD patients eventually commit suicide (Bostwick and Pankratz, 2000).

\subsubsection{Etiology and Pathophysiology}

The etiology of MDD is unknown; however there are genetic, neurobiological and psychosocial risk factors. The familial nature of MDD has been observed for many years. However, many molecular genetic studies have failed to connect potential gene markers to the risk of MDD, because interactions of multiple genes and psychosocial environment were quite complicated (Oswald et al., 2004; Reus and Freimer, 1997). Multiple psychosocial risk factors can influence the vulnerability to MDD, but the influence of environmental stressors from psychosocial factors is also complicated. Over last 50 years 
many studies have investigated the etiology of MDD, and several neurobiological theories have been introduced.

\subsubsection{Monoamine Deficiency in MDD}

The monoamine theory dominated neurobiological studies of depression for several decades. Clinical observations have found decreased monoamine function in the brains of patients with depression, and most antidepressants have been found to enhance serotonin and norepinephrine transmission in the brains of patients with MDD (Berton and Nestler, 2006). Both medication-induced monoamine depletion and dietary restriction of tryptophan can produce depressive symptoms in remitted depressed patients (Krishnan and Nestler, 2008; Moreno et al., 2000). However, antidepressant treatment need weeks to show the mood-enhancing effects in patients with MDD (Berton and Nestler, 2006), which suggests that more neurobiological changes go beyond the monoamine deficiency.

\subsubsection{Hippocampal Neuron Loss in MDD}

Recent neuroimaging studies have demonstrated that the volume of the hippocampus is decreased in brains of patients with MDD (Sheline, 2000). Chronic repeated restraint stress, a behavioral model that mimics a depressive-like state in animals, causes atrophy and loss of pyramidal neurons in the hippocampus. The atrophy and loss of hippocampal neurons are mainly due to lack of neurotrophic support from neurotrophins including the brain-derived neurotrophic factor (BDNF), nerve growth factor (NGF) and neurotrophin3 (NT-3) (Smith et al., 1995). In a postmortem study, the BDNF expression was reduced in the brains of patients with MDD, but it remained unchanged in patients receiving antidepressant treatment (Chen et al., 2001b). Chronic stress-induced hypersecretion of glucocorticoids also decreases neurogenesis and induces neuronal apoptosis in the hippocampus (Joels et al., 2004; Lucassen et al., 2006). 


\subsubsection{Oligodendrocyte Loss in MDD}

Psychiatric disorders such as MDD, schizophrenia and bipolar disorder are associated with white matter deficits in postmortem studies (Fields, 2008). White matter is composed of neuronal axons wrapped in myelin. Oligodendrocytes, found in the white matter, play an important role in information processing by generating myelin which regulates the velocity and synchrony of impulse conduction between different cortical regions.

A reduction in white matter reduction has been observed in the prefrontal cortex and the limbic system in postmortem studies and structural neuroimaging studies such as magnetic resonance imaging (MRI) in patients with MDD (Cotter et al., 2001; Ongur et al., 1998). These brain regions are involved in the neural circuits of emotional behavior. Oligodendroglial density in the prefrontal cortex of MDD patients is $19 \%$ lower than in normal controls (Uranova et al., 2004). On the contrary, there is only a decrease in neuronal size in the same brain area without a significant decrease in neuronal density (Rajkowska et al., 1999). The reduction of the neuronal size is probably due to the loss of oligodendrocyte support. One postmortem study has also found that the decreased number of glia in the amygdala, an essential area for emotional attention, motivation and social behavior (Phelps and LeDoux, 2005), is mainly due to the decreased number of oligodendrocytes in the brains of patients with MDD (Hamidi et al., 2004). The decrease of myelin basic protein (MBP), a mature oligodendrocyte functional protein, is reported in the frontal cortex of MDD patients (Honer et al., 1999). In postmortem studies, downregulations of both oligodendrocyte precursor development-related genes and oligodendrocyte myelin formation-related genes have been observed in the temporal cortex (Aston et al., 2005). The myelin staining of deep white matter in the brains of patients with MDD was decreased in the dorsolateral prefrontal cortex which has extensive axonal connections to the limbic system and to the cortices (Regenold et al., 2007; Taylor et al., 2004). In an in vivo study, the toxin-induced glial cell loss alone was sufficient to induce depressive-like state in the rat without affecting neurons in prefrontal cortex (Banasr and Duman, 2008). Notably, the lifetime risk of MDD for patients with 
multiple sclerosis (MS), a chronic autoimmune disease with myelin loss in the central nervous system (CNS), is around 50\% (Arnett et al., 2008) which suggests that the loss of oligodendrocytes in CNS may be directly related to the onset of depression. These studies suggest that the malfunction and loss of oligodendrocytes in the prefrontal cortex, amygdala and limbic system are involved in the neuropathology of major depression. Oligodendrocytes can express various neurotrophic factors that influence the survival and function of nearby neurons (Du and Dreyfus, 2002). The expressions of BDNF, NT-3 and insulin-like growth factor (IGF) in oligodendrocytes have already been indentified in animal tissue (Dai et al., 2001). Lower numbers of oligodendrocytes may cause the disruption of neurocircuitry and less neurotrophic support for pyramidal neurons in the hippocampus (Angelucci et al., 2005). The loss of hippocampal neurons could be a consequence of oligodendrocyte loss.

\subsection{Treatment of MDD}

The goal of treatment for MDD is to restore the patients' normal working abilities and social functioning. Different options of treatment are chosen based on the severity of the state. Psychotherapy without medicine may be effective for mild to moderate depression. Antidepressant treatment is often used for moderate to severe depression. Generally, 50\% to $70 \%$ of patients respond positively to the antidepressant treatment (Schosser and Kasper, 2009). Electroconvulsive therapy (ECT) may be used for patients with severe depression who have not responded to pharmacotherapy, but the risk of safety and amnesia is usually a concern with ECT treatment. In addition to synthetic antidepressants, herbal products with antidepressant effects are also widely used for depression. There is an increased use of antidepressants by patients with mood disorders (Hsia and Maclennan, 2009; Raymond et al., 2007), and it is important to explore their mechanisms of action and to search for more effective and safer antidepressants. 


\subsubsection{Antidepressants Increase Monoaminergic Neurotransmission}

Most antidepressants affect monoaminergic neurotransmission. Antidepressants exert their acute effect mainly by increasing the availability of serotonin, norepinephrine or both in the synaptic cleft (Berton and Nestler, 2006). Some antidepressants inhibit the presynaptic reuptake transporters of monoamines. Tricyclic antidepressants (TCAs), selective serotonin reuptake inhibitors (SSRIs) and serotonin norepinephrine reuptake inhibitors (SNRIs) are in this category. Others inhibit degradation enzymes of these monoamines, for example monoamine oxidase inhibitors (MAOIs) (Charney, 1998; Schildkraut, 1995). Most newly developed antidepressants are still based on this acute mechanism of action. Although antidepressants immediately increase the monoamine levels in the brain, they need to be administered for at least 2-3 weeks to show the moodenhancing effects (Pacher and Kecskemeti, 2004). It is now generally believed that other mechanisms of action underly the chronic antidepressant treatment.

\subsubsection{Antidepressants Induce Neurogenesis in the Hippocampus}

Currently, the induction of neurogenesis in the hippocampus is considered as one of the mechanisms of action for chronic antidepressant treatment. Chronic treatment with various antidepressants can upregulate cAMP responsive element binding protein (CREB), a transcription factor that activates the genes controlling the expressions of BDNF and its receptor, TrkB (Deogracias et al., 2004; Duman, 2002). In an animal study, activation of CREB has showed antidepressant effects in the forced swim test (Chen et al., 2001a). By upregulating the expressions of BDNF and its receptor in the hippocampus, antidepressants can induce neurogenesis and prevent neurons from stress-induced atrophy and damage (Warner-Schmidt and Duman, 2006). Chronic treatment rather than acute treatment with TCAs, SSRIs or MAOIs increases the expression of BDNF in the hippocampus of animal models (Duman and Monteggia, 2006). 


\subsubsection{Treatment of MDD and Increased Genesis and Survival of Oligodendrocytes}

Although much evidence of pathological changes in oligodendrocytes has been found, only a few studies have begun to evaluate the effects of antidepressant treatment on oligodendrocytes. Fluoxetine, a widely prescribed SSRI for depression, induces both neurogenesis and gliogenesis in the hippocampus and the prefrontal cortex of chronic stress rat model (Czeh et al., 2007). Fluoxetine and imipramine, a TCA for depression, reverse the loss of neural stem cells in the subventricular zone of a mouse brain after chronic stress (Hitoshi et al., 2007), and these surviving neural stem cells may contribute to the neurogenesis and gliogenesis in the hippocampus and the prefrontal cortex in this mouse. ECT increases the number of mature oligodendrocytes and NG2-positive glial cells which are bipotential glial progenitors in the adult rat amygdala (Wennstrom et al., 2004). ECT also induces cell proliferation in the adult rat prefrontal cortex, and $60 \%$ of the newly generated cells have been identified as oligodendrocytes or endothelial cells (Madsen et al., 2005). Environment enrichment has been found to reduce depressive-like behavior in animal model, stimulate proliferation of oligodendrocyte progenitor cells (OPCs) and prevent cell death of OPCs in the mouse amygdala (Brenes et al., 2008; Okuda et al., 2009). Preventing oligodendrocyte loss and promoting genesis of oligodendrocytes are potential mechanisms of action for antidepressant treatment.

\subsection{St. John's Wort in the Treatment of MDD}

\subsubsection{St. John's Wort as a Medicinal Herb for Psychiatric Disorders}

St. John's wort (Hypericum perforatum L., SJW) is a well-known medicinal herb widely distributed in Europe, West Asia and North Africa. It has been used externally or internally to treat respiratory and inflammatory diseases, pectic ulcers and skin wounds for 2000 years (Medina et al., 2006). In the 1500s, the Swiss physician Paracelsus first used SJW as treatment for psychiatric disorders, such as anxiety, neurosis and depression (Bilia et al., 2002). In 1984, the German Federal Health Agency published a monograph 
about SJW, recommending its use for depressive moods, anxiety, and nervous unrest. SJW is now wildly accepted as an herbal alternative to synthetic antidepressant treatment for depression. In Germany, it is prescribed four times more often than commonly used synthetic antidepressants. In the United States, it is the second most used medicinal herb and is consumed by $17 \%$ of Americans (Beaubrun and Gray, 2000).

\subsubsection{Clinical Efficacy of SJW for MDD}

Many randomized and double-blind clinical trials have compared the efficacy and safety of standard SJW extracts to placebos and synthetic antidepressants with inconsistent results. In 2005, a meta-analysis of 37 randomized controlled trials, including 26 comparisons with placebo and 14 comparisons with synthetic antidepressants has concluded that SJW is more effective than placebos (Linde et al., 2005), and is as effective as synthetic antidepressants such as amitriptyline (Wheatley, 1997), fluoxetine (Schrader, 2000) and imipramine (Woelk, 2000) in the treatment of mild to moderate depression. In 2008, the Cochrane Database Systematic Review of SJW for major depression has further suggested that SJW is superior to placebos in patients with MDD and is similarly effective as synthetic antidepressants with fewer side effects than synthetic antidepressants (Linde et al., 2008). This review was composed of 29 trials consisting of 5,489 patients receiving 4 to 12 weeks of treatment, including 18 comparisons with placebos and 17 comparisons with synthetic standard antidepressants. A clinical trial of SJW conducted on behalf of NIH failed to support efficacy in severe MDD (2002). However, patients' plasma levels of hyperforin, a major effective component of SJW, were not detectable after treatment with different preparations of SJW (Vitiello et al., 2005), and SJW was no different from a proven antidepressant, which may suggest a difficult-to-treat population. While the results from the different clinical trials are inconsistent, there appears to be evidence from clinical trials to support the clinical efficacy of SJW for depression with varying severities. SJW is safe and welltolerated compared with synthetic antidepressants, and the side effects of SJW are generally mild and transient (Bilia et al., 2002). 


\subsection{Hyperforin as an Antidepressant Extract of SJW}

The most commonly used standard extracts of SJW are hydroalcoholic extracts of the aerial portion of the plant (Mennini and Gobbi, 2004). There are several categories of compounds in the standard extract of SJW. Phloroglucinols, naphthodianthrones and flavonoids are considered to be related to the antidepressant effect of SJW. Hypericin, a naphtodianthrone, was initially considered as the major antidepressant component in SJW, because it showed inhibitive effect on monoamine oxidase to increase the availability of synaptic monoamines (Suzuki et al., 1984). However, a follow-up study reported that hypericin was not potent enough to inhibit monoamine oxidase from a dosage of $300 \mathrm{mg}$ of SJW three times per day (Bladt and Wagner, 1994). Flavonoids have many pharmacological effects, but very few studies have shown that they act as major antidepressant components in SJW (Paulke et al., 2008).

Hyperforin is a phloroglucinol extracted from SJW (Figure 1.1). It accounts for up to 6\% of the dry weight of SJW extract (Vitiello, 1999). Hyperforin is unstable when exposed to light and oxygen, so it was not considered as a candidate component with antidepressant effect (Maisenbacher and Kovar, 1992). However, in a randomized, double-blind clinical trial of 147 patients, the extract of SJW with 5\% hyperforin showed superior efficacy for depression compared to $0.5 \%$ hyperforin (Laakmann et al., 1998). This study concludes that the hyperforin content in the extract is mainly responsible for the antidepressant effect of SJW. The dicyclohexylammonium salt of hyperforin has been found to be more stable at room temperature with air exposure. Hyperforin.dicyclohexylammonium salt (Hyp.DCHA) (Figure 1.1) has been extensively used in in vivo antidepressant studies. In several animal studies, Hyp.DCHA has shown antidepressant effects, and the potency is correlated to the content of hyperforin (Cervo et al., 2002; Gambarana et al., 2001). Hyperforin is now considered the most important compound responsible for the antidepressant effect in the SJW extract. 


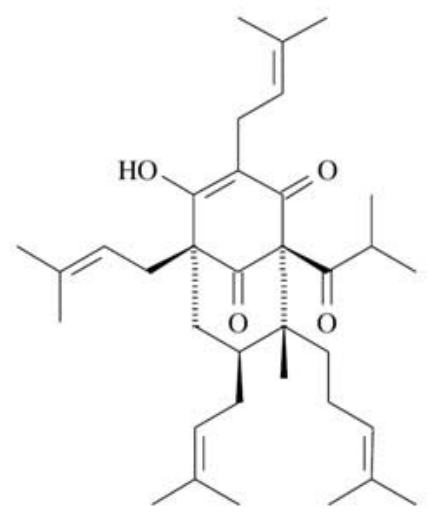

Hyperforin

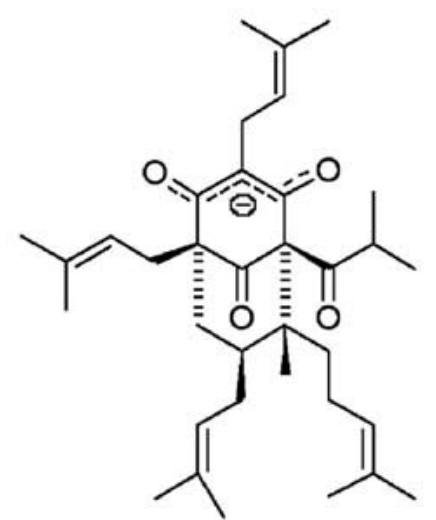

$\mathrm{O}^{\mathrm{C}}$

(Beerhues, 2006; Dona et al., 2004)

\section{Figure 1.1 Chemical structures of hyperforin and Hyp.DCHA salt}

\subsubsection{Pharmacokinetics of Hyperforin as an Antidepressant Compound}

The pharmacokinetic studies of hyperforin in human are only feasible after the application of ${ }^{14} \mathrm{C}$-labelled hyperforin and high-performance liquid chromatography tandem mass spectroscopy (HPLC/MS/MS) system which is a highly sensitive and selective method to detect hyperforin (Caccia, 2005). In rats, the maximum plasma level of hyperforin is approximately $690 \mathrm{nM} 3 \mathrm{~h}$ after oral administration of $300 \mathrm{mg} / \mathrm{kg}$ of SJW extract containing $5 \%$ hyperforin. In healthy human volunteers, the maximum plasma level of hyperforin is approximately $280 \mathrm{nM} 3.5 \mathrm{~h}$ after one time oral administration of $300 \mathrm{mg} /$ day of SJW extract containing 5\% hyperforin. The estimated steady-state plasma concentration of hyperforin after administration of SJW extract (300 mg, three times per day) is around $180 \mathrm{nM}$ in a repeated dose study (Biber et al., 1998). The inhibitory concentration $50\left(\mathrm{IC}_{50}\right)$ of hyperforin as an inhibitor of synaptic uptake of serotonin is between $120 \mathrm{nM}$ and 3,300 nM in different in vitro studies (Jensen et al., 2001; Muller et al., 1998; Singer et al., 1999). The daily consumption of $900 \mathrm{mg}$ of SJW extract is enough to reach the plasma concentration of hyperforin that will inhibit the synaptic 
reuptake of monoamines. The elimination half-life of hyperforin is $11.2 \mathrm{~h}$ in human volunteers at the daily dosage of $900 \mathrm{mg}$ of SJW extract (Biber, 1998). The estimated brain concentration of hyperforin is only between $30 \mathrm{nM}$ and $60 \mathrm{nM}$, about $4 \%$ of the equivalent plasma concentration, in mouse brains after oral administration of SJW extract (Keller et al., 2003).

\subsubsection{Mechanisms of Action for Hyperforin as an Antidepressant Compound}

Studies have revealed that hyperforin affects the monoaminergic neurotransmission by inhibiting synaptic reuptake of monoamines. However, hyperforin exerts this effect through a different mechanism compared with synthetic antidepressants. It shows a broad-band reuptake inhibition of many neurotransmitters such as serotonin, norepinephrine and dopamine at concentrations between $80 \mathrm{nM}$ and $200 \mathrm{nM}$ (Muller et al., 1998), and gamma-aminobutyric acid (GABA) and glutamate at concentrations between $100 \mathrm{nM}$ and $1000 \mathrm{nM}$ (Wonnemann et al., 2000). Follow-up studies provided a possible explanation for this unique mechanism of action for hyperforin. All known neurotransmitter transport proteins need to use the sodium gradient as the driving force. Hyperforin is able to reduce this sodium gradient by activating $\mathrm{Na}^{+}-\mathrm{H}^{+}$ionic channels and increasing sodium uptake into neurons (Muller et al., 2001; Singer et al., 1999). In addition, hyperforin can also increase the release of neurotransmitters into the synaptic cleft by opening presynaptic calcium channels (Chatterjee et al., 2001). Similar to synthetic antidepressants, the antidepressant effect of SJW needs 10 to 14 days of treatment to reduce symptoms (Di Carlo et al., 2001).

\subsection{Does Hyperforin Increase Genesis and Survival of Oligodendrocytes?}

Most mechanism studies have focused on the effects of hyperforin on monoaminergic neurotransmission of neurons. Like synthetic antidepressants, the delayed onset of the antidepressant effect with SJW treatment needed to be examined. Although many studies 
of hyperforin have focused on neurons, there has not been an examination of the effect of SJW or hyperforin on neurogenesis in the hippocampus. However, some studies have indicated that hyperforin may affect the genesis and survival of oligodendrocytes.

\subsubsection{Does Hyperforin Favor the Genesis of Oligodendrocytes?}

Hyperforin inhibits the interferon gamma (IFN $\gamma$ ) production in activated T lymphocytes in an experimental allergic encephalomyelitis (EAE) model, an animal model of MS with significant loss of oligodendrocytes (Cabrelle et al., 2008). Treatment targeting the rescue of oligodendrocytes and the genesis of oligodendrocytes may alleviate symptoms of MS. This study only focused on the protective effect of hyperforin through inhibiting the activation of T lymphocytes and cytotoxicity of IFN $\gamma$. Several studies have shown that an increased number of neural stem cells are generated from the subventricular zone in brains of both MS patients and MS mouse models, but the mobilization and differentiation of these neural stem cells and the replacement of oligodendrocytes are limited (Nait-Oumesmar et al., 2007; Nait-Oumesmar et al., 2008). Whether hyperforin can directly induce genesis of oligodendrocytes or promote differentiation and remyelination from these newly generated neural stem cells was not examined in this study.

\subsubsection{Does Hyperforin Increase Energy Metabolism in Oligodendrocytes?}

SJW and hyperforin concordantly regulate expressions of genes related to increasing glucose metabolism such as enhancement of glycolysis and cellular glucose uptake in a human hepatic cell line (Krusekopf and Roots, 2005). SJW and clomipramine, a TCA for depression, both increased protein expressions involved in the cytoskeleton and energy metabolism in a proteomic investigation with a mouse hippocampal cell line (Pennington et al., 2009). More specifically, SJW increases the expression of pyruvate dehydrogenase which is an important enzyme linking carbohydrate substrates from glycolysis to the citric acid cycle. 
Energy consumption of oligodendrocytes is very high during the process of myelination. To synthesize and maintain the myelin, oligodendrocytes need to operate at the highest metabolic rate of any cell in the brain (Pleasure et al., 1977). Most energy is used for acquiring iron to synthesize cholesterol and lipid in myelin and forming mitochondrial key enzymes to generate energy by oxidative phosphorylation (Connor and Menzies, 1996). During the maximal rate of myelination, energy consumption will reach the peak in the developing brain (Takahashi et al., 1999). Increased energy demand is considered a key factor in the process of differentiation and myelination. Significant malfunction of mitochondria and decreased energy metabolism were reported in the brains of patients with MDD (Buchsbaum et al., 1986; Drevets et al., 1997; Shao et al., 2008). Decreased energy metabolism could cause malfunction or loss of oligodendrocytes in the brains. The effect of hyperforin on the survival or differentiation of oligodendrocytes by increasing mitochondrial energy metabolism has not studied before. 


\subsection{Hypothesis and Objectives}

The acute mechanism of action for hyperforin as an antidepressant compound is increasing monoaminergic neurotransmission. Similar to synthetic antidepressants, this acute mechanism of action can not explain the delayed onset of its antidepressant effect. The chronic antidepressant effect of hyperforin is more likely mediated by increasing oligodendrocyte genesis or function. In this study, we examined the effect of hyperforin on the genesis, mitochondrial function and development of oligodendrocytes.

\subsubsection{Hypothesis}

Hyperforin promotes the genesis, mitochondrial function and development of oligodendrocytes.

\subsubsection{Objectives}

1. Evaluate the effects of hyperforin on proliferation of CG-4 cells and neural stem/progenitor cells (NS/PCs).

2. Evaluate the effects of hyperforin on mitochondrial function in differentiating CG-4 cells and NS/PCs.

3. Evaluate the effects of hyperforin on development of oligodendrocytes in differentiating NS/PCs. 


\section{MATERIALS AND METHODS}

\subsection{Cell Culture}

\subsubsection{The Central Glia-4 Cell Line}

Central glia-4 (CG-4) cell line is spontaneously generated from the glial cell cultures from cerebral cortices of Sprague-Dawley rat (SD rat) pups. The CG-4 cell line used in this study is a generous gift from Dr. Adil Nazarali in the College of Pharmacy and Nutrition, University of Saskatchewan. This cell line is a bipotential oligodendrocytetype 2 astrocyte (O-2A) progenitor cell line (Louis et al., 1992). The O-2A progenitor cells are able to differentiate into either oligodendrocytes or type 2-astrocytes in different culture media. Several kinds of mitogens, for example the platelet-derived growth factor (PDGF) and basic fibroblast growth factor (bFGF), can keep the proliferation of O-2A progenitor cells (Stariha and Kim, 2001). When the CG-4 cell line was first established, it was cultured in the conditioned medium generated from the culture of neuroblastoma B104 cells. Besides mitogens, other ingredients in the conditioned medium may also be responsible for keeping the proliferation of the CG-4 cells.

\subsubsection{Conditioned Medium of B104 Cell Culture}

B104 is a cell line obtained from a rat neuroblastoma (Schubert et al., 1974). B104 cells were maintained in the medium of Dulbecco's Modified Eagle's Medium/Nutrient Mixture F12 Ham's (DMEM/F12) (Fisher, SH30023.02) with 10\% fetal bovine serum (FBS) (Fisher, SH30396.03) (El Bitar et al., 1999). For each T75 flask, B104 cells were seeded at the density of $1 \times 10^{4}$ cells $/ \mathrm{cm}^{2}$ in $10 \mathrm{~mL}$ culture medium. Half of the medium 
was replaced with fresh medium every two days. When the culture was around $60 \%$ to 70\% confluent, cells were washed with Hank's Balanced Salt Solution (HBSS) (Invitrogen, 14170-112) once and fed with DMEM/F12 and N2 supplement (Invitrogen, 17520-048). After B104 cells were confluent in DMEM/F12 with N2 supplement for two days, this medium became the conditioned medium. The conditioned medium in each T75 flask was transferred into a $15 \mathrm{~mL}$ centrifuge tube with an addition of $5 \mu \mathrm{L}$ of 2 $\mathrm{mg} / \mathrm{mL}$ Phenylmethylsulfonyl Fluoride (PMSF) in isopropanol to make a final concentration of $1 \mu \mathrm{g} / \mathrm{mL}$ PMSF. The conditioned medium was centrifuged at $1000 \times \mathrm{g}$ for $10 \mathrm{~min}$. The supernatant was filtered with $0.2 \mu \mathrm{m}$ filter for sterilization and stored at $80^{\circ} \mathrm{C}$ for further use.

The growth medium of CG-4 consisted of $30 \%$ of the B104 conditioned medium, $70 \%$ of DMEM/F12 with N2 supplement, insulin-transferrin-selenium-A (Invitrogen, 51300-044) and human transferrin (Invitrogen, 0030124SA) (Table 2.1). The prepared growth medium maintained good mitogenic activity in $4^{\circ} \mathrm{C}$ for a week (McNulty et al., 2001).

Table 2.1 Recipes of growth medium and differentiation medium for CG-4 cells

\begin{tabular}{cc}
\hline Growth medium & Differentiation medium \\
\hline DMEM/F12 1:1 & DMEM/F12 1:1 \\
N2 supplement & N2 supplement \\
Insulin-Transferrin-Selenium-A & Insulin-Transferrin-Selenium-A \\
human transferrin & human transferrin \\
B104 condition medium & $2 \%$ FBS \\
\hline
\end{tabular}

\subsubsection{Propagation and Differentiation of CG-4 Cells}

CG-4 cells were grown in Poly-D-Lysine (Chemicon, A-003-E) coated 100mm tissue culture dishes with growth medium. The initial density of cells recovered from cryopreservation was $2 \times 10^{3}$ cells $/ \mathrm{cm}^{2}$ in growth medium. Half of the growth medium was replaced every two days, and cells were passaged every three days. To passage CG-4 
cells, cells were washed with $4 \mathrm{~mL}$ of harvesting medium consisting of $50 \%$ of HBSS, $50 \%$ of Versene (Invitrogen, 15040-066) with Insulin-Transferrin-Selenium-A. Cells were triturated 20 times, so they would detach from the surfaces of tissue culture dishes. The cell suspension was transferred into a $15 \mathrm{~mL}$ centrifuge tube and centrifuged at $120 \mathrm{x}$ $\mathrm{g}$ for $5 \mathrm{~min}$. After the supernatant was discarded, cells were resuspended in $4 \mathrm{~mL}$ of growth medium. The cell number was counted in a hemocytometer with $1 \%$ of trypan blue solution. Cells were seeded at a density of $1 \times 10^{3} \mathrm{cells} / \mathrm{cm}^{2}$ in a $100 \mathrm{~mm}$ tissue culture dish with $10 \mathrm{~mL}$ of growth medium. Cells were incubated at $37^{\circ} \mathrm{C}$ in a humidified atmosphere of $5 \% \mathrm{CO}_{2} / 95 \%$ air.

The differentiation of CG-4 cells was initiated by withdrawing the B104 conditioned medium and substituting it with 2\% of FBS (Table 2.1). CG-4 cells mainly differentiated into oligodendrocyte lineage cells in the presence of a low concentration of FBS (2\%) without any mitogen in the medium (Louis et al., 1992). CG-4 cells began to show morphological characteristics of mature oligodendrocytes within two days when maintained in the differentiation medium (Stariha and Kim, 2001).

\subsubsection{Cryopreservation and Recovery of CG-4 Cells}

Half of growth medium was replaced one day before cryopreservation. When cells were around $80 \%$ confluent, cells were harvested and counted with $1 \%$ of trypan blue solution. Cells were cryopreserved at the concentration of $2 \times 10^{4}$ cells $/ \mathrm{mL}$ in freezing medium, containing growth medium with $8 \%$ of dimethyl sulfoxide (DMSO). Cell suspension was transferred into labeled $1.5 \mathrm{~mL}$ cryovials. Cryovials were put in the controlled-rate freezing jar containing isopropyl alcohol. Cryovials were left in the jar at $-80^{\circ} \mathrm{C}$ for $24 \mathrm{~h}$ and then transferred into a liquid nitrogen tank for long-term storage.

Cryovials containing CG-4 cells from a liquid nitrogen tank were quickly transferred into a $37^{\circ} \mathrm{C}$ water bath and swirled for $2 \mathrm{~min}$ to facilitate the thawing. Cell suspension was transferred into a $15 \mathrm{~mL}$ centrifuge tube containing $8 \mathrm{~mL}$ of prewarmed growth medium. After gently being triturated 5 times, cell suspension was centrifuged at $120 \mathrm{x}$ g for $5 \mathrm{~min}$.

The supernatant was discarded. Cells were resuspended at the density of $2 \times 10^{2}$ cells $/ \mathrm{cm}^{2}$ 
in a $100 \mathrm{~mm}$ tissue culture dish with $10 \mathrm{~mL}$ of growth medium. Cells were incubated at $37^{\circ} \mathrm{C}$ in a humidified atmosphere of $5 \% \mathrm{CO}_{2} / 95 \%$ air.

\subsubsection{Neural Stem Cells and Neural Progenitor Cells}

Neural stem cells are undifferentiated cells that maintain the ability to proliferate and self renew. Neural stem cells can be isolated from embryonic and adult brains (Temple and Alvarez-Buylla, 1999). Neural stem cells are multipotent and able to differentiate into three types of functional cells: neurons, astrocytes, and oligodendrocytes. Four conditions are required for the neural stem cell culture: low cell density, an absence of serum, addition of the growth factors, such as epidermal growth factor (EGF) and/or bFGF, and an absence of a strong cell adhesion substrate (Gritti et al., 1999; Reynolds et al., 1992). Under these culture conditions, neural stem cells proliferate and aggregate into floating neurospheres. Neurospheres are a heterogeneous clonal group of cells expressing the neuroepithelial protein nestin, which is considered a marker of NS/PCs. Only a proportion of cells within a neurosphere are neural stem cells, while the other cells are neural progenitor cells. Due to lack of specific markers for neural stem cell, NS/PCs are used to refer to the cell population identified by nestin in the neurosphere culture (Gilyarov, 2008).

\subsubsection{Collection of Embryonic Brain Tissue}

Sterilized ice-cold HBSS containing $50 \mu \mathrm{g} / \mathrm{mL}$ gentamicin was prepared in several 100 $\mathrm{mm}$ and $35 \mathrm{~mm}$ tissue culture dishes for the process of dissection. At gestation day 16, the pregnant SD rat was anesthetized with isoflurane in an air-tight container. The pregnant SD rat was sacrificed by cervical dislocation after being anesthetized. The pregnant rat was laid on the paper towels and sprayed with $70 \%$ ethanol. The abdominal area was thoroughly rinsed with $70 \%$ ethanol. The skin above the genitalia was cut with large scissors to open the peritoneal cavity. The uterus was removed with sterilized scissors and forceps and then put into the first $100 \mathrm{~mm}$ dish with ice-cold HBSS. 
Embryos were removed from the uterus and transferred into the second $100 \mathrm{~mm}$ dish with ice-cold HBSS using a small scissor.

Heads of embryos were cut off just below the cervical region. The head was held with fine curved forceps from the caudal sides at the ears to position the head side up. The skull was cut and opened with microscissors. After the skull was opened, the brain was squeezed out of the skull by pushing on the front of the head. All brains were transferred into the third $100 \mathrm{~mm}$ dish with ice-cold HBSS and put under a dissecting microscope (10X magnification) for dissection. The meninges were teased off with microforceps. The cortices were dissected for primary culture. The dissection was completed in $2 \mathrm{~h}$, before the brain tissue became soft and sticky.

\subsubsection{Primary Culture of NS/PCs from the Cortex}

The cortices were cut into small pieces with microscissors and then transferred into a 15 $\mathrm{mL}$ centrifuge tube. To digest the cortices, $5 \mathrm{~mL}$ of accutase (Sigma, A6964) was added into the tube. The cortices were digested at $37^{\circ} \mathrm{C}$ with often pipetting to make a cloudy cell suspension. The cell suspension was passed through a $40 \mu \mathrm{m}$ sterile mesh to get the single cell suspension. The single cell suspension was centrifuged at $120 \mathrm{~g}$ for $5 \mathrm{~min}$. After the supernatant was discarded, cells were resuspended in $5 \mathrm{~mL}$ of growth medium containing DMEM/F12, B27 supplement (Invitrogen, 17504), $20 \mathrm{ng} / \mathrm{mL}$ bFGF (Chemicon, GF003) and $20 \mathrm{ng} / \mathrm{mL}$ EGF (Chemicon, 01-107) (Table 2.2). Cells were seeded at a density of $5 \times 10^{4}$ cells $/ \mathrm{cm}^{2}$ in a T-75 flask with $12 \mathrm{~mL}$ of growth medium. Cells were incubated at $37^{\circ} \mathrm{C}$ in a humidified atmosphere of $5 \% \mathrm{CO}_{2} / 95 \%$ air. Half of the medium was replaced every two days. The NS/PCs proliferated quickly to form neurospheres. After 5 days of proliferation in the growth medium, the average diameter of the neurospheres reached approximately $100 \mu \mathrm{m}$. From this point, the primary neurospheres were either used for characterization and experiments or passaged to avoid the differentiation and death of the cells inside the neurospheres due to the lack of supply of growth factors or nutrition. 


\subsubsection{Characterization and Differentiation of NS/PCs}

When the neurospheres were ready to be passaged, floating neurospheres were transferred into a well of a 24-well tissue culture plate with $670 \mu \mathrm{L}$ of growth medium. Neurospheres attached to Poly-D-Lysine coated sterile $20 \mathrm{~mm}$ diameter coverslips in the wells of a 24-well tissue culture plate after $4 \mathrm{~h}$. Immunocytochemical staining was used to detect the expression of the nestin in the neurospheres. The rabbit polyclonal to nestin (Abcam, ab5968) was used at a dilution of 1: 200 for the staining. Most cells were found nestin-positive in the neurospheres.

The spontaneous differentiation of NS/PCs was initiated by withdrawing the EGF and bFGF from the basal medium and substituting it with $2 \%$ of FBS (Table 2.2). The PolyD-Lysine coated surface favored the differentiation of the NS/PCs. After $72 \mathrm{~h}$ of differentiation in the differentiation medium, different biological markers were chosen to identify premature neurons, astrocytes and oligodendrocytes in the culture using immunocytochemical staining. NS/PCs in the neurospheres could differentiate into premature neurons, astrocytes and oligodendrocytes.

Table 2.2 Recipes of growth medium and differentiation medium for NS/PCs

\begin{tabular}{cc}
\hline Growth medium & Differentiation medium \\
\hline DMEM/F12 1:1 & DMEM/F12 1:1 \\
B27 supplement & B27 supplement \\
20ng/mL EGF and 20ng/mL bFGF & $2 \%$ FBS \\
\hline
\end{tabular}

\subsubsection{Propagation and Cryopreservation of NS/PCs}

NS/PCs were expanded to create stocks of cells for further experiments. The primary culture was named passage 0 and following passages were named passage 1 and 2, etc. Only passage 1 and passage 2 were used in this study. Neurospheres were transferred into a $15 \mathrm{~mL}$ centrifuge tube. Neurospheres would sink to the bottom of the tube in $10 \mathrm{~min}$. 
The supernatant was removed by suction. At this point, NS/PCs were either cryopreserved or propagated. To cryopreserve NS/PCs, neurospheres were maintained in growth medium containing 10\% DMSO. Neurospheres were transferred into $1.5 \mathrm{~mL}$ cryovials and put in the controlled-rate freezing jar. Cryovials were left in the jar at $-80^{\circ} \mathrm{C}$ for $24 \mathrm{~h}$ and then transferred into liquid nitrogen for long-term storage. To propagate NS/PCs, accutase was added to digest the neurospheres into single cell suspension. The neurospheres were digested at $37^{\circ} \mathrm{C}$ with often pipetting to make a cloudy cell suspension. Single cell suspension was centrifuged at $120 \mathrm{x}$ g for $5 \mathrm{~min}$. After the supernatant was discarded, cells were resuspended in $5 \mathrm{~mL}$ of growth medium. Cells were seeded at a density of $2 \times 10^{4}$ cells $/ \mathrm{cm}^{2}$ in a T-75 flask with $12 \mathrm{~mL}$ of growth medium. Cells were incubated at $37^{\circ} \mathrm{C}$ in a humidified atmosphere of $5 \% \mathrm{CO}_{2} / 95 \%$ air. Half of the growth medium was replaced every two days. Floating single cells would grow into neurospheres of NS/PCs in 5 days.

\subsection{Preparation of Hyperforin}

In this study, the hyperforin.dicyclohexylammonium salt was used instead of pure hyperforin. To prepare a stock solution at the concentration of $7 \mathrm{mM} / \mathrm{mL}, 1 \mathrm{mg}$ of hyperforin.dicyclohexylammonium salt (Alexis, ALX-350-097-M001) was dissolved in $200 \mu \mathrm{L}$ of DMSO. Each aliquot of $10 \mu \mathrm{L}$ stock solution in a $1.5 \mathrm{~mL}$ sterile tube was stored at $-80^{\circ} \mathrm{C}$ avoiding light for long-term storage. Different concentrations of hyperforin were freshly prepared by diluting the stock solution with sterile double distilled water $\left(\mathrm{ddH}_{2} \mathrm{O}\right)$. The concentrations of hyperforin in different assays are chosen based on preliminary studies and literature from similar studies. The dosage range usually is wide enough to show different effects of hyperforin at different concentrations in each assay. The concentrations of DMSO used in dilutions never exceeded $0.05 \%$. The preliminary study has shown that DMSO at these concentrations as a vehicle does not significantly affect all the parameters in this study compared with the control of culture media. There is a comparable amount of DMSO in each $0.0 \mu \mathrm{M}$ group with other treatment groups, and the DMSO does not significantly affect the parameter in each assay. 


\subsubsection{Treatment of CG-4 Cells with Hyperforin}

In growth medium, $0.0 \mu \mathrm{M}, 0.01 \mu \mathrm{M}, 0.05 \mu \mathrm{M}, 0.1 \mu \mathrm{M}, 0.5 \mu \mathrm{M}$ and $1.0 \mu \mathrm{M}$ of hyperforin treatment were used to study proliferation. In differentiation medium, $0.0 \mu \mathrm{M}$, $0.0625 \mu \mathrm{M}, 0.125 \mu \mathrm{M}, 0.25 \mu \mathrm{M}, 0.5 \mu \mathrm{M}$ and $1.0 \mu \mathrm{M}$ of hyperforin treatment were used in MTT assay, ATP assay and Rhodamine123 assay. In WST-8 assay, $0.0 \mu \mathrm{M}, 0.125 \mu \mathrm{M}$, $0.5 \mu \mathrm{M}, 1.0 \mu \mathrm{M}$ of hyperforin were used. In BrdU incorporation assay, $0.0 \mu \mathrm{M}, 0.1 \mu \mathrm{M}$, $0.5 \mu \mathrm{M}, 1.0 \mu \mathrm{M}$ of hyperforin were used.

\subsubsection{Treatment of NS/PCs with Hyperforin}

In growth medium, $0.0 \mu \mathrm{M}, 0.15625 \mu \mathrm{M}, 0.3125 \mu \mathrm{M}, 0.625 \mu \mathrm{M}, 1.25 \mu \mathrm{M}$ and $2.5 \mu \mathrm{M}$ of hyperforin treatment were used in a $24 \mathrm{~h}$ proliferation study and $0.0 \mu \mathrm{M}, 0.05 \mu \mathrm{M}, 0.1$ $\mu \mathrm{M}, 0.5 \mu \mathrm{M}, 1.0 \mu \mathrm{M}$ and $2.5 \mu \mathrm{M}$ of hyperforin treatment were used in a $48 \mathrm{~h}$ proliferation study. In differentiation medium, $0.0 \mu \mathrm{M}, 0.625 \mu \mathrm{M}, 1.25 \mu \mathrm{M}, 2.5 \mu \mathrm{M}, 5.0$ $\mu \mathrm{M}$ and $10 \mu \mathrm{M}$ of hyperforin were used to study mitochondrial function and $0.0 \mu \mathrm{M}$, $0.15625 \mu \mathrm{M}, 0.3125 \mu \mathrm{M}, 0.625 \mu \mathrm{M}, 1.25 \mu \mathrm{M}$ and $2.5 \mu \mathrm{M}$ of hyperforin treatment were used to study development of oligodendrocytes. 


\subsection{Experimental Design}

2.3.1 Effect of Hyperforin on Proliferation in CG-4 Cells and NS/PCs

CG-4 cells (P6-P15) or NS/PCs (P1-P2) in growth medium

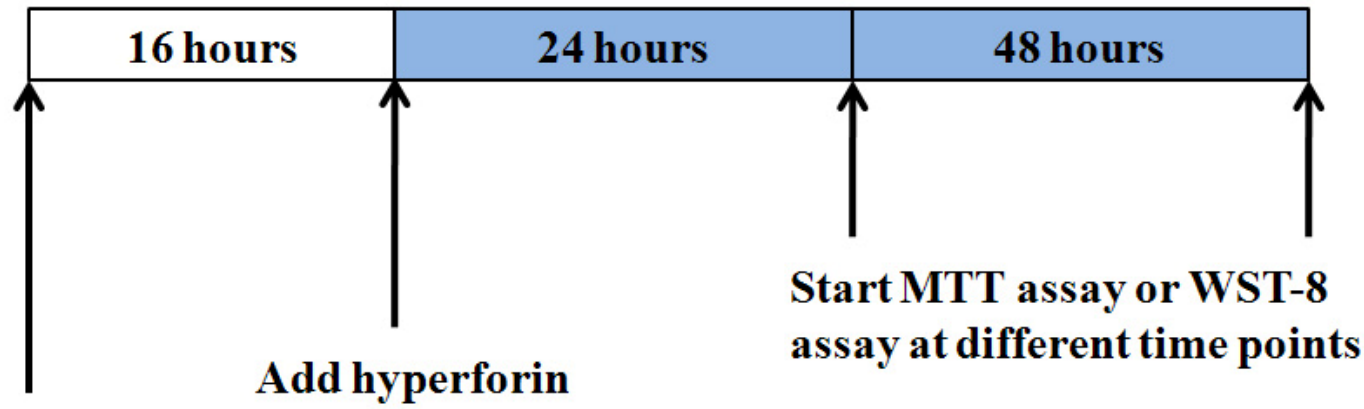

Seed cells in

growth medium

2.3.2 Effect of Hyperforin on Mitochondrial Function in CG4 Cells and NS/PCs

CG-4 cells (P6-P15) or NS/PCs (P1-P2) in differentiation medium

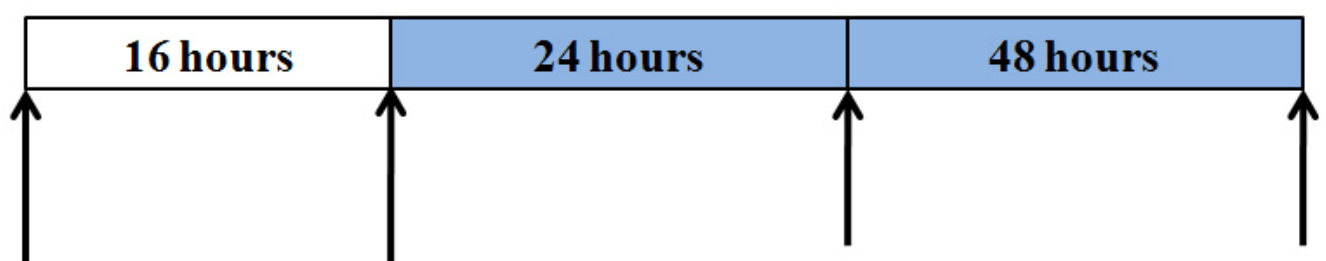

Start a series assays related to

Add hyperforin

Seed cells in mitochondrial function and cell proliferation at different time points

differentiation

medium 
2.3.3 Effect of Hyperforin on Rotenone-induced ATP Depletion

CG-4 cells (P6-P15) in differentiation medium

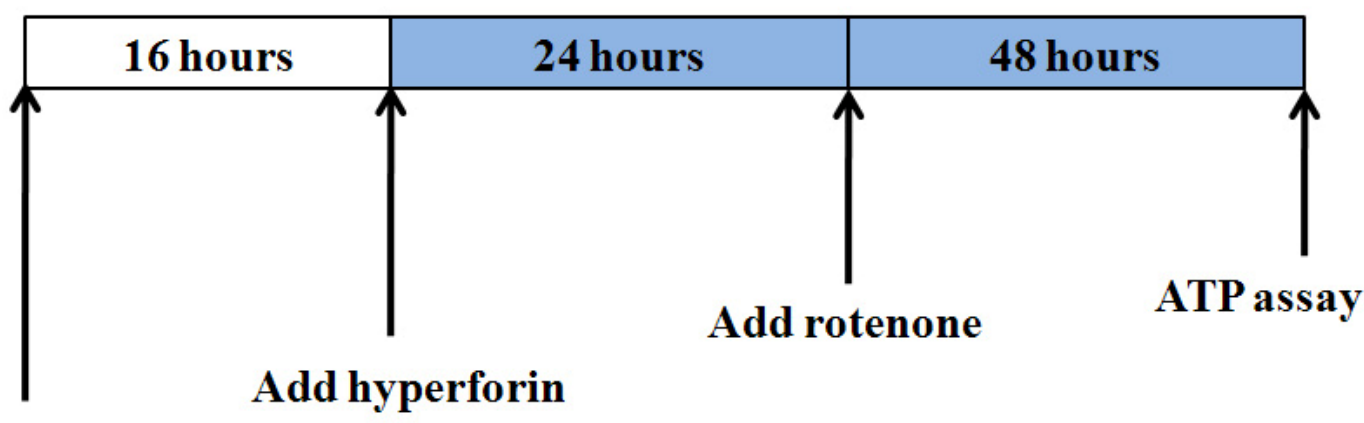

Seed cells in

differentiation

medium

2.3.4 Effect of Hyperforin on the Development of Oligodendrocytes in Differentiating NS/PCs

NS/PCs (P1-P2) in differentiation medium

Collect samples at different time points for immunocytochemical staining and western blot

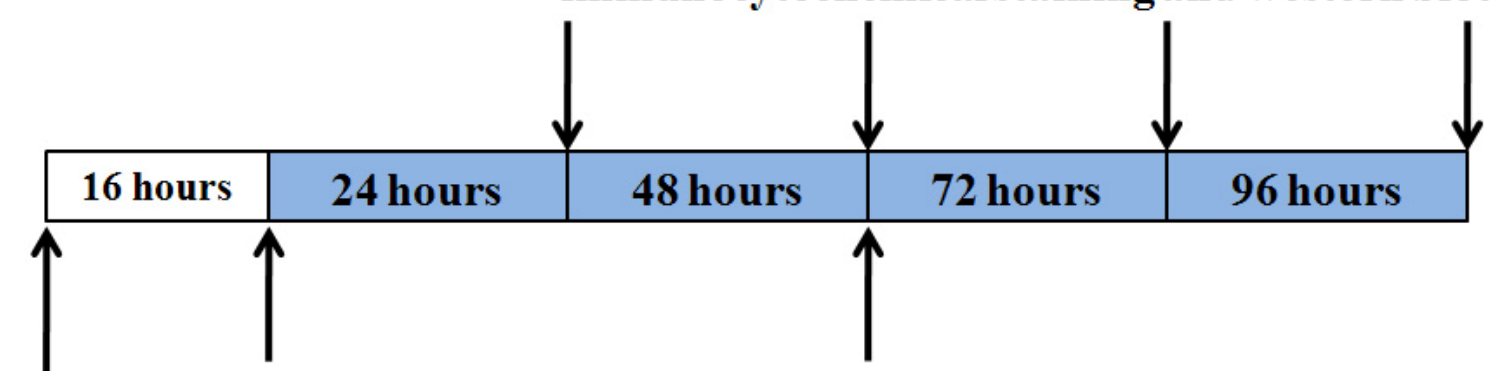

Replace growth medium with Replace half of medium with differentiation medium and fresh differentiation medium add hyperforin and add hyperforin

Seed cells in

growth medium 


\subsection{Tetrazolium Microplate Assays}

\subsubsection{MTT Assay}

3-(4, 5-Dimethylthiazol-2-yl)-2, 5-diphenyltetrazolium bromide (MTT) powder was purchased from Invitrogen (M-6494). To make $5 \mathrm{mg} / \mathrm{mL}$ MTT stock solution, $1 \mathrm{~g}$ of MTT was dissolved in $200 \mathrm{~mL}$ of sterile $0.1 \mathrm{M}$ phosphate buffered saline (PBS). The solution was passed through the $0.2 \mu \mathrm{m}$ filter. The aliquots were stored in $1.5 \mathrm{~mL}$ sterile eppendorf tubes. The stock solution was put into a paper sample box avoiding exposing to light in a $-20^{\circ} \mathrm{C}$ freezer for long-term storage. The stock solution was thawed and added into the cell culture of a 96-well plate to achieve a working concentration of $0.5 \mathrm{mg} / \mathrm{mL}$. The cells were incubated with MTT at $37^{\circ} \mathrm{C}$ in a humidified atmosphere of $5 \% \mathrm{CO}_{2} / 95 \%$ air for $4 \mathrm{~h}$. After the incubation, the culture medium was removed. To dissolve the formazan, $100 \mu \mathrm{L}$ of DMSO was added into each well to get the purple solution. The 96-well tissue culture plate was gently shaken for $1 \mathrm{~min}$ to make sure all the formazans were dissolved before the measurement. The absorbance of the purple solution in each well was measured with a microplate reader (PerkinElmer, VICTOR3 Multilabel Plate Reader) at the wavelength of $550 \mathrm{~nm}$. Triple blank controls were included in each experiment setup. The blank controls contained cultured cells with the same treatment as others but without the addition of MTT. To get the real optical density value for each well, the average value of blank controls was subtracted from the direct readout value.

\subsubsection{WST-8 Assay}

2-(2-methoxy-4-nitrophenyl)-3-(4-nitrophenyl)-5-(2, 4-disulfophenyl)-2H tetrazolium, monosodium salt (WST-8) 10X stock solution was purchased from Dojindo (CK04-11). After the cell cultures were treated with hyperforin and vehicle for $24 \mathrm{~h}$ and $48 \mathrm{~h}, 10 \mu \mathrm{L}$ of WST-8 stock solution was added into each well of a 96-well tissue culture plate. The cells were incubated with WST -8 at $37^{\circ} \mathrm{C}$ in a humidified atmosphere of $5 \% \mathrm{CO}_{2} / 95 \%$ air for $4 \mathrm{~h}$. After the incubation, the absorbance of the soluble formazan in each well was measured with a microplate reader at the wavelength of $450 \mathrm{~nm}$. Triple blank controls 
were included in each experiment setup. The blank controls contained cultured cells with the same treatment as others but without the addition of WST-8. To get the real optical density value for each well, the average value of blank controls was subtracted from the direct readout value.

\subsection{BrdU Incorporation Assay}

5-bromo-2-deoxyuridine (BrdU) is a synthetic analogue of thymidine, which can incorporate into newly replicating DNA during the $\mathrm{S}$ phase of the cell cycle. BrdU can be detected by immunocytochemistry using a monoclonal antibody against the singlestranded DNA containing BrdU (Gratzner, 1982). BrdU incorporation assay is as sensitive as $\left[{ }^{3} \mathrm{H}\right]$-thymidine incorporation assay to study cell proliferation. It is a faster cell proliferation assay without handling radioactive isotopes (Taupin, 2007). The BrdU incorporation assay was used to measure the DNA synthesis in CG-4 cell culture in this study.

The colorimetric cell proliferation enzyme linked immunosorbent assay (ELISA), BrdU assay kit (11647229001) was purchased from Roche Applied Science. Cells were cultured in 96-well tissue culture plates at the density of $5 \times 10^{3} \mathrm{cells} / \mathrm{cm}^{2}$ with different concentrations of hyperforin treatment. After treating the cells with hyperforin or vehicle for $24 \mathrm{~h}$ or $48 \mathrm{~h}, 10 \mu \mathrm{L}$ of BrdU labeling solution was added to each well to get a working concentration of $10 \mu \mathrm{M}$ of BrdU. After $3 \mathrm{~h}$ of incubation, the BrdU labeling solution was removed by pipetting. To fix the cells and denature the DNA, $200 \mu \mathrm{L}$ of FixDenat was added to the cell culture to improve the detection of BrdU by the antibody. The FixDenat solution was removed by pipetting after $30 \mathrm{~min}$ of incubation in a $25^{\circ} \mathrm{C}$ incubator. To bind to the incorporated BrdU in newly synthesized DNA, $100 \mu \mathrm{L}$ of anti-BrdU-POD solution was added to wells. Anti-BrdU-POD solution was removed by pipetting after 90 min of incubation in a $25^{\circ} \mathrm{C}$ incubator. To wash wells, $250 \mu \mathrm{L}$ of $0.01 \mathrm{M}$ PBS was added for rinsing three times. After washing, $100 \mu \mathrm{L}$ of substrate solution was added to initiate the reaction at $25^{\circ} \mathrm{C}$. For the first time experiment, the reaction was not stopped, so the optical density of reaction product was measured at the wavelength of $370 \mathrm{~nm}$ at the 
different time points of $5 \mathrm{~min}, 10 \mathrm{~min}$ and $20 \mathrm{~min}$ to determine the optimal reaction time. After the pilot experiment, 10 min of reaction was determined as the optimal reaction time in this study. To stop the reaction at the time point of $10 \mathrm{~min}, 25 \mu \mathrm{L}$ of $1 \mathrm{M}$ sulphuric acid $\left(\mathrm{H}_{2} \mathrm{SO}_{4}\right)$ was added to each well, and the solution was shaken for approximately $1 \mathrm{~min}$ to mix thoroughly. The optical density of reaction product in each well was measured at the wavelength of $450 \mathrm{~nm}$ after the addition of the stopping reagent. Triple blank controls were included in each experiment setup. The blank controls contained $100 \mu \mathrm{L}$ of culture medium, $10 \mu \mathrm{L}$ of BrdU labeling solution and $10 \mu \mathrm{L}$ of antiBrdU-POD solution. The blank control provided information about the unspecific binding of BrdU and anti-BrdU-POD conjugate to the tissue culture plate. To get the real optical density value for each well, the average value of blank controls was subtracted from the direct readout value.

\subsection{ATP Assay}

Firefly luciferase is widely used to measure the adenosine triphosphate (ATP) levels in isolated mitochondria and permeabilized cells. During the luciferase catalyzed reaction of luciferin, ATP and oxygen to the oxyluciferin, the maximum yellow-green bioluminescence emits at $560 \mathrm{~nm}$ at $\mathrm{pH} 7.75$ (McElroy and DeLuca, 1983). ATP assay is based on the quantitative analyses of the linear relation between the bioluminescence and ATP concentrations (Mueller et al., 2004). It is a very sensitive assay and capable of measuring $1 \times 10^{-11}$ to $1 \times 10^{-16}$ moles of ATP.

Luciferase + Luciferin + ATP $\longrightarrow$ Luciferase - Luciferyl - AMP + PPi

Luciferase - Luciferyl - AMP $+\mathrm{O}_{2} \longrightarrow$ Luciferase + Oxyluciferin + AMP $+\mathrm{CO}_{2}+\mathrm{h} v$ (Deluca, 1976)

\subsubsection{Sample Preparation}

CG-4 cells were cultured in Poly-D-Lysine coated 24-well tissue culture plates at the density of $5 \times 10^{3}$ cells $/ \mathrm{cm}^{2}$ with $670 \mu \mathrm{L}$ of differentiation medium. The cells were treated 
with different concentrations of hyperforin for $24 \mathrm{~h}$ and $48 \mathrm{~h}$, or the combination of hyperforin and rotenone for $24 \mathrm{~h}$.

\subsubsection{ATP Extraction}

Trichloroacetic acid was used to disrupt cell membranes and release adenine nucleotides in the ATP-extracting medium. Trichloroacetic acid also prevented ATP from degradation by ATP eliminator enzymes. Trichloroacetic acid is recognized as the most effective extractant, because the levels of ATP extracted by trichloroacetic acid most closely reflect the actual levels of ATP in cells (Lundin and Thore, 1975). Ethylene diamine tetraacetic acid (EDTA) was also included in the extracting medium to irreversibly inactivate ATP-converting enzymes by chelating the $\mathrm{Mg}^{2+}$. The ATPextracting medium contained $10 \%$ of trichloroacetic acid and 2 mM EDTA (Stanley, 1986). The culture medium was removed from each well of a $24-w e l l$ plate by pipetting. To extract ATP from cells, $500 \mu \mathrm{L}$ of ice-cold ATP-extracting medium was added in each well and the plate was put on ice for $30 \mathrm{~min}$. The plate was gently shaken several times during the extraction. After extraction, $40 \mu \mathrm{L}$ of extracting medium from each well of a 24-well plate was transferred into a well of a 96-well plate. Triple wells were used for the extraction from each treatment group to ensure the accuracy of measurement.

\subsubsection{Sample Dilution}

Trichloroacetic acid strongly inhibited the firefly luciferase reaction, so the trichloroacetic acid in the extracted samples were diluted to a final concentration of less than $0.1 \%$ before the bioluminescent ATP assay was begun (Nichols et al., 1981). The trichloroacetic acid in extracting medium was 1: 40 diluted to a final concentration of $0.05 \%$ by 1: 5 diluted and then 1: 8 diluted with ice-cold sterile $0.1 \mathrm{M}$ Tris-acetate buffer, $2 \mathrm{mM}$ EDTA at $\mathrm{pH}$ 7.75. The diluted sample was placed on ice for assay. 


\subsubsection{Performing ATP Assay}

The ATP Determination Kit was purchased from Invitrogen (A22066). To make $1 \mathrm{~mL}$ of the $10 \mathrm{mM}$ D-luciferin stock solution, $1 \mathrm{~mL}$ of $1 \mathrm{X}$ Reaction Buffer was added to the vial of D-luciferin prepared by the kit on the day of the assay. For long-term storage, $1.62 \mathrm{~mL}$ of $100 \mathrm{mM}$ Dithiothreitol (DTT) stock solution was prepared by sterile $\mathrm{ddH}_{2} \mathrm{O}$ and aliquoted $150 \mu \mathrm{L}$ of solution into each $1.5 \mathrm{~mL}$ eppendorf tube, and $30 \mu \mathrm{L}$ of $5 \mathrm{mM}$ ATP stock solution was aliquoted into each $1.5 \mathrm{~mL}$ eppendorf tube. For long-term storage, 3 $\mu \mathrm{L}$ of $5 \mathrm{mg} / \mathrm{mL}$ luciferase, firefly recombinant enzyme solution was aliquoted into each $1.5 \mathrm{~mL}$ eppendorf tube. All the stock solutions were stored at $-20^{\circ} \mathrm{C}$ and protected from light for further use in several weeks.

On the day of the assay, all the components were combined to make $10 \mathrm{~mL}$ of standard reaction solution using the following recipe:

Sterile $\mathrm{ddH}_{2} \mathrm{O}$

20X Reaction Buffer $\quad 0.5 \mathrm{~mL}$

0.1 M DTT $0.1 \mathrm{~mL}$

$10 \mathrm{mM}$ D-luciferin $\quad 0.5 \mathrm{~mL}$

Firefly luciferase $5 \mathrm{mg} / \mathrm{mL}$ stock solution $\quad 2.5 \mu \mathrm{L}$

The solution was gently mixed to avoid denaturing the firefly luciferase. The standard reaction solution was made right before it was added to the samples to prevent the activity of firefly luciferase decreasing with time at room temperature. To make $1 \mu \mathrm{M}$ of ATP stock solution, $20 \mu \mathrm{L}$ of $5 \mathrm{mM}$ ATP stock solution was diluted at 1:5000 in $10 \mathrm{~mL}$ of sterile $0.1 \mathrm{M}$ Tris-acetate buffer, $2 \mathrm{mM}$ EDTA, $\mathrm{pH}$ 7.75. The following concentrations were used to make the standard curve: $1000 \mathrm{nM}, 500 \mathrm{nM}, 250 \mathrm{nM}, 125 \mathrm{nM}, 62.5 \mathrm{nM}$, $31.25 \mathrm{nM}$ and $0 \mathrm{nM}$. The measurement of the ATP standard curve was included in each microplate experiment setup. For assay, $10 \mu \mathrm{L}$ of each standard ATP solution or sample was added to a well of a sterile nontransparent white sterile microplate (Fisher, 14-245182). Standard ATP solutions were added to the microplate by using double wells. 
Samples were added to the microplate by using triple wells. The reaction was initiated by adding $100 \mu \mathrm{L}$ of standard reaction solution to each well with gentle shaking. The microplate was put at room temperature for $4 \mathrm{~min}$ before the bioluminescence was read to make sure the reaction was stable. The bioluminescence was read in a microplate reader. The amount of ATP in each experimental sample was calculated from the standard curve.

\subsection{Rhodamine123 Assay}

The measurement of mitochondrial membrane potential usually uses noninvasive lipophilic dyes with positive charges. They are actively transported into the mitochondria but they can not freely pass through the membrane (Haydon and Hladky, 1972). They accumulate in mitochondria proportionally to the mitochondrial membrane potential. The first and most widely used dye to measure mitochondrial membrane potential is Rhodamine123 (Chen et al., 1982).

Rhodamine123 was purchased from Sigma (R8004). To make a $50 \mathrm{mM}$ stock solution, $25 \mathrm{mg}$ of Rhodamine123 was dissolved in $1.31 \mathrm{~mL}$ of DMSO. The stock solution was stored at $-20^{\circ} \mathrm{C}$ and protected from light for long-term storage. CG-4 cells were cultured in Poly-D-Lysine coated 24-well tissue culture plates at the density of $5 \times 10^{3} \mathrm{cells} / \mathrm{cm}^{2}$ with $670 \mu \mathrm{L}$ of differentiation medium. The cells were treated with different concentrations of hyperforin for $24 \mathrm{~h}$ and $48 \mathrm{~h}$. Before use, Rhodamine123 stock solution was diluted in culture medium to get a $25 \mathrm{X}$ stock solution at $50 \mu \mathrm{M}$. Rhodamine 123 was added to cell culture at a final concentration of $2 \mu \mathrm{M}$ with gentle shaking. Cells were incubated with Rhodamine 123 for $30 \mathrm{~min}$ at $37^{\circ} \mathrm{C}$. After incubation, cells were washed with cold HBSS three times. After being washed, cells were lysed with $500 \mu \mathrm{L}$ of radio immunoprecipitation assay (RIPA) solution in each well of a 24-well plate. The cell lysate of each well was transferred into a well of a nontransparent black 96-well plate (Fisher, 09-003-34). Samples from each group were added to the microplate by using triple wells. Fluorescence was read at $480 \mathrm{~nm}$ for excitation and $530 \mathrm{~nm}$ for emission with a microplate reader. Triple blank controls were included in each experiment setup. The blank controls contained $100 \mu \mathrm{L}$ of culture medium and $2 \mu \mathrm{M}$ of Rhodamine 123 . 
The blank control provides information about the unspecific binding of Rhodamine123 to the tissue culture plate. To get the real optical density value for each well, the average value of blank controls was subtracted from the direct readout value.

\subsection{Immunocytochemical Staining}

\subsubsection{Plating Cells and Incubation}

For characterization of NS/PCs, neurospheres were seeded in a 24-well tissue culture plate with Poly-D-Lysine coated coverslips at the density of $5 \times 10^{2}$ spheres $/ \mathrm{cm}^{2}$ in growth medium. Neurospheres were incubated at $37^{\circ} \mathrm{C}$ in a humidified atmosphere of $5 \%$ $\mathrm{CO}_{2} / 95 \%$ air for $4 \mathrm{~h}$ to allow attachment to the coverslips. For differentiation assay of NS/PCs, NS/PC single cell suspension was seeded in a 24-well tissue culture plate with coverslips at the density of $5 \times 10^{4}$ cells $/ \mathrm{cm}^{2}$ in growth medium. NS/PCs were incubated at $37^{\circ} \mathrm{C}$ in a humidified atmosphere of $5 \% \mathrm{CO}_{2} / 95 \%$ air for $16 \mathrm{~h}$ to allow attachment to the coverslips. After cells attached to the coverslips, the growth medium was replaced by differentiation medium. NS/PCs began to differentiate into neurons, astrocytes and oligodendrocytes in the differentiation medium. Cells were treated with different doses of hyperforin from $0.0 \mu \mathrm{M}$ to $2.5 \mu \mathrm{M}$ for up to $96 \mathrm{~h}$.

\subsubsection{Fixation and Blocking}

The culture medium was removed and cells were gently rinsed with 0.01 M PBS once. $500 \mu \mathrm{L}$ of freshly made $4 \%$ paraformaldehyde (PFA) were added to each well to fix cells for $15 \mathrm{~min}$ at room temperature. After the 4\% PFA was removed, the fixed cells were washed with $600 \mu \mathrm{L}$ of $0.01 \mathrm{M}$ PBS for three times with gentle shaking, 10 min for each time. The fixed cells were blocked with $500 \mu \mathrm{L}$ of blocking solution containing $5 \%$ of appropriate sera in $0.01 \mathrm{M}$ PBS with $0.3 \%$ of Triton X-100 at room temperature for $1 \mathrm{~h}$ with gentle shaking. The sera for blocking should be from the same type of animal as the animal of the secondary antibody. 


\subsubsection{Antibody Incubation}

After blocking, $400 \mu \mathrm{L}$ of primary antibody solution diluted at the proper concentration in blocking solution was added to each well except the well of the blank control. Cells incubated with primary antibodies were put into a $4{ }^{\circ} \mathrm{C}$ fridge over night. For characterization of NS/PCs, rabbit anti-nestin (Abcam, ab5968) at the dilution of 1: 400 was used to stain NS/PCs. Mouse anti-2', 3'-cyclic nucleotide 3' phosphodiesterase (CNPase) (Millipore, MAB326) at the dilution of 1: 200 and goat anti-MBP (Santa Cruz, sc-13914) at the dilution of 1: 400 were used to stain oligodendrocytes. Mouse anti-Glial fibrillary acidic protein (GFAP) (Millipore, MAB3402) at the dilution of 1: 1000 was used to stain astrocytes. Mouse anti- $\beta$-III tubulin (Millipore, MAB1637) at the dilution of 1: 400 was used to stain neurons. After the incubation with primary antibody, uncoupled primary antibody was washed away by $0.01 \mathrm{M}$ PBS for three times with gentle shaking, 15 min for each time. Blocking solution $(400 \mu \mathrm{L})$ with proper fluorescent secondary antibody at the concentration of $2 \mu \mathrm{g} / \mathrm{mL}$ was added to each well. Plates were covered with aluminum foil to protect the fluorescent secondary antibodies from light. Cells with secondary antibodies were incubated at room temperature for $1 \mathrm{~h}$ with gentle shaking.

\subsubsection{Hoechst 33342 Staining}

After the incubation with secondary antibodies, cells were incubated with $400 \mu \mathrm{L}$ of 1 $\mathrm{mg} / \mathrm{mL}$ Hoechst 33342 in $0.01 \mathrm{M}$ PBS for $5 \mathrm{~min}$ at room temperature to stain the nuclei DNA. Plates were covered with aluminum foil to protect fluorescent Hoechst 33342 from light. Uncoupled secondary antibodies and Hoechst 33342 were washed away with 600 $\mu \mathrm{L}$ of $0.01 \mathrm{M}$ PBS for three times with gentle shaking, $15 \mathrm{~min}$ for each time.

\subsubsection{Mounting}

The PBS used for washing was removed thoroughly before mounting. A drop of fluoromount aqueous mounting medium (Sigma, F4680) was placed on the top of labeled plates. The coverslip was retrieved from the well and placed with cell side down on top 
of the drop of mounting medium by using forceps. Bubbles between the coverslip and the plate were avoided by gently pressing the center of the coverslip with forceps. Mounted slides were stored in an opaque box to let the mounting medium dry and fix for $30 \mathrm{~min}$.

\subsubsection{Detection and Analysis}

Fluorescence was detected by a Nikon microscope (ECLIPSE TE-2000E) and images were acquired by SimplePCI image software from Hamamatsu Corporation. Five different areas were chosen to count the staining cells on each coverslip. All slides were kept in dark sample boxes and put at $-20^{\circ} \mathrm{C}$ for long-term storage. Analysis of fluorescent micrographs was conducted by using Image-Pro Plus software from Media Cybernetics, Inc.

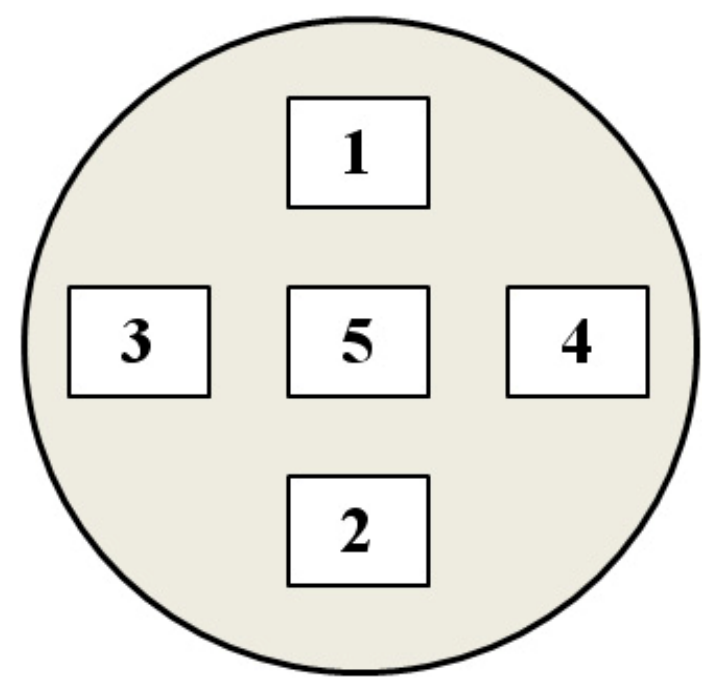

Figure 2.1 Areas of cell counting in immunocytochemical staining

\subsection{Western Blotting}

Western blotting is a very sensitive and efficient assay to detect small amount of proteins. Extracted proteins from samples are separated by sodium dodecyl sulfate-polyacrylamide gel electrophoresis (SDS-PAGE) and then transferred from the gel to a membrane by electroblotting. Finally, the proteins on the membrane are detected by using primary and secondary antibodies and a chemiluminescent reagent. 


\subsubsection{Sample Preparation}

Cells were seeded at the density of $5 \times 10^{4}$ cells $/ \mathrm{cm}^{2}$ in differentiation medium in 6-well tissue culture plates for up to $96 \mathrm{~h}$ to ensure enough amounts of cells for protein extraction. Each well was assigned for a specific concentration of hyperforin treatment. Six samples from one 6-well plate were used for western blotting assay at the same time on the same polyvinylidene fluoride (PVDF) membrane and with the same assay parameters.

\subsubsection{Extraction of Protein}

The 6-well tissue culture plate was removed from $37^{\circ} \mathrm{C}$ incubator and placed on ice. The culture medium was removed by pipetting. Adherent cells were washed with $3 \mathrm{~mL}$ of $0.01 \mathrm{M}$ ice-cold PBS once. After washing, $70 \mu \mathrm{L}$ of ice-cold lysis buffer was added into each well. The lysis buffer consisted of RIPA solution and $1 \%$ of protease inhibitor cocktail (Sigma, P8340). Adherent cells were scraped off plates using a plastic cell scraper. The cell lysate was then transferred into a cool $1.5 \mathrm{~mL}$ eppendorf tube and maintained in ice for $30 \mathrm{~min}$. The cell lysate was centrifuge at $10,000 \mathrm{x}$ g for $15 \mathrm{~min}$ at $4^{\circ} \mathrm{C}$. The supernatant was transferred into a fresh $1.5 \mathrm{~mL}$ eppendorf tube and placed on ice.

\subsubsection{Quantitation of Protein}

The concentrations of proteins were quantified with BCA Protein Assay Kit (Pierce, 23227). Bovine serum albumin (BSA) was used as a standard in the assay. $10 \mu \mathrm{L}$ of each protein sample was used for this assay. The concentrations of all samples were adjusted to $1000 \mu \mathrm{g} / \mathrm{mL}$. The final loading concentrations were adjusted to $800 \mu \mathrm{g} / \mathrm{mL}$ with $5 \mathrm{X}$ loading buffer. The protein samples were denatured in a boiling water bath for $10 \mathrm{~min}$. After being denatured, the protein samples were mixed thoroughly either for electrophoresis or for long-term storage at $-80^{\circ} \mathrm{C}$. 


\subsubsection{Acrylamide Gel Preparation and Electrophoresis}

\subsubsection{Acrylamide Gel Preparation}

SDS-PAGE is used for separating proteins according to their molecular weights. The separation of molecules within a gel is determined by the relative size of the pores formed within the gel. The pore size of a gel is determined by two factors: the total amount of acrylamide present and the amount of cross-linker. In this study, $10 \%$ of acrylamide gels produced from 30\% Acrylamide/Bis Solution, 29: 1 ratio (Bio-Rad, 1610157) were used for separating proteins with molecular weights between $15 \mathrm{kDa}$ and 100 $\mathrm{kDa}$. A glass plate sandwich was assembled on a casting stand, and the gel was poured into the space between the plates. 10\% separating gels and 4\% stacking gels were prepared freshly (Table 2.3). Volumes were for two gels with the Bio-Rad MiniPROTEAN system.

Table 2.3 Recipes of separating gel and stacking gel for SDS-PAGE

\begin{tabular}{ccc}
\hline Components & $10 \%$ separating gel & $4 \%$ stacking gel \\
\hline $30 \%$ Acrylamide & $2.50 \mathrm{~mL}$ & $0.67 \mathrm{~mL}$ \\
ddH ${ }_{2} \mathrm{O}$ & $4.06 \mathrm{~mL}$ & $2.97 \mathrm{~mL}$ \\
$1.5 \mathrm{M}$ Tris-HCl, pH 8.8 & $3.33 \mathrm{~mL}$ & $0.00 \mathrm{~mL}$ \\
$0.5 \mathrm{M}$ Tris-HCl, pH 6.8 & $0.00 \mathrm{~mL}$ & $1.25 \mathrm{~mL}$ \\
$10 \%$ SDS & $100 \mu \mathrm{L}$ & $50 \mu \mathrm{L}$ \\
$10 \%$ ammonium persulfate & $100 \mu \mathrm{L}$ & $100 \mu \mathrm{L}$ \\
Tetramethylethylenediamine & $10 \mu \mathrm{L}$ & $5 \mu \mathrm{L}$ \\
\hline
\end{tabular}

\subsubsection{Electrophoresis}

The electrophoresis system was assembled according to the instruction. Running buffer was poured into the chamber to merge the top and bottom of the gel for electric current to flow through the gel. The comb was removed, and the wells were rinsed with Running 
buffer. Protein samples $(25 \mu \mathrm{L})$ were loaded in wells with loading tips. Pre-stained molecular weight marker $(7 \mu \mathrm{L})$ - (Fisher, BP36031) was loaded with $18 \mu \mathrm{L}$ of $1 \mathrm{X}$ loading buffer in a well. Unused wells were loaded with $25 \mu \mathrm{L}$ of $1 \mathrm{X}$ loading buffer. The two-gel electrophoresis system was run at $70 \mathrm{~V}$ of constant voltage for $2.5 \mathrm{~h}$ until the bromophenol blue dye reached the bottom of the gels.

\subsubsection{Electroblotting and Blocking}

The glass sandwich was removed from the electrophoresis tank after the electrophoresis. The short plate was taken off from the glass sandwich, and then the stacking gel was cut off from the separating gel. The separating gel was gently transferred from the glass plate onto a filter paper in a tray containing $1 X$ Transfer buffer. A PVDF membrane, pretreated with methanol for $5 \mathrm{~min}$, was put on the top of the gel avoiding bubbles, and then another filter paper was put on the PVDF membrane. The gel and PVDF membrane were put into a sandwich and two sandwiches were put into a Bio-Rad electroblotting system containing 1X Transfer buffer. The two-gel electroblotting system was run at $200 \mathrm{~mA}$ of constant current for $1.5 \mathrm{~h}$. The electroblotting system was put in an ice-water bath with ice covering the whole electroblotting tank in order to remove the heat during the transferring process. To check the success of electroblotting, the membrane was washed in Tris-Buffered Saline Tween-20 (TBST) briefly and put into Ponceau S solution $(0.1 \%$ Ponceau $\mathrm{S}$ in 5\% acetic acid) at 1: 10 dilution. The red protein bands showed up after extensive washing in water. The membrane was destained completely by washing it in TBST for three times, 5 min for each wash.

\subsubsection{Immunodetection}

\subsubsection{Blocking the Membrane}

Blocking prevented non-specific background binding of the primary and secondary antibodies to the membrane. The $5 \%$ of skim milk in TBST was used to block membranes for $1 \mathrm{~h}$ with gentle shaking at room temperature. 


\subsubsection{Incubation with Primary and Secondary Antibodies}

The primary antibody was diluted with $5 \%$ of skim milk in TBST at the proper concentration. The primary antibody was incubated at $4^{\circ} \mathrm{C}$ overnight with gentle shaking. After the incubation with primary antibody, the membrane was washed with TBST at room temperature for three times, 15 min for each wash. The horseradish peroxidaseconjugated secondary antibody was diluted with 5\% of skim milk in TBST at dilution of 1:5000. The secondary antibody was incubated at room temperature for $1 \mathrm{~h}$ with gentle shaking. After the incubation with secondary antibody, the membrane was washed with TBST at room temperature for three times, $15 \mathrm{~min}$ for each wash.

\subsubsection{Chemiluminescence Detection}

After the final wash, TBST was drained as much as possible. The membrane was incubated with electrochemiluminescence (ECL) solution (PerkinElmer, NEL104) for 2 min at room temperature. After incubation, the membrane was picked up with forceps, and the ECL solution was drained as much as possible by allowing the membrane to touch a paper towel. The membrane was put between two sheets of plastic wrap to prevent X-ray films from getting wet. The signal was recorded by exposing the membrane to an X-ray film in a dark room. Manual film development was carried out by putting the X-ray film in the developing agent (Sigma, P7042) and fixation agent (Sigma, P7167). The developed X-ray films were scanned by Fluorchem 8900 from Alpha Innotech. The Quantity One software was used to analyze the signals of grayscale images. The $\beta$-actin was used as the loading control to analyze the relative strength of signals.

\subsubsection{Buffer Recipes}

\section{RIPA Buffer}

Sodium chloride

Triton X-100

Sodium deoxycholate
$150 \mathrm{mM}$

$1.0 \%$

$0.5 \%$ 
SDS

Tris, $\mathrm{pH} 8.0$
$0.1 \%$

$50 \mathrm{mM}$

\section{X loading buffer}

$1 \mathrm{M}$ Tris $\mathrm{pH}=6.8$

Glycerol

$\beta$-mercaptoethanol

Bromophenol blue

SDS

Total volume

Aliquot into $1 \mathrm{~mL}$ aliquots and stored at $-20^{\circ} \mathrm{C}$
$2 \mathrm{~mL}$

$4 \mathrm{~mL}$

$2 \mathrm{~mL}$

$30 \mathrm{mg}$

$800 \mathrm{mg}$

$10 \mathrm{~mL}$

\subsection{Tris $\mathrm{pH}=8.8$}

Tris

$0.1 \%$ SDS

Adjust $\mathrm{pH}=8.8$ with $12 \mathrm{~N} \mathrm{HCL}$

Make to $100 \mathrm{~mL}$ with $\mathrm{ddH}_{2} \mathrm{O}$

\section{$0.5 \mathrm{M}$ Tris $\mathrm{pH}=6.8$}

Tris

$0.1 \%$ SDS

Adjust $\mathrm{pH}=6.8$ with $12 \mathrm{~N} \mathrm{HCL}$

Make to $100 \mathrm{~mL}$ with $\mathrm{ddH}_{2} \mathrm{O}$
$18.17 \mathrm{~g}$

$4 \mathrm{~mL}$

$6.06 \mathrm{~g}$

$4 \mathrm{~mL}$ 


\section{X Running buffer}

Tris

Glycine

SDS

Make to 1 liter with $\mathrm{ddH}_{2} \mathrm{O}$
$30 \mathrm{~g}$

$144 \mathrm{~g}$

$10 \mathrm{~g}$

\section{X Running buffer}

10X Running buffer

$100 \mathrm{~mL}$

$\mathrm{ddH}_{2} \mathrm{O}$

$900 \mathrm{~mL}$

10X Transfer buffer

Tris

$30 \mathrm{~g}$

Glycine

$144 \mathrm{~g}$

Make to 1 liter with $\mathrm{ddH}_{2} \mathrm{O}$

1X Transfer buffer

10X Transfer buffer

$100 \mathrm{~mL}$

Methanol

$100 \mathrm{~mL}$

$\mathrm{ddH}_{2} \mathrm{O}$

$800 \mathrm{~mL}$ 


\subsection{Statistical Analysis}

All the raw data from each assay were used for statistical analysis. All results were expressed as Mean \pm SEM. Most of the data were expressed as a relative percentage of the control. The immunocytochemical staining data of MBP, Olig2, GFAP and $\beta$-III tubulin were expressed as ratios of positive staining cells to total cells. The dose-response relationships were analyzed by one-way ANOVAs followed by Bonferroni / Dunn's posthoc test. The effects of hyperforin and rotenone on CG-4 cells were analyzed by two-way ANOVA followed by Bonferroni / Dunn's post-hoc test. Values of $p<0.05$ were considered statistically significant. The software GB-STAT was used to do statistical analysis. 


\section{RESULTS}

\subsection{Effect of Hyperforin on the Proliferation of CG-4 Cells and NS/PCs}

Tetrazolium salts have been widely applied to evaluate cell viability, cell proliferation and cytotoxicity for decades (Mosmann, 1983). MTT and WST-8 are two most extensively used tetrazolium salts. It is generally believed that MTT is reduced by accepting electrons from a variety of intracellular reductants, such as nicotinamide adenine dinucleotide (NADH) and succinate. WST-8 is reduced primarily at the cell surface by accepting trans-plasma electrons driven by intracellular NADH from the mitochondrial citric acid cycle (Berridge et al., 2005). Both reduction processes are dependent on the cellular redox activity, so the reduced formazans from tetrazolium salts are correlated to mitochondrial function (Berridge and Tan, 1993). MTT assay is usually applied in endpoint assays, because MTT is reduced to form an insoluble formazan. WST-8 assay is usually applied in real time assays, because WST-8 is reduced to form a soluble formazan. To examine whether hyperforin increased the genesis of oligodendrocyte progenitors and NS/PCs, MTT assay and WST-8 assay were used to measure the cell viabilities of proliferating CG-4 cells and NS/PCs, because usually the reduction of MTT or WST-8 is proportional to the number of viable cells in the exponential growth phase (Berridge et al., 2005). 


\subsubsection{Hyperforin Did Not Affect the Cell Viability of Proliferating CG-4}

Cells at Concentrations between $0.0 \mu \mathrm{M}$ and $0.1 \mu \mathrm{M}$ but Inhibited the Cell Viability of Proliferating CG-4 Cells at Higher Concentrations

We found hyperforin did not change the cell viability of proliferating CG-4 cells by MTT assay at concentrations between $0.0 \mu \mathrm{M}$ and $0.5 \mu \mathrm{M}$ for $24 \mathrm{~h}$ and between $0.0 \mu \mathrm{M}$ and 0.1 $\mu \mathrm{M}$ for 48 h. (Figure 3.1 and Figure 3.2). However, at higher concentrations, hyperforin decreased the total cell viability at $1.0 \mu \mathrm{M}(43.8 \% \pm 8.3 \%$ of the value at $0.0 \mu \mathrm{M})$ for 24 $\mathrm{h}$; and at $0.5 \mu \mathrm{M}(21.1 \% \pm 2.4 \%$ of the value at $0.0 \mu \mathrm{M})$ and at $1.0 \mu \mathrm{M}(8.2 \% \pm 1.4 \%$ of the value at $0.0 \mu \mathrm{M}$ ) for $48 \mathrm{~h}$ compared to $0.0 \mu \mathrm{M}$ of hyperforin. (Figure 3.1 and Figure 3.2).

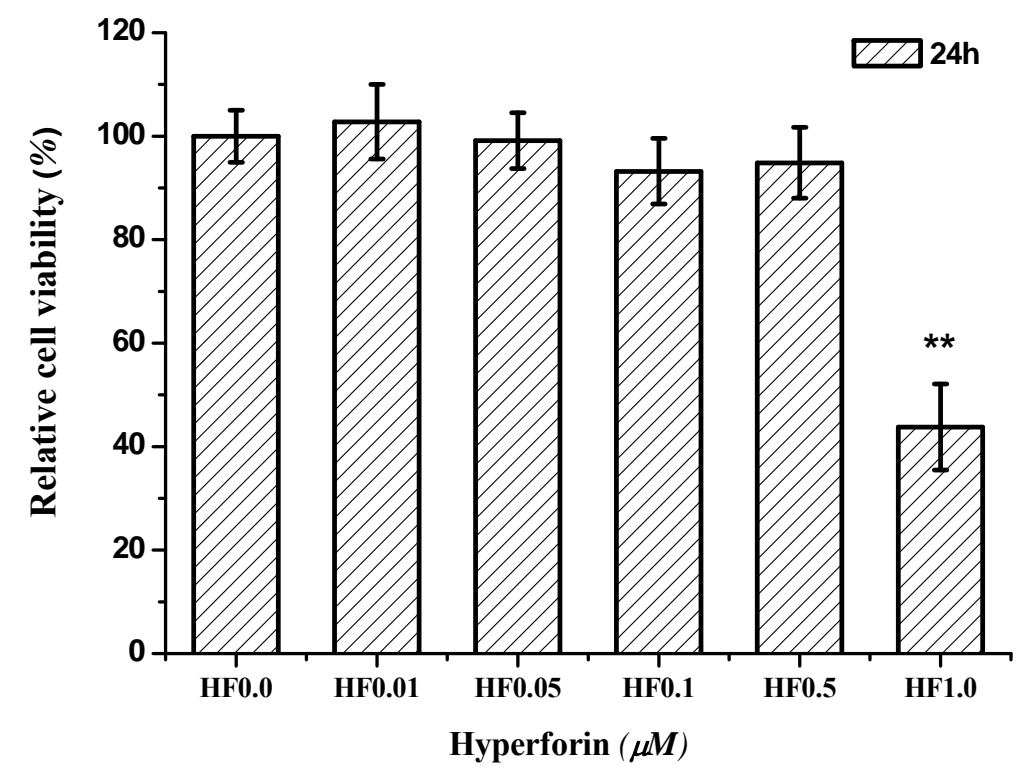

Figure 3.1 Cell viability of proliferating CG-4 cells after $24 \mathrm{~h}$ of hyperforin treatment by MTT assay

Cell viability expressed as a percentage of the level at HF $0.0 \mu \mathrm{M}$ after treatment with hyperforin at escalating doses from $0.0 \mu \mathrm{M}$ to $1.0 \mu \mathrm{M}$ for $24 \mathrm{~h}$ using MTT assay. All groups were compared to $0.0 \mu \mathrm{M}$ of hyperforin and ${ }^{* *} p<0.01$ (Mean \pm SEM, $\mathrm{n}=4$ ). HF: Hyperforin. 


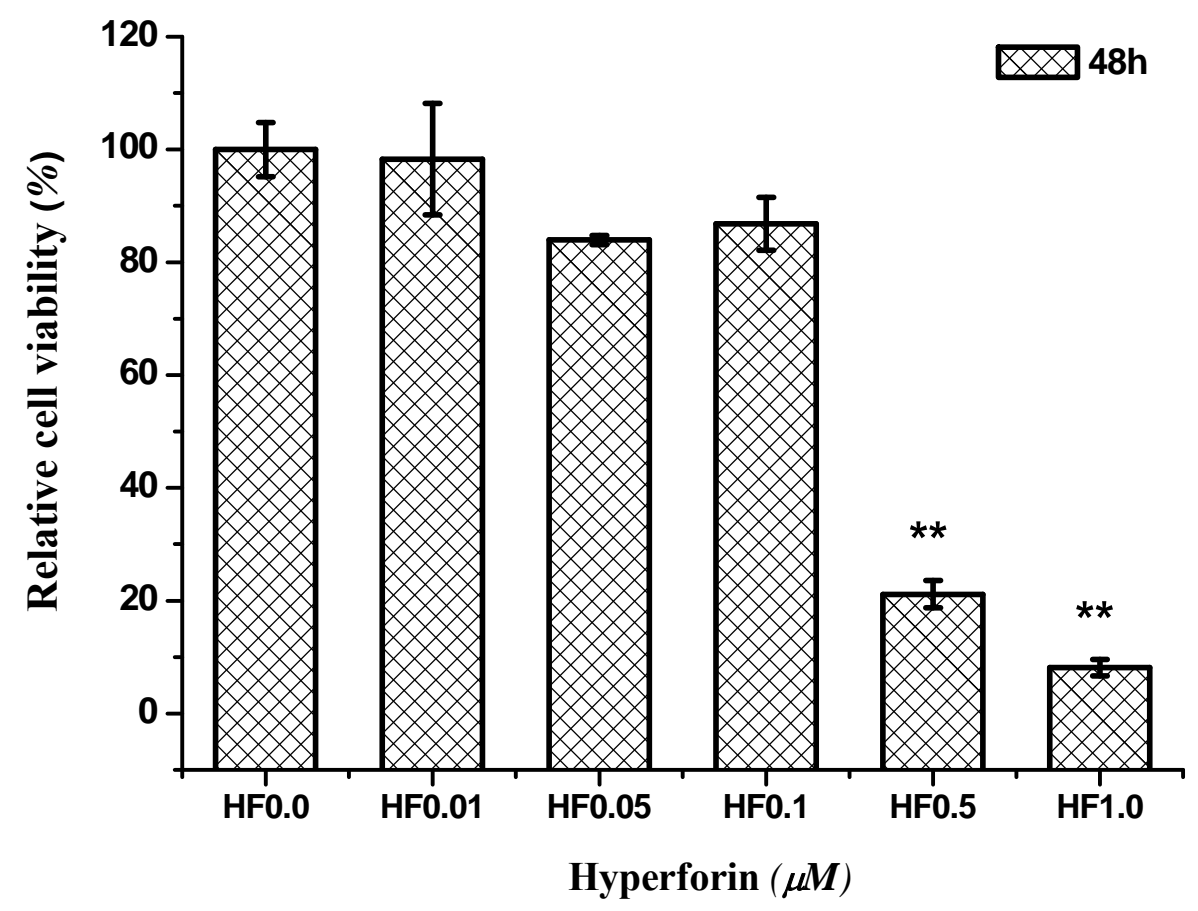

Figure 3.2 Cell viability of proliferating CG-4 cells after $48 \mathrm{~h}$ of hyperforin treatment by MTT assay

Cell viability expressed as a percentage of the level at HF $0.0 \mu \mathrm{M}$ after treatment with hyperforin at escalating doses from $0.0 \mu \mathrm{M}$ to $1.0 \mu \mathrm{M}$ for $48 \mathrm{~h}$ using MTT assay. All groups were compared to $0.0 \mu \mathrm{M}$ of hyperforin and ${ }^{* *} p<0.01$ (Mean \pm SEM, $n=4$ ). HF: Hyperforin. 


\subsubsection{Hyperforin Did Not Affect the Cell Viability of Proliferating NS/PCs at Concentrations between $0.0 \mu \mathrm{M}$ and $2.5 \mu \mathrm{M}$}

We found hyperforin did not change the cell viability of proliferating NS/PCs by WST-8 assay at concentrations between $0.0 \mu \mathrm{M}$ and $2.5 \mu \mathrm{M}$ for both $24 \mathrm{~h}$ and $48 \mathrm{~h}$. (Figure 3.3 and Figure 3.4).

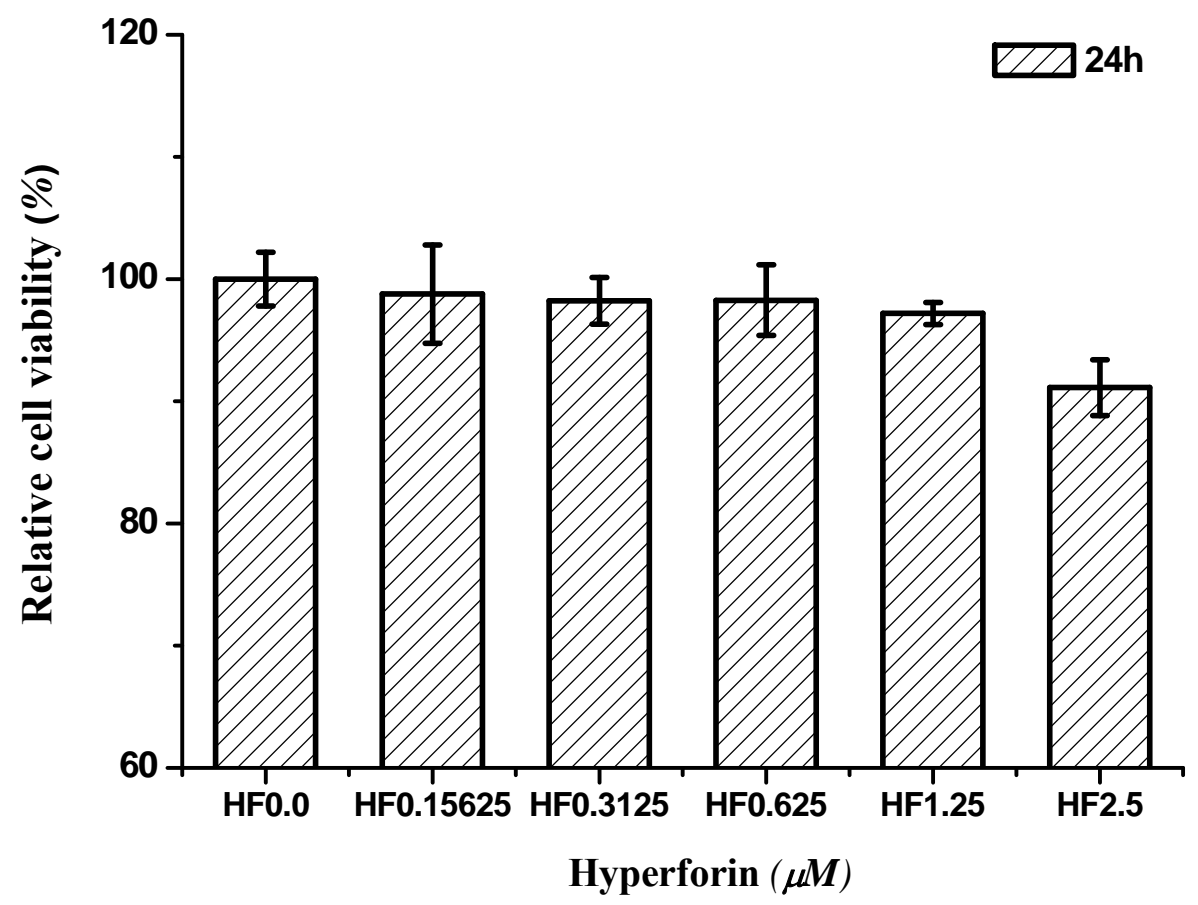

Figure 3.3 Cell viability of proliferating NS/PCs after $24 \mathrm{~h}$ of hyperforin treatment by WST-8 assay

Cell viability expressed as a percentage of the level at $\mathrm{HF} 0.0 \mu \mathrm{M}$ after treatment with hyperforin at escalating doses from $0.0 \mu \mathrm{M}$ to $1.0 \mu \mathrm{M}$ for $24 \mathrm{~h}$ using WST- 8 assay. All groups were compared to $0.0 \mu \mathrm{M}$ of hyperforin (Mean \pm SEM, $n=3$ ). HF: Hyperforin. 


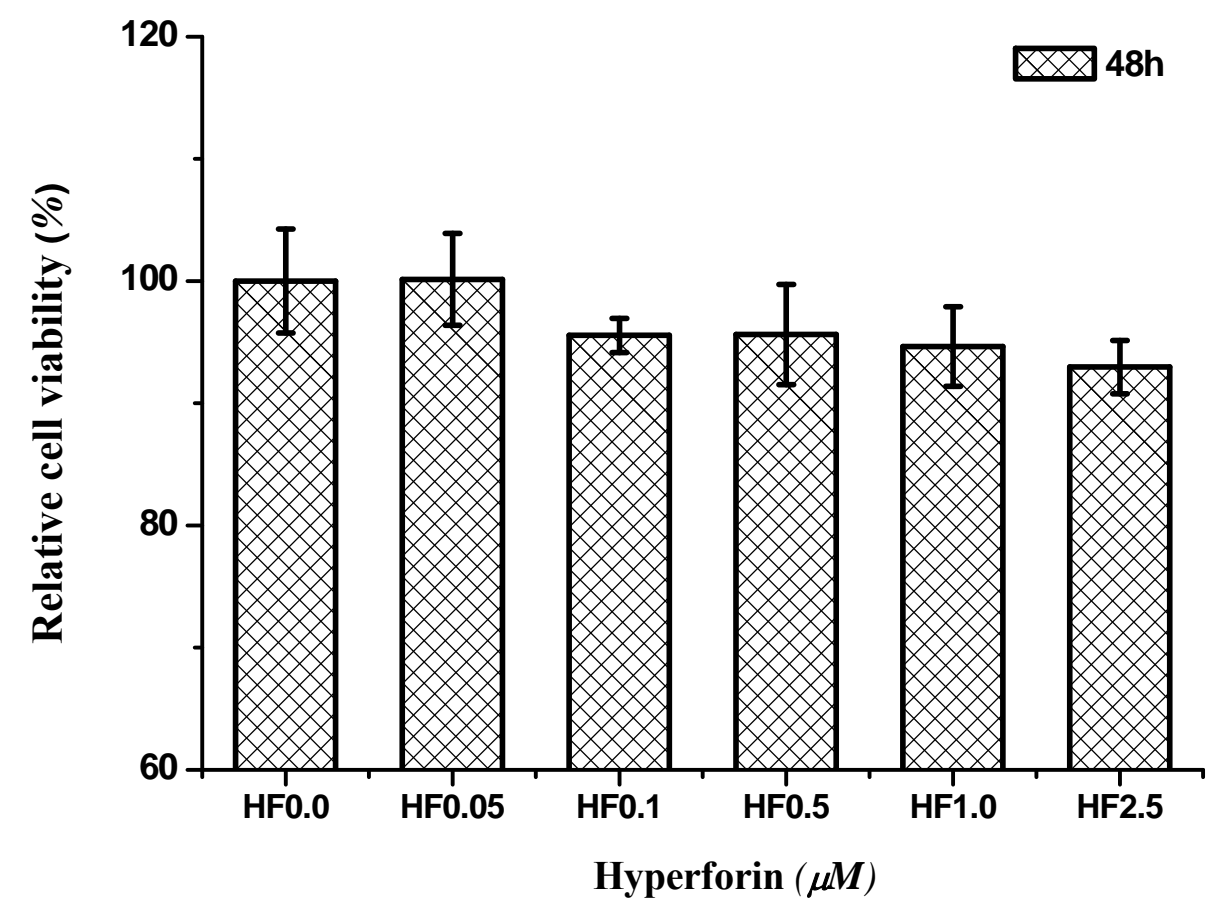

Figure 3.4 Cell viability of proliferating NS/PCs after $48 \mathrm{~h}$ of hyperforin treatment by WST-8 assay

Cell viability expressed as a percentage of the level at HF $0.0 \mu \mathrm{M}$ after treatment with hyperforin at escalating doses from $0.0 \mu \mathrm{M}$ to $1.0 \mu \mathrm{M}$ for $48 \mathrm{~h}$ using WST-8 assay. All groups were compared to $0.0 \mu \mathrm{M}$ of hyperforin (Mean \pm SEM, $n=4$ ). HF: Hyperforin. 


\subsection{Effects of Hyperforin on Mitochondrial Function in Differentiating CG-4 Cells and NS/PCs}

The differentiation of CG-4 cells or NS/PCs was initiated by replacing the growth medium with the differentiation medium. Usually, CG-4 cells began to show morphological characteristics of mature oligodendrocytes within two days (Stariha and Kim, 2001); NS/PCs began to show different types of neural cell markers within four days when maintained in the differentiation medium.

During the differentiation processes of CG-4 cells and NS/PCs, a series of assays were used to evaluate the effects of hyperforin on the mitochondrial function of differentiating CG-4 cells and NS/PCs. The tetrazolium microplate assays including the MTT assay and the WST-8 assay were used to measure the NADH levels generated from glycolysis and the citric acid cycle. ATP is the main energy resource for most cell functions, including biological synthesis, transporting macromolecules and cell signaling. Mitochondria are the major cellular source of ATP synthesis in mammal cells and 95\% of the energy supply is from mitochondrial oxidative phosphorylation. Intracellular ATP levels are considered the most sensitive end points in understanding characteristics of cellular energy metabolism and mitochondrial function in both physiological and pathological states (Maehara et al., 1987). The firefly luciferase ATP assay was used to directly measure the intracellular levels of ATP. There is a proton gradient across the inner mitochondrial membrane. This proton gradient is the result of proton pumping during the electron transport in the mitochondria (Boyer et al., 1977; Mitchell, 1966). This proton gradient generates membrane potential and $\mathrm{pH}$ gradient across the inner membrane. The potential energy stored in these two gradients drives the ATP synthase to generate ATP from adenosine diphosphate (ADP) and inorganic phosphate (Pi) (Boyer, 1987; Mitchell, 1979), which is the last step of oxidative phosphorylation. Mitochondrial membrane potential is an important parameter regulated by the demand of living cells. It represents the bioenergetic state of living cells. Rhodamine123 is actively transported into the mitochondria but it can not freely pass through the membrane (Haydon and Hladky, 
1972), so it accumulates in mitochondria proportionally to the mitochondrial membrane potential. Rhodamine123 assay was used to measure the mitochondrial membrane potential. This assay can further support that increased ATP generation was related to the increased potential energy in mitochondria rather than other reasons, for example, the decrease of ATP consumption.

\subsubsection{Effects of Hyperforin on Mitochondrial Function-related Parameters and Cell Numbers of Differentiating CG-4 Cells at Different Concentrations}

\subsubsection{MTT and WST-8 Assays}

In differentiating CG-4 cells, hyperforin significantly increased cell viability by MTT assay at $0.25 \mu \mathrm{M}(119.9 \% \pm 4.1 \%$ of the value at $0.0 \mu \mathrm{M})$ and at $0.5 \mu \mathrm{M}(124.2 \% \pm 2.6 \%$ of the value at $0.0 \mu \mathrm{M})$ for $24 \mathrm{~h}$ (Figure 3.5); as well as at $0.25 \mu \mathrm{M}(122.5 \% \pm 2.9 \%$ of the value at $0.0 \mu \mathrm{M})$ and at $0.5 \mu \mathrm{M}(131.6 \% \pm 2.5 \%$ of the value at $0.0 \mu \mathrm{M})$ for $48 \mathrm{~h}$ (Figure 3.6) compared to $0.0 \mu \mathrm{M}$ of hyperforin. Hyperforin also significantly increased cell viability by WST-8 assay at $0.5 \mu \mathrm{M}(132.0 \% \pm 5.9 \%$ of the value at $0.0 \mu \mathrm{M})$ for $24 \mathrm{~h}$ (Figure 3.7); as well as at $0.125 \mu \mathrm{M}(122.2 \% \pm 4.9 \%$ of the value at $0.0 \mu \mathrm{M})$ and at 0.5 $\mu \mathrm{M}(162.8 \% \pm 2.4 \%$ of the value at $0.0 \mu \mathrm{M})$ for $48 \mathrm{~h}$ (Figure 3.8) compared to $0.0 \mu \mathrm{M}$ of hyperforin. Hyperforin did not significantly affect the cell viability at $1.0 \mu \mathrm{M}$ for $24 \mathrm{~h}$ of treatment, but it significantly decreased the cell viability at $1.0 \mu \mathrm{M}(76.4 \% \pm 2.3 \%$ of the value at $0.0 \mu \mathrm{M}$ ) for $48 \mathrm{~h}$ compared to $0.0 \mu \mathrm{M}$ of hyperforin by WST- 8 assay (Figure 3.8). 


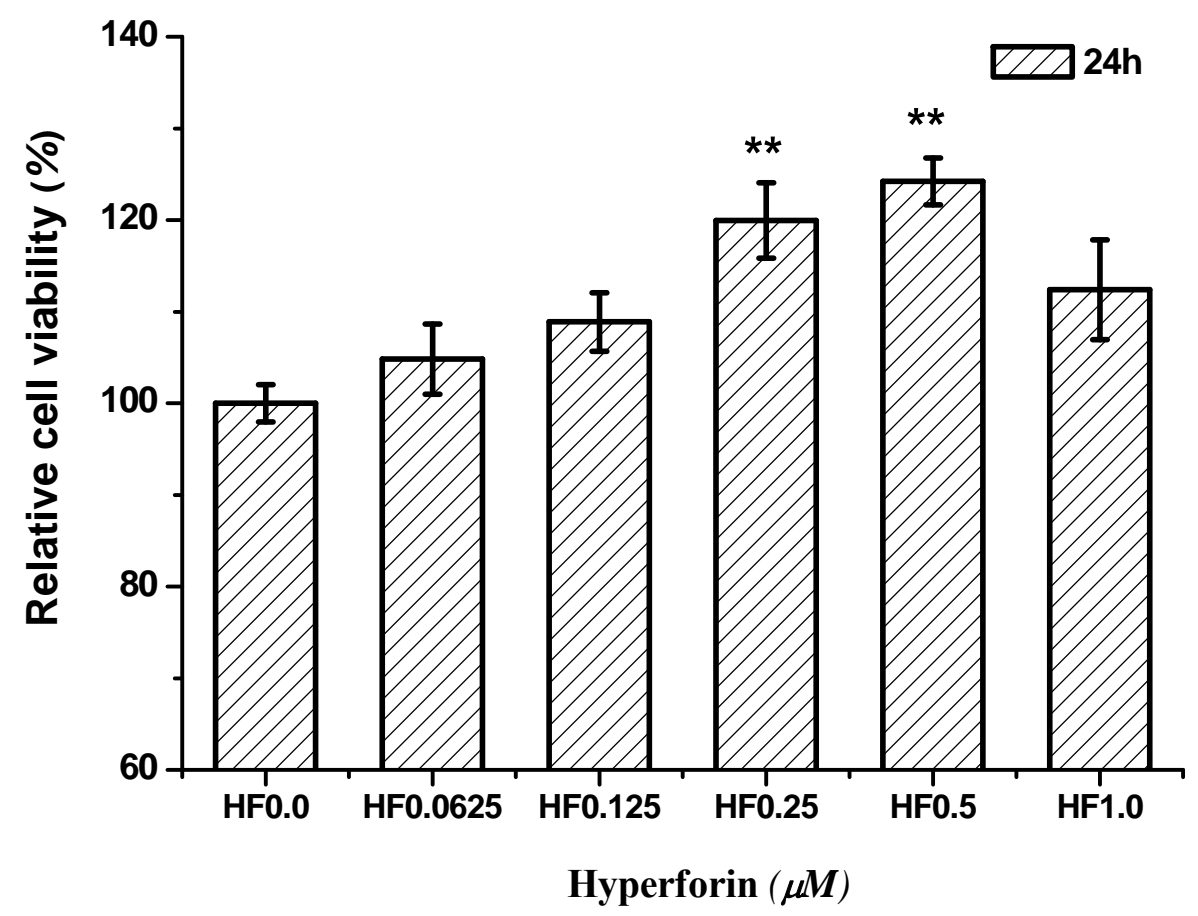

Figure 3.5 Cell viability of differentiating CG-4 cells after $24 \mathrm{~h}$ of hyperforin treatment by MTT assay

Cell viability expressed as a percentage of the level at $\mathrm{HF} 0.0 \mu \mathrm{M}$ after treatment with hyperforin at escalating doses from $0.0 \mu \mathrm{M}$ to $1.0 \mu \mathrm{M}$ for $24 \mathrm{~h}$ using MTT assay. All groups were compared to $0.0 \mu \mathrm{M}$ of hyperforin and ${ }^{* *} p<0.01$ (Mean $\pm \mathrm{SEM}, \mathrm{n}=6$ ). HF: Hyperforin. 


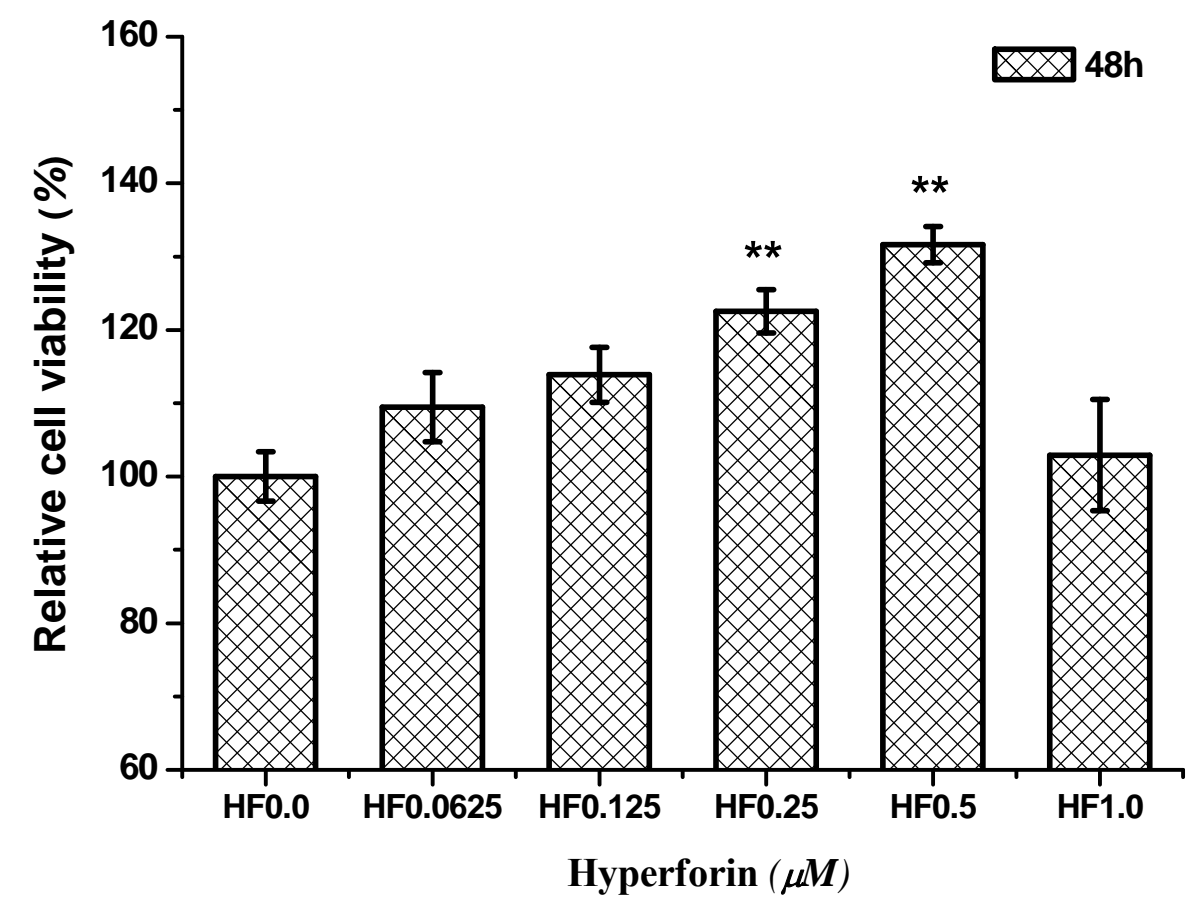

Figure 3.6 Cell viability of differentiating CG-4 cells after $48 \mathrm{~h}$ of hyperforin treatment by MTT assay

Cell viability expressed as a percentage of the level at HF $0.0 \mu \mathrm{M}$ after treatment with hyperforin at escalating doses from $0.0 \mu \mathrm{M}$ to $1.0 \mu \mathrm{M}$ for $48 \mathrm{~h}$ using MTT assay. All groups were compared to $0.0 \mu \mathrm{M}$ of hyperforin and ${ }^{* *} p<0.01$ (Mean $\pm \mathrm{SEM}, \mathrm{n}=6$ ). HF: Hyperforin. 


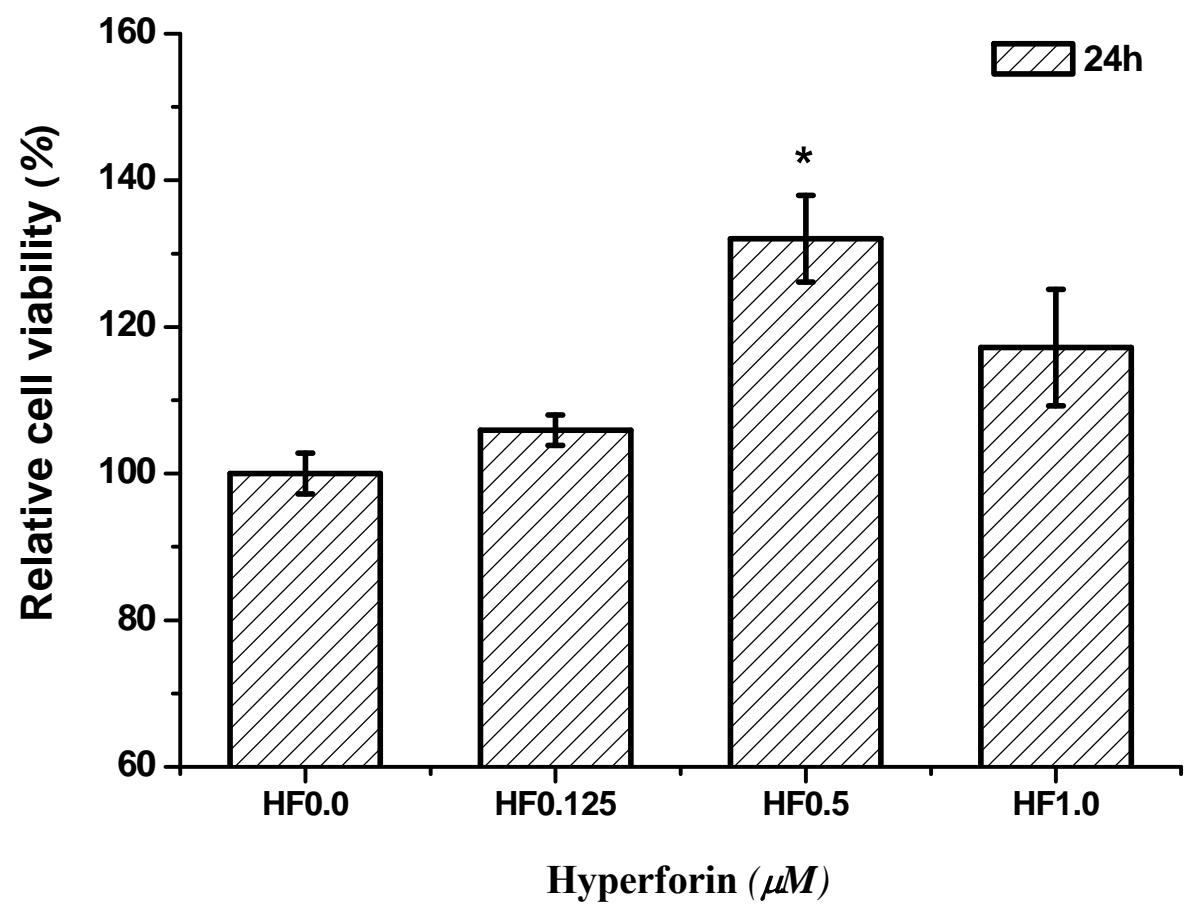

Figure 3.7 Cell viability of differentiating CG-4 cells after $24 \mathrm{~h}$ of hyperforin treatment by WST-8 assay

Cell viability expressed as a percentage of the level at HF $0.0 \mu \mathrm{M}$ after treatment with hyperforin at escalating doses from $0.0 \mu \mathrm{M}$ to $1.0 \mu \mathrm{M}$ for $24 \mathrm{~h}$ using WST-8 assay. All groups were compared to $0.0 \mu \mathrm{M}$ of hyperforin and $* p<0.05$ (Mean \pm SEM, $n=3$ ). HF: Hyperforin. 


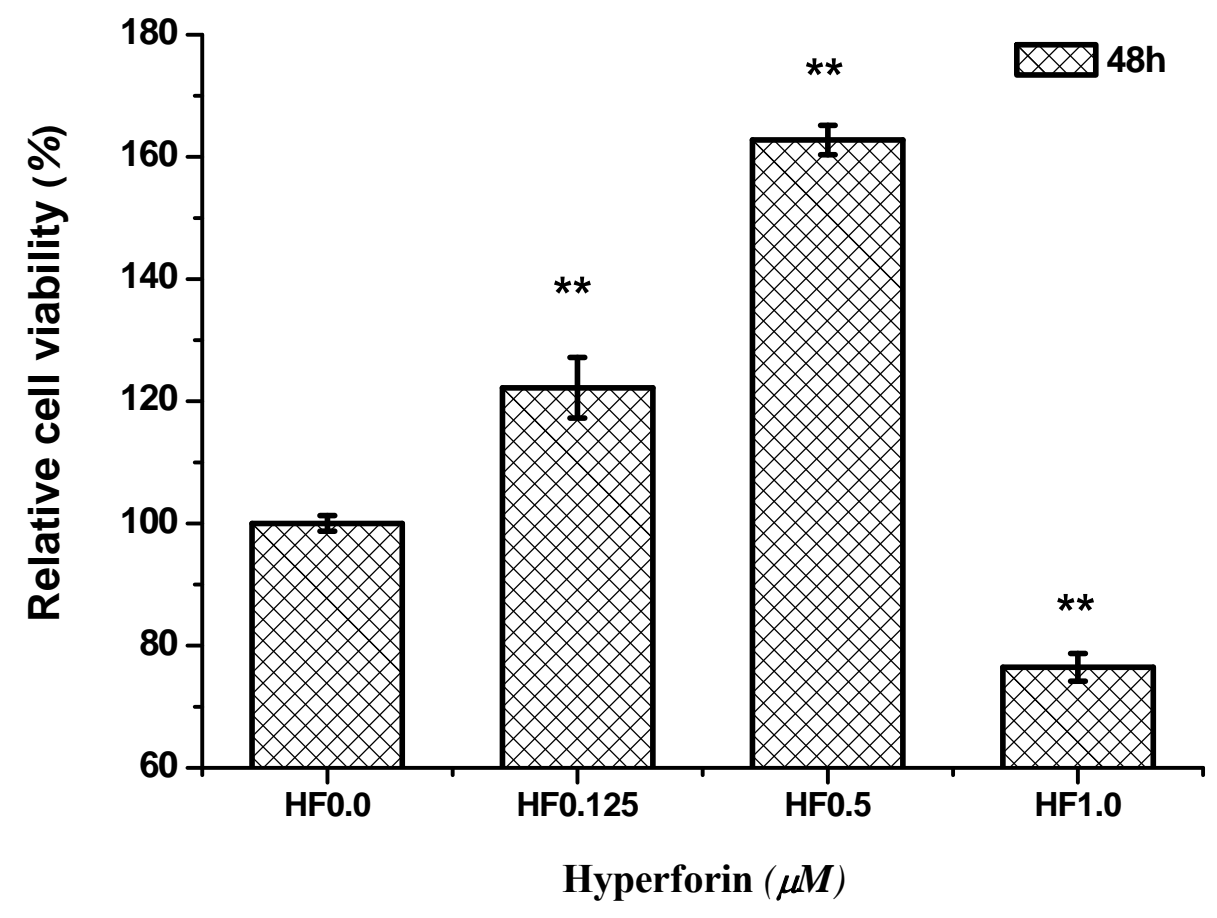

Figure 3.8 Cell viability of differentiating CG-4 cells after 48 h of hyperforin treatment by WST-8 assay

Cell viability expressed as a percentage of the level at HF $0.0 \mu \mathrm{M}$ after treatment with hyperforin at escalating doses from $0.0 \mu \mathrm{M}$ to $1.0 \mu \mathrm{M}$ for $48 \mathrm{~h}$ using WST-8 assay. All groups were compared to $0.0 \mu \mathrm{M}$ of hyperforin and $* * p<0.01$ (Mean \pm SEM, $n=3$ ). HF: Hyperforin. 


\subsubsection{Intracellular ATP Levels}

In differentiating CG-4 cells, hyperforin significantly increased intracellular ATP levels at $0.25 \mu \mathrm{M}(132.0 \% \pm 6.6 \%$ of the value at $0.0 \mu \mathrm{M})$ and at $0.5 \mu \mathrm{M}(134.5 \% \pm 6.8 \%$ of the value at $0.0 \mu \mathrm{M})$ for $24 \mathrm{~h}$ (Figure 3.9); as well as at $0.125 \mu \mathrm{M}(121.9 \% \pm 4.2 \%$ of the value at $0.0 \mu \mathrm{M})$, at $0.25 \mu \mathrm{M}(123.7 \% \pm 4.9 \%$ of the value at $0.0 \mu \mathrm{M})$ and at $0.5 \mu \mathrm{M}$ $(132.3 \% \pm 5.7 \%$ of the value at $0.0 \mu \mathrm{M})$ for $48 \mathrm{~h}$ compared to $0.0 \mu \mathrm{M}$ of hyperforin (Figure 3.10). However, hyperforin significantly decreased intracellular ATP levels at $1.0 \mu \mathrm{M}(32.0 \% \pm 3.0 \%$ of the value at $0.0 \mu \mathrm{M})$ for $48 \mathrm{~h}$ compared to $0.0 \mu \mathrm{M}$ of hyperforin (Figure 3.10).

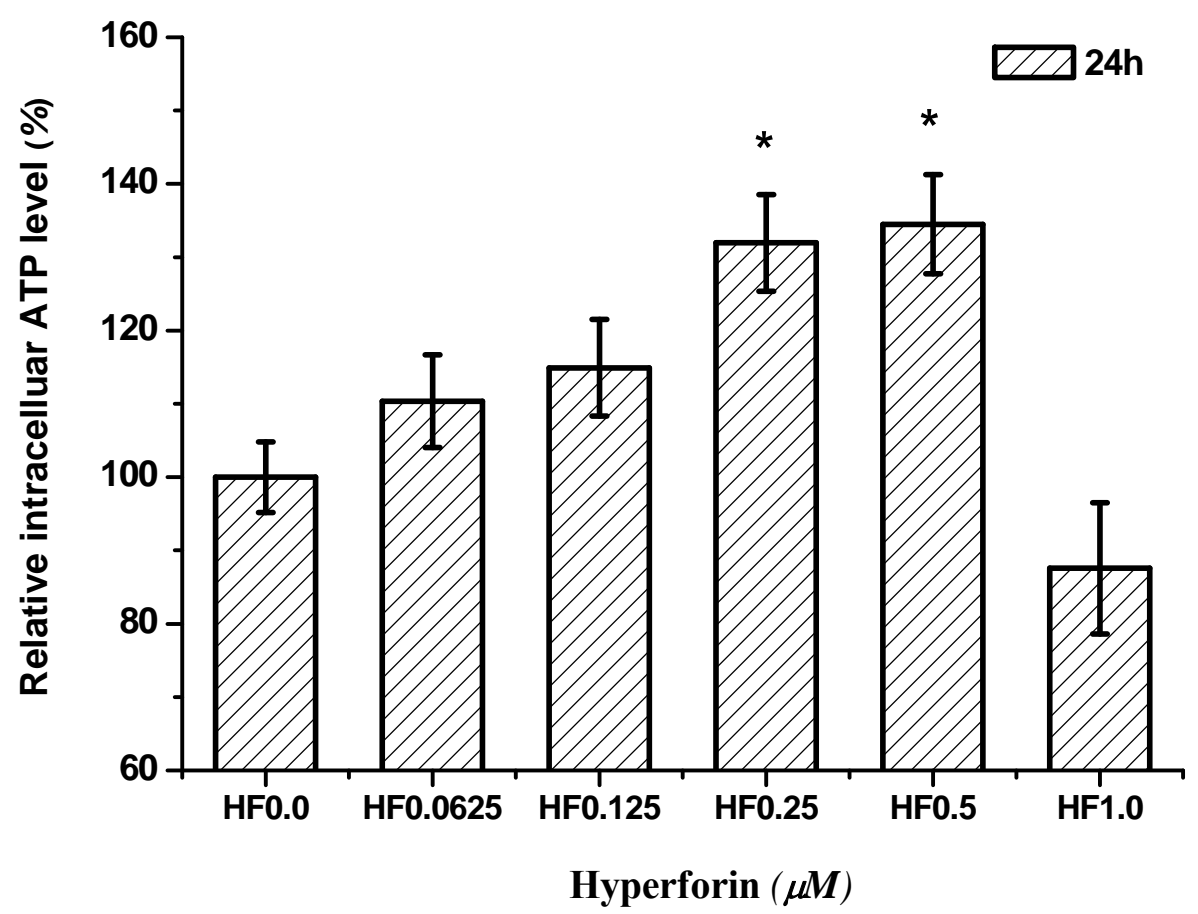

Figure 3.9 Intracellular ATP levels in differentiating CG-4 cells after 24 h of hyperforin treatment

Intracellular ATP levels expressed as a percentage of the level at HF $0.0 \mu \mathrm{M}$ after treatment with hyperforin at escalating doses from $0.0 \mu \mathrm{M}$ to $1.0 \mu \mathrm{M}$ for $24 \mathrm{~h}$. All groups were compared to $0.0 \mu \mathrm{M}$ of hyperforin and $* p<0.05$ (Mean \pm SEM, $\mathrm{n}=8$ ). HF: Hyperforin. 


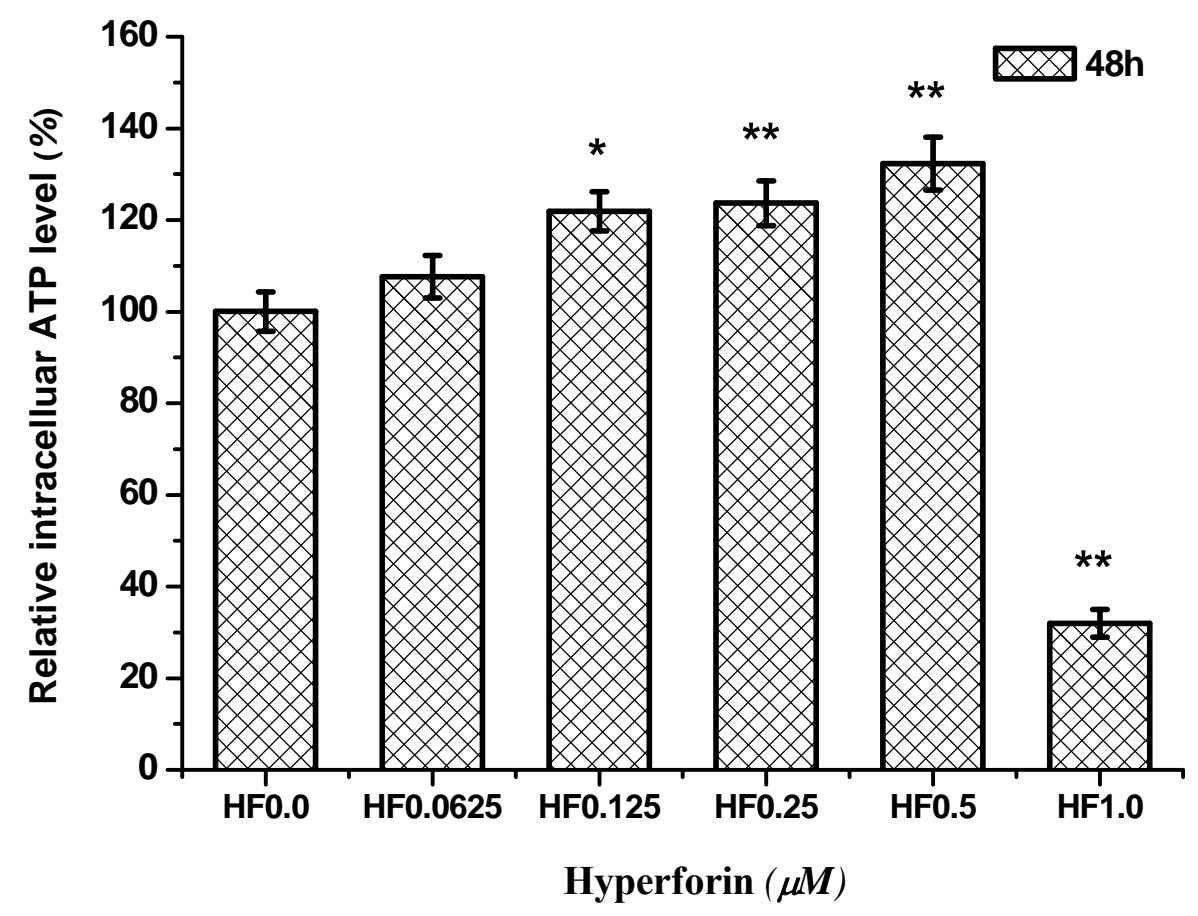

Figure 3.10 Intracellular ATP levels in differentiating CG-4 cells after $48 \mathrm{~h}$ of hyperforin treatment

Intracellular ATP levels expressed as a percentage of the level at HF $0.0 \mu \mathrm{M}$ after treatment with hyperforin at escalating doses from $0.0 \mu \mathrm{M}$ to $1.0 \mu \mathrm{M}$ for $48 \mathrm{~h}$. All groups were compared to $0.0 \mu \mathrm{M}$ of hyperforin and ${ }^{*} p<0.05,{ }^{* *} p<0.01$ (Mean \pm SEM, $\mathrm{n}=8$ ). HF: Hyperforin. 


\subsubsection{Rhodamine123 Uptake}

In differentiating CG-4 cells, hyperforin significantly increased Rhodamine123 uptake at $0.125 \mu \mathrm{M}(119.5 \% \pm 2.5 \%$ of the value at $0.0 \mu \mathrm{M})$, at $0.25 \mu \mathrm{M}(119.1 \% \pm 1.6 \%$ of the value at $0.0 \mu \mathrm{M})$ and at $0.5 \mu \mathrm{M}(119.5 \% \pm 5.4 \%$ of the value at $0.0 \mu \mathrm{M})$ for $24 \mathrm{~h}($ Figure 3.11); as well as at $0.125 \mu \mathrm{M}(130.0 \% \pm 4.7 \%$ of the value at $0.0 \mu \mathrm{M})$, at $0.25 \mu \mathrm{M}$ $(134.5 \% \pm 5.2 \%$ of the value at $0.0 \mu \mathrm{M})$ and at $0.5 \mu \mathrm{M}(123.7 \% \pm 5.7 \%$ of the value at $0.0 \mu \mathrm{M}$ ) for $48 \mathrm{~h}$ compared to $0.0 \mu \mathrm{M}$ of hyperforin (Figure 3.12). However, hyperforin significantly decreased Rhodamine 123 uptake at $1.0 \mu \mathrm{M}(62.6 \% \pm 2.5 \%$ of the value at $0.0 \mu \mathrm{M})$ for $24 \mathrm{~h}$ (Figure 3.11); as well as at $1.0 \mu \mathrm{M}(33.2 \% \pm 3.6 \%$ of the value at 0.0 $\mu \mathrm{M}$ ) for $48 \mathrm{~h}$ compared to $0.0 \mu \mathrm{M}$ of hyperforin (Figure 3.12).

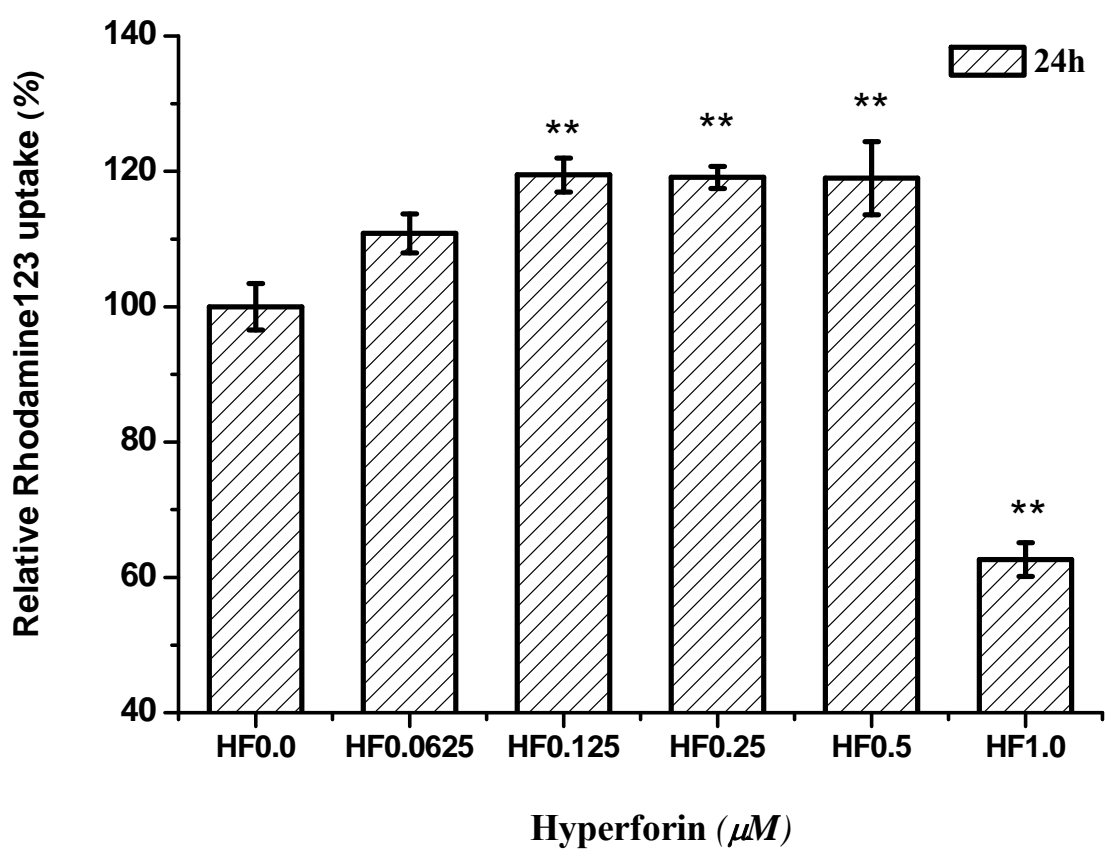

Figure 3.11 Rhodamine123 uptake in differentiating CG-4 cells after $24 \mathrm{~h}$ of hyperforin treatment

Rhodamine 123 uptake expressed as a percentage of the level at HF $0.0 \mu \mathrm{M}$ after treatment with hyperforin at escalating doses from $0.0 \mu \mathrm{M}$ to $1.0 \mu \mathrm{M}$ for $24 \mathrm{~h}$. All groups were compared to $0.0 \mu \mathrm{M}$ of hyperforin and $* * p<0.01$ (Mean \pm SEM, $\mathrm{n}=7$ ). HF: Hyperforin. 


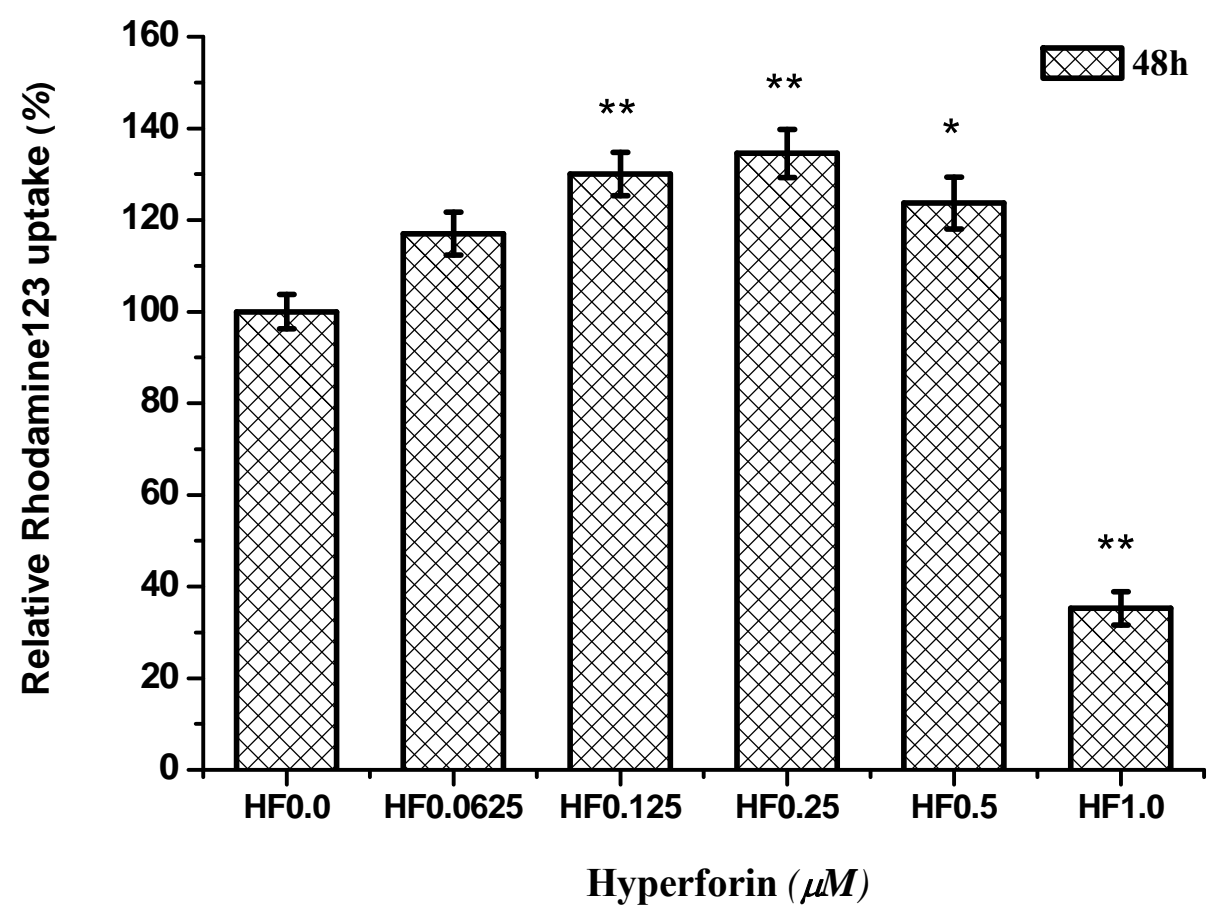

Figure 3.12 Rhodamine123 uptake in differentiating CG-4 cells after $48 \mathrm{~h}$ of hyperforin treatment

Rhodamine 123 uptake expressed as a percentage of the level at HF $0.0 \mu \mathrm{M}$ after treatment with hyperforin at escalating doses from $0.0 \mu \mathrm{M}$ to $1.0 \mu \mathrm{M}$ for $48 \mathrm{~h}$. All groups were compared to $0.0 \mu \mathrm{M}$ of hyperforin and ${ }^{*} p<0.05,{ }^{* *} p<0.01$ (Mean \pm SEM, $\mathrm{n}=7$ ). HF: Hyperforin. 


\subsubsection{BrdU Incorporation and Viable Cell Number}

CG-4 cells began to differentiate in the differentiation medium, but they can still maintain a certain ability to increase cell numbers, because certain portion of CG-4 cells are still in the cell-division cycle (Louis et al., 1992). BrdU assay and viable cell number counting were used to exclude the possibility that the increased cell viability was due to the lower level of cell proliferation.

In differentiating CG-4 cells, hyperforin did not significant change BrdU incorporation (Figure 3.13 and Figure 3.14) and total CG-4 cell numbers (Figure 3.15) at concentrations between $0.0 \mu \mathrm{M}$ and $0.5 \mu \mathrm{M}$ for $24 \mathrm{~h}$ and $48 \mathrm{~h}$. However, hyperforin significantly decreased BrdU incorporation at $1.0 \mu \mathrm{M}(44.1 \% \pm 4.3 \%$ of the value at 0.0 $\mu \mathrm{M})$ for $48 \mathrm{~h}$; as well as the viable cell numbers at $0.75 \mu \mathrm{M}(66.2 \% \pm 5.6 \%$ of the value at $0.0 \mu \mathrm{M})$ and at $1.0 \mu \mathrm{M}(47.2 \% \pm 5.7 \%$ of the value at $0.0 \mu \mathrm{M})$ for $48 \mathrm{~h}$ compared to 0.0 $\mu \mathrm{M}$ of hyperforin (Figure 3.15).

These results demonstrated that hyperforin increased mitochondrial function-related parameters in differentiating CG-4 cells without affecting the viable cell numbers at concentrations between $0.25 \mu \mathrm{M}$ and $0.5 \mu \mathrm{M}$ for both $24 \mathrm{~h}$ and $48 \mathrm{~h}$ compared to $0.0 \mu \mathrm{M}$ of hyperforin. Hyperforin significantly decreased most mitochondrial function-related parameters, BrdU incorporation as well as the viable cell number at $1.0 \mu \mathrm{M}$ for $48 \mathrm{~h}$ compared to $0.0 \mu \mathrm{M}$ of hyperforin. 


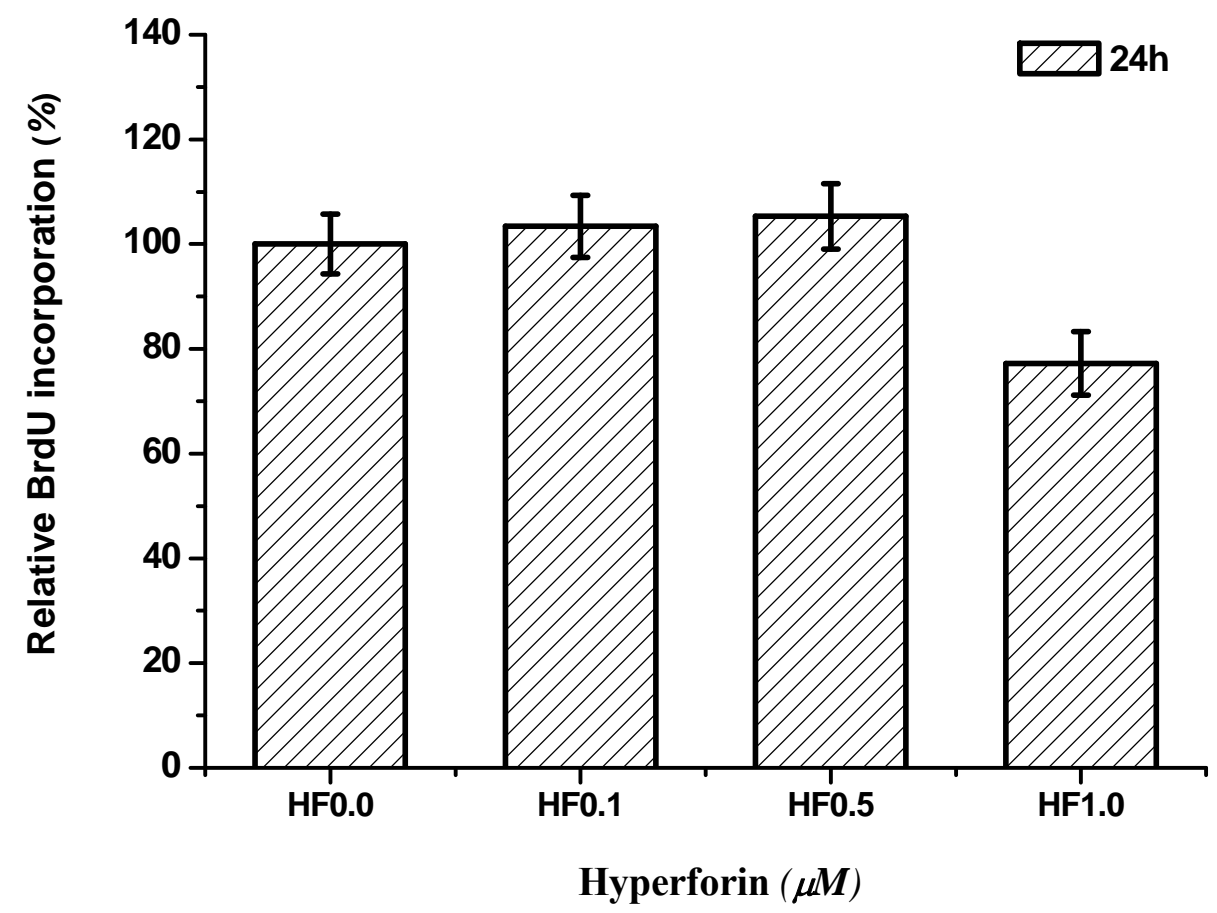

Figure 3.13 BrdU incorporation in differentiating CG-4 cells after $24 \mathrm{~h}$ of hyperforin treatment

BrdU incorporation expressed as a percentage of the level at $\mathrm{HF} 0.0 \mu \mathrm{M}$ after treatment with hyperforin at escalating doses from $0.0 \mu \mathrm{M}$ to $1.0 \mu \mathrm{M}$ for $24 \mathrm{~h}$. All groups were compared to $0.0 \mu \mathrm{M}$ of hyperforin (Mean \pm SEM, $n=3$ ). HF: Hyperforin. 


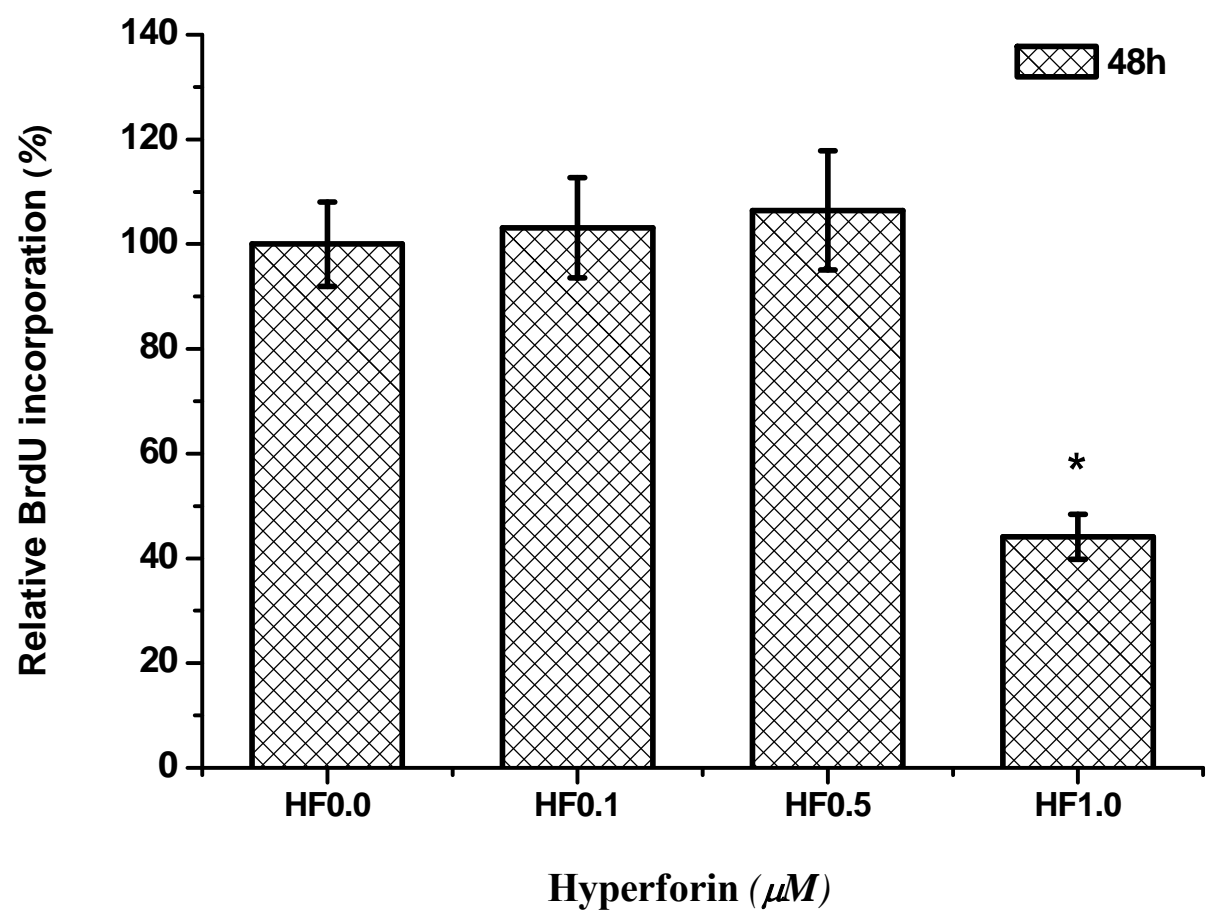

Figure 3.14 BrdU incorporation in differentiating CG-4 cells after $48 \mathrm{~h}$ of hyperforin treatment

BrdU incorporation expressed as a percentage of the level at $\mathrm{HF} 0.0 \mu \mathrm{M}$ after treatment with hyperforin at escalating doses from $0.0 \mu \mathrm{M}$ to $1.0 \mu \mathrm{M}$ for $48 \mathrm{~h}$. All groups were compared to $0.0 \mu \mathrm{M}$ of hyperforin and ${ }^{*} p<0.05$ (Mean \pm SEM, $\mathrm{n}=3$ ). HF: Hyperforin. 


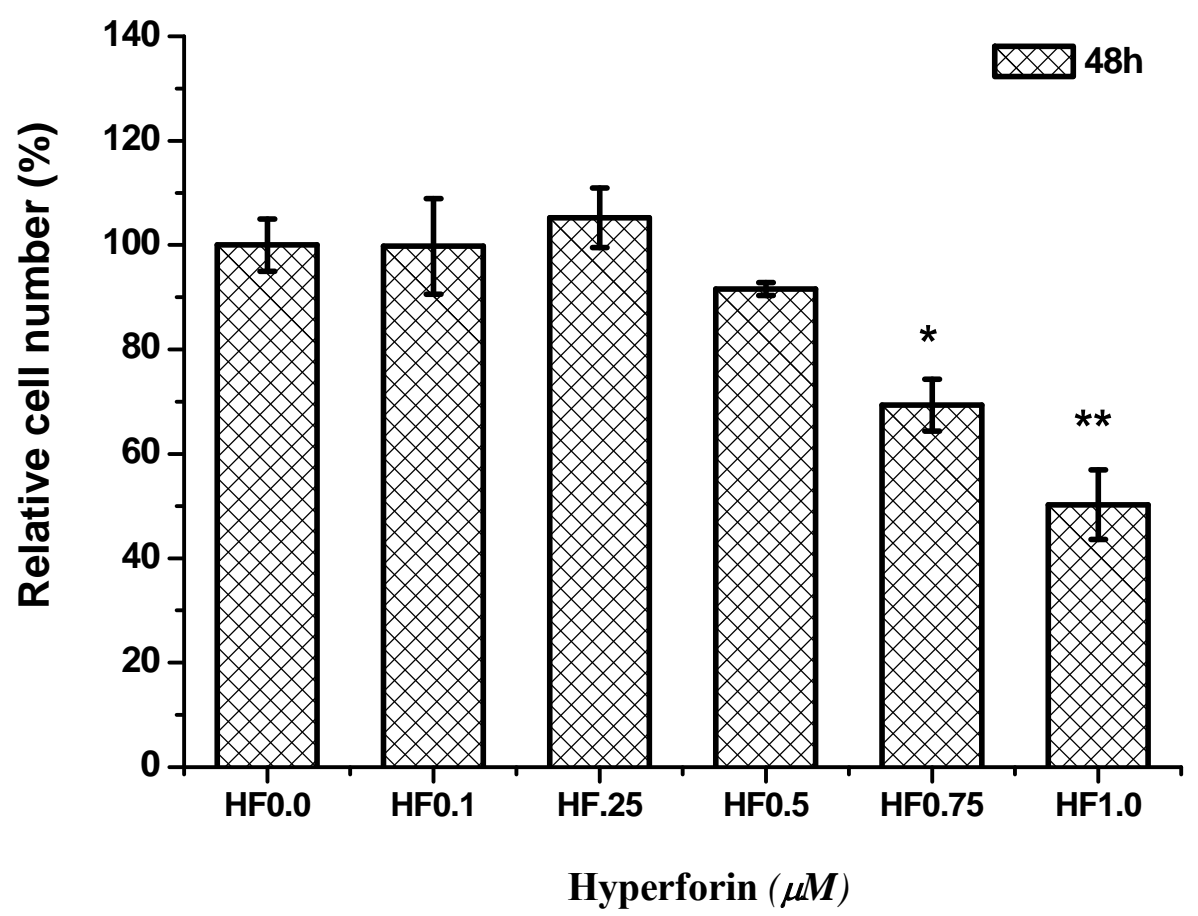

Figure 3.15 Viable cell numbers in differentiating CG-4 cell culture after $48 \mathrm{~h}$ of hyperforin treatment

Viable cell numbers expressed as a percentage of the level at HF $0.0 \mu \mathrm{M}$ after treatment with hyperforin at escalating doses from $0.0 \mu \mathrm{M}$ to $1.0 \mu \mathrm{M}$ for $48 \mathrm{~h}$. All groups were compared to $0.0 \mu \mathrm{M}$ of hyperforin and ${ }^{*} p<0.05,{ }^{* *} p<0.01$ (Mean \pm SEM, $\left.\mathrm{n}=4\right)$. HF: Hyperforin. 


\subsubsection{Hyperforin Prevented Rotenone-induced ATP Depletion in Differentiating CG-4 Cells}

Rotenone is a potent natural cytotoxic compound extracted from tropical plants and is commonly used as an insecticide. Rotenone is extremely lipophilic, so it is able to freely cross cellular membranes and accumulate in mitochondria (Talpade et al., 2000), where it impairs oxidative phosphorylation by inhibiting complex I of the mitochondrial electrontransport chain (Schuler and Casida, 2001). Rotenone-induced inhibition of complex I causes acute ATP depletion and generation of reactive oxygen species (ROS). Increased oxidative stress can damage mitochondrial DNA and proteins to induce apoptosis (Sherer et al., 2003). Rotenone is now used as a classical inhibitor of complex I in cell culture and experimental animal models (Betarbet et al., 2000).

In differentiating CG-4 cells, $24 \mathrm{~h}$ insult of rotenone showed a dose-dependent trend to significantly decrease the intracellular ATP levels at concentrations of $31.25 \mathrm{nM}(58.4 \%$ $\pm 3.7 \%$ of the control value), $62.5 \mathrm{nM}(40.1 \% \pm 2.7 \%$ of the control value $)$ and $125 \mathrm{nM}$ $(27.8 \% \pm 3.0 \%$ of the control value) compared to control. Consistently, $48 \mathrm{~h}$ treatment of hyperforin significantly increased the intracellular ATP level at $0.25 \mu \mathrm{M}(136.0 \% \pm 7.5 \%$ of the control value) compared to control. We pretreated CG-4 cells with $0.25 \mu \mathrm{M}$ of hyperforin for $24 \mathrm{~h}$, and then we introduced the insults of different concentrations of rotenone to evaluate the protective effect of hyperforin on rotenone-induced cytotoxicity. During the $24 \mathrm{~h}$ insult of the rotenone, the hyperforin pretreatment remained in the culture medium.

Our results indicated that pretreatment with hyperforin at $0.25 \mu \mathrm{M}$ for $24 \mathrm{~h}$ significantly prevented the decrease of the intracellular ATP level induced by the insult of rotenone at $31.25 \mathrm{nM}$ (Figure 3.16). The protective effect of hyperforin maintained the intracellular ATP at the level $(83.1 \% \pm 6.4 \%$ of the control value) which was not significantly different from that of control. However, hyperforin was not able to prevent the decrease of the intracellular ATP level induced by insults of rotenone at $62.5 \mathrm{nM}$ and $125 \mathrm{nM}$. Although hyperforin tended to prevent the ATP depletion in these groups, there were no 
significant differences in intracellular ATP levels between the hyperforin pretreatment groups and rotenone only groups.

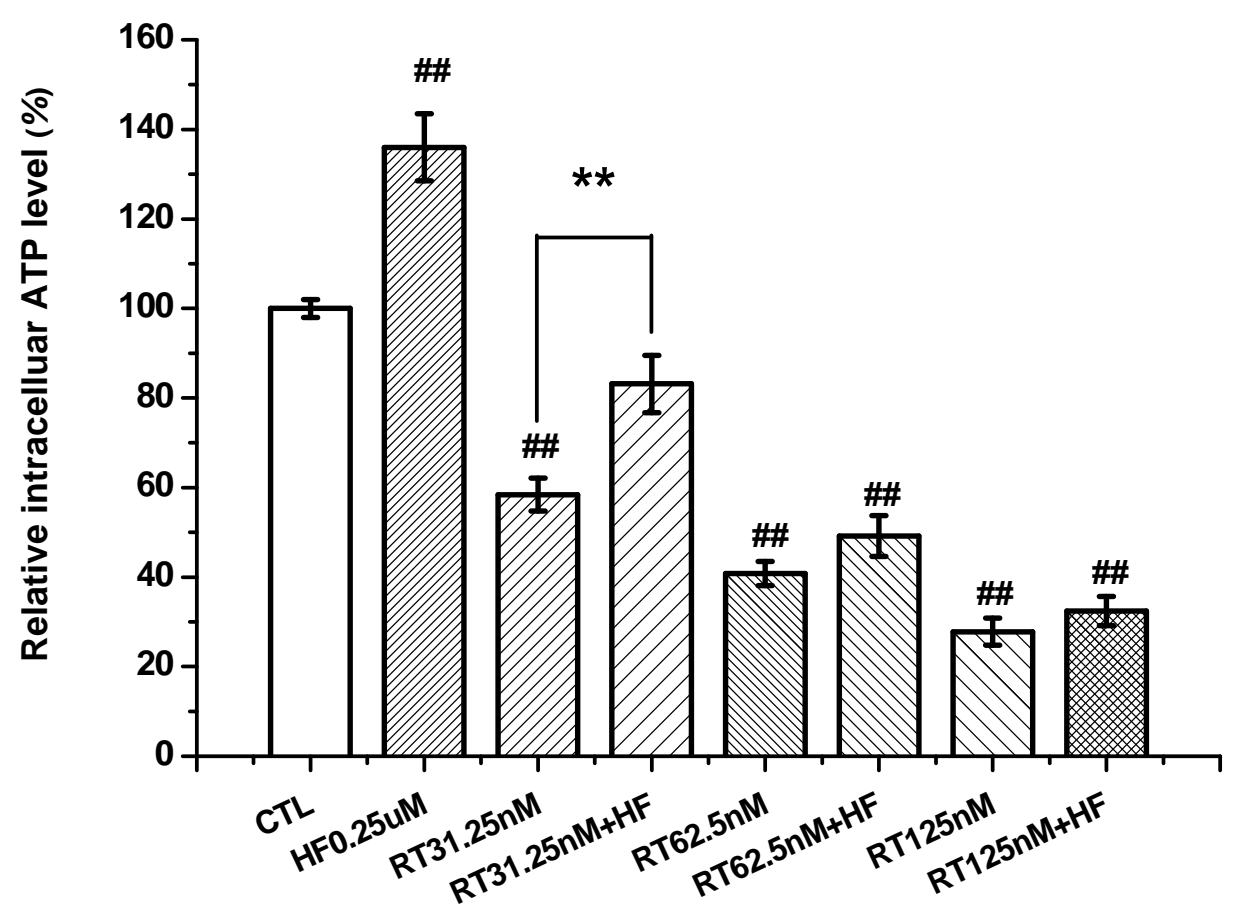

Figure 3.16 Intracellular ATP levels in differentiating CG-4 cells after $24 \mathrm{~h}$ pretreatment of hyperforin and $24 \mathrm{~h}$ insult of rotenone

Intracellular ATP levels expressed as a percentage of the control after pretreatment with hyperforin at 0.25 $\mu \mathrm{M}$ for $24 \mathrm{~h}$ and insults of rotenone from $31.25 \mathrm{nM}$ to $125 \mathrm{nM}$ for another $24 \mathrm{~h}$. During the $24 \mathrm{~h}$ insult of the rotenone, the hyperforin pretreatment remained in the culture medium. ${ }^{*} p<0.01$ compared to RT $31.25 \mathrm{nM} ;{ }^{\# \#} p<0.01$ compared to CTL (Mean \pm SEM, $n=8$ ). CTL: control; HF: hyperforin; RT: rotenone. 


\subsubsection{Effects of Hyperforin on Mitochondrial Function-related Parameters of Differentiating NS/PCs at Different Concentrations}

\subsubsection{MTT Assay}

In differentiating NS/PCs, hyperforin significantly increased the cell viability by MTT assay at $5.0 \mu \mathrm{M}(125.9 \% \pm 5.1 \%$ of the value at $0.0 \mu \mathrm{M})$ for $24 \mathrm{~h}$ (Figure 3.17); as well as at $2.5 \mu \mathrm{M}(127.9 \% \pm 3.6 \%$ of the value at $0.0 \mu \mathrm{M})$ and at $5.0 \mu \mathrm{M}(144.1 \% \pm 6.4 \%$ of the value at $0.0 \mu \mathrm{M}$ ) for $48 \mathrm{~h}$ compared to $0.0 \mu \mathrm{M}$ of hyperforin (Figure 3.18).

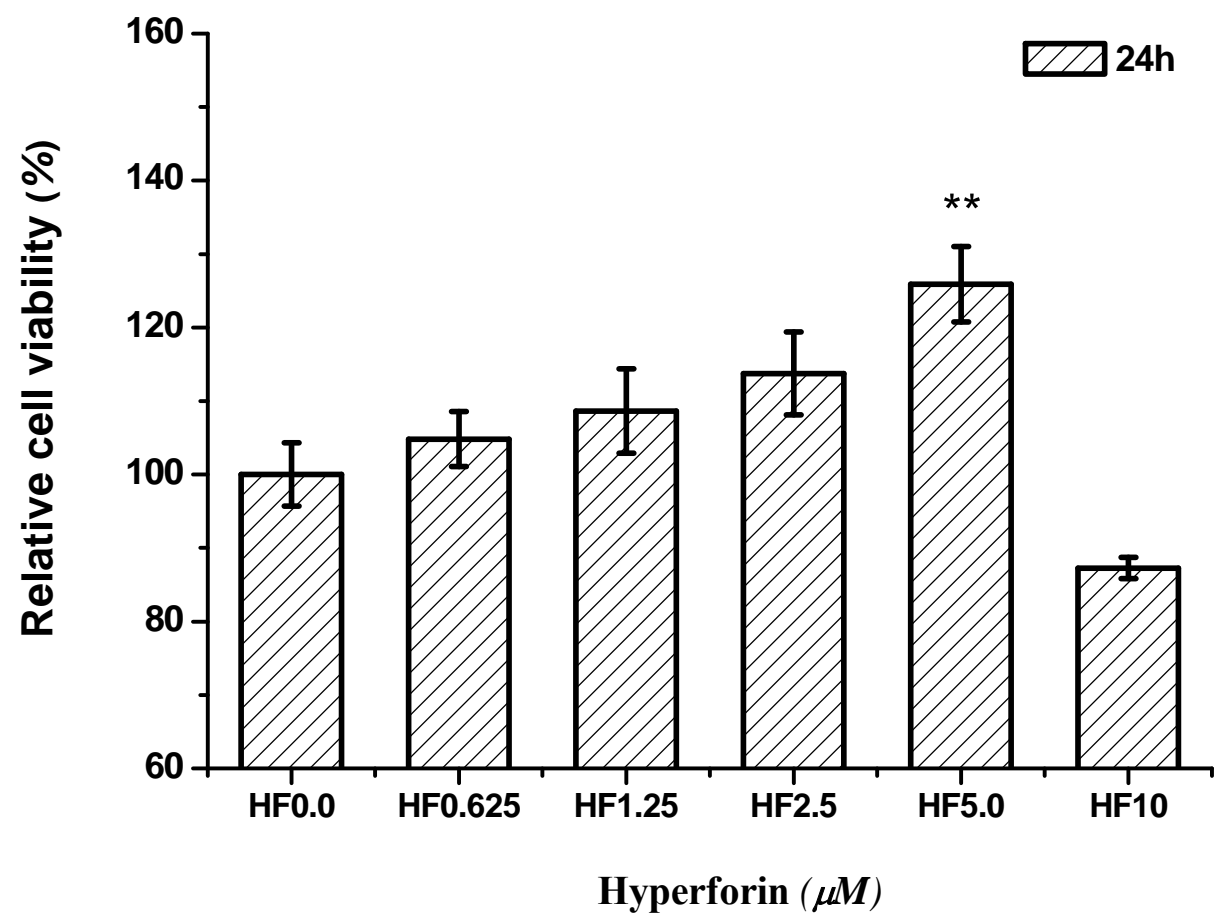

Figure 3.17 Cell viability of differentiating NS/PCs after 24 h of hyperforin treatment

Cell viability expressed as a percentage of the level at HF $0.0 \mu \mathrm{M}$ after treatment with hyperforin at escalating doses from $0.0 \mu \mathrm{M}$ to $10 \mu \mathrm{M}$ for $24 \mathrm{~h}$ using MTT assay. All groups were compared to $0.0 \mu \mathrm{M}$ of hyperforin and ${ }^{* *} p<0.01$ (Mean \pm SEM, $\mathrm{n}=5$ ). HF: Hyperforin. 


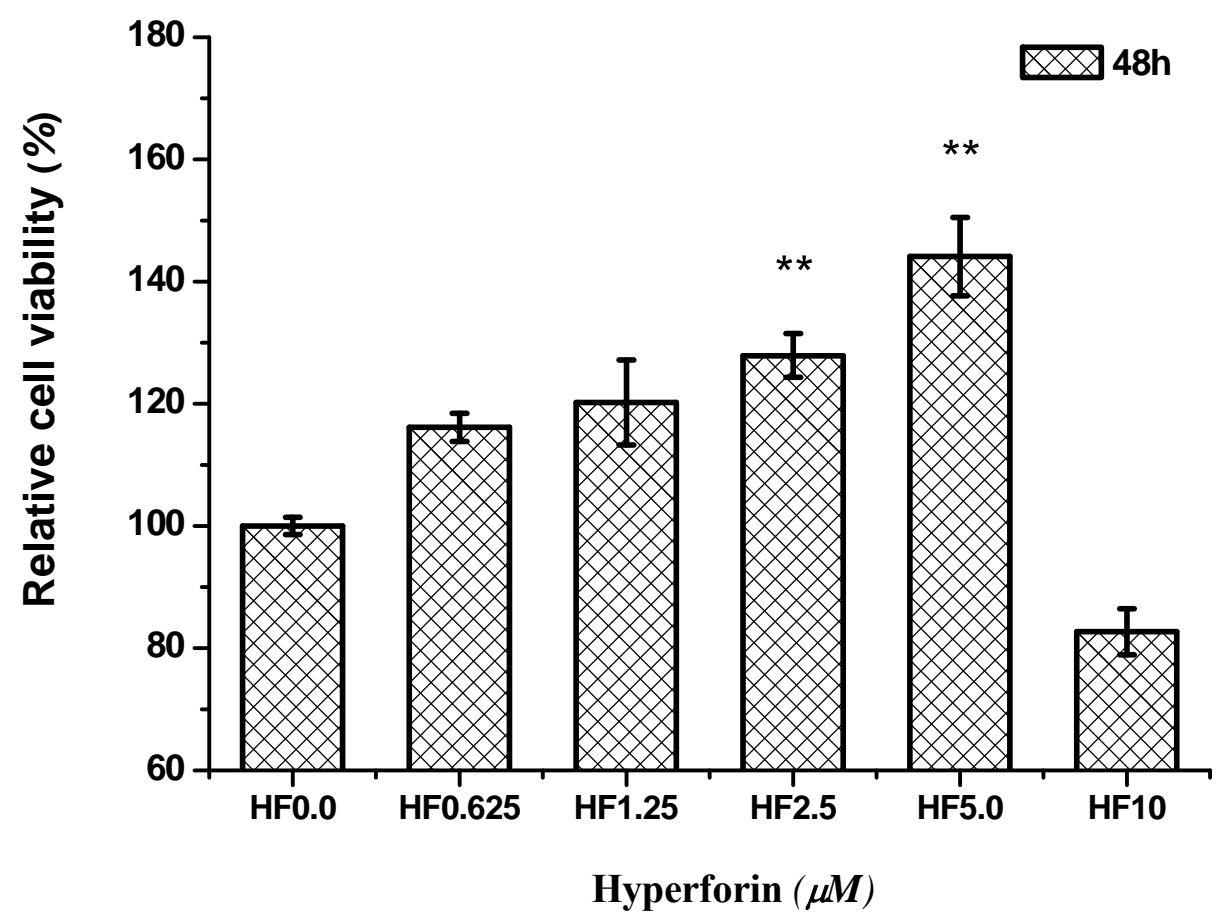

Figure 3.18 Cell viability of differentiating NS/PCs after $48 \mathrm{~h}$ of hyperforin treatment

Cell viability expressed as a percentage of the level at HF $0.0 \mu \mathrm{M}$ after treatment with hyperforin at escalating doses from $0.0 \mu \mathrm{M}$ to $10 \mu \mathrm{M}$ for $48 \mathrm{~h}$ using MTT assay. All groups were compared to $0.0 \mu \mathrm{M}$ of hyperforin and ${ }^{* *} p<0.01$ (Mean $\pm \mathrm{SEM}, \mathrm{n}=5$ ). HF: Hyperforin. 


\subsubsection{Intracellular ATP Levels}

In differentiating NS/PCs, hyperforin significantly increased intracellular ATP levels at $5.0 \mu \mathrm{M}(129.2 \% \pm 2.9 \%$ of the value at $0.0 \mu \mathrm{M})$ for $24 \mathrm{~h}$ (Figure 3.19); as well as at 2.5 $\mu \mathrm{M}(117.4 \% \pm 5.3 \%$ of the value at $0.0 \mu \mathrm{M})$ and at $5.0 \mu \mathrm{M}(120.6 \% \pm 2.5 \%$ of the value at $0.0 \mu \mathrm{M}$ ) for $48 \mathrm{~h}$ compared to $0.0 \mu \mathrm{M}$ of hyperforin (Figure 3.20). However, hyperforin significantly decreased intracellular ATP levels at $10 \mu \mathrm{M}(72.9 \% \pm 8.6 \%$ of the value at $0.0 \mu \mathrm{M})$ for $24 \mathrm{~h}$ and at $10 \mu \mathrm{M}(77.8 \% \pm 1.2 \%$ of the value at $0.0 \mu \mathrm{M})$ for 48 h compared to $0.0 \mu \mathrm{M}$ of hyperforin (Figure 3.19 and Figure 3.20).

These results indicated that hyperforin increased cell viability and intracellular ATP levels in differentiating NS/PCs cells at concentrations between $2.5 \mu \mathrm{M}$ and $5.0 \mu \mathrm{M}$ for $24 \mathrm{~h}$ and $48 \mathrm{~h}$. Hyperforin decreased the intracellular ATP levels at the concentration of $10 \mu \mathrm{M}$ for $24 \mathrm{~h}$ and $48 \mathrm{~h}$. 


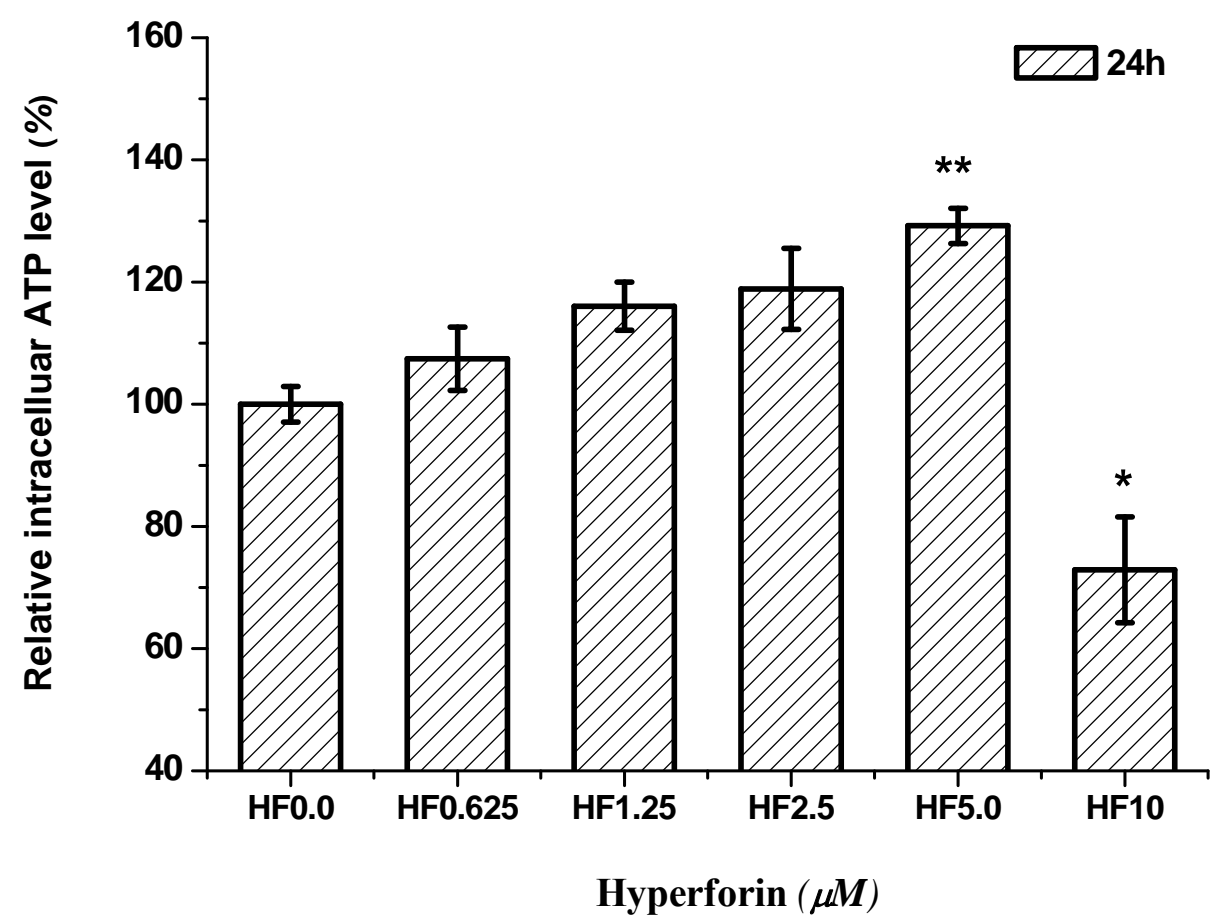

Figure 3.19 Intracellular ATP levels in differentiating NS/PCs after $24 \mathrm{~h}$ of hyperforin treatment

Intracellular ATP levels expressed as a percentage of the level at HF $0.0 \mu \mathrm{M}$ after treatment with hyperforin at escalating doses from $0.0 \mu \mathrm{M}$ to $10 \mu \mathrm{M}$ for $24 \mathrm{~h}$. All groups were compared to $0.0 \mu \mathrm{M}$ of hyperforin and ${ }^{*} p<0.05,{ }^{* *} p<0.01$ (Mean \pm SEM, $\mathrm{n}=5$ ). HF: Hyperforin. 


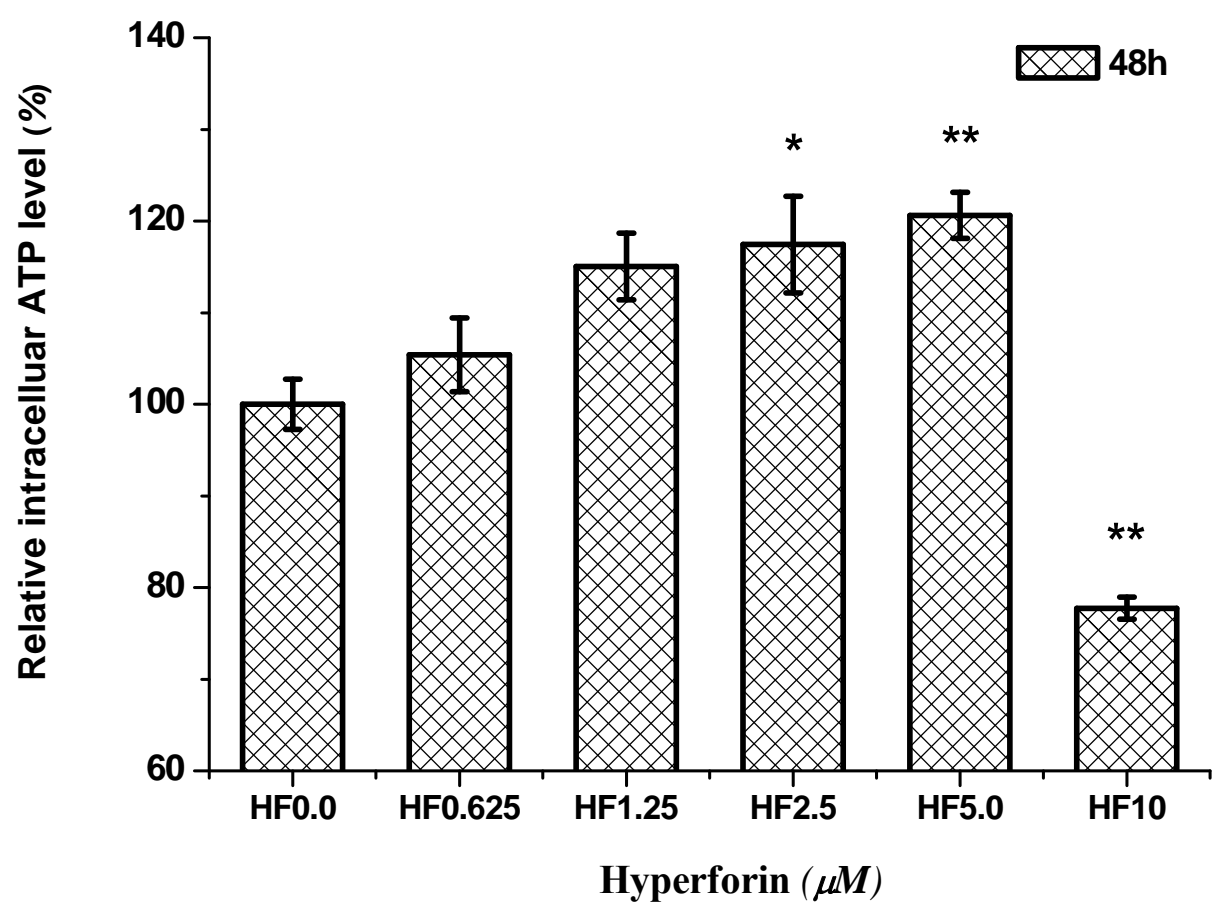

Figure 3.20 Intracellular ATP levels in differentiating NS/PCs after $48 \mathrm{~h}$ of hyperforin treatment

Intracellular ATP levels expressed as a percentage of the level at HF $0.0 \mu \mathrm{M}$ after treatment with hyperforin at escalating doses from $0.0 \mu \mathrm{M}$ to $10 \mu \mathrm{M}$ for $48 \mathrm{~h}$. All groups were compared to $0.0 \mu \mathrm{M}$ of hyperforin and ${ }^{*} p<0.05,{ }^{* *} p<0.01$ (Mean \pm SEM, $\mathrm{n}=5$ ). HF: Hyperforin. 


\subsection{Effects of Hyperforin on Development of Oligodendrocytes in Differentiating NS/PCs}

\subsubsection{Characterization and Differentiation of NS/PCs}

Nestin is a class VI intermediate filament protein with a molecular weight of $198 \mathrm{kDa}$ (Hockfield and McKay, 1985; Lendahl et al., 1990). It is expressed predominantly in NS/PCs of the central nervous system (Frederiksen and McKay, 1988). Nestin has been observed in cells of nervous tissue formation during the embryonic period of ontogenesis, in various neural precursors and in cells of various nervous system tumors (Gilyarov, 2008; Uchida et al., 2000). Nestin has been the most extensively used marker to identify NS/PCs within developing nervous system and in cultured cells.

CNPase is a $46 \mathrm{kDa}$ protein comprising $4 \%$ of total myelin proteins (Vogel and Thompson, 1988). CNPase may play an initial role in oligodendrocyte differentiation. Studies on the developmental expression of CNPase indicate that CNPase appears in early myelination and is maintained at a high level as myelin is produced (Sprinkle et al., 1978). It is enriched in CNS myelin and oligodendrocytes, so it is commonly used as a marker for myelinating oligodendrocytes.

GFAP is an intermediate filament protein with a molecular weight of $50 \mathrm{kDa}$. GFAP is the major protein constituent of glial cytoskeletal filaments in differentiated astrocytes of the CNS. GFAP plays an important role in modulating astrocyte motility and shape by providing structural stability to extensions of astroglial processes (Eng et al., 2000). GFAP has proven to be a reliable marker for normal and neoplastic cells of astroglial lineage.

$\beta$-III tubulin is one of the subunit protein of microtubules with a molecular weight of 50 $\mathrm{kDa}$. $\beta$-III tubulin expression was originally used as a marker of the early phase of neuronal differentiation in human embryonic development (Luduena, 1998). 
The fast proliferating neurospheres in growth medium were stained by NS/PCs marker nestin. Different cell type specific markers including CNPase, GFAP and $\beta$-III tubulin were used to detect different cell lineages including oligodendrocytes, astrocyte and neurons. The nuclei were stained with Hoechst 33342. All the fluorescent microphotographs from immunocytochemical staining showed that most of the proliferating cells in neurospheres were NS/PCs, and they were able to differentiate into different cell lineages of oligodendrocytes, astrocyte and neurons after $72 \mathrm{~h}$ of differentiation (Figure 3.21).
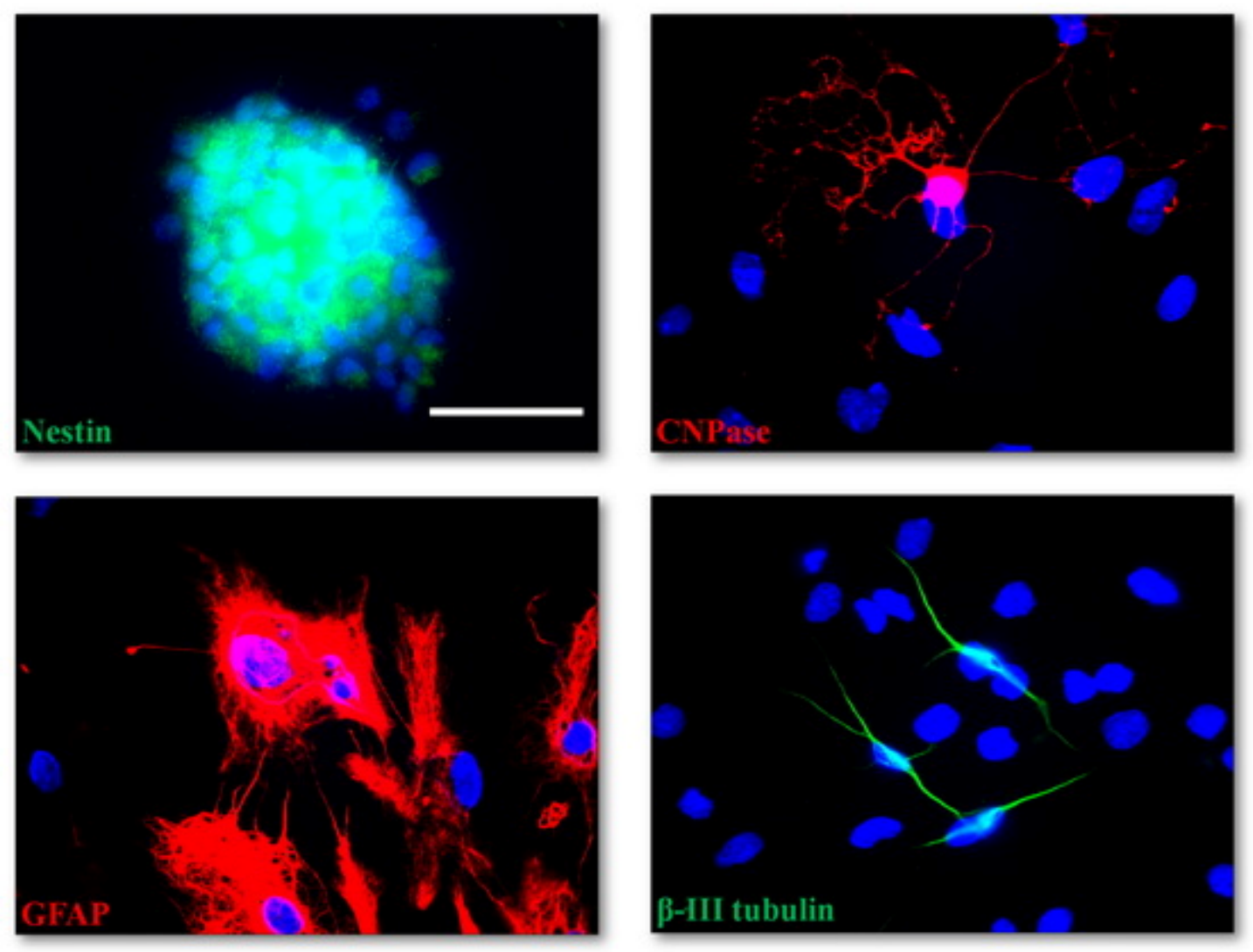

\section{Figure 3.21 Fluorescent microphotographs of proliferating NS/PCs and differentiating NS/PCs}

Neurospheres were maintained in growth medium for $4 \mathrm{~h}$ to allow attachment to the Poly-D-Lysine coated coverslip before proceeding the immunocytochemical staining. Differentiating NS/PCs were maintained in differentiation medium for $72 \mathrm{~h}$ before proceeding the immunocytochemical staining. The scale bar represents $50 \mu \mathrm{m}$. 


\subsubsection{Hyperforin Increased Expressions of Proteins Related to Oligodendrocyte Development but not the Ratio of Oligodendrocyte Lineage Cells in Differentiating NS/PCs}

MBP is a structural protein essential for formation of CNS myelin membranes, which optimizes transmission of action potentials in axons by saltatory conduction. It comprises $30 \%$ of the total protein of myelin (Harauz et al., 2004). MBP presents both in the CNS and peripheral nervous system (PNS) with a variety of isoforms. There are four isoforms of $21.5 \mathrm{kDa}, 20.2 \mathrm{kDa}, 18.5 \mathrm{kDa}$, and $17.2 \mathrm{kDa}$ in humans and four isoforms of $21.5 \mathrm{kDa}$, $18.5 \mathrm{kDa}, 17.0 \mathrm{kDa}$ and $14.0 \mathrm{kDa}$ in rat (Boggs, 2006). MBP plays a key role in the formation of compact myelin by bringing the cytoplasmic surfaces of the myelin membrane together (Jacobs, 2005). MBP has been extensively used as a mature oligodendrocyte marker. MBP and CNPase were used in this study to indentify the premature and mature oligodendrocytes in the differentiating NS/PC system. By comparing the expressions of both proteins in different hyperforin treatment groups, we were able to determine the effect of hyperforin on the development process of oligodendrocytes.

Oligodendrocyte lineage transcription factor 2 (Olig2), is a basic helix-loop-helix transcription factor essential for oligodendrocyte lineage determination. It is specific to the oligodendrocyte lineage during the early stage of CNS development (Rowitch et al., 2002). Expression of Olig2 is before the expression of early oligodendrocyte progenitor marker, such as PDGF receptor- $\alpha$ (Stolt et al., 2002). Therefore, Olig2 is considered the earliest marker available so far for oligodendrocyte lineage. Olig2 was used to determine how many NS/PCs became oligodendroglial lineage cells in differentiating NS/PCs. The expression of Olig2 was also used to evaluate the extent of maturation of oligodendrocytes because of its close relationship to this process (Lu et al., 2000). 


\subsubsection{Hyperforin Increased both Ratios of MBP-positive Cells and Expressions of MBP in Differentiating NS/PCs}

MBP expressions were detectable by immunocytochemical staining in NS/PCs after $96 \mathrm{~h}$ of differentiation (Figure 3.22). Hyperforin caused no difference on total viable cell numbers at concentrations between $0.0 \mu \mathrm{M}$ and $2.5 \mu \mathrm{M}$ for $96 \mathrm{~h}$ (Table 3.1 and Figure 3.24). Hyperforin significantly increased ratios of MBP-positive cells in differentiating $\mathrm{NS} / \mathrm{PCs}$ at concentrations of $0.625 \mu \mathrm{M}(4.1 \% \pm 0.3 \%)$ and $1.25 \mu \mathrm{M}(4.5 \% \pm 0.5 \%)$ for 96 h compared to $0.0 \mu \mathrm{M}(2.1 \% \pm 0.1 \%)$ of hyperforin (Table 3.1, Figure 3.23 and Figure 3.25). Hyperforin increased ratios of MBP-positive cells by increasing the numbers of MBP-positive cells rather than decreasing the total viable cell numbers (Table 3.1). Accordantly, hyperforin significantly increased expressions of MBP (two bands detected by goat anti-MBP) in differentiating NS/PCs at concentrations of $0.625 \mu \mathrm{M}(180.8 \% \pm$ $12.7 \%$ of the value at $0.0 \mu \mathrm{M})$ and $1.25 \mu \mathrm{M}(185.8 \% \pm 15.8 \%$ of the value at $0.0 \mu \mathrm{M})$ for $96 \mathrm{~h}$ compared to $0.0 \mu \mathrm{M}$ of hyperforin as determined by Western blot (Figure 3.26). Hyperforin did not significantly affect either ratios of MBP-positive cells or expressions of MBP at other concentrations in this study. 

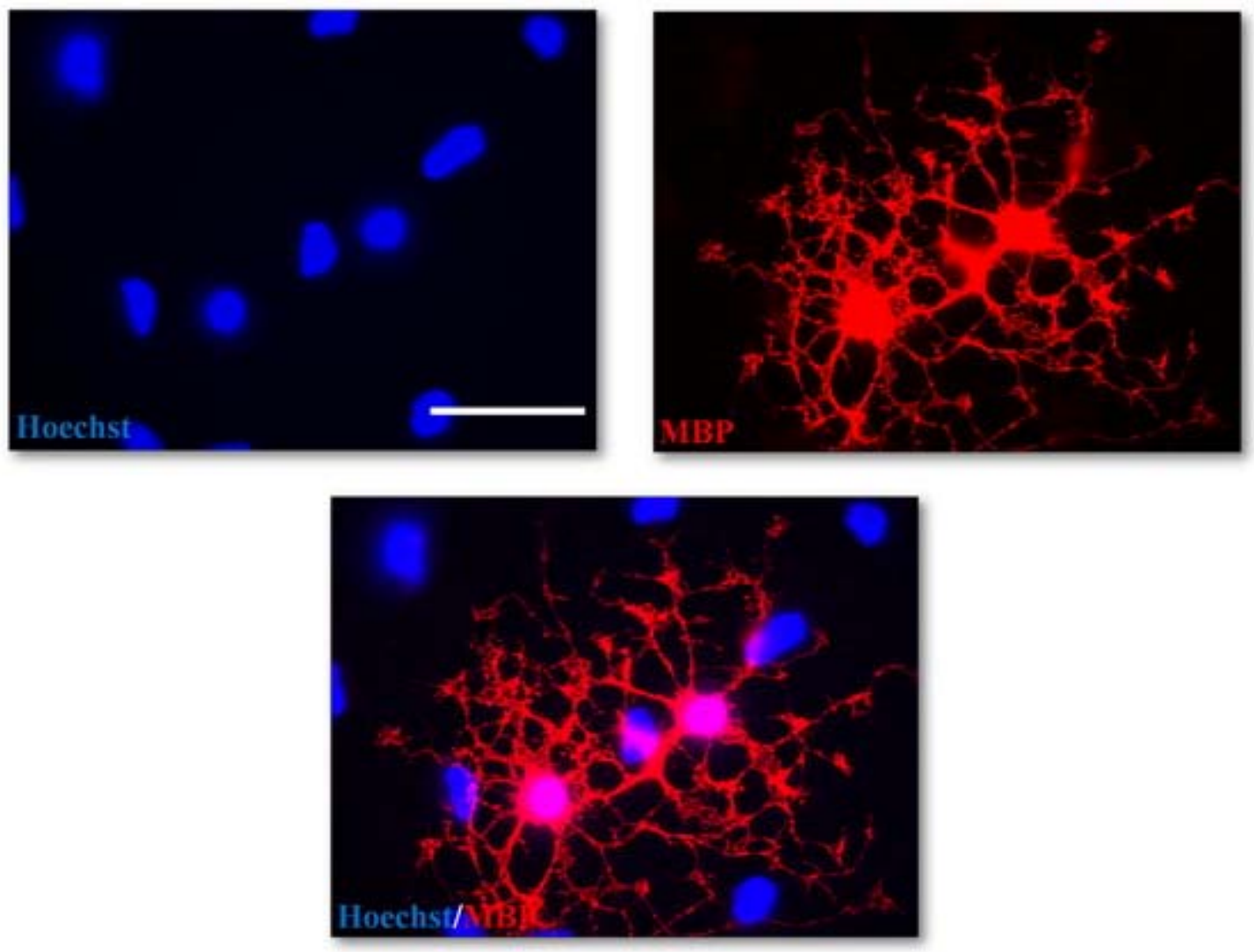

Figure 3.22 Fluorescent microphotographs of NS/PCs expressing MBP after $96 \mathrm{~h}$ of differentiation

The scale bar represents $50 \mu \mathrm{m}$. 

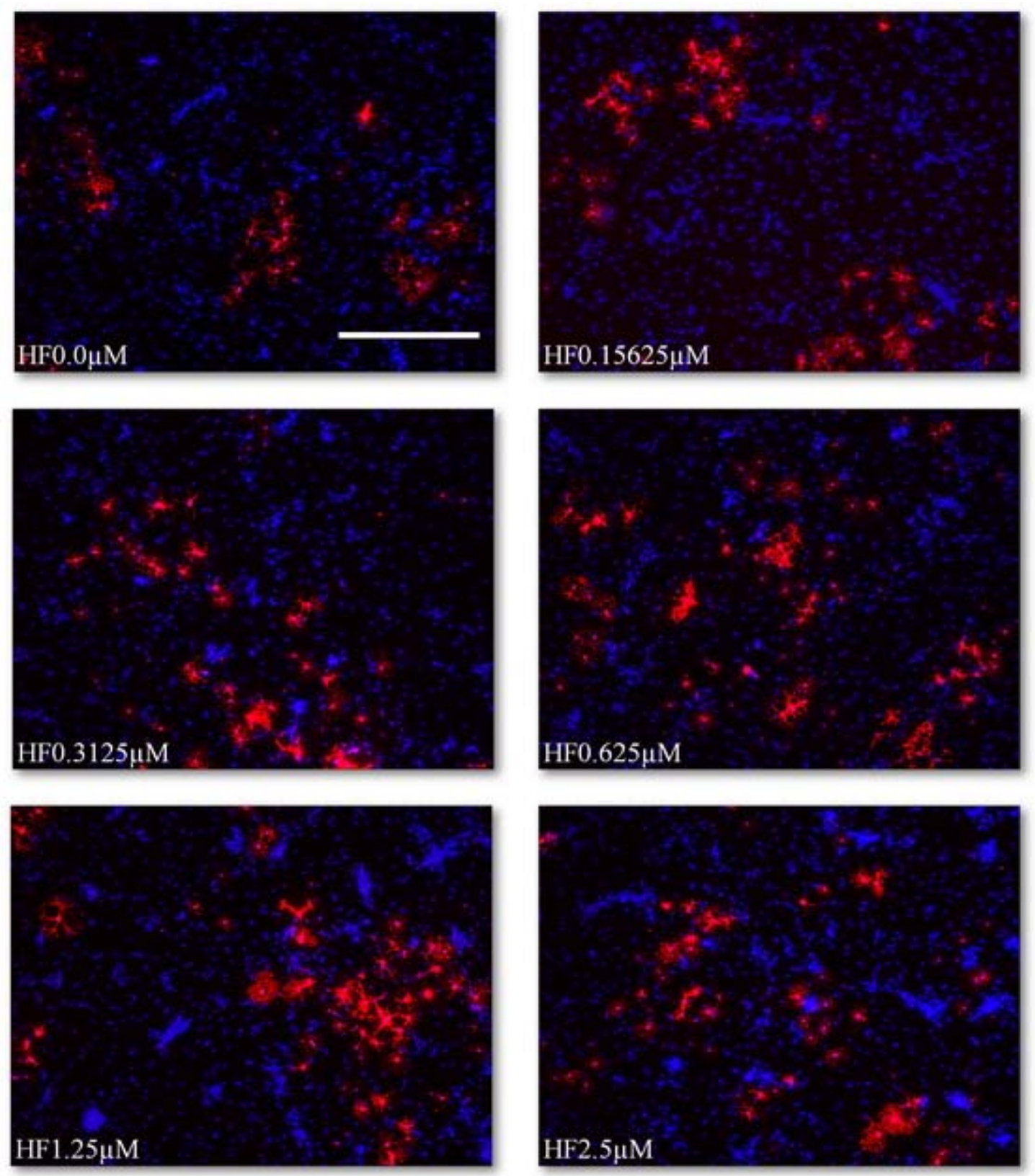

Figure 3.23 Fluorescent microphotographs of differentiating NS/PCs expressing MBP after $96 \mathrm{~h}$ of differentiation with hyperforin treatment

NS/PCs were treated with hyperforin at escalating doses from $0.0 \mu \mathrm{M}$ to $2.5 \mu \mathrm{M}$ for $96 \mathrm{~h}$ in differentiation medium. NS/PCs were stained with Hoechst 33342 (blue) and MBP (red). HF: Hyperforin. The scale bar represents $500 \mu \mathrm{m}$. 
Table 3.1 Ratios of MBP-positive cells to total NS/PCs after $96 \mathrm{~h}$ of hyperforin treatment

\begin{tabular}{|c|c|c|c|c|c|c|c|}
\hline Experiment & Description & $\mathrm{HF} 0.0 \mu \mathrm{M}$ & HF0.15625 $\mu \mathrm{M}$ & $\mathrm{HF} 0.3125 \mu \mathrm{M}$ & $\mathrm{HF} 0.625 \mu \mathrm{M}$ & $\mathrm{HF} 1.25 \mu \mathrm{M}$ & $\mathrm{HF} 2.5 \mu \mathrm{M}$ \\
\hline & Total cells & 996.4 & 1029.8 & 988.8 & 1030.2 & 999.0 & 989.8 \\
\hline \multirow[t]{3}{*}{1} & $\mathrm{MBP}+$ cells & 21.4 & 33.0 & 29.0 & 39.6 & 49.6 & 32.2 \\
\hline & Ratio & $2.2 \%$ & $3.2 \%$ & $2.9 \%$ & $3.8 \%$ & $5.0 \%$ & $3.3 \%$ \\
\hline & Total cells & 965.5 & 986.8 & 952.8 & 826.8 & 886.8 & 883.8 \\
\hline \multirow[t]{3}{*}{2} & $\mathrm{MBP}+$ cells & 21.8 & 25.8 & 26.4 & 28.2 & 40.0 & 20.2 \\
\hline & Ratio & $2.2 \%$ & $2.6 \%$ & $2.8 \%$ & $3.4 \%$ & $4.5 \%$ & $2.3 \%$ \\
\hline & Total cells & 983.5 & 956.5 & 901.6 & 980.5 & 911.8 & 910.4 \\
\hline \multirow[t]{3}{*}{3} & $\mathrm{MBP}+$ cells & 22.5 & 15.3 & 22.0 & 47.3 & 34.6 & 16.4 \\
\hline & Ratio & $2.3 \%$ & $1.6 \%$ & $2.4 \%$ & $4.8 \%$ & $3.8 \%$ & $1.8 \%$ \\
\hline & Total cells & 924.0 & 852.0 & 874.4 & 895.0 & 801.0 & 760.6 \\
\hline \multirow[t]{3}{*}{4} & $\mathrm{MBP}+$ cells & 17.5 & 17.2 & 19.4 & 34.3 & 24.3 & 9.2 \\
\hline & Ratio & $1.9 \%$ & $2.0 \%$ & $2.2 \%$ & $3.8 \%$ & $3.0 \%$ & $1.2 \%$ \\
\hline & Total cells & 863.0 & 863.2 & 844.2 & 880.8 & 924.0 & 876.8 \\
\hline \multirow[t]{3}{*}{5} & $\mathrm{MBP}+$ cells & 15.4 & 23.6 & 35.2 & 41.2 & 55.8 & 15.2 \\
\hline & Ratio & $1.8 \%$ & $2.7 \%$ & $4.2 \%$ & $4.7 \%$ & $6.0 \%$ & $1.7 \%$ \\
\hline & Total cells & $946.5 \pm 24.2$ & $937.6 \pm 34.7$ & $912.4 \pm 26.2$ & $922.7 \pm 36.5$ & $904.5 \pm 31.9$ & $884.3 \pm 36.9$ \\
\hline \multirow[t]{2}{*}{ Mean \pm SEM } & $\mathrm{MBP}+$ cells & $19.7 \pm 1.4$ & $23.0 \pm 3.2$ & $26.4 \pm 2.8$ & $38.1 \pm 3.2 *$ & $40.8 \pm 5.5^{* *}$ & $18.6 \pm 3.8$ \\
\hline & Ratio & $2.1 \% \pm 0.1 \%$ & $2.4 \% \pm 0.3 \%$ & $2.9 \% \pm 0.3 \%$ & $4.1 \% \pm 0.3 \% * *$ & $4.5 \% \pm 0.5 \% * *$ & $2.1 \% \pm 0.3 \%$ \\
\hline
\end{tabular}

NS/PCs were treated with hyperforin at escalating doses from $0.0 \mu \mathrm{M}$ to $2.5 \mu \mathrm{M}$ for $96 \mathrm{~h}$. All groups were compared to $0.0 \mu \mathrm{M}$ of hyperforin and ${ }^{*} p<0.05,{ }^{* *} p<0.01$ (Mean \pm SEM, $\mathrm{n}=5$ ). HF: hyperforin. 


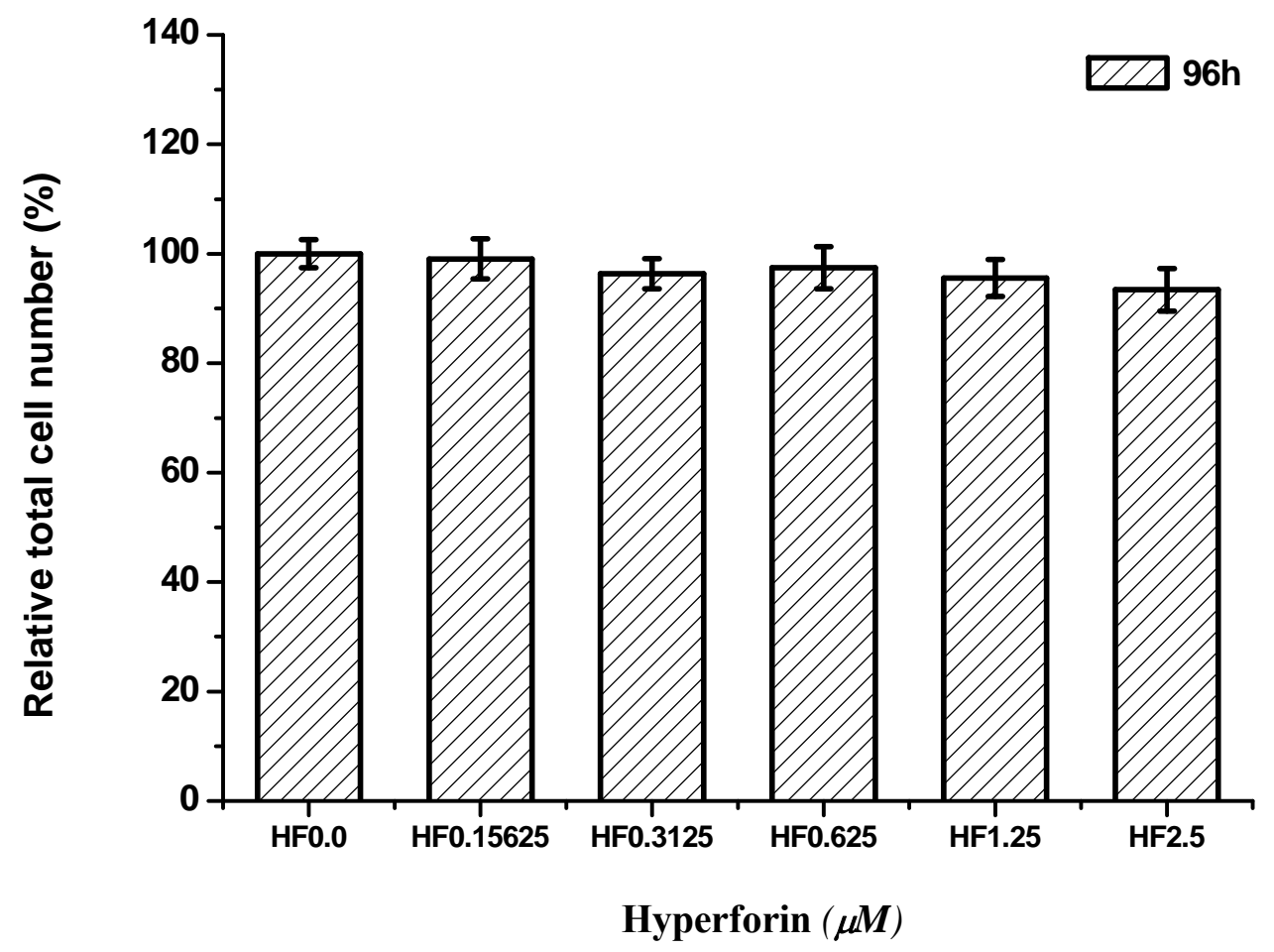

Figure 3.24 Total viable cell numbers of NS/PCs after $96 \mathrm{~h}$ of differentiation with hyperforin treatment

Total viable cell number expressed as a percentage of the number at HF $0.0 \mu \mathrm{M}$ after treatment with hyperforin at escalating doses from $0.0 \mu \mathrm{M}$ to $2.5 \mu \mathrm{M}$ for $96 \mathrm{~h}$. All groups were compared to $0.0 \mu \mathrm{M}$ of hyperforin (Mean \pm SEM, $n=5$ ). HF: Hyperforin. 


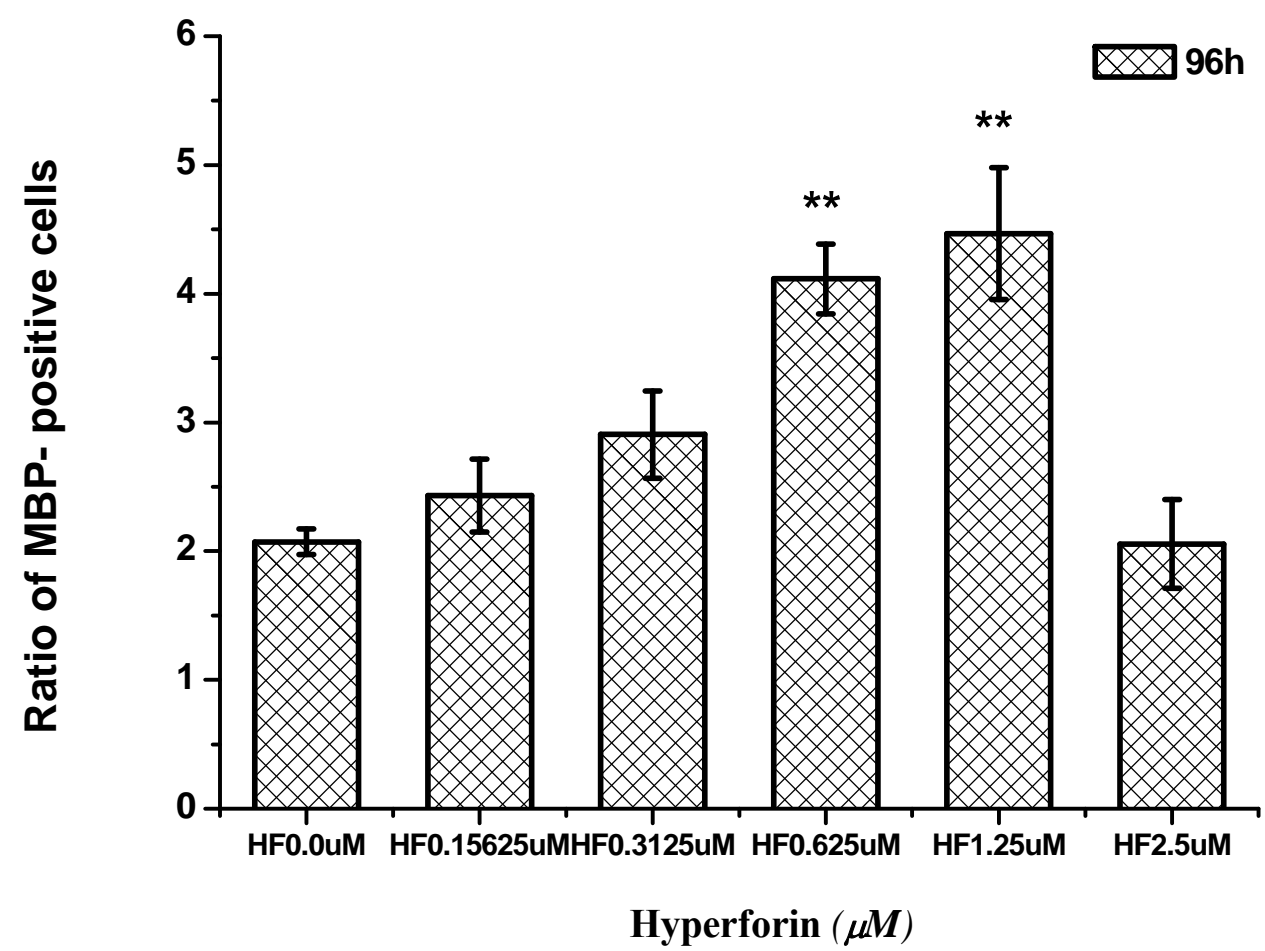

Figure 3.25 Ratios of MBP-positive cells to total NS/PCs after $96 \mathrm{~h}$ of differentiation with hyperforin treatment

Ratios of MBP-positive cells were calculated after treatment with hyperforin at escalating doses from 0.0 $\mu \mathrm{M}$ to $2.5 \mu \mathrm{M}$ for $96 \mathrm{~h}$. All groups were compared to $0.0 \mu \mathrm{M}$ of hyperforin and ${ }^{* *} p<0.01$ (Mean $\pm \mathrm{SEM}$, $\mathrm{n}=5)$. HF: Hyperforin. 

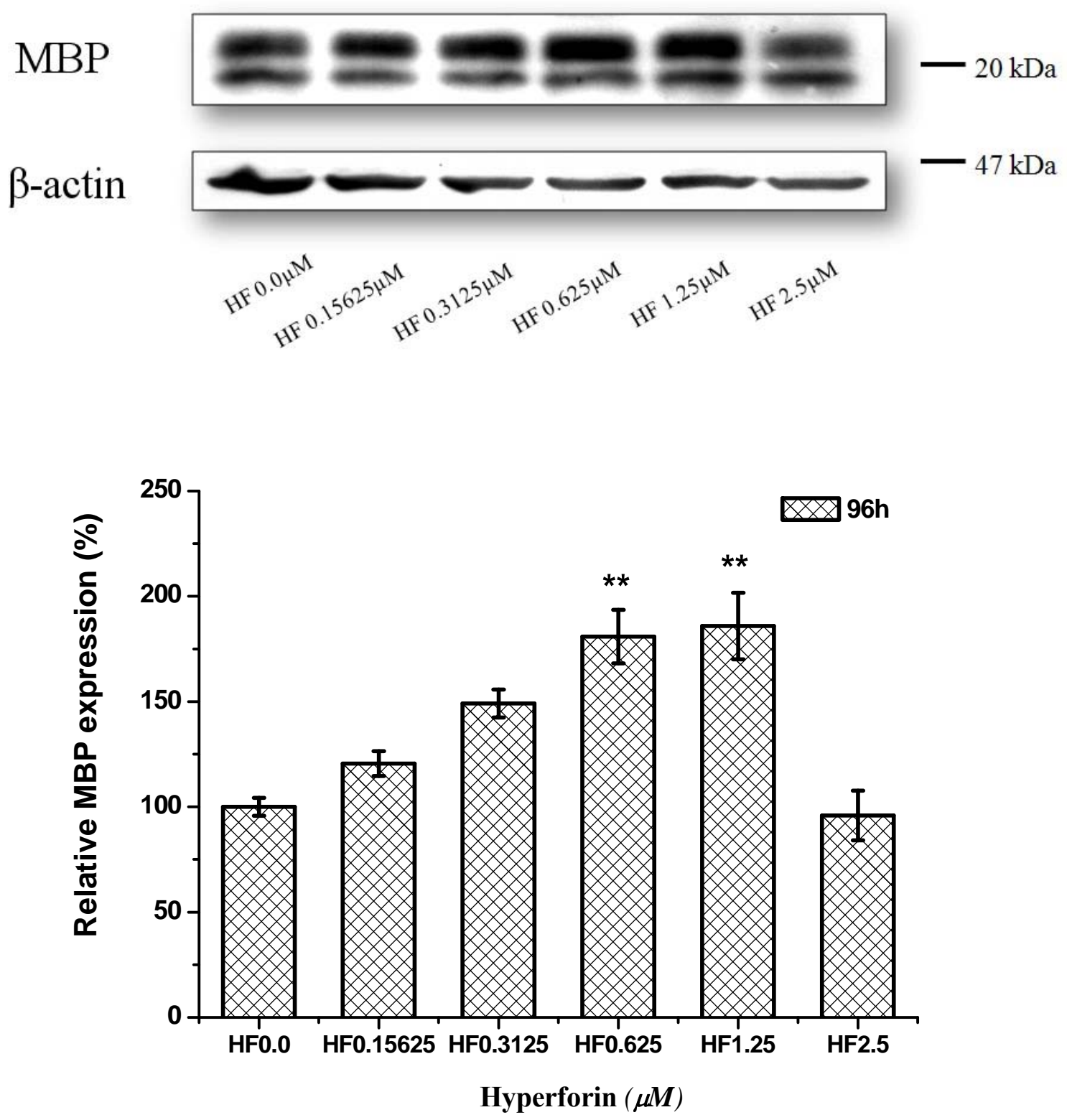

Figure 3.26 Chemiluminescent detections of MBP and $\beta$-actin in NS/PCs after $96 \mathrm{~h}$ of differentiation with hyperforin treatment

MBP expression expressed as a percentage of the level at $\mathrm{HF} 0.0 \mu \mathrm{M}$ after treatment with hyperforin at escalating doses from 0.0 to $2.5 \mu \mathrm{M}$ for $96 \mathrm{~h}$. All groups were compared to $0.0 \mu \mathrm{M}$ of hyperforin and ${ }^{* *} p<$ 0.01 (Mean \pm SEM, $n=5$ ). HF: Hyperforin. 


\subsubsection{Hyperforin Increased Expressions of CNPase in Differentiating NS/PCs}

Hyperforin significantly increased expressions of CNPase at concentrations of $0.625 \mu \mathrm{M}$ $(183.4 \pm 13.3 \%$ of the value at $0.0 \mu \mathrm{M}), 1.25 \mu \mathrm{M}(194.0 \pm 14.5 \%$ of the value at $0.0 \mu \mathrm{M})$ and $2.5 \mu \mathrm{M}(181.5 \pm 20.6 \%$ of the value at $0.0 \mu \mathrm{M})$ for $48 \mathrm{~h}$ compared to $0.0 \mu \mathrm{M}$ of hyperforin as determined by Western blot (Figure 3.27). Hyperforin significantly increased the CNPase expression at $0.3125 \mu \mathrm{M}(158.2 \pm 15.9 \%$ of the value at $0.0 \mu \mathrm{M})$ and $0.625 \mu \mathrm{M}(161.5 \pm 14.8 \%$ of the value at $0.0 \mu \mathrm{M})$ for $96 \mathrm{~h}$ compared to $0.0 \mu \mathrm{M}$ of hyperforin (Figure 3.28). Although the CNPase expressions were maintained at high levels after hyperforin treatment at $1.25 \mu \mathrm{M}$ and $2.5 \mu \mathrm{M}$ for $96 \mathrm{~h}$, they were not significantly different from that at $0.0 \mu \mathrm{M}$ of hyperforin treatment. 

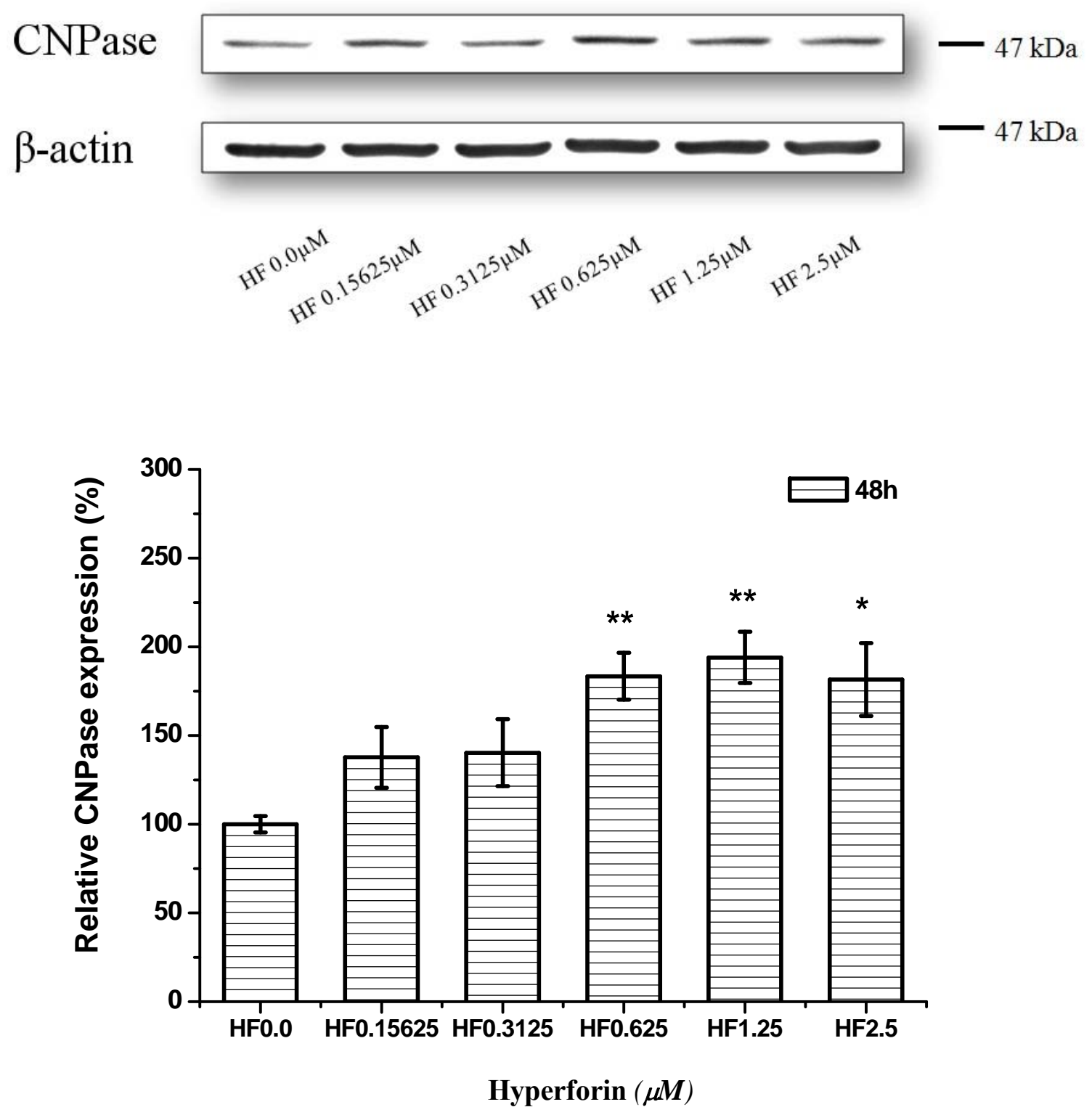

Figure 3.27 Chemiluminescent detections of CNPase and $\beta$-actin in NS/PCs after 48 h of differentiation with hyperforin treatment

CNPase expression expressed as a percentage of the level at HF $0.0 \mu \mathrm{M}$ after treatment with hyperforin at escalating doses from 0.0 to $2.5 \mu \mathrm{M}$ for $48 \mathrm{~h}$. All groups were compared to $0.0 \mu \mathrm{M}$ of hyperforin and ${ }^{*} p<$ $0.05, * * p<0.01($ Mean \pm SEM, $\mathrm{n}=5)$. HF: Hyperforin. 

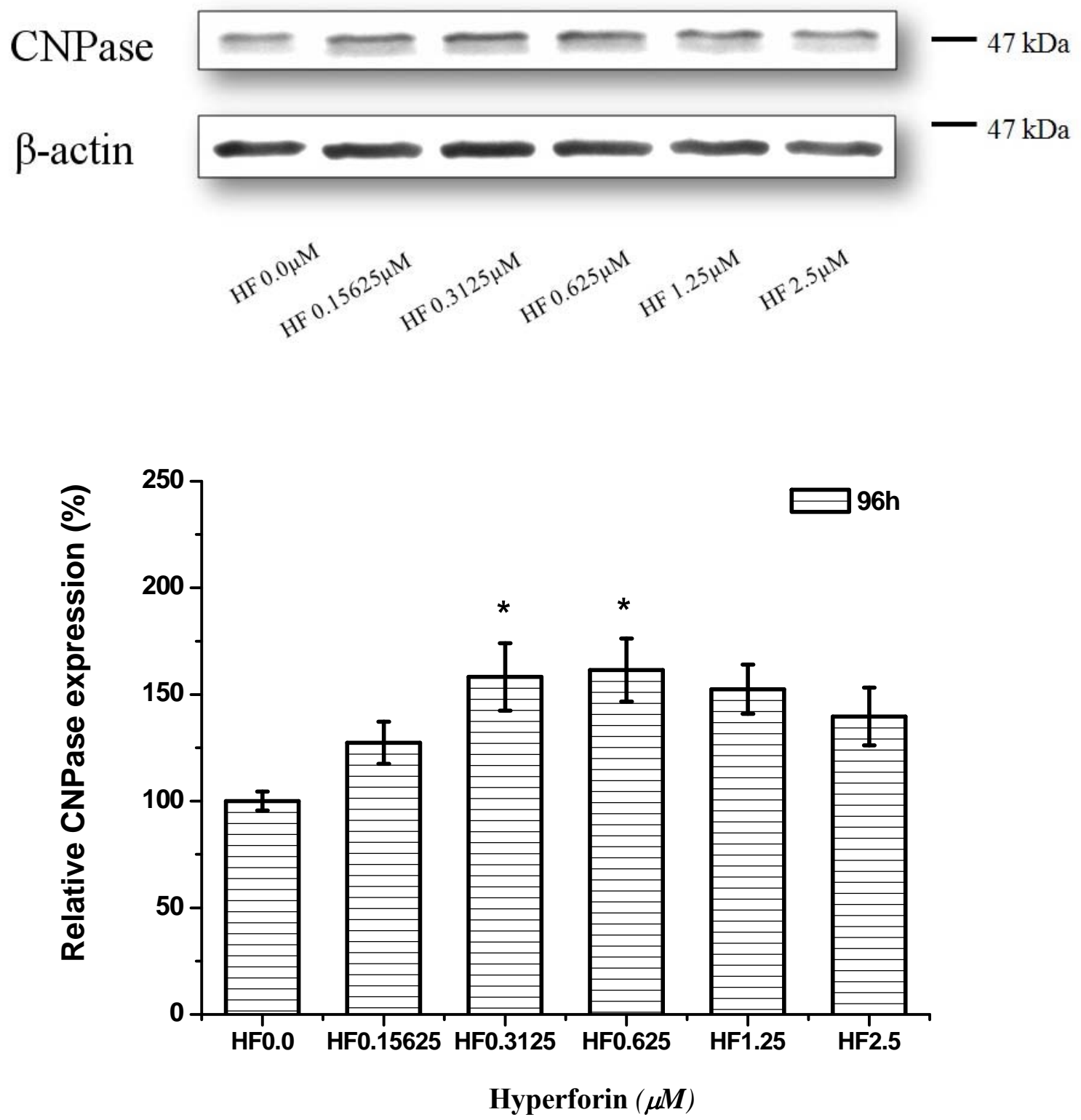

Figure 3.28 Chemiluminescent detections of CNPase and $\beta$-actin in NS/PCs after 96 $h$ of differentiation with hyperforin treatment

CNPase expression expressed as a percentage of the level at HF $0.0 \mu \mathrm{M}$ after treatment with hyperforin at escalating doses from 0.0 to $2.5 \mu \mathrm{M}$ for $96 \mathrm{~h}$. All groups were compared to $0.0 \mu \mathrm{M}$ of hyperforin and ${ }^{*} p<$ 0.05 (Mean \pm SEM, $n=5$ ). HF: Hyperforin. 


\subsubsection{Hyperforin Increased Expressions of Olig2 but not Ratios of Olig2-positive Cells in Differentiating NS/PCs}

Olig2 expressions were detectable by immunocytochemical staining in NS/PCs after 24 to $96 \mathrm{~h}$ of differentiation (Figure 3.29). Hyperforin did not change the ratios of Olig2positive cells in differentiating NS/PCs at concentrations between $0.0 \mu \mathrm{M}$ and $2.5 \mu \mathrm{M}$ for $24 \mathrm{~h}$ (Figure 3.31, Table 3.2 and Figure 3.32) and $96 \mathrm{~h}$ (Figure 3.33, Table 3.3 and Figure 3.34) as determined by immunocytochemical staining. The ratio of Olig2positive cells in the differentiating NS/PCs was approximately 30\% with different concentrations of hyperforin treatment for $24 \mathrm{~h}$ (Table 3.2) and were approximately $40 \%$ for $96 \mathrm{~h}$ (Table 3.3).

Hyperforin significantly increased the expression of Olig2 at $2.5 \mu \mathrm{M}(207.3 \pm 21.9 \%$ of the value at $0.0 \mu \mathrm{M}$ ) for $48 \mathrm{~h}$ (Figure 3.36). Hyperforin also significantly increased expressions of Olig2 at $0.3125 \mu \mathrm{M}(173.2 \pm 20.0 \%$ of the value at $0.0 \mu \mathrm{M}), 0.625 \mu \mathrm{M}$ $(187.2 \pm 5.8 \%$ of the value at $0.0 \mu \mathrm{M})$ and $1.25 \mu \mathrm{M}(170.6 \pm 15.5 \%$ of the value at 0.0 $\mu \mathrm{M})$ for $96 \mathrm{~h}$ (Figure 3.37). Hyperforin did not change expressions of Olig2 at concentrations between $0.0 \mu \mathrm{M}$ and $2.5 \mu \mathrm{M}$ for $24 \mathrm{~h}$ (Figure 3.35). The colocalization of Olig2 and MBP after $96 \mathrm{~h}$ of differentiation indicated that Olig2 was expressed during the maturation of oligodendrocytes (Figure 3.30). Hyperforin increased expressions of Olig2, CNPase and MBP to high levels at concentrations between $0.3125 \mu \mathrm{M}$ and $1.25 \mu \mathrm{M}$ for $96 \mathrm{~h}$. Hyperforin at $0.625 \mu \mathrm{M}$ simultaneously increased expressions of all three oligodendrocyte development-related proteins (Figure 3.38). This suggested that more mature oligodendrocytes expressed more Olig2. Hyperforin also simultaneously increased the expression of Olig2 and CNPase, the reduction of MTT and the intracellular ATP level at $2.5 \mu \mathrm{M}$ for $48 \mathrm{~h}$ (Figure 3.36, Figure 3.27, Figure 3.18 and Figure 3.20). 

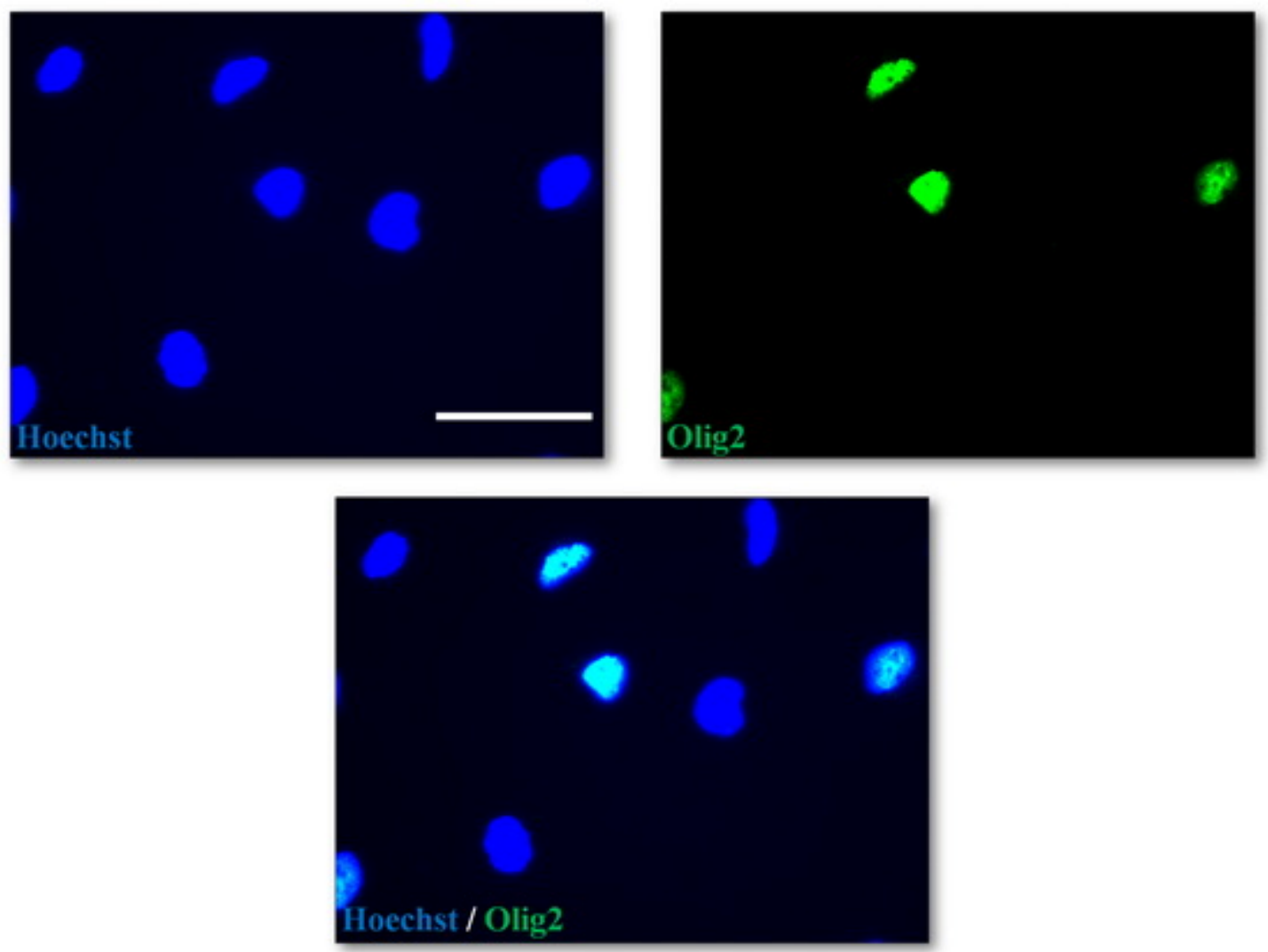

Figure 3.29 Fluorescent microphotographs of differentiating NS/PCs expressing Olig2 after $96 \mathrm{~h}$ of differentiation

The scale bar represents $50 \mu \mathrm{m}$. 

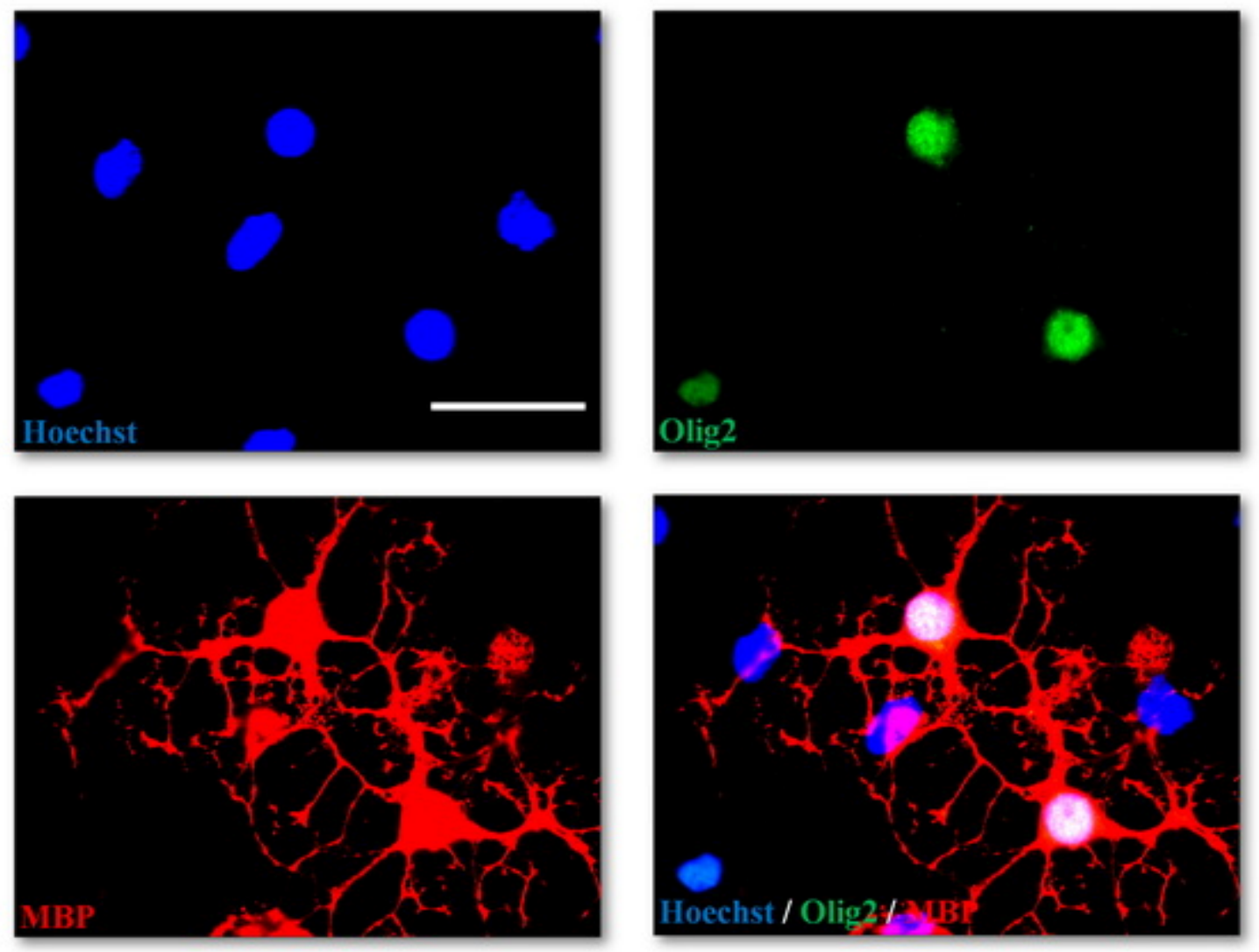

Figure 3.30 Fluorescent microphotographs of differentiating NS/PCs expressing Olig2 and MBP after $96 \mathrm{~h}$ of differentiation

The scale bar represents $50 \mu \mathrm{m}$. 

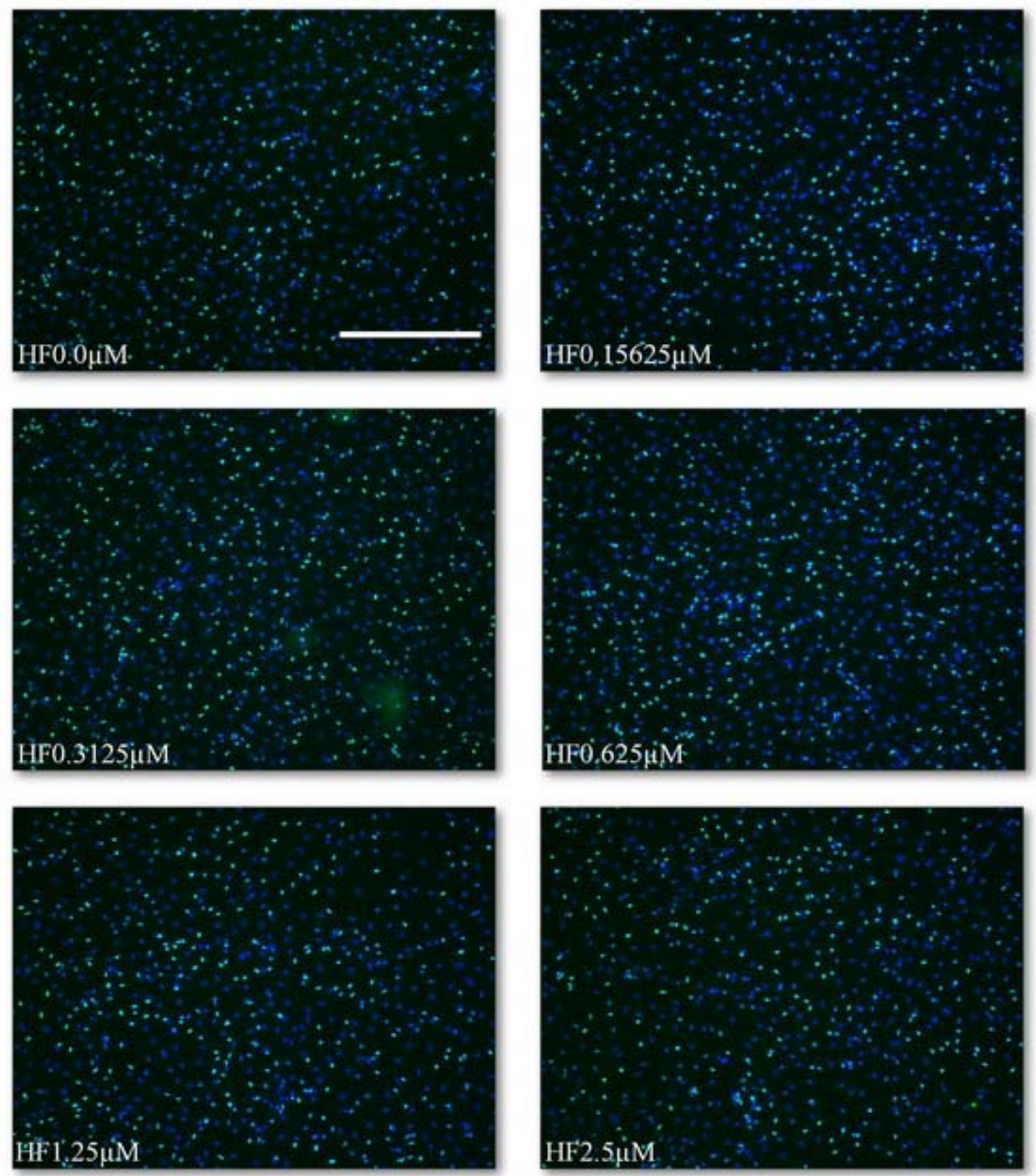

Figure 3.31 Fluorescent microphotographs of differentiating NS/PCs expressing Olig2 after $24 \mathrm{~h}$ of differentiation with hyperforin treatment

NS/PCs were treated with hyperforin at escalating doses from $0.0 \mu \mathrm{M}$ to $2.5 \mu \mathrm{M}$ for $24 \mathrm{~h}$. NS/PCs were stained with Hoechst 33342 (blue) and Olig2 (Green). HF: Hyperforin. The scale bar represents $500 \mu \mathrm{m}$. 
Table 3.2 Ratios of Olig2-positive cells to total NS/PCs after $24 \mathrm{~h}$ of hyperforin treatment

\begin{tabular}{ccccccc}
\hline Experiment & $\mathrm{HF} 0.0 \mu \mathrm{M}$ & $\mathrm{HF} 0.15625 \mu \mathrm{M}$ & $\mathrm{HF} 0.3125 \mu \mathrm{M}$ & $\mathrm{HF} 0.625 \mu \mathrm{M}$ & $\mathrm{HF} 1.25 \mu \mathrm{M}$ & $\mathrm{HF} 2.5 \mu \mathrm{M}$ \\
\hline 1 & $32.2 \%$ & $37.2 \%$ & $38.8 \%$ & $38.1 \%$ & $42.6 \%$ & $36.4 \%$ \\
2 & $27.7 \%$ & $33.9 \%$ & $34.3 \%$ & $34.2 \%$ & $31.2 \%$ & $33.9 \%$ \\
3 & $30.8 \%$ & $41.0 \%$ & $37.6 \%$ & $45.6 \%$ & $41.3 \%$ & $44.0 \%$ \\
4 & $30.7 \%$ & $34.4 \%$ & $37.0 \%$ & $33.1 \%$ & $32.9 \%$ & $35.3 \%$ \\
\hline
\end{tabular}

NS/PCs were treated with hyperforin at escalating doses from $0.0 \mu \mathrm{M}$ to $2.5 \mu \mathrm{M}$ for $24 \mathrm{~h}$. All groups were compared to $0.0 \mu \mathrm{M}$ of hyperforin (Mean $\pm \mathrm{SEM}, \mathrm{n}=4$ ). HF: hyperforin.

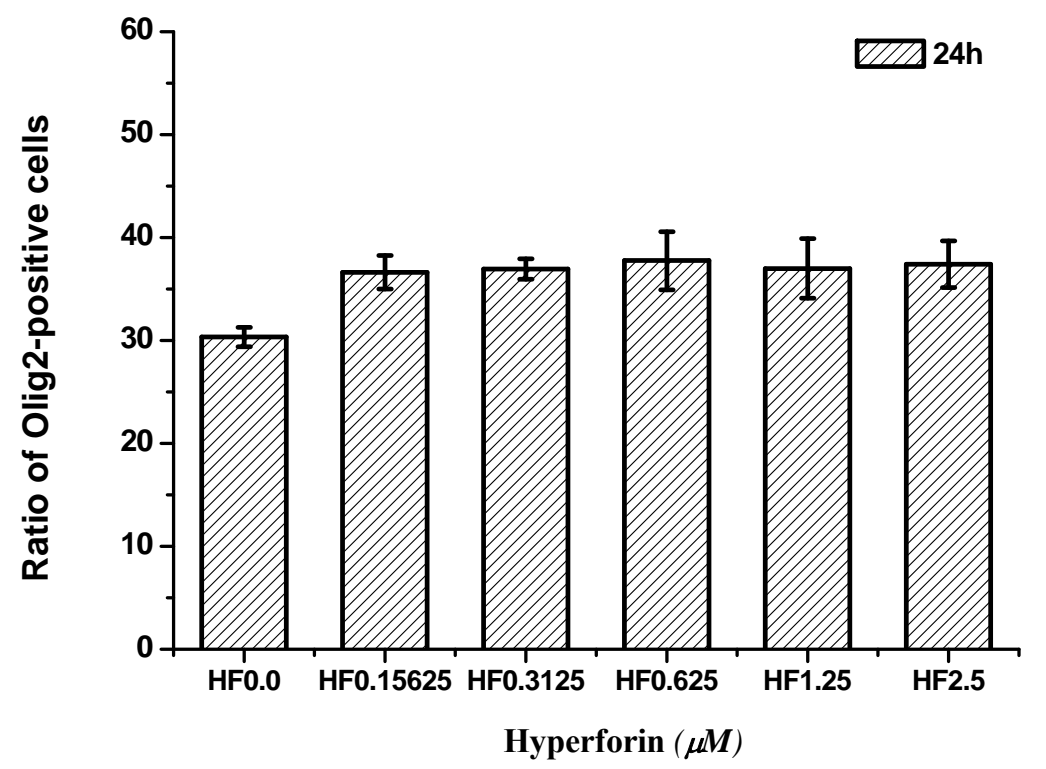

Figure 3.32 Ratios of Olig2-positive cells to total NS/PCs after $24 \mathrm{~h}$ of differentiation with hyperforin treatment

Ratios of Olig2-positive cells were calculated after treatment with hyperforin at escalating doses from 0.0 $\mu \mathrm{M}$ to $2.5 \mu \mathrm{M}$ for $24 \mathrm{~h}$. All groups were compared to $0.0 \mu \mathrm{M}$ of hyperforin (Mean $\pm \mathrm{SEM}, \mathrm{n}=4$ ). HF: Hyperforin. 

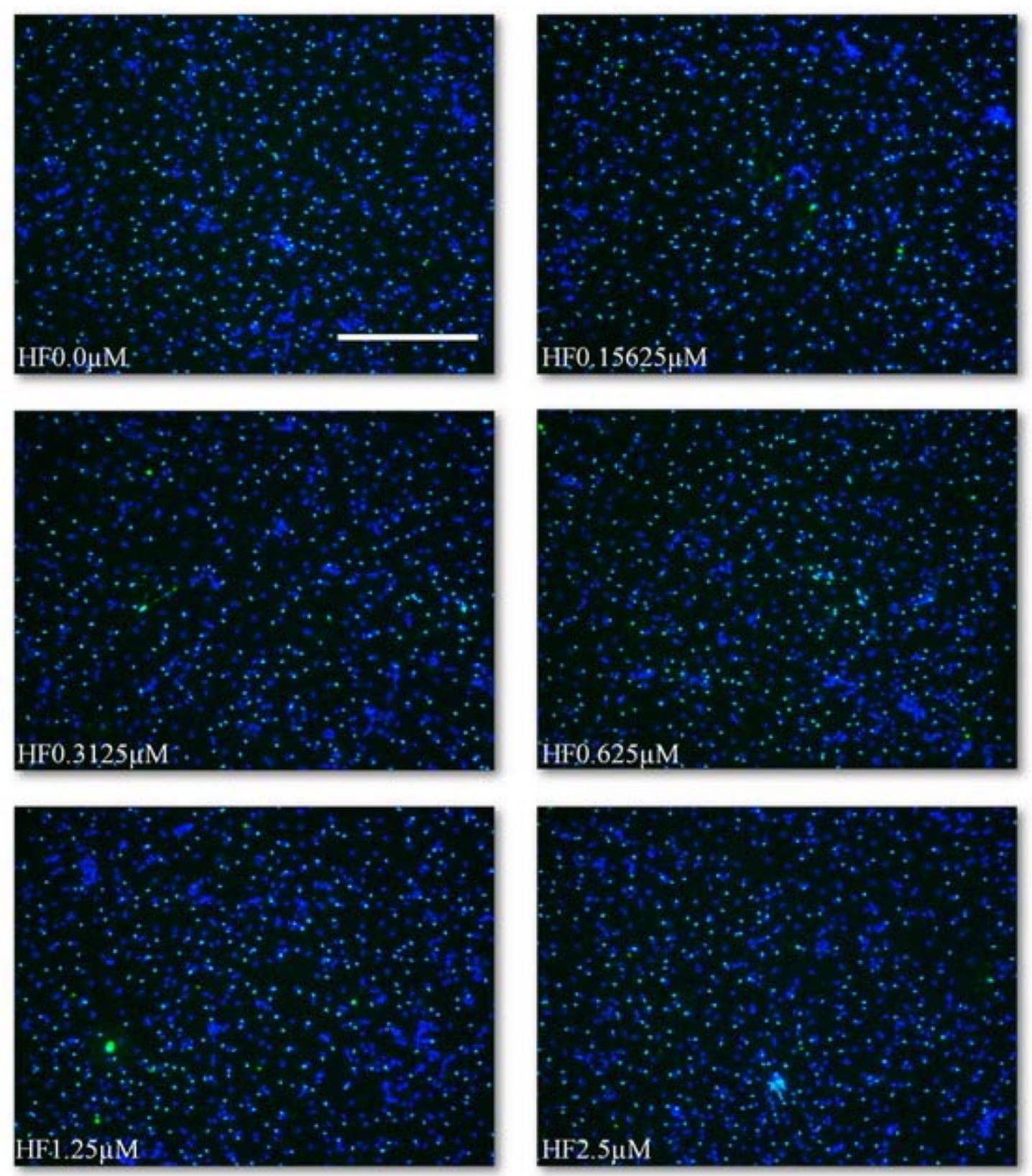

Figure 3.33 Fluorescent microphotographs of differentiating NS/PCs expressing Olig2 after $96 \mathrm{~h}$ of differentiation with hyperforin treatment

NS/PCs were treated with hyperforin at escalating doses from $0.0 \mu \mathrm{M}$ to $2.5 \mu \mathrm{M}$ for $96 \mathrm{~h}$. NS/PCs were stained with Hoechst 33342 (blue) and Olig2 (Green). HF: Hyperforin. The scale bar represents $500 \mu \mathrm{m}$. 
Table 3.3 Ratios of Olig2-positive cells to total NS/PCs after 96 h of hyperforin treatment

\begin{tabular}{|c|c|c|c|c|c|c|}
\hline Experiment & HF0.0 $\mu \mathrm{M}$ & HF0.15625 $\mu \mathrm{M}$ & $\mathrm{HF} 0.3125 \mu \mathrm{M}$ & $\mathrm{HF} 0.625 \mu \mathrm{M}$ & $\mathrm{HF} 1.25 \mu \mathrm{M}$ & $\mathrm{HF} 2.5 \mu \mathrm{M}$ \\
\hline 1 & $43.7 \%$ & $41.5 \%$ & $42.2 \%$ & $46.8 \%$ & $45.6 \%$ & $39.1 \%$ \\
\hline 2 & $44.1 \%$ & $41.3 \%$ & $39.2 \%$ & $40.8 \%$ & $42.1 \%$ & $36.2 \%$ \\
\hline 3 & $41.0 \%$ & $37.3 \%$ & $40.4 \%$ & $37.6 \%$ & $36.6 \%$ & $35.5 \%$ \\
\hline 4 & $30.4 \%$ & $37.5 \%$ & $32.3 \%$ & $40.1 \%$ & $36.9 \%$ & $35.0 \%$ \\
\hline Mean \pm SEM & $39.8 \% \pm 3.2 \%$ & $39.4 \% \pm 1.2 \%$ & $38.5 \% \pm 2.2 \%$ & $41.3 \% \pm 2.0 \%$ & $40.3 \% \pm 2.2 \%$ & $36.4 \% \pm 0.9 \%$ \\
\hline
\end{tabular}

NS/PCs were treated with hyperforin at escalating doses from $0.0 \mu \mathrm{M}$ to $2.5 \mu \mathrm{M}$ for $96 \mathrm{~h}$. All groups were compared to $0.0 \mu \mathrm{M}$ of hyperforin (Mean $\pm \mathrm{SEM}, \mathrm{n}=4$ ). HF: hyperforin.

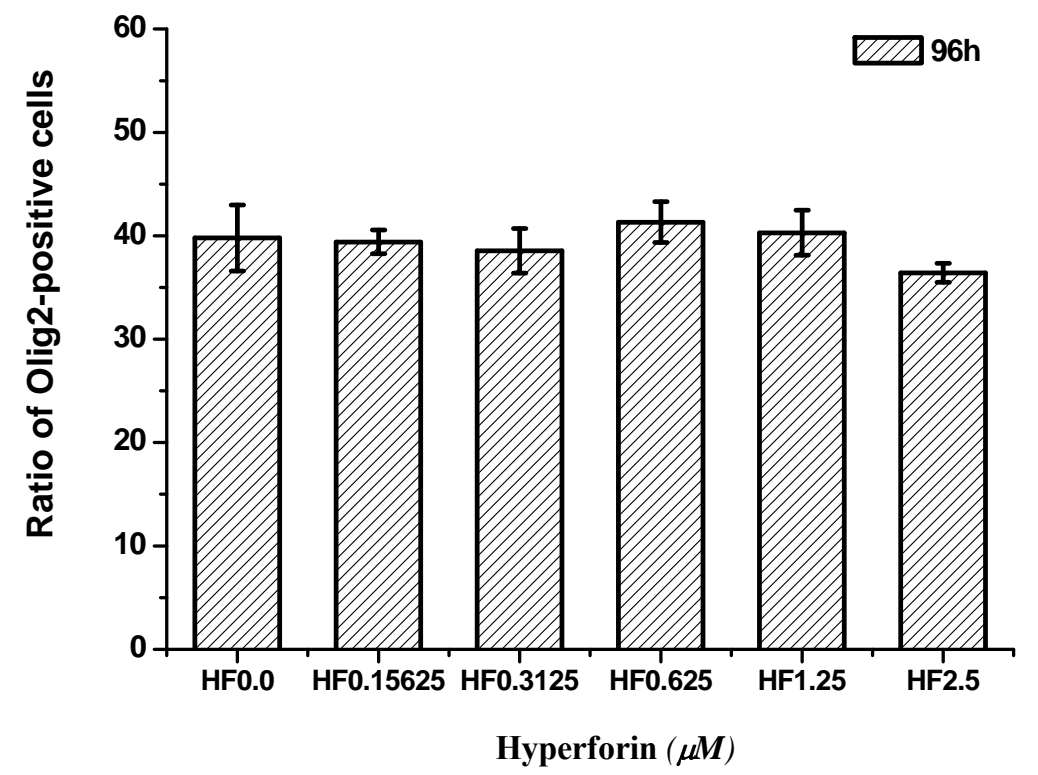

Figure 3.34 Ratios of Olig2-positive cells to total NS/PCs after $96 \mathrm{~h}$ of differentiation with hyperforin treatment

Ratios of Olig2-positive cells were calculated after treatment with hyperforin at escalating doses from 0.0 $\mu \mathrm{M}$ to $2.5 \mu \mathrm{M}$ for $96 \mathrm{~h}$. All groups were compared to $0.0 \mu \mathrm{M}$ of hyperforin (Mean $\pm \mathrm{SEM}, \mathrm{n}=4$ ). HF: Hyperforin. 

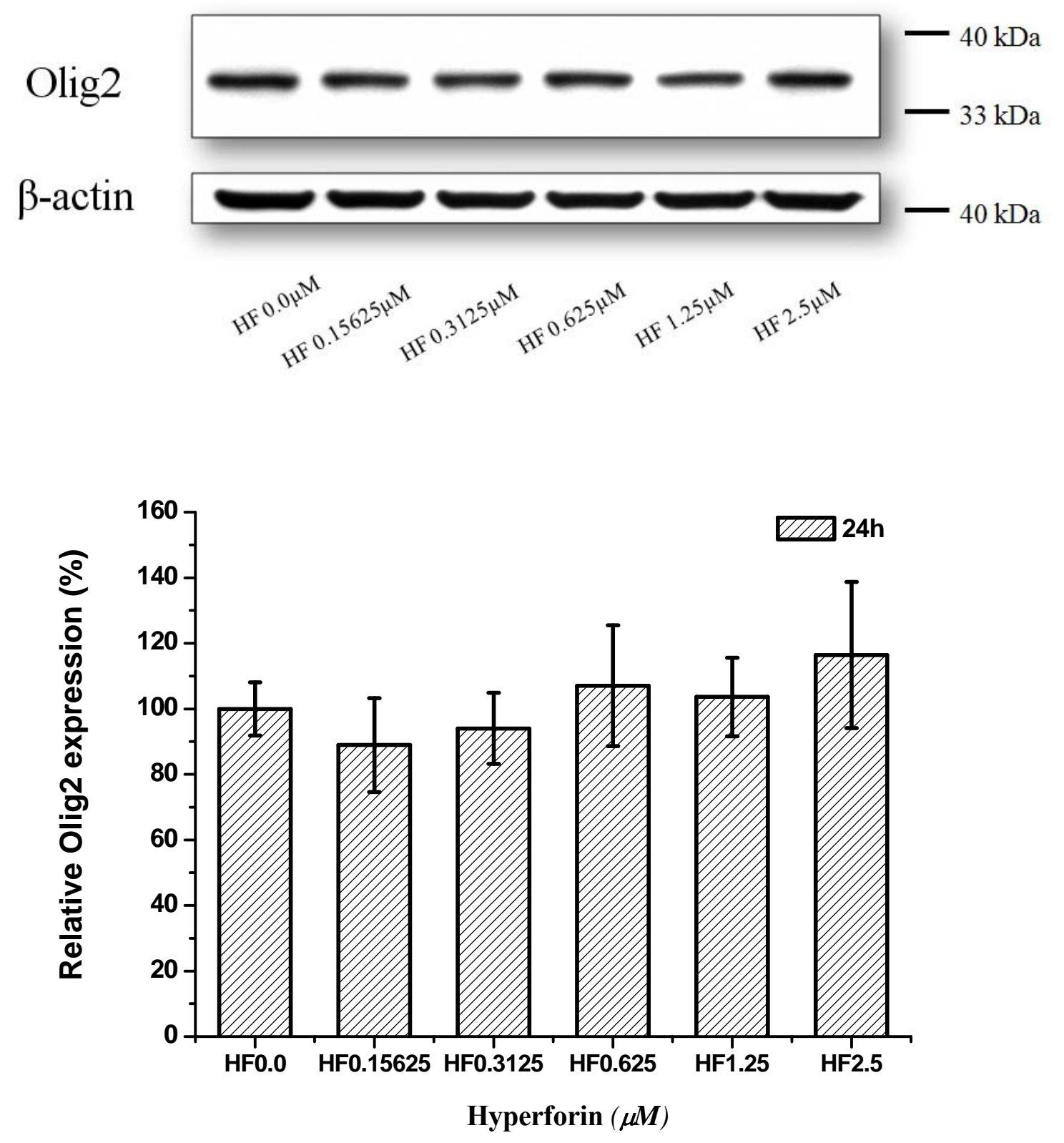

Figure 3.35 Chemiluminescent detections of Olig2 and $\beta$-actin in NS/PCs after 24 h of differentiation with hyperforin treatment

Olig2 expression expressed as a percentage of the level at $\mathrm{HF} 0.0 \mu \mathrm{M}$ after treatment with hyperforin at escalating doses from 0.0 to $2.5 \mu \mathrm{M}$ for $24 \mathrm{~h}$. All groups were compared to $0.0 \mu \mathrm{M}$ of hyperforin (Mean \pm SEM, $n=4)$. HF: Hyperforin. 


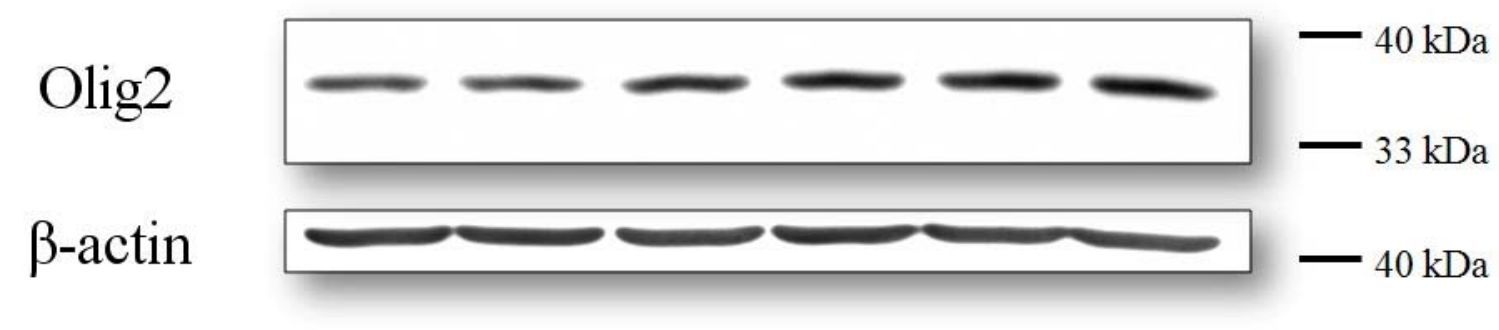

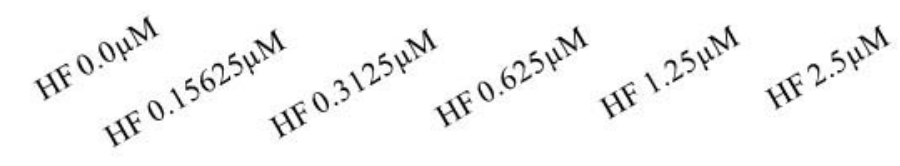

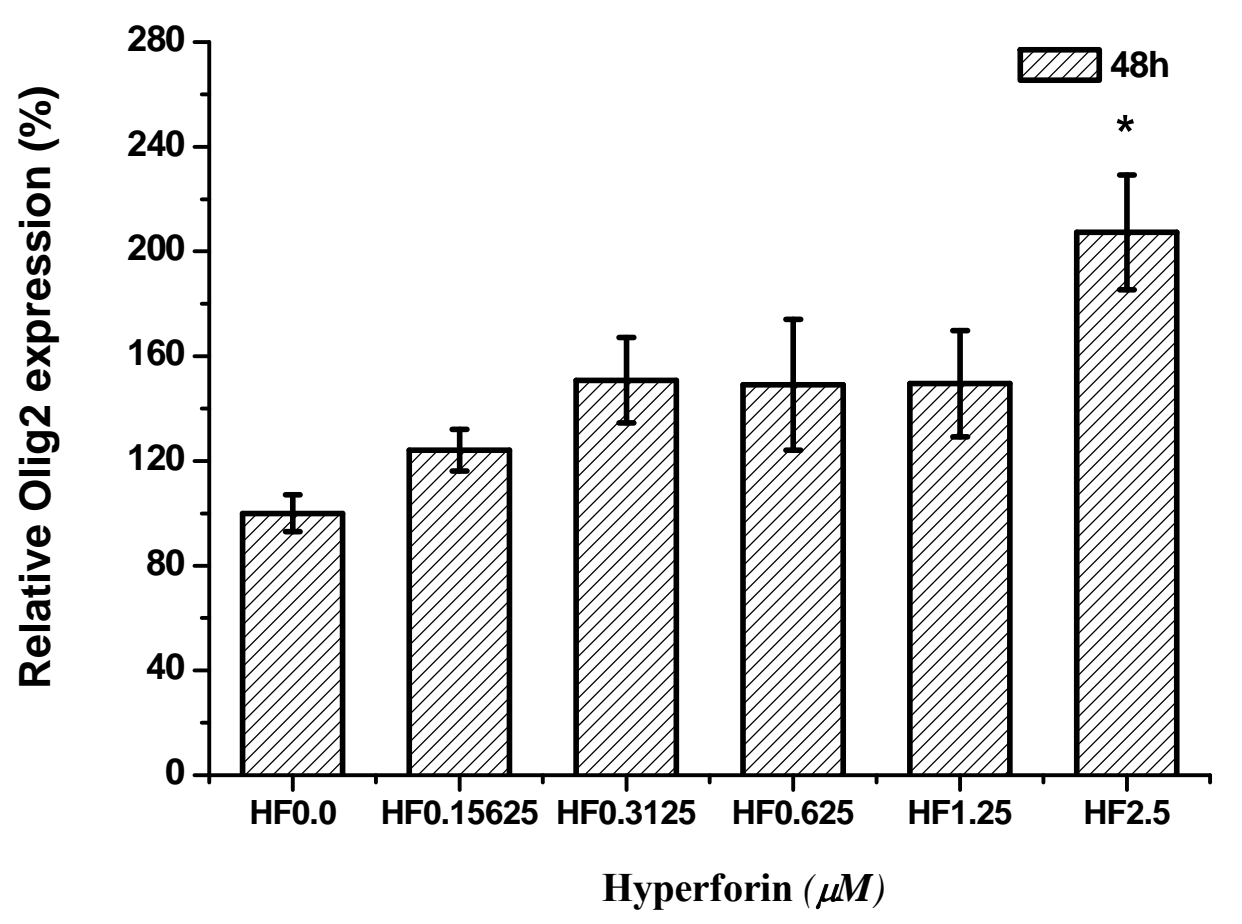

Figure 3.36 Chemiluminescent detections of Olig2 and $\beta$-actin in NS/PCs after 48 h of differentiation with hyperforin treatment

Olig2 expression expressed as a percentage of the level at $\mathrm{HF} 0.0 \mu \mathrm{M}$ after treatment with hyperforin at escalating doses from 0.0 to $2.5 \mu \mathrm{M}$ for $48 \mathrm{~h}$. All groups were compared to $0.0 \mu \mathrm{M}$ of hyperforin and $* p<$ 0.05 (Mean \pm SEM, n=4). HF: Hyperforin. 

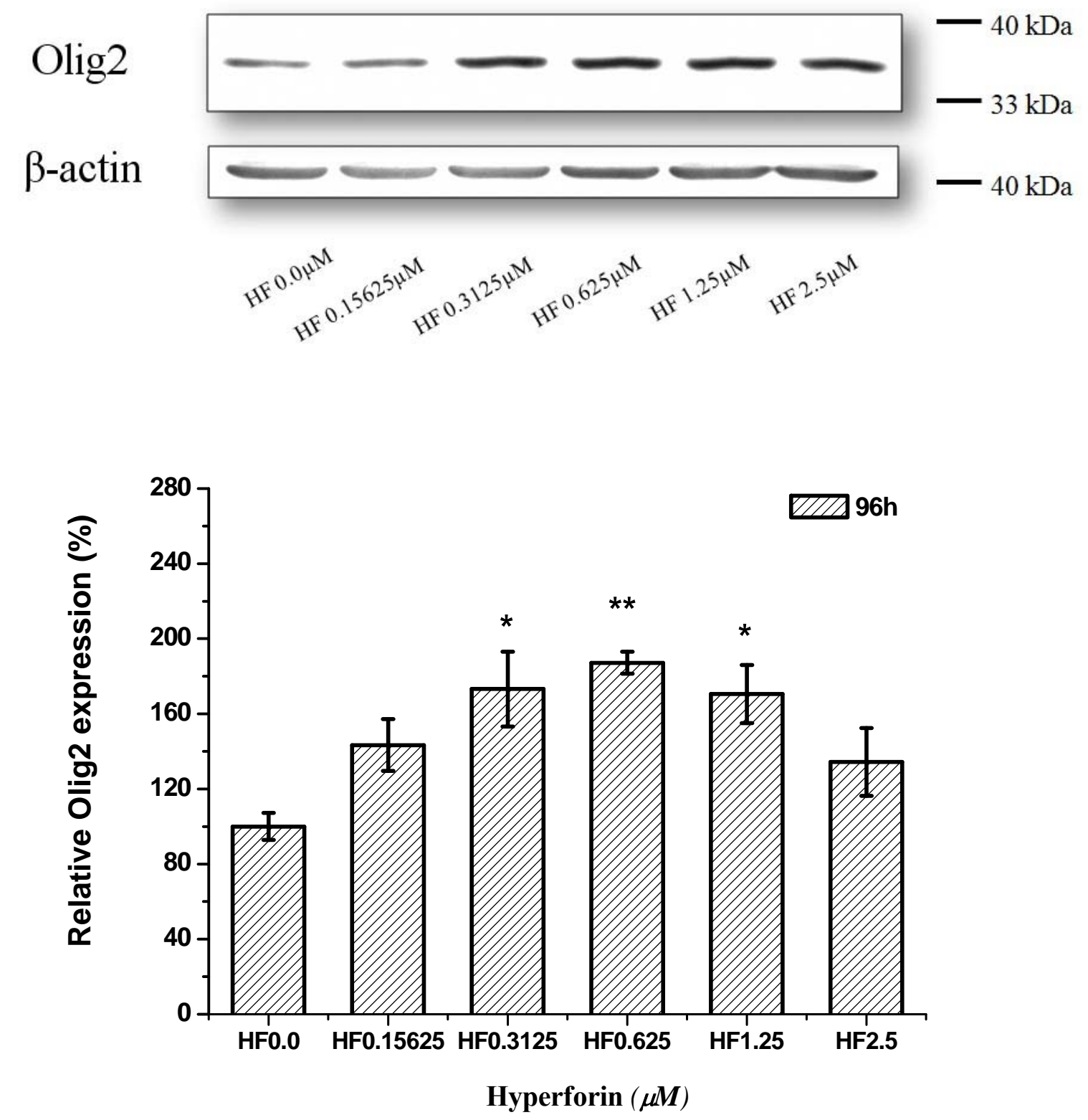

Figure 3.37 Chemiluminescent detections of Olig2 and $\beta$-actin in NS/PCs after $96 \mathrm{~h}$ of differentiation with hyperforin treatment

Olig2 expression expressed as a percentage of the level at $\mathrm{HF} 0.0 \mu \mathrm{M}$ after treatment with hyperforin at escalating doses from 0.0 to $2.5 \mu \mathrm{M}$ for $96 \mathrm{~h}$. All groups were compared to $0.0 \mu \mathrm{M}$ of hyperforin and $* p<$ $0.05, * * p<0.01$ (Mean \pm SEM, $\mathrm{n}=5$ ). HF: Hyperforin. 


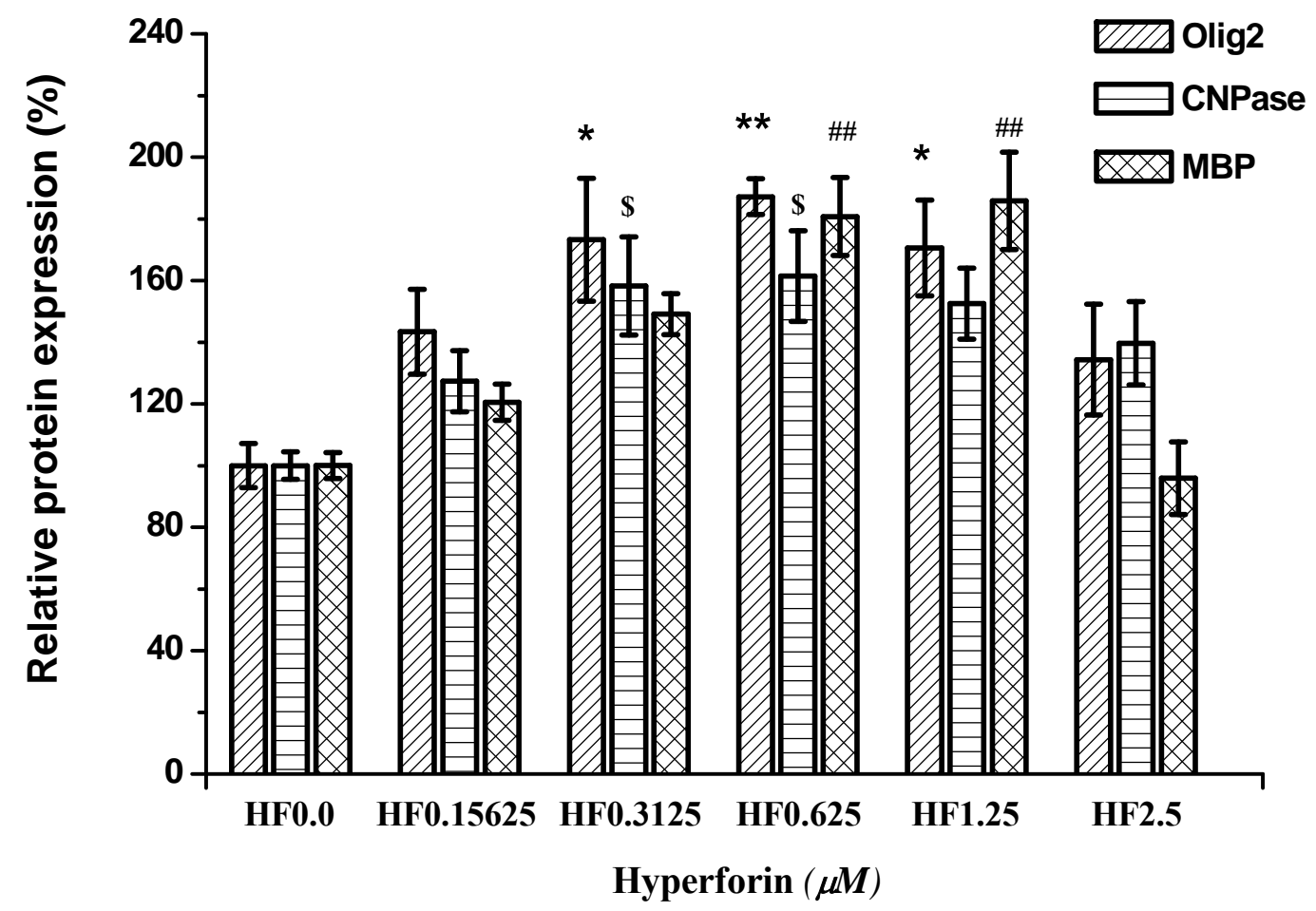

Figure 3.38 Expressions of Olig2, CNPase and MBP in NS/PCs after 96 h of hyperforin treatment

Protein expression levels expressed as a percentage of the level at HF $0.0 \mu \mathrm{M}$ after treatment with hyperforin at escalating doses from 0.0 to $2.5 \mu \mathrm{M}$ for $96 \mathrm{~h}$. In each protein expression study, all groups were compared to $0.0 \mu \mathrm{M}$ of hyperforin. In Olig2 expression, ${ }^{*} p<0.05,{ }^{* *} p<0.01$ (Mean $\pm \mathrm{SEM}, \mathrm{n}=5$ ); in CNPase expression, ${ }^{\$} p<0.05$ (Mean \pm SEM, $n=5$ ); in MBP expression, ${ }^{\# \#} p<0.01$ (Mean \pm SEM, $n=5$ ). HF: Hyperforin. 


\subsubsection{Hyperforin did not Change Ratios of Astrocytes and Neurons and the Expression of GFAP in Differentiating NS/PCs}

The ratios of astrocyte and neurons in differentiating NS/PCs were determined by immunocytochemical staining using GFAP (Figure 3.39) and $\beta$-III tubulin (Figure 3.43). Hyperforin did not change ratios of either GFAP-positive cells (Figure 3.40, Table 3.4 and Figure 3.41) or $\beta$-III tubulin-positive cells (Figure 3.44, Table 3.5 and Figure 3.45) in differentiating NS/PCs at concentrations between $0.0 \mu \mathrm{M}$ and $2.5 \mu \mathrm{M}$ for $96 \mathrm{~h}$. The ratios of GFAP-positive cells were approximately 30\% (Table 3.4) after $96 \mathrm{~h}$ of

differentiation. The ratios of $\beta$-III tubulin-positive cells were approximately $10 \%$ (Table 3.5) after $96 \mathrm{~h}$ of differentiation. Hyperforin did not change the expression of GFAP at concentrations between $0.0 \mu \mathrm{M}$ and $2.5 \mu \mathrm{M}$ for $96 \mathrm{~h}$ as determined by Western blot (Figure 3.42). 

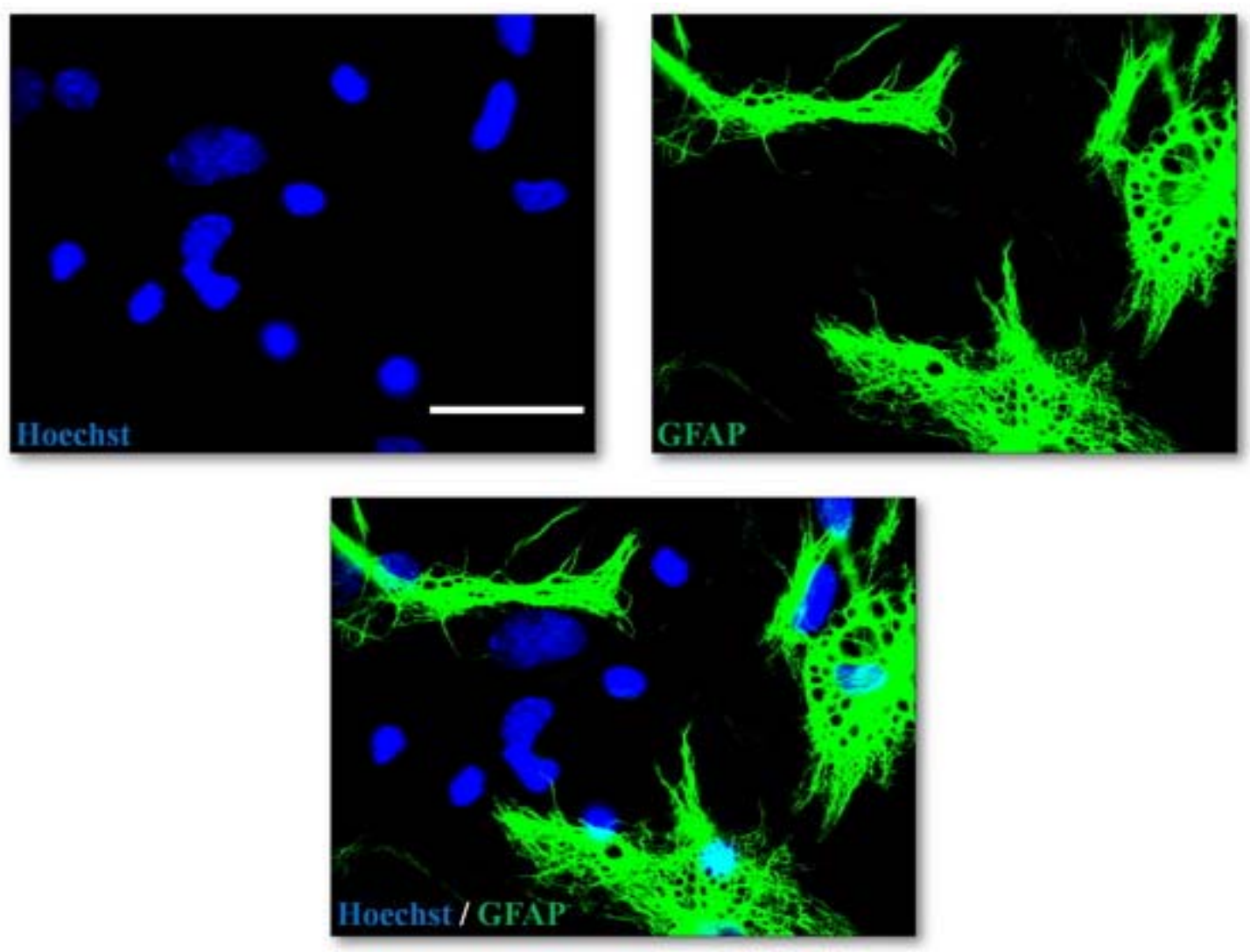

Figure 3.39 Fluorescent microphotographs of differentiating NS/PCs expressing GFAP after $96 \mathrm{~h}$ of differentiation

The scale bar represents $50 \mu \mathrm{m}$. 

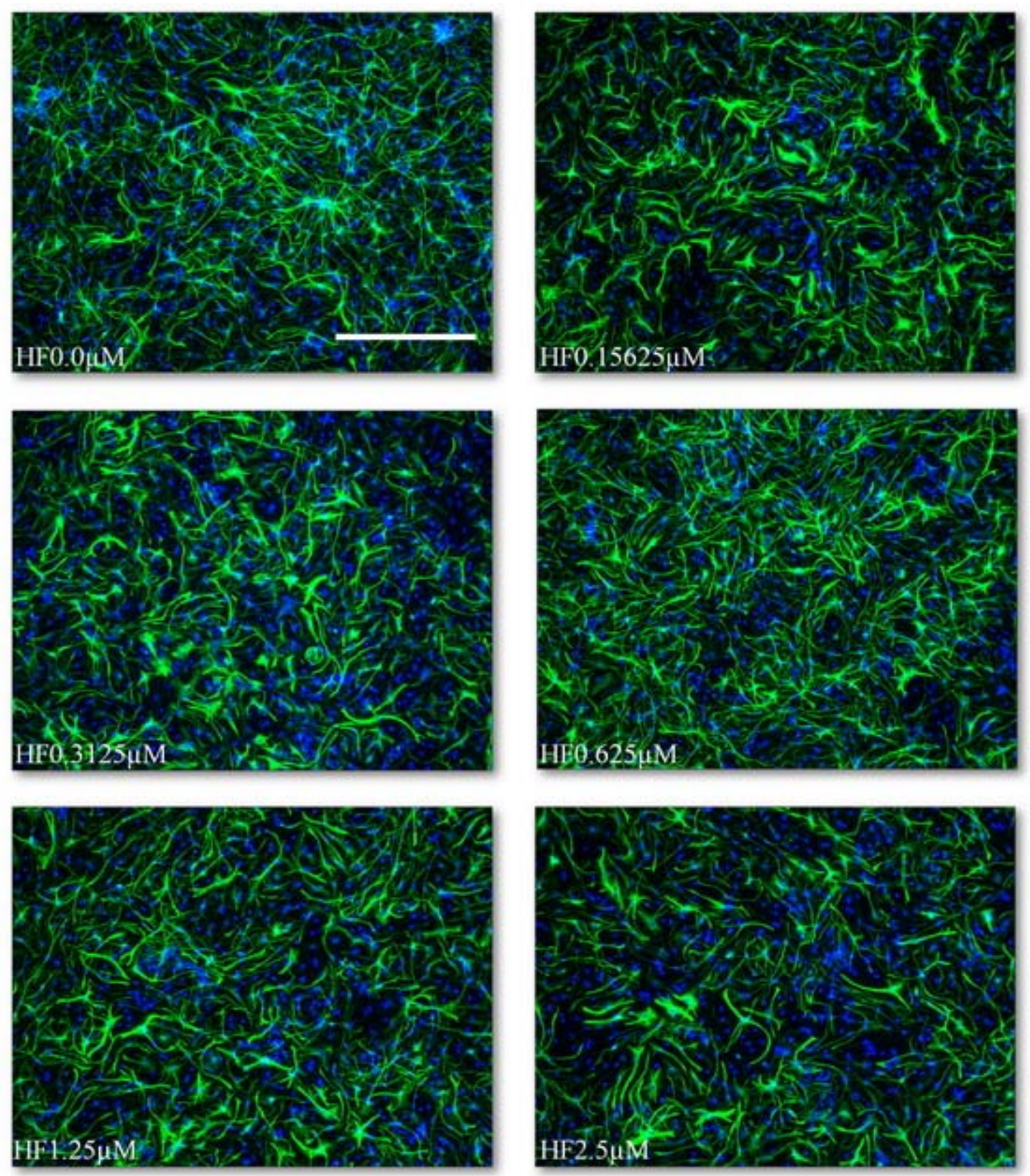

Figure 3.40 Fluorescent microphotographs of differentiating NS/PCs expressing GFAP after $96 \mathrm{~h}$ of differentiation with hyperforin treatment

NS/PCs were treated with hyperforin at escalating doses from $0.0 \mu \mathrm{M}$ to $2.5 \mu \mathrm{M}$ for $96 \mathrm{~h}$. NS/PCs were stained with Hoechst 33342 (blue) and GFAP (Green). HF: Hyperforin. The scale bar represents $500 \mu \mathrm{m}$. 
Table 3.4 Ratios of GFAP-positive cells to total NS/PCs after $96 \mathrm{~h}$ of hyperforin treatment

\begin{tabular}{ccccccc}
\hline Experiment & $\mathrm{HF} 0.0 \mu \mathrm{M}$ & $\mathrm{HF} 0.15625 \mu \mathrm{M}$ & $\mathrm{HF} 0.3125 \mu \mathrm{M}$ & $\mathrm{HF} 0.625 \mu \mathrm{M}$ & $\mathrm{HF} 1.25 \mu \mathrm{M}$ & $\mathrm{HF} 2.5 \mu \mathrm{M}$ \\
\hline 1 & $31.8 \%$ & $31.4 \%$ & $29.3 \%$ & $30.2 \%$ & $35.0 \%$ & $33.3 \%$ \\
2 & $31.0 \%$ & $26.0 \%$ & $29.9 \%$ & $28.2 \%$ & $28.0 \%$ & $28.8 \%$ \\
3 & $36.8 \%$ & $35.0 \%$ & $34.6 \%$ & $33.6 \%$ & $35.6 \%$ & $35.3 \%$ \\
4 & $31.0 \%$ & $28.6 \%$ & $29.7 \%$ & $28.6 \%$ & $27.5 \%$ & $32.9 \%$ \\
Mean \pm SEM & $32.6 \% \pm 1.4 \%$ & $30.2 \% \pm 1.9 \%$ & $30.9 \% \pm 1.2 \%$ & $30.1 \% \pm 1.2 \%$ & $31.5 \% \pm 2.2 \%$ & $32.6 \% \pm 1.4 \%$ \\
\hline
\end{tabular}

NS/PCs were treated with hyperforin at escalating doses from $0.0 \mu \mathrm{M}$ to $2.5 \mu \mathrm{M}$ for $96 \mathrm{~h}$. All groups were compared to $0.0 \mu \mathrm{M}$ of hyperforin (Mean $\pm \mathrm{SEM}, \mathrm{n}=4$ ). HF: hyperforin.

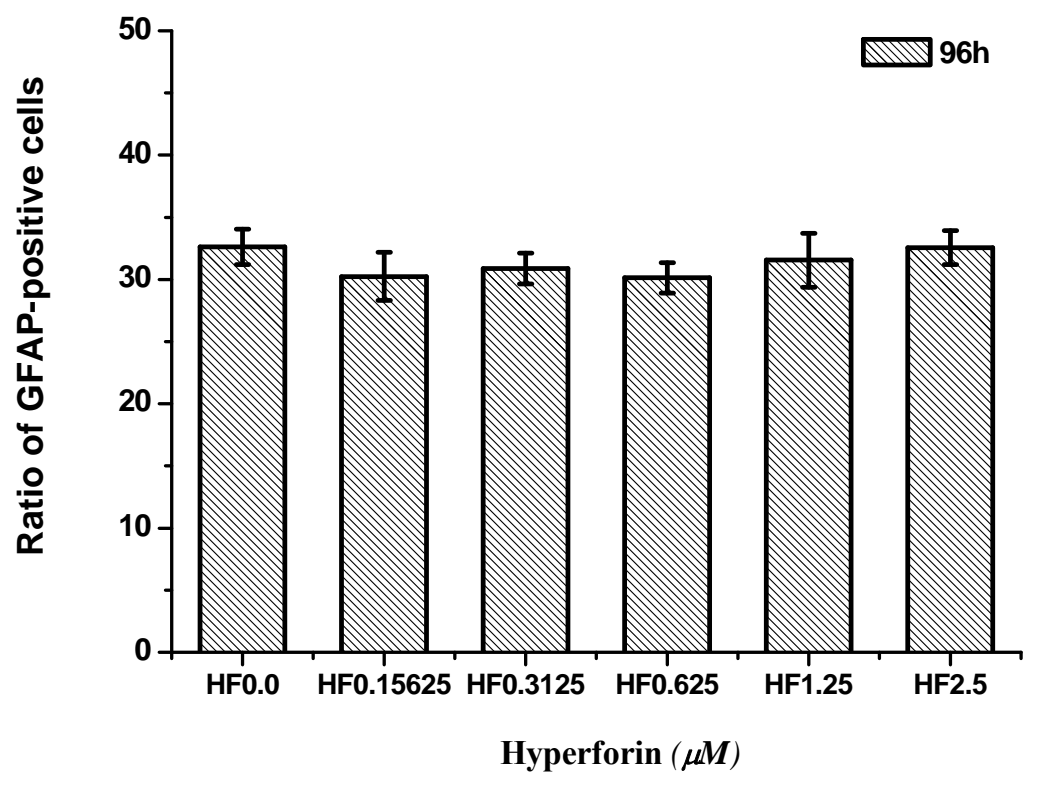

Figure 3.41 Ratios of GFAP-positive cells to total NS/PCs after 96 h of differentiation with hyperforin treatment

Ratios of GFAP -positive cells were calculated after treatment with hyperforin at escalating doses from 0.0 $\mu \mathrm{M}$ to $2.5 \mu \mathrm{M}$ for $96 \mathrm{~h}$. All groups were compared to $0.0 \mu \mathrm{M}$ of hyperforin (Mean $\pm \mathrm{SEM}, \mathrm{n}=4$ ). HF: Hyperforin. 

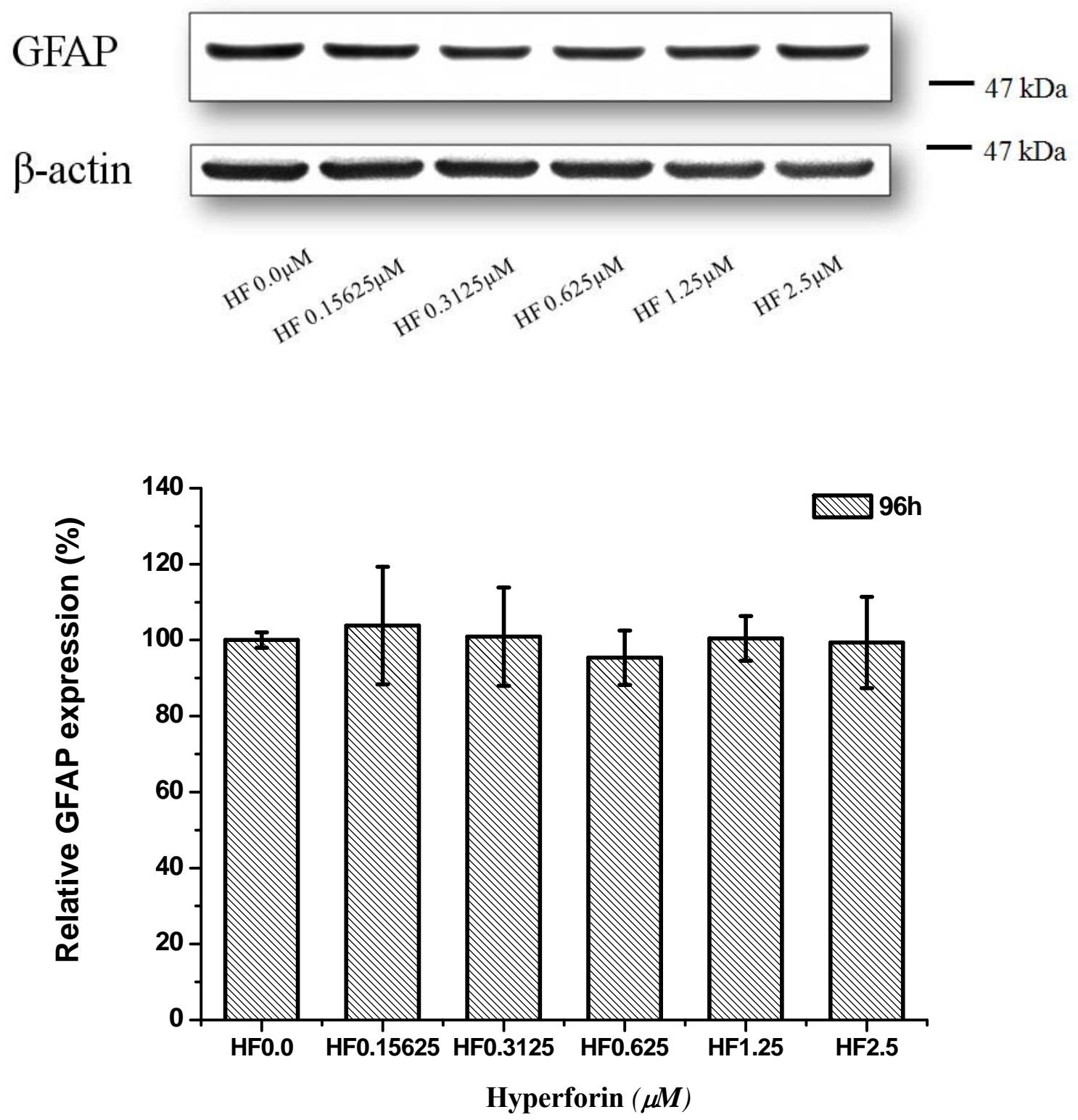

Figure 3.42 Chemiluminescent detections of GFAP and $\beta$-actin in NS/PCs after $96 \mathrm{~h}$ of differentiation with hyperforin treatment

GFAP expression expressed as a percentage of the level at HF $0.0 \mu \mathrm{M}$ after treatment with hyperforin at escalating doses from 0.0 to $2.5 \mu \mathrm{M}$ for $96 \mathrm{~h}$. All groups were compared to $0.0 \mu \mathrm{M}$ of hyperforin (Mean \pm SEM, $n=5)$. HF: Hyperforin. 

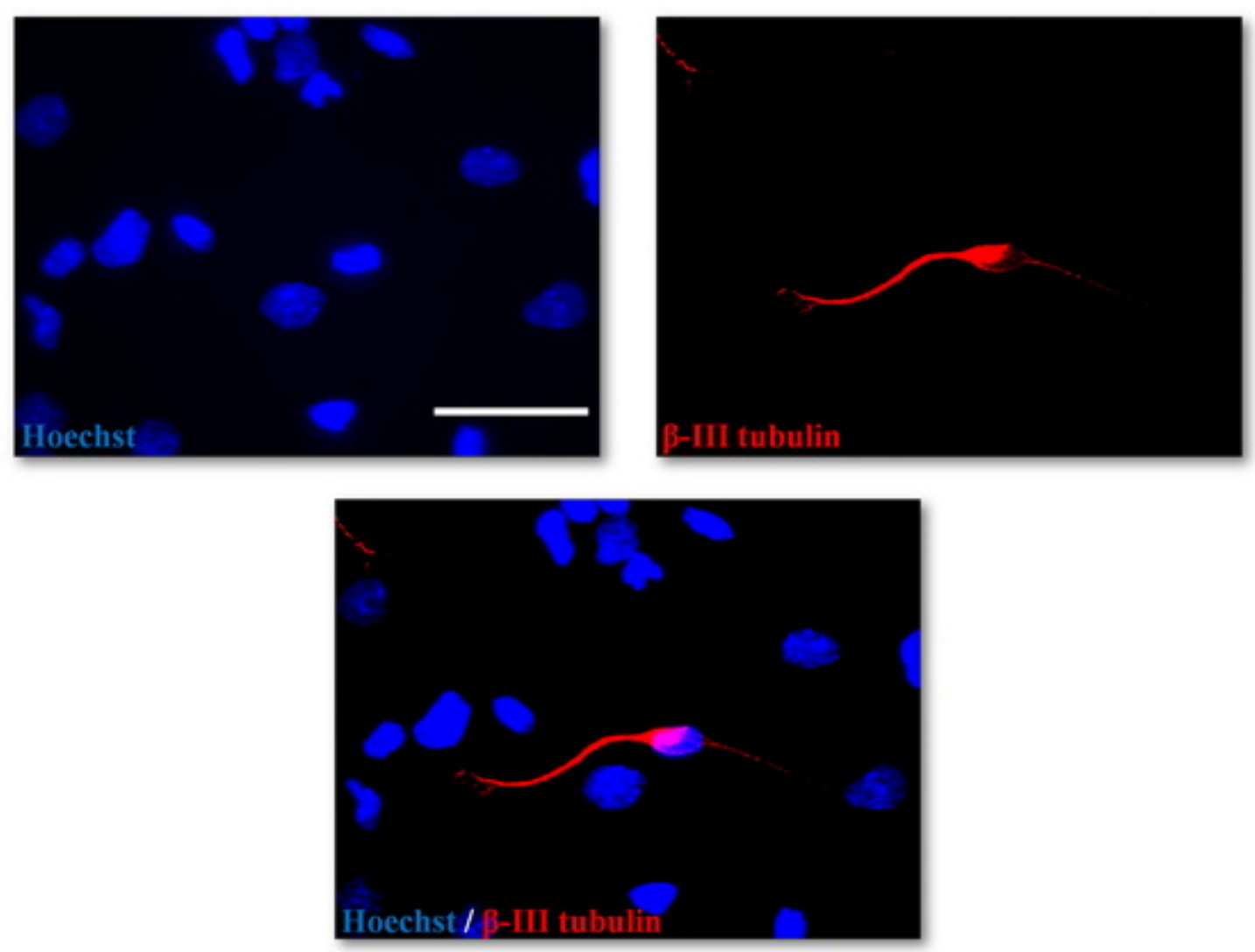

Figure 3.43 Fluorescent microphotographs of differentiating NS/PCs expressing $\beta$ III tubulin after $96 \mathrm{~h}$ of differentiation

The scale bar represents $50 \mu \mathrm{m}$. 

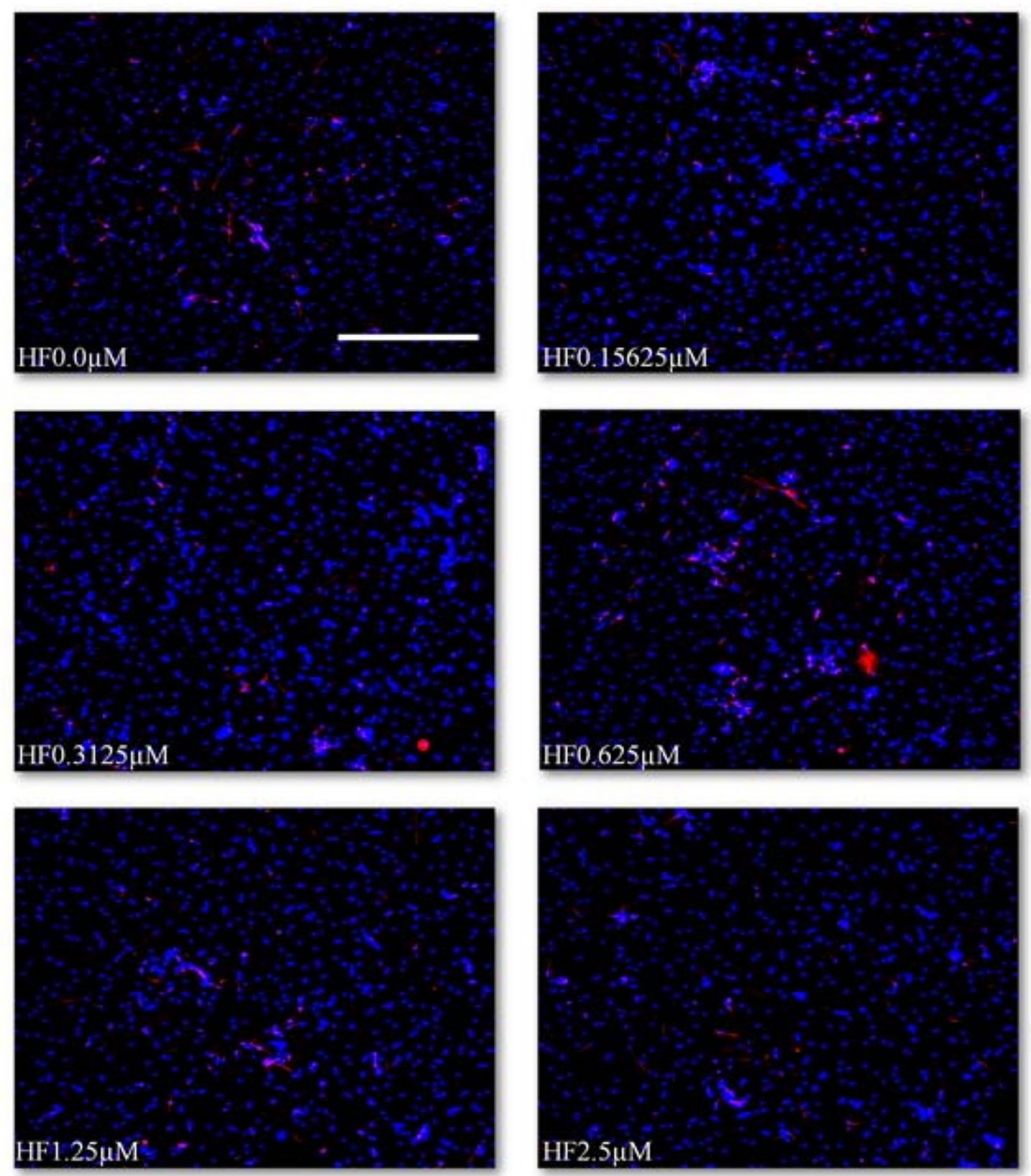

Figure 3.44 Fluorescent microphotographs of differentiating NS/PCs expressing $\beta$ III tubulin after $96 \mathrm{~h}$ of differentiation with hyperforin treatment

NS/PCs were treated with hyperforin at escalating doses from $0.0 \mu \mathrm{M}$ to $2.5 \mu \mathrm{M}$ for $96 \mathrm{~h}$. NS/PCs were stained with Hoechst 33342 (blue) and $\beta$-III tubulin (Red). HF: Hyperforin. The scale bar represents 500 $\mu \mathrm{m}$. 
Table 3.5 Ratios of $\beta$-III tubulin-positive cells to total NS/PCs after 96 h of hyperforin treatment

\begin{tabular}{ccccccc}
\hline Experiment & $\mathrm{CTL}$ & $\mathrm{HF} 0.15625 \mu \mathrm{M}$ & $\mathrm{HF} 0.3125 \mu \mathrm{M}$ & $\mathrm{HF} 0.625 \mu \mathrm{M}$ & $\mathrm{HF} 1.25 \mu \mathrm{M}$ & $\mathrm{HF} 2.5 \mu \mathrm{M}$ \\
\hline 1 & $11.8 \%$ & $12.4 \%$ & $9.8 \%$ & $11.5 \%$ & $12.0 \%$ & $10.4 \%$ \\
2 & $11.3 \%$ & $11.2 \%$ & $9.0 \%$ & $10.0 \%$ & $7.9 \%$ & $10.1 \%$ \\
3 & $10.1 \%$ & $8.6 \%$ & $11.0 \%$ & $11.1 \%$ & $10.3 \%$ & $10.0 \%$ \\
Mean \pm SEM & $11.1 \% \pm 0.5 \%$ & $10.7 \% \pm 1.1 \%$ & $9.9 \% \pm 0.6 \%$ & $10.9 \% \pm 0.4 \%$ & $10.1 \% \pm 1.2 \%$ & $10.2 \% \pm 0.1 \%$ \\
\hline
\end{tabular}

$\mathrm{NS} / \mathrm{PCs}$ were treated with hyperforin at escalating doses from $0.0 \mu \mathrm{M}$ to $2.5 \mu \mathrm{M}$ for $96 \mathrm{~h}$. All groups were compared to $0.0 \mu \mathrm{M}$ of hyperforin (Mean $\pm \mathrm{SEM}, \mathrm{n}=4)$. HF: hyperforin.

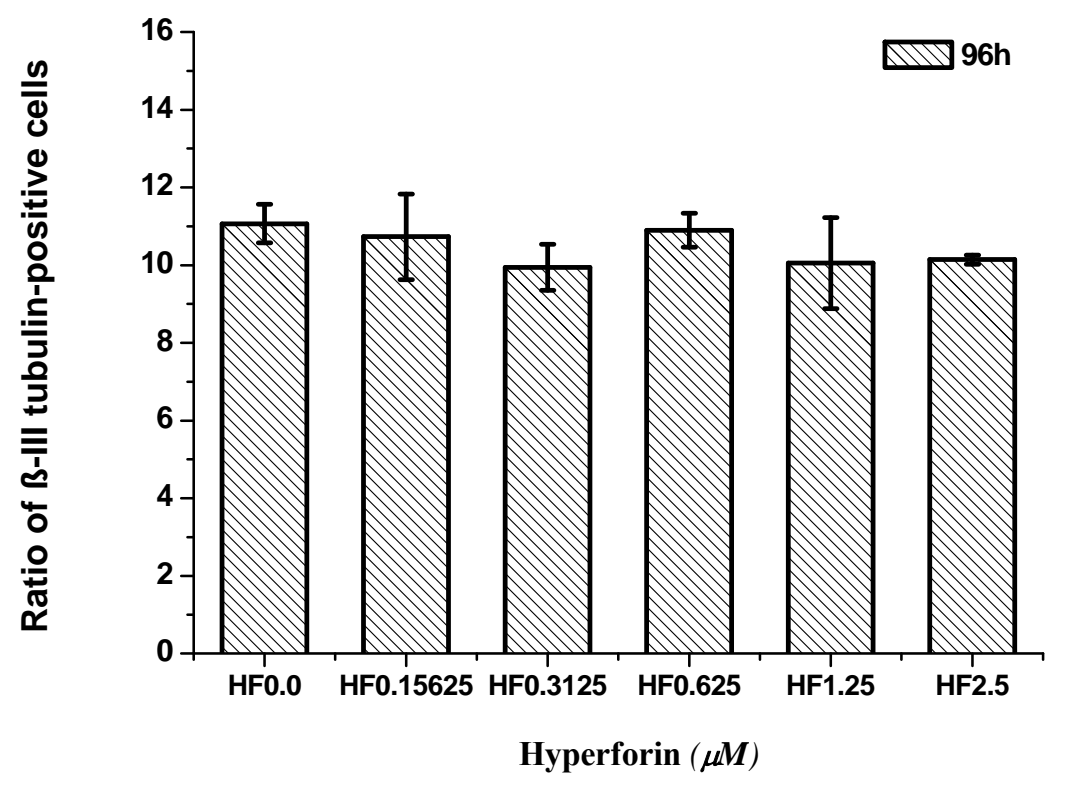

Figure 3.45 Ratios of $\beta$-III tubulin-positive cells to total NS/PCs after $96 \mathrm{~h}$ of differentiation with hyperforin treatment

Ratios of $\beta$-III tubulin-positive cells were calculated after treatment with hyperforin at escalating doses from $0.0 \mu \mathrm{M}$ to $2.5 \mu \mathrm{M}$ for $96 \mathrm{~h}$. All groups were compared to $0.0 \mu \mathrm{M}$ of hyperforin (Mean $\pm \mathrm{SEM}, \mathrm{n}=3$ ). HF: Hyperforin. 


\section{DISCUSSION}

\subsection{Effects of Hyperforin on the Proliferation of CG-4 Cells and NS/PCs}

The reduction of MTT or WST-8 is usually proportional to the number of viable cells in the exponential growth phase (Berridge et al., 2005). The increased cell viability measured by MTT assay or WST-8 assay usually correlates to the increased cell proliferation (Mosmann, 1983). Data from MTT assays or WST-8 assays have indicated that hyperforin does not increase the proliferation of either CG-4 cells or NS/PCs. We have also found that hyperforin inhibits the proliferation of CG-4 cells, but not the primary NS/PCs, at relatively higher concentrations. The growth media of these cell cultures contain strong mitogens such as bFGF, EGF and other mitogens (Louis et al., 1992), hyperforin is not likely to increase rates of proliferation of these fast growing CG4 cells and NS/PCs. Some studies have reported that hyperforin decreases proliferation of several human and rat cell lines at the growth inhibition $50\left(\mathrm{GI}_{50}\right)$ concentrations between $3 \mu \mathrm{M}$ and $15 \mu \mathrm{M}$ (Dona et al., 2004; Schempp et al., 2002), which suggests that hyperforin has a strong anticancer effect. The CG-4 is a spontaneous mutant cell line from primary culture of $\mathrm{O}-2 \mathrm{~A}$ progenitor cells. Its immortal property due to mutation probably makes CG-4 more susceptible to the anticancer effect of hyperforin. Therefore, higher concentrations of hyperforin may inhibit or decrease the proliferation of CG-4 cells by inducing cell cycle arrest or apoptosis. This may also explain why concentrations of hyperforin that inhibit the proliferation of CG-4 cells are still quite tolerable for proliferating primary NS/PCs. This study has also demonstrated that hyperforin can accelerate the differentiation of OPCs into mature oligodendrocytes, so hyperforin may 
induce the proliferating cells to exit from the cell cycle. This effect could be more apparent with CG-4 cells than with NS/PCs, because only part of NS/PCs will differentiate into OPCs. Finally, the recipes for growth media and developmental stages are quite different for these two cell cultures. These differences could cause the different distribution or sensitivities of receptors responding to hyperforin treatment.

\subsection{Effects of Hyperforin on Mitochondrial Function and Survival of Differentiating CG-4 Cells and NS/PCs}

The results have demonstrated that hyperforin increases the cell viability, intracellular ATP levels and mitochondrial membrane potential in differentiating CG-4 cells at 0.25 $\mu \mathrm{M}$ and $0.5 \mu \mathrm{M}$. Hyperforin at $0.25 \mu \mathrm{M}$ protects differentiating CG-4 cells from rotenone-induced ATP depletion. Hyperforin also increases the cell viability and intracellular ATP levels in differentiating NS/PCs at $2.5 \mu \mathrm{M}$ and $5.0 \mu \mathrm{M}$; approximately $40 \%$ of differentiating NS/PCs are OPCs in this study. At these concentrations, hyperforin increases all mitochondrial function related parameters without increasing the viable cell numbers. That means hyperforin increases the mitochondrial function of each cell in these culture systems. All these findings suggest that hyperforin promotes mitochondrial function and survival of CG-4 cells and OPCs in vitro at these concentrations. However, if hyperforin is administered at higher concentrations than those optimal concentrations $(0.25 \mu \mathrm{M}$ and $0.5 \mu \mathrm{M}$ for OPCs; and $2.5 \mu \mathrm{M}$ and $5.0 \mu \mathrm{M}$ for $\mathrm{NS} / \mathrm{PCs}$ ), it can cause a decrease in the mitochondrial function in these cells.

\subsubsection{Hyperforin Increases Mitochondrial Function of Differentiating CG-4 Cells at Lower Concentrations}

We have confirmed that hyperforin increases cell viability, ATP and mitochondrial membrane potential by increasing enzyme activities in mitochondrial citric acid cycle and oxidative phosphorylation rather than decreasing energy consumption of cells. Previous studies have shown that SJW and hyperforin concordantly regulate the expression of genes related to increasing glucose metabolism in a human hepatic cell line (Krusekopf 
and Roots, 2005). SJW has been found to increase the gene expression of pyruvate dehydrogenase which is an important enzyme linking carbohydrate substrates from glycolysis to the citric acid cycle (Pennington et al., 2009). Our findings directly prove that hyperforin, an important extract in SJW, enhances mitochondrial function by increasing activities of key enzymes related to energy production. Decreased generation of ATP and mitochondrial membrane potential at higher toxic concentrations can be explained by the same mechanism. In physiological conditions, about $1-2 \%$ of oxygen is not completely reduced to water in mitochondria. This oxygen is first reduced to the superoxide anion by leaked electrons and then further reduced by superoxide dismutase and glutathione peroxidase into water (Sas et al., 2007). The extreme concentrations of hyperforin cause over-activated mitochondrial oxidative phosphorylation, which can lead to massive accumulation of hydrogen peroxide that is reduced from superoxide anion by superoxide dismutase. Excessive hydrogen peroxide that exceeds the ability of glutathione peroxidase to remove it will react with transition metal ions to generate highly reactive hydroxyl radicals. The consequent oxidative stress can cause damages to DNA and proteins in mitochondria because they are more prone to free radical damage than cellular DNA and proteins (Van Houten et al., 2006). Damaged mitochondria will lose mitochondrial membrane potential, decrease ATP generation, and release cell death signals, such as cytochrome c inducing mitochondria-mediated apoptosis (Brookes et al., 2004). This explains how hyperforin decreased both ATP generations and mitochondrial membrane potential at high toxic concentrations. Our finding that hyperforin increases mitochondrial enzyme activity can further explain the previous report that the proapoptotic effect of hyperforin is associated with mitochondria-mediated apoptosis (Schempp et al., 2002). We suggest that hyperforin will contribute to the optimal function of mitochondria, if it is administered at ideal concentrations. 


\subsubsection{Hyperforin Protects CG-4 Cells from Rotenone-induced ATP Depletion}

Rotenone disrupts the mitochondrial electron-transport chain at complex I and causes acute ATP depletion and generation of massive ROS (Drechsel and Patel, 2008). This study has demonstrated the protective effect of hyperforin on attenuating rotenoneinduced cytotoxicity in differentiating CG-4 cells. Two properties of hyperforin may contribute to its protective effect. First, the antioxidant effects of hyperforin can protect CG-4 cells from oxidative stress induced by rotenone. Hyperforin has been found to prevent the endothelial cell mediated low-density lipoprotein oxidation in vitro by absorbing free radicals through its chain-breaking antioxidant activity (Laggner et al., 2007). Hyperforin prevents ROS release through inhibiting the activation of immune cells in rat brains (Cabrelle et al., 2008). Hyperforin has also prevented the $\beta$-amyloid induced neurotoxicity to hippocampal neurons in a rodent model by preventing the $\beta$-amyloidinduced ROS and inflammation (Dinamarca et al., 2006). A standard extract of SJW can increase the gene expression of antioxidant enzymes on rotenone-exposed rats (SanchezReus et al., 2007). Hyperforin may protect CG-4 cells from rotenone-induced oxidative stress by absorbing free radicals and increasing the efficiency of antioxidant enzymes. The antioxidant effect of hyperforin can also prevent the intracellular oxidative stress in CG-4 cells and NS/PCs due to increased redox activities induced by hyperforin itself. With the balanced generation and removal of free radicals, CG-4 cells and NS/PCs can live with increased mitochondrial functions without showing any oxidative stress. Secondly, hyperforin may directly increase mitochondrial function by enhancing the activity of mitochondrial complex I. Hyperforin can prevent the ATP depletion induced by lower concentration of rotenone, but not by higher concentration of rotenone. This suggests that hyperforin and rotenone may compete with each other to bind to the mitochondrial complex I. This is the first study to locate the site of action for hyperforin increasing mitochondrial function. Future studies should investigate the dose-response relationship between hyperforin and the activity of mitochondrial complex I and confirm these findings. 


\subsubsection{Hyperforin Increases Mitochondrial Function of CG-4 Cells and NS/PCs at Different Dose Ranges}

Hyperforin causes similar patterns of change in mitochondrial function in CG-4 cells and NS/PCs, but the effective dose ranges of hyperforin are different. Concentrations of hyperforin that either increase or decrease mitochondrial functions in CG-4 cells are lower than those in NS/PCs. There are two possible reasons for these differences. The first reason could be the differences between the cell line and primary culture. CG-4 as a cell line is more susceptible to hyperforin-induced mitochondria-mediated apoptosis at relatively higher concentrations. This reason could be also the cause of dose-related differences in the proliferation study. The second reason could be the differences between single-type cell cultures and mixed cell cultures. During the process of differentiation, most CG-4 cells become oligodendrocytes, but NS/PCs are able to differentiate into astrocytes, neurons, oligodendrocytes or even other types of neural cells (Reynolds et al., 1992). The ratios of astrocytes, neurons and oligodendrocytes differentiated from NS/PCs are approximately 33: 11: 40 respectively in this study. The biological markers used in immunocytochemical staining may not identify other types of neural cells (Gritti et al., 1996). The presence of astrocytes and neurons could possibly reduce the distribution of hyperforin in oligodendrocytes, because both astrocytes and neurons can consume some hyperforin for inhibiting neurotransmitter uptake and stimulating cellular receptors in them (Neary et al., 2001). The neurotrophic support and interactions of different cell types could also contribute to the increased tolerability to higher concentrations of hyperforin in differentiating NS/PCs. In differentiating NS/PCs, OPCs only make up $40 \%$ of the total cells. Therefore, if they cause significant changes (25\% of increase) in the whole culture system, they may need to reach a higher level of mitochondrial function. In other words, higher tolerable concentrations of hyperforin are needed to cause similar increases of mitochondrial function in differentiating NS/PCs. In this study, different concentrations of hyperforin cause approximately $25 \%$ of increases of the cell viability and ATP levels in two cell cultures. A future study investigating pure primary OPC culture will help us to understand the dose difference, because primary OPC cultures 
have better tolerability to higher concentrations of hyperforin and less interference from other cells compared to CG-4 and NS/PC cultures.

\subsection{Effects of Hyperforin on Development of Oligodendrocytes}

NS/PCs show several advantages in the study of oligodendrocyte development. First, OPCs derived from primary embryonic NS/PCs more closely represent the OPCs in animal brains. The effects of hyperforin on the development of oligodendrocytes found in this model will provide a more reliable outcome of hyperforin treatment in animal studies. Second, we can also use this model to determine whether hyperforin has effects on the fate decision of NS/PCs. This model may answer whether hyperforin can induce more generations of OPCs from differentiating NS/PCs, which can not be evaluated in CG-4 model. Third, there are some differences between the CG-4 cell line and primary OPCs in the study of oligodendrocyte development. CG-4 can provide unlimited numbers of oligodendrocyte-like cells. However, unlike the primary O-2A progenitor, CG-4 has no real physiological counterpart. During the differentiation into mature oligodendrocytes, CG-4 cells express lesser ganglioside GM3, a component of the cell plasma membrane involved in cell signal transduction events. CG-4 cells express less myelin associated glycoprotein (MAG) and galactocerebroside (GalC) which are important proteins in myelin (Bichenkov and Ellingson, 1999; Yim et al., 1995). Only approximately 50\% of the differentiated CG-4 cells express MBP as determined by immunocytochemical staining (Louis et al., 1992). These data suggest that CG-4 may have a lesser degree of differentiation than primary O-2A progenitors. In one study, they identified the roles of protein kinase $\mathrm{C}$ (PKC) pathway and extracellular signal-regulated kinase (ERK) pathway in the differentiation and maturation of oligodendrocytes and found differences with CG-4 and primary O-2A progenitors (Stariha and Kim, 2001). Other than these reported differences, the CG-4 cell line is a valuable model to study oligodendrocyte biology.

Olig2 is essential for oligodendrocyte formation, but Olig2 is also transiently expressed in astrocyte progenitor cells (Cai et al., 2007). Some study suggests that Olig2 
progressively disappears from the nucleus and is sometimes detected in the cytoplasm, when NS/PCs begin to differentiate into GFAP-positive astrocytes (Fukuda et al., 2004). In the adult brain, the translocation of Olig2 into the cytoplasm is found in the process of astroglial activation during brain injury and inflammation (Cassiani-Ingoni et al., 2006; Magnus et al., 2007). All these suggest that the downregulated Olig2 expression and its translocation into cytoplasma are associated with the maturation and activation of astrocytes. In our study, the Olig2-positive staining in the nuclei after $96 \mathrm{~h}$ of differentiation was used to count the ratio of oligodendrocyte lineage cells to the total NS/PCs, and the Olig2 expression was be used to evaluate the maturation of oligodendrocytes, because interference from mature astrocytes on the Olig2 expression was very limited after $96 \mathrm{~h}$ of differentiation. Our previous unpublished data in animal study also suggest that the overlapping of double staining with Olig2 and GFAP is hardly found in adult animal brains. Olig2 can also be expressed by the progenitor cells of peripheral motor neurons in the murine spinal cord (Lu et al., 2002). However, we use the NS/PCs from the cortex which are not likely to develop into peripheral motor neurons in this culture system. The percentages of oligodendrocyte lineage cells remained constant at approximately $40 \%$ in the control condition and in different concentrations of hyperforin treatment as determined by staining the nuclei with Olig2. The percentages of astrocytes lineage and neuron also remained constant at approximately $30 \%$ and $10 \%$ respectively in the control condition and in different concentrations of hyperforin treatment as determined by staining of GFAP and $\beta$-III tubulin. Data from MBP staining have shown that more MBP-positive cells are detectable in the differentiating NS/PCs after being treated with $0.625 \mu \mathrm{M}$ and $1.25 \mu \mathrm{M}$ of hyperforin for $96 \mathrm{~h}$. Data from Western Blot have shown that hyperforin increases expressions of MBP and CNPase, and Olig2 at concentrations of $0.625 \mu \mathrm{M}$ and $1.25 \mu \mathrm{M}$ for $96 \mathrm{~h}$. These results indicate that hyperforin accelerates the maturation process of oligodendrocytes without affecting the fate decision of NS/PCs at concentrations of $0.625 \mu \mathrm{M}$ and $1.25 \mu \mathrm{M}$ after $96 \mathrm{~h}$ of treatment.

The patterns of expressions of Olig2, CNPase and MBP are almost the same after $96 \mathrm{~h}$ of hyperforin treatment at the dose range between $0.0 \mu \mathrm{M}$ and $2.5 \mu \mathrm{M}$. This indicates that 
the increased expression of Olig2 in NS/PCs is associated with the increased differentiation and maturation of oligodendrocytes. Animal studies have shown that Olig2 is strongly and continuously expressed in oligodendrocytes in the developing and adult CNS (Lu et al., 2000). Olig2 overexpression promotes the differentiation of NS/PCs into mature oligodendrocytes in vitro (Copray et al., 2006). However, the early increases of Olig2 at $24 \mathrm{~h}$ and $48 \mathrm{~h}$ are not significant at concentrations of $0.625 \mu \mathrm{M}$ and $1.25 \mu \mathrm{M}$, so the increased expression of Olig2 could be the result of accelerated maturation of oligodendrocytes. Hyperforin may affect other differentiation-related transcription factors such as NK2 homeobox 2 (Nkx2.2), because Olig2 accompanying with other transcription factors including $\mathrm{Nkx} 2.2$ collaboratively regulate the differentiation of oligodendrocytes from neural progenitor cells (Zhou et al., 2001). Recent studies have also shown that expression of Olig2 can induce early oligodendrocyte precursor markers such as PDGF receptor $\alpha$, but not later markers such as MBP (Zhou et al., 2001). Nkx2.2 expression appears to be necessary for proliferation and migration of OPCs, and it is also crucial for the expression of MBP in mature oligodendrocytes (Qi et al., 2001; Xu et al., 2000). Nkx2.2 expression is downregulated with oligodendrocyte differentiation, which is different from the expression of Olig2 (Xu et al., 2000). A future study should evaluate the effect of hyperforin on $\mathrm{Nkx} 2.2$ or other important factors on the regulation of oligodendrocyte development.

\subsubsection{The Relationship between Increased Mitochondrial Function and Accelerated Development of Oligodendrocytes}

We have demonstrated that hyperforin increases both mitochondrial function and development of OPCs into mature oligodendrocytes. It was observed that the pattern of early increased mitochondrial function as determined by the MTT assay and the ATP assay resembled the patterns of expressions of Olig2 and CNPase at the early stage of oligodendrocyte development. These parameters were significantly increased after 2.5 $\mu \mathrm{M}$ of hyperforin treatment for $48 \mathrm{~h}$. There may be some correlation between the 
increased mitochondrial function and accelerated differentiation and maturation of oligodendrocytes.

Increased mitochondrial function will provide beneficial support for the differentiation and maturation of OPCs, because of the high energy consumption in developing oligodendrocytes during the process of myelination (Connor and Menzies, 1996; Pleasure et al., 1977). Furthermore, recent studies have shown that intracellular redox status play an important role in modulating the balance between self-renewal proliferation and differentiation in dividing O-2A progenitor cells (Noble et al., 2003). Signaling molecules that promote $\mathrm{O}-2 \mathrm{~A}$ progenitor cell differentiation into oligodendrocytes cause greater intracellular oxidative turnover, whereas signaling molecules that promote selfrenewal cause more reduced intracellular states. Pharmacological agents that antagonize the redox effects of these molecules also antagonize their effects on self-renewal and differentiation (Smith et al., 2000). We have found that hyperforin increases the mitochondrial function by increasing the oxidative phosphorylation, and this effect could be due to the promotion of OPCs differentiation into oligodendrocytes.

It is also possible that hyperforin-induced maturation of oligodendrocytes requires cells to increase mitochondrial function and generate more ATP to meet the demand of energy consumption for faster synthesis of myelin. The latest study of myelin function discloses that isolated myelin vesicles are able to consume oxygen and produce ATP through the operation of a proton gradient across their membranes. It also shows the colocalization of the ATP synthase and MBP on isolated myelin vesicles and axon nerves (Ravera et al., 2009). This evidence suggests that myelin sheath could also be the site of oxygen absorption and aerobic metabolism for the axons, so the increased myelin production could also be a resource for increased energy production in myelinating oligodendrocytes.

It is also possible that both processes are controlled by a common pathway that can be affected by hyperforin, so they will increase together with hyperforin treatment. A genomic study reports that the gene of peroxisome proliferator activated receptor- $\gamma$ (PPAR- $\gamma$ ) is significantly unregulated by treatment of SJW and hyperforin (Houseknecht 
et al., 2002; Krusekopf and Roots, 2005). PPAR- $\gamma$ has been found in adult and developing brains and spinal cords (Heneka and Landreth, 2007). PPAR- $\gamma$ regulates the expression of several genes related to lipid uptake and synthesis (Walczak and Tontonoz, 2002) as well as the enhancement of cellular glucose uptake (Gervois et al., 2007). Oligodendrocytes are major lipid producing cells with high energy consumption in the CNS, so PPAR- $\gamma$ is likely to affect the maturation and function of oligodendrocytes by regulating the lipid synthesis and energy supply during the myelination. PPAR- $\gamma$ is also involved in the proliferation and differentiation of neural stem cells (Wada et al., 2006). PPAR- $\gamma$ agonists are found to promote the differentiation of cultured spinal cord oligodendrocytes by the increasing percentage of cells expressing MBP (Roth et al., 2003). In another study, PPAR- $\gamma$ agonists not only promote the differentiation of primary rat OPCs but also enhance their antioxidant defenses by increasing the levels of catalase and superoxide dismutase (Bernardo et al., 2009; Sim et al., 2008). A novel thiadiazolidinone, a PPAR- $\gamma$ agonist, has shown antidepressant effects in the forced swimming test, and this effect is inhibited by PPAR- $\gamma$ antagonists (Rosa et al., 2008). Hyperforin may increase the mitochondrial energy metabolism and development of OPCs at the same time by stimulating expression of PPAR- $\gamma$, and these effects on oligodendrocytes may eventually contribute to the antidepressant effect of hyperforin.

\subsection{Implications of Antidepressant Treatment on Mitochondrial Function and Development of Oligodendrocytes in MDD}

This study has demonstrated that hyperforin promotes mitochondrial function and development of oligodendrocytes in vitro. Many studies have already shown that the clinical symptoms and pathological changes in MDD are related to the mitochondrial malfunction and loss of oligodendrocytes. Antidepressant treatment including antidepressants and ECT have shown a tendency to increase both mitochondrial function and available functioning oligodendrocytes in the brain. It is possible that these are common effects shared by different antidepressant treatment. 


\subsubsection{Antidepressant Treatment May Prevent the Mitochondrial Dysfunction-Related Oligodendrocyte Malfunction in MDD}

Functional neuroimaging studies with positron emission tomography (PET) have found decreased cerebral blood flow and glucose metabolism in the prefrontal cortex, the basal ganglia and the hippocampus in brains of MDD patients (Buchsbaum et al., 1986; Drevets et al., 1997). Blood flow and glucose metabolism were normalized when patients recovered from MDD (Videbech, 2000). In a study measuring high-energy phosphates in MDD using ${ }^{31}$ phosphorus magnetic resonance spectroscopy $\left({ }^{31} \mathrm{P}-\mathrm{MRS}\right)$, the ATP levels were found to be lower in patients than in normal controls (Moore et al., 1997). Creatine phosphate is a high-energy phosphate that can be readily transferred to ATP by the enzyme creatine kinase. The levels of creatine phosphate were lower in the severe depression group compared to the mild depression group. This study suggests that the deficiency of the energy metabolism may be related to the severity of depression (Kato et al., 1998). Genetic studies have shown that decreased mitochondrial DNA transcription and mitochondrial diseases are highly correlated to MDD (Fattal et al., 2006; Shao et al., 2008). In chronic stress animal models of depression, the activities of complex I, II, III and IV in mitochondrial electron-transport chain were inhibited after 21 days and 40 days of stress (Madrigal et al., 2001; Rezin et al., 2008). The complexes I, III and IV were only inhibited in the cerebral cortex and cerebellum (Rezin et al., 2008), where structural abnormalities have also been found in patients with mood disorders (Konarski et al., 2008). These studies suggest that mitochondrial dysfunction is closely related to the severities of symptoms and structural abnormalities found in patients with MDD. Furthermore, both mitochondrial dysfunction and oligodendrocyte loss or malfunctions are found around the prefrontal cortex and the limbic system in the brains of patients with MDD (Buchsbaum et al., 1986; Hamidi et al., 2004; Honer et al., 1999). In these areas, decreased mitochondrial function may directly affect the function of oligodendrocytes and the myelination process, because reduced energy supply may not be enough for 
oligodendrocytes to maintain and generate a large amount of myelin (Connor and Menzies, 1996; Pleasure et al., 1977). Impaired oligodendrocytes will affect the information transduction in those brain areas; which are important for emotion and social behavior (Phelps and LeDoux, 2005).

In this study, hyperforin specifically increases the mitochondrial function in

differentiating CG-4 cells and protects these cells from neurotoxin-induced mitochondrial malfunction. Several studies have shown that SJW and hyperforin can upregulate gene expressions related to increasing glycolysis and cellular glucose uptake in the hippocampus and other tissue (Krusekopf and Roots, 2005; Pennington et al., 2009). A recent ${ }^{31} \mathrm{P}$-MRS study suggests that agents with the ability to increase brain ATP levels may show antidepressant effect (Moretti et al., 2003). A variety of antidepressants including imipramine, amitriptyline and clomipramine increase the ATP generation of astrocytes in vitro and this may affect the differentiation of astrocytes (Trzeciak et al., 1995). Fluoxetine has been found to enhance glycogenolysis in cultured astrocytes and could thus improve energy supply in rodent brains (Kong et al., 2002; Zhang et al., 1993). ECT treatment has been found to increase activities of mitochondrial complexes II and IV in brains of rats (Burigo et al., 2006). Another study indicates that the antidepressant effect of thyroid hormone augmentation of SSRIs is correlated with significant increases in ATP levels and other bioenergetics in the brains of patients with MDD (Iosifescu et al., 2008). These studies suggest that antidepressants may increase energy metabolism by increasing mitochondrial function in the brain. This effect may attenuate the oligodendrocyte malfunction that would be induced by an energy deficiency in the brains of patients with MDD.

\subsubsection{Antidepressant Treatment May Increase Functioning of Oligodendrocytes in MDD}

Myelination is not complete after birth, and it continues into the fifth decade of human life (Bartzokis et al., 2001; Benes et al., 1994). The continuous myelination allows oligodendrocytes to keep modifying the synaptic connections. It is believed that this 
ongoing modification helps the brain to achieve the optimal information processing according to life experiences, such as increased social interaction and cognitive stimulation (Fields, 2005). The molecular mechanism of remodeling synaptic function has recently been discovered. Oligodendrocytes are able to sense the impulse activity in axons via their ion channels and membrane receptors and dynamically change myelination patterns for optimal function according to the impulse (Stevens et al., 1998). Furthermore, communication through synaptic junctions between axon terminals and the processes of OPCs also help newly generated OPCs to migrate and form myelin at optimal locations (Bergles et al., 2000). Oligodendrocytes are more actively involved in the dynamic control of the output of neuronal communication than previously believed (Yamazaki et al., 2009). To fulfill the dynamic control and remodeling of the neuronal conductions, the brain needs to maintain sufficient levels of functioning oligodendrocytes and newly generated OPCs. After CNS development is complete, some OPCs remain in the adult brain and spinal cord. These OPCs can further differentiate into mature oligodendrocytes (Noble et al., 1992). The genesis of NG2-positive cells that can differentiate into OPCs is also very common throughout the brain (Kornack and Rakic, 2001). A gene study of postmortem brain tissues of patients with MDD has revealed that expressions of 17 genes related to myelination are decreased. Eight of these 17 genes encode the structural components of myelin including CNPase and MAG. Several oligodendrocyte development genes including Olig2 are also decreased in MDD (Aston et al., 2005). The decreases of oligodendrocyte density, myelin staining and MBP expressions have also been found in the brains of patients with MDD (Hamidi et al., 2004; Honer et al., 1999; Regenold et al., 2007). Both genesis and myelination of oligodendrocytes are impaired in MDD.

This study has demonstrated that hyperforin prevents the loss of OPCs and accelerates the development of OPCs into mature oligodendrocytes by increasing expressions of Olig2, CNPase and MBP. This suggests that hyperforin as an extract in SJW can reverse the pathophysiological changes in oligodendrocytes in the brains of patients with MDD, which could be a possible mechanism of action for its clinical efficacy. However, 
hyperforin did not induce the proliferation of OPCs and NS/PCs in this study, so it can not show more effects by enlarging these pools of OPCs. Other antidepressant treatment has been found to have effects on promoting genesis of oligodendrocytes. Fluoxetine and imipramine prevent the loss of neural stem cells in a chronic stress animal model (Hitoshi et al., 2007). Fluoxetine and ECT can induce the genesis of bipotential glial progenitors and OPCs in animal brains (Hitoshi et al., 2007; Wennstrom et al., 2004). Fluoxetine has also shown an ability to promote the development of oligodendrocytes by increasing the expressions of insulin-like growth factor I (IGF-I) and its receptor in rat brains (Grunbaum-Novak et al., 2008). These findings suggest a possible outcome of antidepressant treatment is to increase the available functioning oligodendrocytes in the brains of patients with MDD by increasing the genesis or development of OPCs.

Most treatment for depression, including hyperforin in SJW, synthetic antidepressants and ECT increases the synaptic serotonin or norepinephrine levels (Berton and Nestler, 2006; Muller et al., 1998; Taylor, 2007). By increasing the monoaminergic neurotransmission, chronic antidepressant treatment increases cAMP and upregulates the function and expression of the transcription factor CREB, which can increase the expressions of neurotrophic factors (Duman, 2002). Expression of IGF-I could also be increased by modulating cAMP levels (Palacios et al., 2005). A recent study has shown that chronic treatment of fluoxetine increases the levels of both IGF-1 mRNA and IGF-I receptors in the frontal cortex but not the hippocampus in rat brains (Grunbaum-Novak et al., 2008). Furthermore, intracerebroventricular administration of IGF-I has shown antidepressant-like behavioral effects with increased serotonin transmissions in rodent models (Hoshaw et al., 2008). CREB is also highly expressed in oligodendrocytes (SatoBigbee and Yu, 1993; Sato-Bigbee et al., 1994). Studies have shown that IGF-I can induce multipotent adult neural progenitor cells to become oligodendrocytes (Hsieh et al., 2004). IGF-I also stimulates oligodendrocyte development and myelination in vitro (Mozell and McMorris, 1991) and in mouse brains (Zeger et al., 2007). Through regulating CREB and expressions of IGF-I and its receptors, chronic antidepressant 
treatment may promote the genesis and development of oligodendrocytes from neural progenitor cells in the brain.

This study and previous studies suggest that increasing the genesis and development of oligodendrocytes could be a mechanism of action for chronic antidepressant treatment. This mechanism would explain some of the pathological changes in depression and the effects of chronic antidepressant treatment on oligodendrocytes. It also necessary to examine whether the antidepressants that induce both genesis and development of oligodendrocytes have a better efficacy than antidepressants that have a single effect on oligodendrocytes.

\subsubsection{The Mechanism of Action for Chronic Antidepressant Treatment May be Mediated through Oligodendrocytes}

This study and previous studies suggest that antidepressant treatment may promote mitochondrial function and development of oligodendrocytes. Antidepressants may increase functioning oligodendrocytes, which may compensate for the loss and malfunction of oligodendrocytes in the brains of patients with MDD. If this is a possible mechanism of action for chronic antidepressant treatment, drug development could focus on oligodendrocytes as a therapeutic target. Recent studies have reported that quetiapine, an atypical antipsychotic approved for depression treatment, promotes both the proliferation of the NS/PCs and maturation of oligodendrocytes in cell cultures as well as in a demyelination animal model (Xiao et al., 2008; Zhang et al., 2008). Chronic administration of quetiapine has also shown efficacy as an effective monotherapy for MDD in clinical trials (Cutler et al., 2009; Weisler et al., 2009). Quetiapine shows a moderate effect on serotonin receptors, which could contribute to the efficacy; but the effect is different from that of synthetic antidepressants (Yatham et al., 2005). However, chronic treatment of quetiapine is still needed to reduce depressive symptoms in clinical trials. The close relationship between oligodendrocyte function and the chronic treatment with quetiapine suggests that the antidepressant effect may also be mediated through enhancing oligodendrocyte function. 


\subsection{Future Studies Are Needed to Decipher the Underlying Mechanism of Hyperforin in Promoting Oligodendrocyte Function}

We have demonstrated that hyperforin promotes both mitochondrial function and development of oligodendrocytes at optimal concentrations. Hyperforin can directly increase the intracellular the cell viability and enzyme activity of complex I on the mitochondrial electron-transport chain. It is also possible that hyperforin works on other targets that can induce increased energy metabolism and differentiation of oligodendrocytes. We think PPAR- $\gamma$ is a candidate to examine. The possible increase of PPAR- $\gamma$ expression will also explain the anti-inflammatory effect of hyperforin in the CNS, because PPAR- $\gamma$ is also involved in the immunoresponse and cytokine release (Heneka and Landreth, 2007).

Neural stem cells differentiate into different cell types at the same time in the human brain, so the differentiating NS/PC model closely resembles the differentiating neural stem cells in human brains. We have demonstrated that hyperforin promotes the development of oligodendrocytes without affecting the ratios of different cell lineages. However, astrocytes, neurons or other neural cells may still contribute to the development of oligodendrocytes. Astrocytes can release a specific cytokine into its surrounding environment, which induces the differentiation and myelination of oligodendrocytes (Ishibashi et al., 2006). The primary culture of OPCs will be very useful in further identifying the mechanism by which hyperforin promotes oligodendrocyte development.

Hyperforin has shown efficacy in reversing depressive-like behavior in animal models (Cervo et al., 2002; Gambarana et al., 2001), so the examination of oligodendrocyte changes in the brains of control animals and hyperforin-treated animals will provide more information on the relationship among reduced symptoms, oligodendrocyte changes and hyperforin treatment. Although several studies have shown antidepressant treatment can 
induce genesis of neural stem cells and promote their survival (Hitoshi et al., 2007; Wennstrom et al., 2004), this is the first study to provide direct evidence that an antidepressant compound promotes the development of OPCs from neural stem cells. Whether other synthetic antidepressants share the same effects as hyperforin on oligodendrocytes needs to be confirmed by future studies. 


\section{CONCLUSION}

Hyperforin increases mitochondrial function and prevents mitochondrial toxin-induced cytotoxicity in differentiating oligodendrocytes. Hyperforin also promotes the development of differentiating oligodendrocytes rather than increasing the proliferation of OPCs and NS/PCs. These findings suggest that hyperforin may increase the available functioning oligodendrocytes by promoting the mitochondrial function, survival and development of oligodendrocytes. Our findings in conjunction with past studies suggest that the mechanism of action of chronic antidepressant treatment may be increasing the function of oligodendrocytes in the brains of patients with MDD. Future studies should explore the detailed mechanisms of hyperforin and other antidepressants on promoting mitochondrial function and development of oligodendrocytes in cell cultures and animal models. 


\section{LIST OF REFERENCES}

2000. Diagnostic and Statistical Manual of Mental Disorders, Fourth Edition - Text Revision (DSMIV-TR).

2001. Clinical guidelines for the treatment of depressive disorders. Can J Psychiatry. 46 Suppl 1, 5S-90S.

2002. Effect of Hypericum perforatum (St John's wort) in major depressive disorder: a randomized controlled trial. JAMA. 287, 1807-14.

Angelucci, F., Brene, S., Mathe, A.A., 2005. BDNF in schizophrenia, depression and corresponding animal models. Mol Psychiatry. 10, 345-52.

Arnett, P.A., Barwick, F.H., Beeney, J.E., 2008. Depression in multiple sclerosis: review and theoretical proposal. J Int Neuropsychol Soc. 14, 691-724.

Aston, C., Jiang, L., Sokolov, B.P., 2005. Transcriptional profiling reveals evidence for signaling and oligodendroglial abnormalities in the temporal cortex from patients with major depressive disorder. In: Molecular Psychiatry. Vol. 10. Nature Publishing Group, pp. 309-322.

Banasr, M., Duman, R.S., 2008. Glial loss in the prefrontal cortex is sufficient to induce depressive-like behaviors. Biol Psychiatry. 64, 863-70.

Bartzokis, G., Beckson, M., Lu, P.H., Nuechterlein, K.H., Edwards, N., Mintz, J., 2001. Agerelated changes in frontal and temporal lobe volumes in men: a magnetic resonance imaging study. Arch Gen Psychiatry. 58, 461-5.

Beaubrun, G., Gray, G.E., 2000. A review of herbal medicines for psychiatric disorders. Psychiatr Serv. 51, 1130-4.

Beerhues, L., 2006. Hyperforin. Phytochemistry. 67, 2201-7.

Benes, F.M., Turtle, M., Khan, Y., Farol, P., 1994. Myelination of a key relay zone in the hippocampal formation occurs in the human brain during childhood, adolescence, and adulthood. Arch Gen Psychiatry. 51, 477-84.

Bergles, D.E., Roberts, J.D., Somogyi, P., Jahr, C.E., 2000. Glutamatergic synapses on oligodendrocyte precursor cells in the hippocampus. Nature. 405, 187-91.

Bernardo, A., Bianchi, D., Magnaghi, V., Minghetti, L., 2009. Peroxisome Proliferator-Activated Receptor-gamma Agonists Promote Differentiation and Antioxidant Defenses of Oligodendrocyte Progenitor Cells. J Neuropathol Exp Neurol. 68, 797-808.

Berridge, M.V., Tan, A.S., 1993. Characterization of the cellular reduction of 3-(4,5dimethylthiazol-2-yl)-2,5-diphenyltetrazolium bromide (MTT): subcellular localization, substrate dependence, and involvement of mitochondrial electron transport in MTT reduction. Arch Biochem Biophys. 303, 474-82.

Berridge, M.V., Herst, P.M., Tan, A.S., 2005. Tetrazolium dyes as tools in cell biology: new insights into their cellular reduction. Biotechnol Annu Rev. 11, 127-52.

Berton, O., Nestler, E.J., 2006. New approaches to antidepressant drug discovery: beyond monoamines. Nat Rev Neurosci. 7, 137-51.

Betarbet, R., Sherer, T.B., MacKenzie, G., Garcia-Osuna, M., Panov, A.V., Greenamyre, J.T., 2000. Chronic systemic pesticide exposure reproduces features of Parkinson's disease. Nat Neurosci. 3, 1301-6.

Biber, A., Fischer, H., Romer, A., Chatterjee, S.S., 1998. Oral bioavailability of hyperforin from hypericum extracts in rats and human volunteers. Pharmacopsychiatry. 31 Suppl 1, 36-43.

Biber, A., et al, 1998. Oral bioavailability of hyperforin from hypericum extracts in rats and human volunteers. Pharmacopsychiatry. 
Bichenkov, E., Ellingson, J.S., 1999. Temporal and quantitative expression of the myelinassociated lipids, ethanolamine plasmalogen, galactocerebroside, and sulfatide, in the differentiating CG-4 glial cell line. Neurochemical Research. 24, 1549-56.

Bilia, A.R., Gallori, S., Vincieri, F.F., 2002. St. John's wort and depression: efficacy, safety and tolerability-an update. Life Sci. 70, 3077-96.

Bladt, S., Wagner, H., 1994. Inhibition of MAO by fractions and constituents of hypericum extract. J Geriatr Psychiatry Neurol. 7 Suppl 1, S57-9.

Blazer, D.G., Kessler, R.C., McGonagle, K.A., Swartz, M.S., 1994. The prevalence and distribution of major depression in a national community sample: the National Comorbidity Survey. Am J Psychiatry. 151, 979-86.

Boggs, J.M., 2006. Myelin basic protein: a multifunctional protein. Cell Mol Life Sci. 63, 194561.

Bostwick, J.M., Pankratz, V.S., 2000. Affective disorders and suicide risk: a reexamination. Am J Psychiatry. 157, 1925-32.

Boyer, P.D., Chance, B., Ernster, L., Mitchell, P., Racker, E., Slater, E.C., 1977. Oxidative phosphorylation and photophosphorylation. Annu Rev Biochem. 46, 955-66.

Boyer, P.D., 1987. The unusual enzymology of ATP synthase. Biochemistry. 26, 8503-7.

Brenes, J.C., Rodriguez, O., Fornaguera, J., 2008. Differential effect of environment enrichment and social isolation on depressive-like behavior, spontaneous activity and serotonin and norepinephrine concentration in prefrontal cortex and ventral striatum. Pharmacol Biochem Behav. 89, 85-93.

Brookes, P.S., Yoon, Y., Robotham, J.L., Anders, M.W., Sheu, S.-S., 2004. Calcium, ATP, and ROS: a mitochondrial love-hate triangle. Am J Physiol Cell Physiol. 287, C817-833.

Buchsbaum, M.S., Wu, J., DeLisi, L.E., Holcomb, H., Kessler, R., Johnson, J., King, A.C., Hazlett, E., Langston, K., Post, R.M., 1986. Frontal cortex and basal ganglia metabolic rates assessed by positron emission tomography with [18F]2-deoxyglucose in affective illness. J Affect Disord. 10, 137-52.

Burigo, M., Roza, C.A., Bassani, C., Fagundes, D.A., Rezin, G.T., Feier, G., Dal-Pizzol, F., Quevedo, J., Streck, E.L., 2006. Effect of electroconvulsive shock on mitochondrial respiratory chain in rat brain. Neurochem Res. 31, 1375-9.

Cabrelle, A., Dell'Aica, I., Melchiori, L., Carraro, S., Brunetta, E., Niero, R., Scquizzato, E., D'Intino, G., Calza, L., Garbisa, S., Agostini, C., 2008. Hyperforin down-regulates effector function of activated $\mathrm{T}$ lymphocytes and shows efficacy against Th1-triggered CNS inflammatory-demyelinating disease. J Leukoc Biol. 83, 212-9.

Caccia, S., 2005. Antidepressant-like components of Hypericum perforatum extracts: an overview of their pharmacokinetics and metabolism. Curr Drug Metab. 6, 531-43.

Cai, J., Chen, Y., Cai, W.H., Hurlock, E.C., Wu, H., Kernie, S.G., Parada, L.F., Lu, Q.R., 2007. A crucial role for Olig2 in white matter astrocyte development. Development. 134, 1887-99.

Cassiani-Ingoni, R., Coksaygan, T., Xue, H., Reichert-Scrivner, S.A., Wiendl, H., Rao, M.S., Magnus, T., 2006. Cytoplasmic translocation of Olig2 in adult glial progenitors marks the generation of reactive astrocytes following autoimmune inflammation. Exp Neurol. 201, 349-58.

Cervo, L., Rozio, M., Ekalle-Soppo, C.B., Guiso, G., Morazzoni, P., Caccia, S., 2002. Role of hyperforin in the antidepressant-like activity of Hypericum perforatum extracts. Psychopharmacology (Berl). 164, 423-8.

Charney, D.S., 1998. Monoamine dysfunction and the pathophysiology and treatment of depression. J Clin Psychiatry. 59 Suppl 14, 11-4. 
Chatterjee, S.S., Biber, A., Weibezahn, C., 2001. Stimulation of glutamate, aspartate and gammaaminobutyric acid release from synaptosomes by hyperforin. Pharmacopsychiatry. 34 Suppl 1, S11-9.

Chen, A.C., Shirayama, Y., Shin, K.H., Neve, R.L., Duman, R.S., 2001a. Expression of the cAMP response element binding protein (CREB) in hippocampus produces an antidepressant effect. Biol Psychiatry. 49, 753-62.

Chen, B., Dowlatshahi, D., MacQueen, G.M., Wang, J.F., Young, L.T., 2001b. Increased hippocampal BDNF immunoreactivity in subjects treated with antidepressant medication. Biol Psychiatry. 50, 260-5.

Chen, L.B., Summerhayes, I.C., Johnson, L.V., Walsh, M.L., Bernal, S.D., Lampidis, T.J., 1982. Probing mitochondria in living cells with rhodamine 123. Cold Spring Harb Symp Quant Biol. 46 Pt 1, 141-55.

Connor, J.R., Menzies, S.L., 1996. Relationship of iron to oligodendrocytes and myelination. Glia. 17, 83-93.

Copray, S., Balasubramaniyan, V., Levenga, J., de Bruijn, J., Liem, R., Boddeke, E., 2006. Olig2 overexpression induces the in vitro differentiation of neural stem cells into mature oligodendrocytes. Stem Cells. 24, 1001-10.

Cotter, D., Mackay, D., Landau, S., Kerwin, R., Everall, I., 2001. Reduced glial cell density and neuronal size in the anterior cingulate cortex in major depressive disorder. Arch Gen Psychiatry. 58, 545-53.

Cutler, A.J., Montgomery, S.A., Feifel, D., Lazarus, A., Astrom, M., Brecher, M., 2009. Extended release quetiapine fumarate monotherapy in major depressive disorder: a placebo- and duloxetine-controlled study. J Clin Psychiatry. 70, 526-39.

Czeh, B., Muller-Keuker, J.I., Rygula, R., Abumaria, N., Hiemke, C., Domenici, E., Fuchs, E., 2007. Chronic social stress inhibits cell proliferation in the adult medial prefrontal cortex: hemispheric asymmetry and reversal by fluoxetine treatment. Neuropsychopharmacology. 32, 1490-503.

Dai, X., Qu, P., Dreyfus, C.F., 2001. Neuronal signals regulate neurotrophin expression in oligodendrocytes of the basal forebrain. Glia. 34, 234-9.

Deluca, M., 1976. Firefly luciferase. Adv Enzymol Relat Areas Mol Biol. 44, 37-68.

Deogracias, R., Espliguero, G., Iglesias, T., Rodriguez-Pena, A., 2004. Expression of the neurotrophin receptor trkB is regulated by the cAMP/CREB pathway in neurons. Mol Cell Neurosci. 26, 470-80.

Di Carlo, G., Borrelli, F., Ernst, E., Izzo, A.A., 2001. St John's wort: Prozac from the plant kingdom. Trends in Pharmacological Sciences. 22, 292-297.

Dinamarca, M.C., Cerpa, W., Garrido, J., Hancke, J.L., Inestrosa, N.C., 2006. Hyperforin prevents beta-amyloid neurotoxicity and spatial memory impairments by disaggregation of Alzheimer's amyloid-beta-deposits. Molecular Psychiatry. 11, 1032-1048.

Dona, M., Dell'Aica, I., Pezzato, E., Sartor, L., Calabrese, F., Della Barbera, M., Donella-Deana, A., Appendino, G., Borsarini, A., Caniato, R., Garbisa, S., 2004. Hyperforin inhibits cancer invasion and metastasis. Cancer Res. 64, 6225-32.

Drechsel, D.A., Patel, M., 2008. Role of reactive oxygen species in the neurotoxicity of environmental agents implicated in Parkinson's disease. Free Radic Biol Med. 44, 187386.

Drevets, W.C., Price, J.L., Simpson, J.R., Jr., Todd, R.D., Reich, T., Vannier, M., Raichle, M.E., 1997. Subgenual prefrontal cortex abnormalities in mood disorders. Nature. 386, 824-7.

Du, Y., Dreyfus, C.F., 2002. Oligodendrocytes as providers of growth factors. J Neurosci Res. 68, 647-54. 
Duman, R.S., 2002. Pathophysiology of depression: the concept of synaptic plasticity. Eur Psychiatry. 17 Suppl 3, 306-10.

Duman, R.S., Monteggia, L.M., 2006. A neurotrophic model for stress-related mood disorders. Biol Psychiatry. 59, 1116-27.

El Bitar, F., Dastugue, B., Meiniel, A., 1999. Neuroblastoma B104 cell line as a model for analysis of neurite outgrowth and neuronal aggregation induced by Reissner's fiber material. Cell and Tissue Research. 298, 233-242.

Eng, L.F., Ghirnikar, R.S., Lee, Y.L., 2000. Glial fibrillary acidic protein: GFAP-thirty-one years (1969-2000). Neurochem Res. 25, 1439-51.

Fattal, O., Budur, K., Vaughan, A.J., Franco, K., 2006. Review of the literature on major mental disorders in adult patients with mitochondrial diseases. Psychosomatics. 47, 1-7.

Fields, R.D., 2005. Myelination: an overlooked mechanism of synaptic plasticity? Neuroscientist. $11,528-31$.

Fields, R.D., 2008. White matter in learning, cognition and psychiatric disorders. Trends Neurosci. 31, 361-70.

Frederiksen, K., McKay, R.D., 1988. Proliferation and differentiation of rat neuroepithelial precursor cells in vivo. J Neurosci. 8, 1144-51.

Fukuda, S., Kondo, T., Takebayashi, H., Taga, T., 2004. Negative regulatory effect of an oligodendrocytic bHLH factor OLIG2 on the astrocytic differentiation pathway. Cell Death Differ. 11, 196-202.

Gambarana, C., Tolu, P.L., Masi, F., Rinaldi, M., Giachetti, D., Morazzoni, P., De Montis, M.G., 2001. A study of the antidepressant activity of Hypericum perforatum on animal models. Pharmacopsychiatry. 34 Suppl 1, S42-4.

Gervois, P., Fruchart, J.C., Staels, B., 2007. Drug Insight: mechanisms of action and therapeutic applications for agonists of peroxisome proliferator-activated receptors. Nat Clin Pract Endocrinol Metab. 3, 145-56.

Gilyarov, A.V., 2008. Nestin in central nervous system cells. Neurosci Behav Physiol. 38, 165-9.

Gratzner, H.G., 1982. Monoclonal antibody to 5-bromo- and 5-iododeoxyuridine: A new reagent for detection of DNA replication. Science. 218, 474-5.

Gritti, A., Parati, E.A., Cova, L., Frolichsthal, P., Galli, R., Wanke, E., Faravelli, L., Morassutti, D.J., Roisen, F., Nickel, D.D., Vescovi, A.L., 1996. Multipotential stem cells from the adult mouse brain proliferate and self-renew in response to basic fibroblast growth factor. J Neurosci. 16, 1091-100.

Gritti, A., Frolichsthal-Schoeller, P., Galli, R., Parati, E.A., Cova, L., Pagano, S.F., Bjornson, C.R., Vescovi, A.L., 1999. Epidermal and fibroblast growth factors behave as mitogenic regulators for a single multipotent stem cell-like population from the subventricular region of the adult mouse forebrain. J Neurosci. 19, 3287-97.

Grunbaum-Novak, N., Taler, M., Gil-Ad, I., Weizman, A., Cohen, H., Weizman, R., 2008. Relationship between antidepressants and IGF-1 system in the brain: possible role in cognition. Eur Neuropsychopharmacol. 18, 431-8.

Guze, S.B., Robins, E., 1970. Suicide and primary affective disorders. Br J Psychiatry. 117, 437-8.

Hamidi, M., Drevets, W.C., Price, J.L., 2004. Glial reduction in amygdala in major depressive disorder is due to oligodendrocytes. Biological Psychiatry. 55, 563-569.

Harauz, G., Ishiyama, N., Hill, C.M., Bates, I.R., Libich, D.S., Fares, C., 2004. Myelin basic protein-diverse conformational states of an intrinsically unstructured protein and its roles in myelin assembly and multiple sclerosis. Micron. 35, 503-42.

Haydon, D.A., Hladky, S.B., 1972. Ion transport across thin lipid membranes: a critical discussion of mechanisms in selected systems. Q Rev Biophys. 5, 187-282.

Heneka, M.T., Landreth, G.E., 2007. PPARs in the brain. Biochim Biophys Acta. 1771, 1031-45. 
Hitoshi, S., Maruta, N., Higashi, M., Kumar, A., Kato, N., Ikenaka, K., 2007. Antidepressant drugs reverse the loss of adult neural stem cells following chronic stress. J Neurosci Res. $85,3574-85$.

Hockfield, S., McKay, R.D., 1985. Identification of major cell classes in the developing mammalian nervous system. J Neurosci. 5, 3310-28.

Honer, W.G., Falkai, P., Chen, C., Arango, V., Mann, J.J., Dwork, A.J., 1999. Synaptic and plasticity-associated proteins in anterior frontal cortex in severe mental illness. Neuroscience. 91, 1247-55.

Hoshaw, B.A., Hill, T.I., Crowley, J.J., Malberg, J.E., Khawaja, X., Rosenzweig-Lipson, S., Schechter, L.E., Lucki, I., 2008. Antidepressant-like behavioral effects of IGF-I produced by enhanced serotonin transmission. Eur J Pharmacol. 594, 109-16.

Houseknecht, K.L., Cole, B.M., Steele, P.J., 2002. Peroxisome proliferator-activated receptor gamma (PPARgamma) and its ligands: a review. Domest Anim Endocrinol. 22, 1-23.

Hsia, Y., Maclennan, K., 2009. Rise in psychotropic drug prescribing in children and adolescents during 1992-2001: a population-based study in the UK. Eur J Epidemiol. 24, 211-6.

Hsieh, J., Aimone, J.B., Kaspar, B.K., Kuwabara, T., Nakashima, K., Gage, F.H., 2004. IGF-I instructs multipotent adult neural progenitor cells to become oligodendrocytes. J Cell Biol. 164, 111-22.

Iosifescu, D.V., Bolo, N.R., Nierenberg, A.A., Jensen, J.E., Fava, M., Renshaw, P.F., 2008. Brain bioenergetics and response to triiodothyronine augmentation in major depressive disorder. Biol Psychiatry. 63, 1127-34.

Ishibashi, T., Dakin, K.A., Stevens, B., Lee, P.R., Kozlov, S.V., Stewart, C.L., Fields, R.D., 2006. Astrocytes promote myelination in response to electrical impulses. Neuron. 49, 823-32.

Jacobs, E.C., 2005. Genetic alterations in the mouse myelin basic proteins result in a range of dysmyelinating disorders. J Neurol Sci. 228, 195-7.

Jensen, A.G., Hansen, S.H., Nielsen, E.O., 2001. Adhyperforin as a contributor to the effect of Hypericum perforatum L. in biochemical models of antidepressant activity. Life Sci. 68, 1593-605.

Joels, M., Karst, H., Alfarez, D., Heine, V.M., Qin, Y., van Riel, E., Verkuyl, M., Lucassen, P.J., Krugers, H.J., 2004. Effects of chronic stress on structure and cell function in rat hippocampus and hypothalamus. Stress. 7, 221-31.

Kato, T., Inubushi, T., Kato, N., 1998. Magnetic resonance spectroscopy in affective disorders. J Neuropsychiatry Clin Neurosci. 10, 133-47.

Keller, J.H., Karas, M., Muller, W.E., Volmer, D.A., Eckert, G.P., Tawab, M.A., Blume, H.H., Dingermann, T., Schubert-Zsilavecz, M., 2003. Determination of hyperforin in mouse brain by high-performance liquid chromatography/tandem mass spectrometry. Anal Chem. 75, 6084-8.

Konarski, J.Z., McIntyre, R.S., Kennedy, S.H., Rafi-Tari, S., Soczynska, J.K., Ketter, T.A., 2008. Volumetric neuroimaging investigations in mood disorders: bipolar disorder versus major depressive disorder. Bipolar Disord. 10, 1-37.

Kong, E.K., Peng, L., Chen, Y., Yu, A.C., Hertz, L., 2002. Up-regulation of 5-HT2B receptor density and receptor-mediated glycogenolysis in mouse astrocytes by long-term fluoxetine administration. Neurochem Res. 27, 113-20.

Kornack, D.R., Rakic, P., 2001. Cell proliferation without neurogenesis in adult primate neocortex. Science. 294, 2127-30.

Krishnan, V., Nestler, E.J., 2008. The molecular neurobiology of depression. Nature. 455, 894902. 
Krusekopf, S., Roots, I., 2005. St. John's wort and its constituent hyperforin concordantly regulate expression of genes encoding enzymes involved in basic cellular pathways. Pharmacogenet Genomics. 15, 817-29.

Laakmann, G., Schule, C., Baghai, T., Kieser, M., 1998. St. John's wort in mild to moderate depression: the relevance of hyperforin for the clinical efficacy. Pharmacopsychiatry. 31 Suppl 1, 54-9.

Laggner, H., Schreier, S., Hermann, M., Exner, M., Muhl, A., Gmeiner, B.M., Kapiotis, S., 2007. The main components of St John's Wort inhibit low-density lipoprotein atherogenic modification: a beneficial "side effect" of an OTC antidepressant drug? Free Radic Res. 41, 234-41.

Lendahl, U., Zimmerman, L.B., McKay, R.D., 1990. CNS stem cells express a new class of intermediate filament protein. Cell. 60, 585-95.

Linde, K., Berner, M., Egger, M., Mulrow, C., 2005. St John's wort for depression: meta-analysis of randomised controlled trials. Br J Psychiatry. 186, 99-107.

Linde, K., Berner, M.M., Kriston, L., 2008. St John's wort for major depression. Cochrane Database Syst Rev. CD000448.

Louis, J.C., Magal, E., Muir, D., Manthorpe, M., Varon, S., 1992. CG-4, a new bipotential glial cell line from rat brain, is capable of differentiating in vitro into either mature oligodendrocytes or type-2 astrocytes. Journal of Neuroscience Research. 31, 193-204.

Lu, Q.R., Yuk, D., Alberta, J.A., Zhu, Z., Pawlitzky, I., Chan, J., McMahon, A.P., Stiles, C.D., Rowitch, D.H., 2000. Sonic hedgehog--regulated oligodendrocyte lineage genes encoding bHLH proteins in the mammalian central nervous system. Neuron. 25, 317-29.

Lu, Q.R., Sun, T., Zhu, Z., Ma, N., Garcia, M., Stiles, C.D., Rowitch, D.H., 2002. Common developmental requirement for Olig function indicates a motor neuron/oligodendrocyte connection. Cell. 109, 75-86.

Lucassen, P.J., Heine, V.M., Muller, M.B., van der Beek, E.M., Wiegant, V.M., De Kloet, E.R., Joels, M., Fuchs, E., Swaab, D.F., Czeh, B., 2006. Stress, depression and hippocampal apoptosis. CNS Neurol Disord Drug Targets. 5, 531-46.

Luduena, R.F., 1998. Multiple forms of tubulin: different gene products and covalent modifications. Int Rev Cytol. 178, 207-75.

Lundin, A., Thore, A., 1975. Comparison of methods for extraction of bacterial adenine nucleotides determined by firefly assay. Appl Microbiol. 30, 713-21.

Madrigal, J.L., Olivenza, R., Moro, M.A., Lizasoain, I., Lorenzo, P., Rodrigo, J., Leza, J.C., 2001. Glutathione depletion, lipid peroxidation and mitochondrial dysfunction are induced by chronic stress in rat brain. Neuropsychopharmacology. 24, 420-9.

Madsen, T.M., Yeh, D.D., Valentine, G.W., Duman, R.S., 2005. Electroconvulsive seizure treatment increases cell proliferation in rat frontal cortex. Neuropsychopharmacology. 30, 27-34.

Maehara, Y., Anai, H., Tamada, R., Sugimachi, K., 1987. The ATP assay is more sensitive than the succinate dehydrogenase inhibition test for predicting cell viability. Eur J Cancer Clin Oncol. 23, 273-6.

Magnus, T., Coksaygan, T., Korn, T., Xue, H., Arumugam, T.V., Mughal, M.R., Eckley, D.M., Tang, S.C., Detolla, L., Rao, M.S., Cassiani-Ingoni, R., Mattson, M.P., 2007. Evidence that nucleocytoplasmic Olig2 translocation mediates brain-injury-induced differentiation of glial precursors to astrocytes. J Neurosci Res. 85, 2126-37.

Maisenbacher, P., Kovar, K.A., 1992. Analysis and stability of Hyperici oleum. Planta Med. 58, 351-4.

McElroy, W.D., DeLuca, M.A., 1983. Firefly and bacterial luminescence: basic science and applications. J Appl Biochem. 5, 197-209. 
McNulty, S., Crouch, M., Smart, D., Rumsby, M., 2001. Differentiation of bipolar CG-4 line oligodendrocytes is associated with regulation of CREB, MAP kinase and PKC signalling pathways. Neuroscience Research. 41, 217-226.

Medina, M.A., Martinez-Poveda, B., Amores-Sanchez, M.I., Quesada, A.R., 2006. Hyperforin: More than an antidepressant bioactive compound? Life Sciences. 79, 105-111.

Mennini, T., Gobbi, M., 2004. The antidepressant mechanism of Hypericum perforatum. Life Sci. $75,1021-7$.

Mitchell, P., 1966. Chemiosmotic coupling in oxidative and photosynthetic phosphorylation. Biol Rev Camb Philos Soc. 41, 445-502.

Mitchell, P., 1979. Keilin's respiratory chain concept and its chemiosmotic consequences. Science. 206, 1148-59.

Moore, C.M., Christensen, J.D., Lafer, B., Fava, M., Renshaw, P.F., 1997. Lower levels of nucleoside triphosphate in the basal ganglia of depressed subjects: a phosphorous-31 magnetic resonance spectroscopy study. Am J Psychiatry. 154, 116-8.

Moreno, F.A., Heninger, G.R., McGahuey, C.A., Delgado, P.L., 2000. Tryptophan depletion and risk of depression relapse: a prospective study of tryptophan depletion as a potential predictor of depressive episodes. Biol Psychiatry. 48, 327-9.

Moretti, A., Gorini, A., Villa, R.F., 2003. Affective disorders, antidepressant drugs and brain metabolism. Mol Psychiatry. 8, 773-85.

Mosmann, T., 1983. Rapid colorimetric assay for cellular growth and survival: application to proliferation and cytotoxicity assays. J Immunol Methods. 65, 55-63.

Mozell, R.L., McMorris, F.A., 1991. Insulin-like growth factor I stimulates oligodendrocyte development and myelination in rat brain aggregate cultures. J Neurosci Res. 30, 382-90.

Mueller, H., Kassack, M.U., Wiese, M., 2004. Comparison of the usefulness of the MTT, ATP, and calcein assays to predict the potency of cytotoxic agents in various human cancer cell lines. J Biomol Screen. 9, 506-15.

Muller, W.E., Singer, A., Wonnemann, M., Hafner, U., Rolli, M., Schafer, C., 1998. Hyperforin represents the neurotransmitter reuptake inhibiting constituent of hypericum extract. Pharmacopsychiatry. 31 Suppl 1, 16-21.

Muller, W.E., Singer, A., Wonnemann, M., 2001. Hyperforin--antidepressant activity by a novel mechanism of action. Pharmacopsychiatry. 34 Suppl 1, S98-102.

Nait-Oumesmar, B., Picard-Riera, N., Kerninon, C., Decker, L., Seilhean, D., Hoglinger, G.U., Hirsch, E.C., Reynolds, R., Baron-Van Evercooren, A., 2007. Activation of the subventricular zone in multiple sclerosis: evidence for early glial progenitors. Proc Natl Acad Sci U S A. 104, 4694-9.

Nait-Oumesmar, B., Picard-Riera, N., Kerninon, C., Baron-Van Evercooren, A., 2008. The role of SVZ-derived neural precursors in demyelinating diseases: from animal models to multiple sclerosis. J Neurol Sci. 265, 26-31.

Neary, J.T., Whittemore, S.R., Bu, Y., Mehta, H., Shi, Y.F., 2001. Biochemical mechanisms of action of Hypericum LI 160 in glial and neuronal cells: inhibition of neurotransmitter uptake and stimulation of extracellular signal regulated protein kinase. Pharmacopsychiatry. 34 Suppl 1, S103-7.

Nichols, W.W., Curtis, G.D., Johnston, H.H., 1981. Choice of buffer anion for the assay of adenosine 5'-triphosphate using firefly luciferase. Anal Biochem. 114, 396-7.

Noble, M., Wren, D., Wolswijk, G., 1992. The O-2A(adult) progenitor cell: a glial stem cell of the adult central nervous system. Semin Cell Biol. 3, 413-22.

Noble, M., Smith, J., Power, J., Mayer-Proschel, M., 2003. Redox state as a central modulator of precursor cell function. Ann N Y Acad Sci. 991, 251-71. 
Okuda, H., Tatsumi, K., Makinodan, M., Yamauchi, T., Kishimoto, T., Wanaka, A., 2009. Environmental enrichment stimulates progenitor cell proliferation in the amygdala. $\mathrm{J}$ Neurosci Res.

Ongur, D., Drevets, W.C., Price, J.L., 1998. Glial reduction in the subgenual prefrontal cortex in mood disorders. Proc Natl Acad Sci U S A. 95, 13290-5.

Oswald, P., Souery, D., Mendlewicz, J., 2004. Molecular genetics of affective disorders. Prog Neuropsychopharmacol Biol Psychiatry. 28, 865-77.

Pacher, P., Kecskemeti, V., 2004. Trends in the development of new antidepressants. Is there a light at the end of the tunnel? Curr Med Chem. 11, 925-43.

Palacios, N., Sanchez-Franco, F., Fernandez, M., Sanchez, I., Cacicedo, L., 2005. Intracellular events mediating insulin-like growth factor I-induced oligodendrocyte development: modulation by cyclic AMP. J Neurochem. 95, 1091-107.

Paulke, A., Noldner, M., Schubert-Zsilavecz, M., Wurglics, M., 2008. St. John's wort flavonoids and their metabolites show antidepressant activity and accumulate in brain after multiple oral doses. Pharmazie. 63, 296-302.

Pennington, K., Focking, M., McManus, C., Pariante, C., Dunn, M., Cotter, D., 2009. A proteomic investigation of similarities between conventional and herbal antidepressant treatments. J Psychopharmacol. 23, 520-30.

Phelps, E.A., LeDoux, J.E., 2005. Contributions of the amygdala to emotion processing: from animal models to human behavior. Neuron. 48, 175-87.

Pleasure, D., Abramsky, O., Silberberg, D., Quinn, B., Parris, J., Saida, T., 1977. Lipid synthesis by an oligodendroglial fraction in suspension culture. Brain Res. 134, 377-82.

Qi, Y., Cai, J., Wu, Y., Wu, R., Lee, J., Fu, H., Rao, M., Sussel, L., Rubenstein, J., Qiu, M., 2001. Control of oligodendrocyte differentiation by the Nkx2.2 homeodomain transcription factor. Development. 128, 2723-33.

Rajkowska, G., Miguel-Hidalgo, J.J., Wei, J., Dilley, G., Pittman, S.D., Meltzer, H.Y., Overholser, J.C., Roth, B.L., Stockmeier, C.A., 1999. Morphometric evidence for neuronal and glial prefrontal cell pathology in major depression. Biol Psychiatry. 45, 1085-98.

Ravera, S., Panfoli, I., Calzia, D., Aluigi, M.G., Bianchini, P., Diaspro, A., Mancardi, G., Morelli, A., 2009. Evidence for aerobic ATP synthesis in isolated myelin vesicles. Int J Biochem Cell Biol. 41, 1581-91.

Raymond, C.B., Morgan, S.G., Caetano, P.A., 2007. Antidepressant utilization in British Columbia from 1996 to 2004: increasing prevalence but not incidence. Psychiatr Serv. 58, 79-84.

Regenold, W.T., Phatak, P., Marano, C.M., Gearhart, L., Viens, C.H., Hisley, K.C., 2007. Myelin staining of deep white matter in the dorsolateral prefrontal cortex in schizophrenia, bipolar disorder, and unipolar major depression. Psychiatry Res. 151, 179-88.

Reus, V.I., Freimer, N.B., 1997. Understanding the genetic basis of mood disorders: where do we stand? Am J Hum Genet. 60, 1283-8.

Reynolds, B.A., Tetzlaff, W., Weiss, S., 1992. A multipotent EGF-responsive striatal embryonic progenitor cell produces neurons and astrocytes. J Neurosci. 12, 4565-74.

Rezin, G.T., Cardoso, M.R., Goncalves, C.L., Scaini, G., Fraga, D.B., Riegel, R.E., Comim, C.M., Quevedo, J., Streck, E.L., 2008. Inhibition of mitochondrial respiratory chain in brain of rats subjected to an experimental model of depression. Neurochem Int. 53, 395-400.

Rosa, A.O., Kaster, M.P., Binfare, R.W., Morales, S., Martin-Aparicio, E., Navarro-Rico, M.L., Martinez, A., Medina, M., Garcia, A.G., Lopez, M.G., Rodrigues, A.L., 2008. Antidepressant-like effect of the novel thiadiazolidinone NP031115 in mice. Prog Neuropsychopharmacol Biol Psychiatry. 32, 1549-56. 
Roth, A.D., Leisewitz, A.V., Jung, J.E., Cassina, P., Barbeito, L., Inestrosa, N.C., Bronfman, M., 2003. PPAR gamma activators induce growth arrest and process extension in B12 oligodendrocyte-like cells and terminal differentiation of cultured oligodendrocytes. $\mathrm{J}$ Neurosci Res. 72, 425-35.

Rowitch, D.H., Lu, Q.R., Kessaris, N., Richardson, W.D., 2002. An 'oligarchy' rules neural development. Trends Neurosci. 25, 417-22.

Sanchez-Reus, M.I., Gomez del Rio, M.A., Iglesias, I., Elorza, M., Slowing, K., Benedi, J., 2007. Standardized Hypericum perforatum reduces oxidative stress and increases gene expression of antioxidant enzymes on rotenone-exposed rats. Neuropharmacology. 52, 606-616.

Sas, K., Robotka, H., Toldi, J., Vecsei, L., 2007. Mitochondria, metabolic disturbances, oxidative stress and the kynurenine system, with focus on neurodegenerative disorders. J Neurol Sci. 257, 221-39.

Sato-Bigbee, C., Yu, R.K., 1993. Presence of cyclic AMP response element-binding protein in oligodendrocytes. J Neurochem. 60, 2106-10.

Sato-Bigbee, C., Chan, E.L., Yu, R.K., 1994. Oligodendroglial cyclic AMP response elementbinding protein: a member of the CREB family of transcription factors. J Neurosci Res. $38,621-8$.

Schempp, C.M., Kirkin, V., Simon-Haarhaus, B., Kersten, A., Kiss, J., Termeer, C.C., Gilb, B., Kaufmann, T., Borner, C., Sleeman, J.P., Simon, J.C., 2002. Inhibition of tumour cell growth by hyperforin, a novel anticancer drug from St. John's wort that acts by induction of apoptosis. Oncogene. 21, 1242-50.

Schildkraut, J.J., 1995. The catecholamine hypothesis of affective disorders: a review of supporting evidence. 1965. J Neuropsychiatry Clin Neurosci. 7, 524-33; discussion 523-4.

Schosser, A., Kasper, S., 2009. The role of pharmacogenetics in the treatment of depression and anxiety disorders. Int Clin Psychopharmacol.

Schrader, E., 2000. Equivalence of St John's wort extract (Ze 117) and fluoxetine: a randomized, controlled study in mild-moderate depression. Int Clin Psychopharmacol. 15, 61-8.

Schubert, D., Heinemann, S., Carlisle, W., Tarikas, H., Kimes, B., Patrick, J., Steinbach, J.H., Culp, W., Brandt, B.L., 1974. Clonal cell lines from the rat central nervous system. Nature. 249, 224-7.

Schuler, F., Casida, J.E., 2001. Functional coupling of PSST and ND1 subunits in NADH:ubiquinone oxidoreductase established by photoaffinity labeling. Biochim Biophys Acta. 1506, 79-87.

Shao, L., Martin, M.V., Watson, S.J., Schatzberg, A., Akil, H., Myers, R.M., Jones, E.G., Bunney, W.E., Vawter, M.P., 2008. Mitochondrial involvement in psychiatric disorders. Ann Med. 40, 281-95.

Sheline, Y.I., 2000. 3D MRI studies of neuroanatomic changes in unipolar major depression: the role of stress and medical comorbidity. Biol Psychiatry. 48, 791-800.

Sherer, T.B., Betarbet, R., Testa, C.M., Seo, B.B., Richardson, J.R., Kim, J.H., Miller, G.W., Yagi, T., Matsuno-Yagi, A., Greenamyre, J.T., 2003. Mechanism of toxicity in rotenone models of Parkinson's disease. J Neurosci. 23, 10756-64.

Sim, F.J., Lang, J.K., Ali, T.A., Roy, N.S., Vates, G.E., Pilcher, W.H., Goldman, S.A., 2008. Statin treatment of adult human glial progenitors induces PPAR gamma-mediated oligodendrocytic differentiation. Glia. 56, 954-62.

Singer, A., Wonnemann, M., Muller, W.E., 1999. Hyperforin, a major antidepressant constituent of St. John's Wort, inhibits serotonin uptake by elevating free intracellular $\mathrm{Na}+1$. J Pharmacol Exp Ther. 290, 1363-8. 
Smith, J., Ladi, E., Mayer-Proschel, M., Noble, M., 2000. Redox state is a central modulator of the balance between self-renewal and differentiation in a dividing glial precursor cell. Proc Natl Acad Sci U S A. 97, 10032-7.

Smith, M.A., Makino, S., Kvetnansky, R., Post, R.M., 1995. Stress and glucocorticoids affect the expression of brain-derived neurotrophic factor and neurotrophin-3 mRNAs in the hippocampus. J Neurosci. 15, 1768-77.

Sprinkle, T.J., Zaruba, M.E., McKhann, G.M., 1978. Activity of 2',3'-cyclic-nucleotide 3'phosphodiesterase in regions of rat brain during development: quantitative relationship to myelin basic protein. J Neurochem. 30, 309-14.

Stanley, P.E., 1986. Extraction of adenosine triphosphate from microbial and somatic cells. Methods Enzymol. 133, 14-22.

Stariha, R.L., Kim, S.U., 2001. Mitogen-activated protein kinase signalling in oligodendrocytes: a comparison of primary cultures and CG-4. International Journal of Developmental Neuroscience. 19, 427-437.

Stevens, B., Tanner, S., Fields, R.D., 1998. Control of myelination by specific patterns of neural impulses. J Neurosci. 18, 9303-11.

Stolt, C.C., Rehberg, S., Ader, M., Lommes, P., Riethmacher, D., Schachner, M., Bartsch, U., Wegner, M., 2002. Terminal differentiation of myelin-forming oligodendrocytes depends on the transcription factor Sox10. Genes Dev. 16, 165-70.

Suzuki, O., Katsumata, Y., Oya, M., Bladt, S., Wagner, H., 1984. Inhibition of monoamine oxidase by hypericin. Planta Med. 50, 272-4.

Takahashi, T., Shirane, R., Sato, S., Yoshimoto, T., 1999. Developmental changes of cerebral blood flow and oxygen metabolism in children. AJNR Am J Neuroradiol. 20, 917-22.

Talpade, D.J., Greene, J.G., Higgins, D.S., Jr., Greenamyre, J.T., 2000. In vivo labeling of mitochondrial complex I (NADH:ubiquinone oxidoreductase) in rat brain using [(3)H]dihydrorotenone. J Neurochem. 75, 2611-21.

Taupin, P., 2007. BrdU immunohistochemistry for studying adult neurogenesis: paradigms, pitfalls, limitations, and validation. Brain Res Rev. 53, 198-214.

Taylor, S., 2007. Electroconvulsive therapy: a review of history, patient selection, technique, and medication management. South Med J. 100, 494-8.

Taylor, W.D., MacFall, J.R., Payne, M.E., McQuoid, D.R., Provenzale, J.M., Steffens, D.C., Krishnan, K.R., 2004. Late-life depression and microstructural abnormalities in dorsolateral prefrontal cortex white matter. Am J Psychiatry. 161, 1293-6.

Temple, S., Alvarez-Buylla, A., 1999. Stem cells in the adult mammalian central nervous system. Curr Opin Neurobiol. 9, 135-41.

Trzeciak, H.I., Pudelko, A., Gabryel, B., Malecki, A., Kozlowski, A., Ciesslik, P., 1995. Effect of antidepressants on ATP content, 3H-valine incorporation and cell morphometry of astrocytes cultured from rat brain. Dev Neurosci. 17, 292-9.

Uchida, N., Buck, D.W., He, D., Reitsma, M.J., Masek, M., Phan, T.V., Tsukamoto, A.S., Gage, F.H., Weissman, I.L., 2000. Direct isolation of human central nervous system stem cells. Proc Natl Acad Sci U S A. 97, 14720-5.

Uranova, N.A., Vostrikov, V.M., Orlovskaya, D.D., Rachmanova, V.I., 2004. Oligodendroglial density in the prefrontal cortex in schizophrenia and mood disorders: a study from the Stanley Neuropathology Consortium. Schizophr Res. 67, 269-75.

Van Houten, B., Woshner, V., Santos, J.H., 2006. Role of mitochondrial DNA in toxic responses to oxidative stress. DNA Repair (Amst). 5, 145-52.

Videbech, P., 2000. PET measurements of brain glucose metabolism and blood flow in major depressive disorder: a critical review. Acta Psychiatr Scand. 101, 11-20. 
Vitiello, B., 1999. Hypericum perforatum extracts as potential antidepressants. J Pharm Pharmacol. 51, 513-7.

Vitiello, B., Shader, R.I., Parker, C.B., Ritz, L., Harlan, W., Greenblatt, D.J., Gadde, K.M., Krishnan, K.R., Davidson, J.R., 2005. Hyperforin plasma level as a marker of treatment adherence in the National Institutes of Health Hypericum Depression Trial. J Clin Psychopharmacol. 25, 243-9.

Vogel, U.S., Thompson, R.J., 1988. Molecular structure, localization, and possible functions of the myelin-associated enzyme 2',3'-cyclic nucleotide 3'-phosphodiesterase. J Neurochem. 50, 1667-77.

Wada, K., Nakajima, A., Katayama, K., Kudo, C., Shibuya, A., Kubota, N., Terauchi, Y., Tachibana, M., Miyoshi, H., Kamisaki, Y., Mayumi, T., Kadowaki, T., Blumberg, R.S., 2006. Peroxisome proliferator-activated receptor gamma-mediated regulation of neural stem cell proliferation and differentiation. J Biol Chem. 281, 12673-81.

Walczak, R., Tontonoz, P., 2002. PPARadigms and PPARadoxes: expanding roles for PPARgamma in the control of lipid metabolism. J Lipid Res. 43, 177-86.

Warner-Schmidt, J.L., Duman, R.S., 2006. Hippocampal neurogenesis: opposing effects of stress and antidepressant treatment. Hippocampus. 16, 239-49.

Weisler, R., Joyce, M., McGill, L., Lazarus, A., Szamosi, J., Eriksson, H., 2009. Extended release quetiapine fumarate monotherapy for major depressive disorder: results of a double-blind, randomized, placebo-controlled study. CNS Spectr. 14, 299-313.

Wennstrom, M., Hellsten, J., Tingstrom, A., 2004. Electroconvulsive seizures induce proliferation of NG2-expressing glial cells in adult rat amygdala. Biol Psychiatry. 55, 464-71.

Wheatley, D., 1997. LI 160, an extract of St. John's wort, versus amitriptyline in mildly to moderately depressed outpatients--a controlled 6-week clinical trial. Pharmacopsychiatry. 30 Suppl 2, 77-80.

Woelk, H., 2000. Comparison of St John's wort and imipramine for treating depression: randomised controlled trial. BMJ. 321, 536-9.

Wonnemann, M., Singer, A., Muller, W.E., 2000. Inhibition of synaptosomal uptake of 3H-Lglutamate and 3H-GABA by hyperforin, a major constituent of St. John's Wort: the role of amiloride sensitive sodium conductive pathways. Neuropsychopharmacology. 23, 18897.

Xiao, L., Xu, H., Zhang, Y., Wei, Z., He, J., Jiang, W., Li, X., Dyck, L.E., Devon, R.M., Deng, Y., Li, X.M., 2008. Quetiapine facilitates oligodendrocyte development and prevents mice from myelin breakdown and behavioral changes. Mol Psychiatry. 13, 697-708.

Xu, X., Cai, J., Fu, H., Wu, R., Qi, Y., Modderman, G., Liu, R., Qiu, M., 2000. Selective expression of Nkx-2.2 transcription factor in chicken oligodendrocyte progenitors and implications for the embryonic origin of oligodendrocytes. Mol Cell Neurosci. 16, 740-53.

Yamazaki, Y., Hozumi, Y., Kaneko, K., Fujii, S., Goto, K., Kato, H., 2009. Oligodendrocytes: Facilitating Axonal Conduction by More Than Myelination. Neuroscientist.

Yatham, L.N., Goldstein, J.M., Vieta, E., Bowden, C.L., Grunze, H., Post, R.M., Suppes, T., Calabrese, J.R., 2005. Atypical antipsychotics in bipolar depression: potential mechanisms of action. J Clin Psychiatry. 66 Suppl 5, 40-8.

Yim, S.H., Farrer, R.G., Quarles, R.H., 1995. Expression of glycolipids and myelin-associated glycoprotein during the differentiation of oligodendrocytes: comparison of the CG-4 glial cell line to primary cultures. Dev Neurosci. 17, 171-80.

Zeger, M., Popken, G., Zhang, J., Xuan, S., Lu, Q.R., Schwab, M.H., Nave, K.A., Rowitch, D., D'Ercole, A.J., Ye, P., 2007. Insulin-like growth factor type 1 receptor signaling in the cells of oligodendrocyte lineage is required for normal in vivo oligodendrocyte development and myelination. Glia. 55, 400-11. 
Zhang, X., Peng, L., Chen, Y., Hertz, L., 1993. Stimulation of glycogenolysis in astrocytes by fluoxetine, an antidepressant acting like 5-HT. Neuroreport. 4, 1235-8.

Zhang, Y., Xu, H., Jiang, W., Xiao, L., Yan, B., He, J., Wang, Y., Bi, X., Li, X., Kong, J., Li, X.M., 2008. Quetiapine alleviates the cuprizone-induced white matter pathology in the brain of C57BL/6 mouse. Schizophr Res. 106, 182-91.

Zhou, Q., Choi, G., Anderson, D.J., 2001. The bHLH transcription factor Olig2 promotes oligodendrocyte differentiation in collaboration with Nkx2.2. Neuron. 31, 791-807. 